\title{
UNDERSTANDING DISTANCE EDUCATION
}

By

\section{AILSA MCLARDY}

B.A., The University of British Columbia, 1967

A THESIS SUBMITTED IN PARTIAL FULFILLMENT OF

THE REQUIREMENTS FOR THE DEGREE OF

MASTER OF ARTS

in

THE FACULTY OF GRADUATE STUDIES

(Department of Administrative, Adult and Higher Education)

We accept this thesis as conforming

to the required standard

THE UNIVERSITY OF BRITISH COLUMBIA

September 1991

(c) Ailsa McLardy, 1991 
In presenting this thesis in partial fulfilment of the requirements for an advanced degree at the University of British Columbia, I agree that the Library shall make it freely available for reference and study. I further agree that permission for extensive copying of this thesis for scholarly purposes may be granted by the head of my department or by his or her representatives. It is understood that copying or publication of this thesis for financial gain shall not be allowed without my written permission.

Department of Administrative, Adult and Higher Education

The University of British Columbia

Vancouver, Canada

Date October 2, 1991 


\section{ABSTRACT}

"Get a university degree at home in your spare time!" proclaim the back covers of magazines. Is this distance education? In fact, what is distance education?

There are many definitions of distance education in the literature. They represent distance educators' understanding of the field, and it is partly on the basis of this understanding that professionals develop progams and services. Do learners have the same understanding of distance education? If learners hold different views from educators, the discrepancy may create problems.

Therefore, the writer investigated the conceptions of distance education held by learners who had recently begun distance studies at the university level. She interviewed fifteen learners and analyzed the interviews using phenomenography. This is a qualitative methodology with certain limitations which are discussed in the study. Phenomenogaphy attempts to reveal phenomena as they are perceived by individuals. Consequently, it was the most appropriate methodology to discover learners' conceptions of distance education.

The investigator found four conceptions of distance education; they can be seen as a seed with a sprout. The kernel is distance education perceived as structure and learner actions; this conception is inward-looking. Around the kernel can develop two other conceptions: distance 
education as freedom and flexibility and distance education as difficulties counterbalanced by other factors. The fourth conception has two parts: distance education as a door opener (a) to future goals and (b) in everyday life. This is the sprout growing out of the kernel; it is an outward-looking conception.

An analysis of the definitions of distance education in the literature revealed nine themes representing educators' understanding of distance education. There is a close relationship between these themes and two conceptions: "distance education as structure and learner actions" and "distance education as difficulties". On the other hand, important aspects of these and the other conceptions are not represented by the themes. Those missing aspects are all learner-centred.

Although much is written about learners being the focus of distance education, the definitions in the literature indicate a drift from that ideal. It is time for educators to make distance education truly learner-centred. 


\section{TABLE OF CONTENTS}

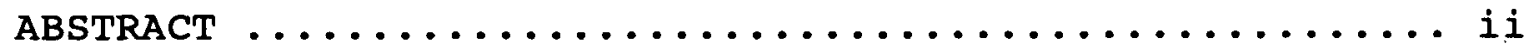

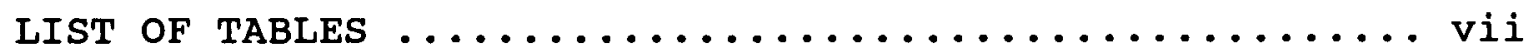

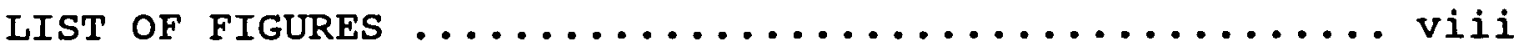

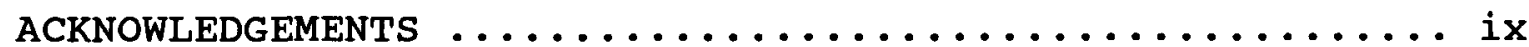

I. INTRODUCTION: THE MEANING OF DISTANCE EDUCATION $\ldots \ldots 1$ Distance Education and Open Learning .......... 2 Distance Education Themes in the Literature ...... 3 The Need for a Qualitative Approach ...........4 Why Identify Conceptions? ................6

II. REVIEW OF THE LiteratuRE $\ldots \ldots \ldots \ldots \ldots \ldots \ldots \ldots \ldots$ Definitions of Distance Education in the

Literature $\ldots \ldots \ldots \ldots \ldots \ldots \ldots \ldots \ldots \ldots \ldots \ldots$

Themes in Definitions of Distance Education ...... 14 The Importance of Context ................ 16 Learners' Understanding of Distance Education .... 19 III. METHODOLOGY $\ldots \ldots \ldots \ldots \ldots \ldots \ldots \ldots \ldots \ldots \ldots \ldots \ldots$ The Naturalistic Paradigm ................. 31 Phenomenography $\ldots \ldots \ldots \ldots \ldots \ldots \ldots \ldots \ldots \ldots \ldots \ldots$ Selection of subjects $\ldots \ldots \ldots \ldots \ldots \ldots \ldots \ldots \ldots$ Data Collection ..................... 41

Data Analysis ..................... 44

Trustworthiness $\ldots \ldots \ldots \ldots \ldots \ldots \ldots \ldots \ldots \ldots \ldots$

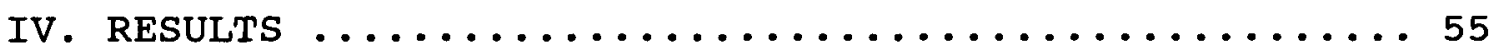

The Outcome Space: Conceptions of Distance

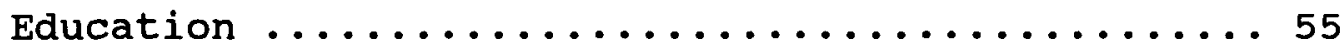


Relationships between Conceptions ............ 68

Relationships between Conceptions and Definitions

in the Literature $\ldots \ldots \ldots \ldots \ldots \ldots \ldots \ldots \ldots \ldots$

Other Definitions of Distance Education ........ 80

Learners Holding Each Conception $\ldots \ldots \ldots \ldots \ldots \ldots 82$

V. DISCUSSION AND IMPLICATIONS $\ldots \ldots \ldots \ldots \ldots \ldots \ldots \ldots$

The Philosophical and Epistemological Basis ..... 85

The Investigator as Research Instrument ....... 89

Learners' Conceptions and Theories/Models in Adult

Education and Distance Education ........... 92

Limitations of the study $\ldots \ldots \ldots \ldots \ldots \ldots \ldots \ldots 9$

Learners' Conceptions and Educators' Understandings

of Distance Education: Discussion .......... 102

Understanding Distance Education: Narrowing the

Gap ................................ 105



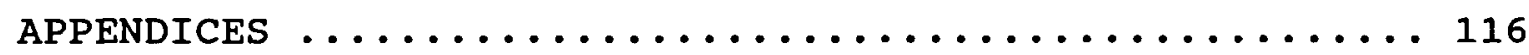

Appendix A: Description of the study enclosed with Open Learning Agency initial letter .. 116

Appendix B: Consent form given at interview ..... 117

Appendix c: Set interview questions ......... 118

Appendix D: Personal information form ......... 119

Appendix E: Letter sent to respondent with

transcript .................. 120

Appendix F: Results of independent judge reliability

tests $\ldots \ldots \ldots \ldots \ldots \ldots \ldots \ldots \ldots \ldots \ldots \ldots \ldots \ldots \ldots \ldots 121$ 
Appendix G: Interview transcripts ............ 122 
Table I: $\quad$ Summary of conceptions of distance education in the outcome space ................. 56

Table II: Aspects of each conception of distance education .........................69

Table III: Relationships between themes and

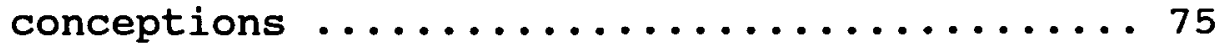

Table IV: Learners holding each conception .........84 


\section{LIBT OF FIGURES}

Figure 1: Relationships between conceptions of distance education ....................... 71

viii 


\section{ACRNOWLEDGEMENTS}

There are many people who made this research and thesis not only possible but also a tremendous learning experience for me. Dan Pratt, my adviser, was constantly supportive and ready to answer numerous questions. Tony Bates, Tom Sork, and Roger Boshier all contributed their expertise and helped to broaden my perspective.

I would also like to thank the open Learning Agency and, in particular, Don Black, who (through much paperwork!) identified interviewees. Those interviewees made the project possible, and they were, without exception, cooperative and a pleasure to talk to.

I learnt that I have wonderful friends. During all stages of the research and writing Elizabeth Carriere was an unfailing source of encouragement, constructive criticism, and coffee. I also had many an enthusiastic discussion with Pamela Welgan. In addition to Pam, I would like to thank Carol Wilson and Georgia Brown, who willingly gave their time to act as co-judges. 
CHAPTER I

\section{INTRODUCTION: THE MEANING OF DISTANCE EDUCATION}

What is distance education? Envelopes delivered through the mail, papers to read and questions to answer, perhaps a few television programs? The man in the street would probably express some such vague idea. On the other hand, professionals, as represented by the literature, present very definite views of distance education. Their definitions are derived from principles of learning and teaching as well as from practice in the field.

It is probable that most distance learners entering courses for the first time have a very unclear idea of what constitutes distance education. They do not know what kind of course materials to expect, what interaction they will have with the institution and tutor, what flexibility there will be in scheduling, and so on. Consequently, many new learners soon find that they have registered for a course which does not meet their expectations. Some inevitably drop out; others carry on, sometimes still struggling with misconceptions.

Yet, in the literature distance education is quite consistently defined in terms of a number of basic themes. This indicates that distance educators have a more or less common understanding of what constitutes distance education, 
even if they differ as to which aspects are of greatest importance.

\section{Distance Education and Open Learning}

At this point it is necessary to make a distinction between distance education and open learning (or open education), particularly since the subjects of this study were learners from the Open Learning Agency (OLA) of British Columbia. Rumble (1989b) pointed out: "That distance education and open learning are not opposing concepts stems from the fact that the two concepts deal with different things, the former stressing the means by which education is achieved, the latter the objectives and character of the educational process" (p.30).

Foks (1987) made the same point. Open learning is a student-oriented approach which

... seeks to provide students with as much control and choice as possible of the content, time, place, pace and method of their learning. Open learning should not be equated with any one mode of learning, nor should its learning resources automatically be based on any one medium or technology. (p.90)

Thus, institutions such as the OLA are concerned about providing students with freer access to education plus greater choice of where, when, and how to learn. of importance are criteria related to the place and pace of learning, the structure of programs, dialogue, support services, and the means used. The last refers to both the mode (contiguous or distance) and the media. While all of 
these elements are also mentioned in definitions of distance education, the emphasis is different. In distance education the overriding concern is with means; there is less concern with flexibility and the removal of restrictions for learners.

Therefore, distance education and open education are overlapping concepts, and in institutions like the OLA the trend is towards greater openness. However, in most countries the emphasis is still on "the means", not on "the objectives and character of the educational process". This is not surprising when one considers developing countries in particular. Since the 1970's one of the major trends in education has been the establishment of distance teaching universities (van Enckevort, Harry, Morin, \& Schutze, 1986). The large size of these universities and of other distance teaching programs in developing countries almost precludes openness; the emphasis is generally on dissemination.

The writer is especially interested in education at a distance as it is practised worldwide. Therefore, she chose to focus on distance education rather than open education, which is not such a widespread phenomenon.

Distance Education Themes in the Literature

There are certain themes that recur in definitions of distance education in the literature. The writer analyzed thirty-five definitions and found nine themes. 
The most frequently mentioned is the physical, and sometimes temporal, separation of the learner from the teacher or institution. Other significant themes are the individualized nature of study and the use of media/ technology.

These three themes, along with six others, represent the professional's understanding of distance education. On the other hand, studies of what the learner understands by distance education are virtually nonexistent.

\section{The Need for a Qualitative Approach}

As Calvert (1989) pointed out, understanding the learner is one of the major themes in distance education research. Many studies have focused on demographic characteristics of learners; many surveys have attempted to uncover learners' perceptions of different aspects of distance education. "However, though this type of work is recognized as essential for institutional management, there is growing criticism of its usefulness for a real understanding of students" (p.41).

Gibson (1990), too, stated: "Previous research and theoretical frameworks provide a beginning to our thinking and model-building. Inductive studies conducted with distance learners will provide additional breadth to our search for meaningful variables and relationships" (p.132). In recent years some researchers have begun to use intensive interviews to reveal learners' perceptions. This 
has represented a shift from institution-centred to learnercentred analysis and is a logical step if we are to understand why distance education learners act as they do. In Rockhill's words: "Learning is a fundamental social process, and it is a cultural process, as well as a psychological and cognitive process. Participation in adult education is an act that is integral to the life-world of the individual; its meaning waits to be explored" (1982, p.17) •

Hence, research into learners' understanding of the meaning of distance education may reveal conceptions of central importance, conceptions that relate to learning and, perhaps, to persistence or dropout. An individual's conceptions of a phenomenon affect the way he/she acts in relation to that phenomenon. Therefore, it follows that a learner's conceptions of distance education may contribute to persistence or dropout; since a significant proportion of all dropouts occur early in a program, the conceptions of new distance learners are of particular interest (Roberts, 1984). While there has been qualitative research of distance learners' perceptions of learning, of their approaches to study, and of their goals and motives, there have been no studies of students understanding of distance education as such.

Therefore, the questions posed in this study were: 
1. What are the conceptions of distance education held by adults who have recently begun participating in universitylevel distance education courses?

2. How do these conceptions compare or contrast with the definitions of distance education in the literature?

To investigate distance learners' conceptions of distance education, the writer used the method of phenomenography. It is a method by which the researcher attempts to identify people's understandings, or conceptions, of a phenomenon, in this case distance education. Standardized open-ended interviews were carried out, and the transcripts were rigorously analyzed, resulting in a range of conceptions.

\section{Why Identify Conceptions?}

But what is the use of identifying conceptions of distance education? The learners' conceptions are their understanding of what distance education is, and these conceptions are "where they're at". People act on the basis of their conceptions, as has been shown through phenomenographic studies of learning. These studies found that the way learners tackled their studies was closely related to their conceptions of learning (Marton \& Saljo, 1984; Marton \& Svensson, 1982; Saljo, 1979).

Bagnall (1989), too, has written: "While, potentially, all educational distance is undesirable whenever it occurs, 
the extent to which it is so depends upon the participant's creative perception of it" (p.24).

Thus, distance learners carry out their studies on the basis of the conceptions that they hold. At the same time, distance educators develop programs and support services in accordance with their understanding of distance education. That understanding is, at least in part, based on models and theories of distance education; these models and theories are, in turn, developed from definitions of distance education (Rumble, 1986).

If learners' conceptions and educators' understanding of distance education match, it is likely that learners will meet few unexpected problems in their studies. This would also indicate that distance educators can, with some confidence, continue to develop practice on the basis of present definitions of distance education. On the other hand, if learners' conceptions and educators' understanding of distance education are different, the learners will probably find discrepancies between their expectations and the reality of distance education. This may lead to dissatisfaction, frustration, and dropout.

Therefore, identification of distance learners' conceptions of distance education can be of value in itself. It reveals learners' understanding of the phenomenon, understanding from which expectations and actions arise. Identification of the themes that educators find significant in distance education reveals their understanding of the 
phenomenon as well. Their understanding is translated into distance education programs and support services.

Are learners and educators involved in a mutually understood enterprise, or are they sometimes working at cross purposes? A comparison of educators' understanding of distance education as expressed in the literature with learners' conceptions can help to answer this question. Where discrepancies exist, the findings could suggest a starting point for narrowing the gap. 


\section{CHAPTER II}

\section{REVIEW OF THE IITERATURE}

The term distance education has been in common use since the 1970's. However, education at a distance is sometimes given different names, some of them being independent study, distance study, distance teaching, and external studies. Definitions in the professional literature reflect the different emphases suggested by these names; the definitions sometimes reflect distance education's origin in correspondence study as well. All of them focus on features that differentiate distance education from conventional education.

\section{Definitions of Distance Education in the Literature}

Two early definitions illustrate how differently educators can view distance education. Wedemeyer's 1971 definition is:

Independent study consists of various forms of teaching-learning arrangements in which teachers and learners carry out their essential tasks and responsibilities apart from one another, communicating in a variety of ways, for the purposes of freeing internal learners from inappropriate class pacings or patterns, of providing external learners with opportunities to continue learning in their own environments, and developing in all learners the capacity to carry on selfdirected learning, the ultimate maturity required of the educated person. Independent study programs offer learners varying degrees 
of freedom in the self-determination of goals and activities, and in starting, stopping and pacing individualized learning programs which are carried on to the greatest extent possible at the convenience of the learners. (In Wedemeyer, 1981, p.51)

To wedemeyer the salient feature of distance education is the autonomy of the learner. On the other hand, Peters' 1973 definition is:

Distance teaching/education (Fernunterricht) is a method of imparting knowledge, skills and attitudes which is rationalised by the application of division of labour and organisational principles as well as by the extensive use of technical media, especially for the purpose of reproducing high quality teaching material which makes it possible to instruct great numbers of students at the same time wherever they live. It is an industrialised form of teaching and learning. (In Keegan, 1986, p.41)

To Peters the central feature of distance education is its industrialized form, which makes it possible to carry on mass education.

In 1977 Moore published a six-part "Theory of Independent study". The first part was:

Definition 1: Independent study is any educational programme in which the learning programme occurs separate in time and place from the teaching programme, and in which the learner has an influence at least equal to the teacher in determining goals, resources and evaluation decisions. (p.11)

That "...the learning programme occurs separate in time and place from the teaching programme..." apparently excludes the use of real-time communication such as teleconferencing; this may be seen as a holdover from correspondence study. The fifth part of the theory was: 
Definition 5: Distance, or Telemathic Teaching is a teaching programme in which, because of the physical separateness of learners and teachers, the interactions between them are conducted through print, mechanical or electronic devices. (p.12)

According to Moore, distance depends on two variables: (1) the extent of dialogue in the teacher-learner relationship and (2) the extent of structure in the teaching program with more rigid structure creating greater distance. Therefore, two-way communication and the structuredness of the teaching program are important variables. The relationship between them, i.e. between dialogue and structure, is the basis of the concept of "transactional distance" later put forward by Moore (1983).

Holmberg presented a definition in the same year as Moore.
The term 'distance education' covers the various forms of study at all levels which are not under the continuous, immediate supervision of tutors present with their students in lecture rooms or on the same premises, but which, nevertheless, benefit from the planning, guidance and tuition of a tutorial organisation. (In Keegan, 1986, pp. 41-42)

An important element here is "a tutorial organisation"; that is, distance education is institutionalized.

Holmberg has also developed a theory of "guided didactic conversation". For the distance learner there is:

...interaction with tutors and a supporting organization. The indirect presentation of study matter and the direct written or telephone interaction between the student and the tutor provide the instruments of conversation. The conversation is thus both real and simulated. (Holmberg, 1979, p.20) 
"Simulated conversation" means, in part, internalized

conversation. Therefore, two-way conversation is again seen as an important aspect of distance education.

In 1986 Keegan proposed a comprehensive definition of distance education.

Distance education is a form of education characterised by

- the quasi-permanent separation of teacher and learner throughout the length of the learning process; this distinguishes it from conventional face-to-face education.

- the influence of an educational organisation both in the planning and preparation of learning materials and in the provision of student support services; this distinguishes it from private study and teach-yourself programmes.

- the use of technical media; print, audio, video or computer, to unite teacher and learner and carry the content of the course.

- the provision of two-way communication so that the student may benefit from or even initiate dialogue; this distinguishes it from other uses of technology in education.

- the quasi-permanent absence of the learning group throughout the length of the learning process so that people are usually taught as individuals and not in groups, with the possibility of occasional meetings for both didactic and socialisation purposes.

Distance education is to be regarded as being constituted of these five interdependent elements, which remain constant essential components even if their content is different in separate institutional situations. In addition there are two socio-cultural determinants which are both necessary preconditions and necessary consequences of distance education. These are:

- the presence of more industrialised features than in conventional oral education.

- the privatisation of institutional learning. (pp.49-50) 
This definition synthesizes the work of others, but it does not include autonomy of the learner as an element of distance education.

Garrison and Shale (1987) found that Keegan's definition was too restrictive and offered instead "three criteria essential for characterising the distance education process...." They are:

1. Distance education implies that the majority of educational communication between (among) teacher and student(s) occurs noncontiguously.

2. Distance education must involve two-way communication between (among) teacher and student(s) for the purpose of facilitating and supporting the educational process.

3. Distance education uses technology to mediate the necessary two-way communication. (p.11)

Their emphasis is on the non-contiguity of the process and on the importance of two-way communication which uses technology.

One of the most recent attempts to define distance education has been by Rumble (1989a). Also drawing on others' contributions, he has proposed a very comprehensive, if cumbersome, definition.

1. In any distance education process there must be: a teacher; one or more students; a course or curriculum that the teacher is capable of teaching and the student is trying to learn; and a contract, implicit or explicit, between the student and the teacher or the institution employing the teacher, which acknowledges their respective teachinglearning roles.

2. Distance education is a method of education

in which the learner is physically separate from the teacher. It may be used on its own, 
or in conjunction with other forms of education, including face-to-face.

3. [optional] In distance education learners are physically separated from the institution that sponsors the instruction.

4. The teaching/learning contract requires that the student be taught, assessed, given guidance and, where appropriate, prepared for examinations that may or may not be conducted by the institution. This must be accomplished by two-way communication. Learning may be undertaken either individually or in groups; in either case it is accomplished in the physical absence of the teacher.

5. Where distance teaching materials are provided to learners, they are often structured in ways that facilitate learning at a distance. (pp.18-19)

Although the definition seems to cover nearly all possible variations of distance education, Carl has pointed out that it is, in fact, not all-inclusive. This is because it concentrates on education as a function of an institution and is based on traditional forms of education (Carl, 1989). While Carl may disagree with defining distance education as institutionally based, most of the definitions in the literature do, in fact, state or imply that an organization is central to distance education. This is just one of the themes that runs through the definitions.

Themes in Definitions of Distance Education

In order to identify themes in the definitions of distance education that are found in the literature, the writer analyzed thirty-five statements by twenty-six distance educators. These statements were mostly 
definitions; a few of them were supporting descriptions.

The method was as described below.

When Keegan (1986) surveyed the definitions of distance education, he analyzed each one by listing its elements. The writer followed the same procedure. When a single author had published a definition more than one time, all the elements of the earliest were listed then only additional elements in the later definitions. A total of twenty-three different elements was found, and the writer noted how many times each occurred. If an element occurred five or more times, it was considered a theme. Nine themes emerged; they are listed below in descending order of frequency.

1. There is physical, and sometimes temporal, separation of the learner and the teacher or institution.

2. Study is usually individualized or privatized.

3. Media/technology are used.

4. An institution organizes the education.

5. Face-to-face contact and group learning are possible.

6. The learning materials are prepared/structured by an institution.

7. There is two-way communication, sometimes referred to as interaction, between the learner and the teacher or institution.

8. There is an instructional process with a diversity of instructional methods. 
9. The teacher or institution dispenses or imparts instruction.

There are several elements that did not emerge as themes although they might have been expected to. The industrialized form of distance education and its potential for mass education were mentioned by only three authors. similarly, only three writers cited autonomy as a desirable goal or attribute of learners.

Another theme that might have been expected, namely the purpose of distance education, was mentioned only by Garrison and Shale (1987). To them "...the distinguishing feature of distance education is that it is a means of extending access to education to those who might otherwise be excluded from an educational experience" (pp.10-11). Unfortunately, they contradicted this statement in the same article when they stated, "...distance education is distinguished by the process that it employs and should not be exclusively associated with particular aims, content, or institutions" (p.12).

Thus, nine separate themes were identified in the definitions of distance education found in the literature. They were later compared to the conceptions of distance education held by distance learners.

The Importance of Context

Definitions form a basis for theories and models, which in turn influence the development of distance education 
programs. However, the converse is true as well; an educator's definition grows out of his/her own experience of distance education.

The above themes were derived from thirty-five definitions or supporting descriptions, and they do, indeed, show that different distance educators have different understandings as to what constitute the essentials of distance education. This is no doubt due to the diversity of distance education itself.

Mugridge (1989) pointed out that "... as they [distance and open learning systems] have been and are being set up in different parts of the world, they have taken account of the widely differing geographical, demographic, historical, societal situations in which they are placed" (p.84).

Thus, distance educators in diverse regions are working in diverse systems. Seabourne and Zuckernick (1986), writing of course design and development in Canada alone, stated:

Throughout Canada, the practice of distance education is eclectic. The tendency of almost every institution involved in a programme of distance education is to adapt and refine components of selected models in order to install a system appropriate to the needs of its particular clientele. (p.37)

Therefore, it can be assumed that the open Learning Agency has developed a particular view of distance education from the British columbia context. In fact, the OLA has produced two booklets defining both distance education and open learning. The earlier (Open Learning Agency of British 
Columbia, 1989) focused on distance education much more than it focused on open learning. The definition and description of open learning is one paragraph; that of distance learning takes up five times as much space. The first paragraph about distance learning reads:

Open learning encompasses the spectrum of learning opportunities -- from entirely selfdirected to the traditional classroom. "Distance education" refers to those approaches in the open learning spectrum that involve the development of specially designed instructional materials and their structured delivery to individuals separated from the institution by space and/or time. Communication between the two, learner and institution, need not be contiguous in a distance learning situation. (p.2)

The remainder is almost entirely about the media or technologies used.

The second booklet (Open Learning Agency, 1991a) focused very largely on open learning and much less on distance education. This time the definition of open learning is lengthy and distance education is mentioned in only one paragraph:

While these terms [open learning and distance education] are often used to mean the same thing, they describe different concepts. Put simply, open learning refers to an educational policy while distance education describes a means by which instruction is offered. The two are linked, however, in the sense that open learning frequently makes use of distance education in delivering instruction. On the other hand, distance education does not necessarily occur in the context of open learning. (p.5)

To answer the second question posed by this thesis (How do learners' conceptions compare or contrast with the definitions of distance education in the literature?) it was 
necessary to consider not only the literature as a whole but also that of the OLA in particular.

\section{Learners' Understanding of Distance Education}

Do learners see distance education in the same light as distance educators? It seems doubtful.

There has been very little investigation of learners' understanding of phenomena in adult education in general or distance education in particular. Some research has looked at learners' attitudes and perceptions; even less research has focused on actual understandings.

In both adult education and distance education some of the principal concerns of researchers are participation, non-participation, and dropout. A large proportion of all research is directed towards understanding these phenomena, and the ultimate reason for many other studies is also to improve participation. Both model builders and researchers have concerned themselves with learner attitudes, perceptions, and understanding but usually to a very limited extent.

There are a number of examples of such models. One is Miller's force-field analysis of participation in adult education. Miller (1967) hypothesized that positive and negative forces, including attitudes, create a balance which leads to participation or non-participation. Another example is Boshier's congruence model for participation and dropout. An individual's self-concept, i.e. perception of 
him/herself, is an important factor in participation or dropout (Boshier, 1973). A third example is Rubenson's expectancy-valence model. Expectancy is closely related to perceptions, and valence "expresses an affective attitude to the result of an action", while a further component of the model is "perception and interpretation of the environment" (Rubenson, 1977, pp.8\&35). Cross (1981) developed the Chain-of-Response Model on the basis of these others. It includes "self-evaluation" and "attitudes about education" (p.124). As Hayes and Darkenwald (1990) have pointed out, attitudes are viewed as unidimensional in the cross model. Two other models emphasize social variables in participation but bring in attitudes as well. Darkenwald and Merriam (1982) presented the Psychosocial Interaction Model. "The model emphasizes social-environmental forces, particularly socioeconomic status, not because individual traits or attitudes are unimportant but because less is known about their influence on participation" (p.142). One component of this linear model is "perceived value and utility of education", that is, attitudes and perceptions of adult education. Cookson (1986), too, stressed the social aspects of participation when he adapted the "interdisciplinary, sequential-specificity, time-allocation, life-span (ISSTAL) model" (p.131) of participation in social and political activities. "Attitudinal dispositions", which encompasses values, attitudes, expectations, and intentions, is one of the variables. 
All of these models illustrate that attitudes and perceptions are generally recognized as a factor in participation in adult education. However, other factors are given greater emphasis.

An early study of the relationship of participation in and attitudes toward continuing education was carried out by Seaman and Schroeder (1970). They administered a preexisting instrument to measure "participation in educative behavior" (p.103) and developed another instrument to measure attitudes. Relationships among variables were found by using statistical analyses. One finding was that "Attitudes toward continuing education are not always reflected in extent of educative behavior" (p.104). Another was that factors other than those considered in the study affect the extent to which attitudes influence participation. The latter is no surprise since their two instruments inevitably restricted the scope of their results.

One of the main focuses of participation research in the last three decades has been learner motivation or orientation. Motivation includes "...attitudes to learning and oneself, priorities for the use of time, beliefs about the importance of schooling, and the like" (Cropley, 1989, p.145). It was Houle's 1961 study of adults' orientations to learning that formed the basis for further research. Among the others who followed up on Houle's work were Boshier (1971), Morstain and Smart (1974), Beder and 
Valentine (1990), and Lowe (1991). Each of them found a number of factors, or motivations, for participation. To arrive at these factors the researchers gave questionnaires to learners; in responding to the statements in those questionnaires, the learners expressed their attitudes and perceptions. It should also be noted here that research into motivation has been very largely in the positivist paradigm. Factor analysis of information obtained through questionnaires has been prevalent.

Hayes and Darkenwald (1990) also used factor analysis. "Recognizing the complexity of attitudes", they gathered data using an attitude scale based on a two-attitude model. They found three factors in the structure of attitudes toward adult education: "enjoyment of learning activities", "importance of adult education", and "intrinsic value of adult education" (pp.159\& 162). A three-dimensional view of attitudes is an improvement over a unidimensional view; however, it can hardly be called complex.

On the other hand, stalker (1989) countered the positivist trend in her phenomenographic study. She investigated people in groups generally identified as nonparticipants in adult education, rigorously analyzing interviews with twenty individuals in order to arrive at "...the conceptions of the uses of participation in organized adult education activities held by those in the workplace..." (p.ii). Taking a holistic view of individuals, stalker interviewed them in the workplace; she 
also did purposive sampling in order to emphasize dissimilarities rather than similarities among the interviewees. One of the main findings was that the conceptions of participants and non-participants in adult education did not differ. This was partly because individuals understood "participation" and "nonparticipation" differently.

Studies of non-participation, like those of participation and dropout, have usually looked at attitudes and perceptions using a quantitative perspective. Attempting to explain non-participation, Rubenson (1983) classified barriers to participation into three categories, one of them being dispositional barriers. As cross pointed out, "Dispositional barriers are those related to attitudes and self-perceptions about oneself as a learner" (Cross, 1981, p.98). Scanlan and Darkenwald (1984) identified six factors that are deterrents to participation. The first is "disengagement"; most of the statements loaded onto this factor reflect attitudes and perceptions.

one study of non-participation stands out from the others, however. This is Quigley's analysis of why functionally illiterate adults resist participation in adult basic education. With a theoretical basis in resistance theory and using phenomenological methodology, Quigley analyzed ten literary works of fiction about resisters who challenged the American school system. His main finding was that non-participants resist the values inherent in the 
school system, values different from their own. clearly attitudes and perceptions are of tantamount importance (Quigley, 1987, 1990).

Thus, adult education model building and research of participation, non-participation, and dropout have included some investigation of learners' attitudes, perceptions, and understandings. However, these have seldom been the main focus of studies. Even when researchers have used interviews, analysis has generally been by quantitative methods.

In distance education research of participation, nonparticipation, and dropout, there has been only a little model building; there have been attempts to adapt models from outside the field. Kennedy and Powell (1976) developed a descriptive model of risk of dropout, and learners' selfconcept is a factor involved. Kember (1989) proposed "a linear-process model of drop-out from distance education"; attitudes and perceptions do not play an explicit part in the model.

Sweet (1986) tested Tinto's model of dropout in higher education and found that it was also an appropriate framework for investigation of dropout in distance education. One of the variables in the model is "attitude orientation". Brindley (1988) adapted Bean and Metzner's model of attrition among adult part-time students. one category of variables in the modified model is 
"psychological outcomes". The factors comprising this category reflect attitudes and perceptions.

In their 1983 study of student dropout at the UK Open University, Woodley and Parlett made indirect reference to attitudes and perceptions under "motivational factors" and "other factors" (p.7). Other distance education studies of participation, non-participation, and dropout have not explicitly attended to attitudes, perceptions, or understandings.

Another UK Open University study by Mason and Morgan (1986) asked for students' opinions about certain aspects of their experience as Open University students. Open-ended questions attached to a questionnaire elicited these opinions. To analyze the answers, "The author ... read and re-read students' responses so as to 'immerse' herself in the data and to draw out what appear[ed] to be the 'significant phenomena' in students' experiences of oU study" (p.1). She found seven main areas of concern; for each area she summarized the main opinions and gave sample quotes. Her principal conclusion was: "Students can be seen to 'connect' with particular parts of the system which meet their preferred patterns of study" (p.14).

The research was undertaken for practical purposes, and therefore, its scope was limited. Nevertheless, the study is of special interest for two reasons: It asked students about their experience of ou studies. Also, the author used 
an inductive process to discover what was significant to the students.

There have been a good number of studies investigating attitudes and perceptions of particular aspects of distance education. Attitudes towards the use of various media have been explored most often (Hosie, 1985; Eckles \& Miller, 1987; Catchpole, 1988; Davie, 1988; Smith, 1988). Other researchers have focused on components of teaching programs, especially teaching materials (Willen, 1981; Kelly \& Swift, 1983; McCormick, 1985). Still others have investigated learners' expectations of problems related to distance studying (Cutress, Morrison, \& Palmer, 1983). All of these studies relied on questionnaires for gathering data, which were generally analyzed by statistical means.

Thompson (1990) first used questionnaires to identify students who were negatively disposed to correspondence education. He then interviewed forty-eight of them in order to find their attitudes to the teaching method. The most important finding was that learners wanted more interaction with the instructor; a minority wanted more interaction with other students. These results were obtained by statistical analysis of structured questions and content analysis of open-ended questions.

The studies by Mason and Morgan and by Thompson, which used interviews for data collection, partially reflected a shift towards the qualitative perspective. Another example of this shift was Parer's 1988 study in which he examined 
learners' self-report diaries to find, among other things, how learners perceived their experience of distance education study.

Hodgson (1986) interviewed learners in an attempt to find a relationship between, on the one hand, learning materials and the support system and, on the other hand, the learners' approaches to learning and "their experience of doing a distance learning course" (p.57). Attitudes and perceptions were central. Melton and zimmer (1987) interviewed faculty, students, and tutors in order to find their various perspectives on problems faced at the British Open University. After analysis of the interviews discussions based on the findings took place.

The last three studies gave no clear description of the actual process used to analyze the diaries or the interviews. Taylor and Morgan (1986), on the other hand, used a rigorous methodology, phenomenography, to analyze their interviews with British Open University students. From interviews carried out over six years they found learners' conceptions of learning, that is, learners' understanding of the meaning of learning. They also found that "...skill in learning involves students in developing confidence in learning and also competence in learning.... The importance of these issues is that they appear to constrain students in how they tackle a task--i.e. their approach to study" (p.15). Therefore, not only did Taylor and Morgan bring to light valuable knowledge about learners' 
understanding of learning, but they also demonstrated why it is useful to know what learners' conceptions are.

Herrman (1988) developed a conceptual framework for understanding changing attitudes, beliefs, and behaviours of students when they become involved in external studies. In his interviews he used questions "...to stimulate the interviewees to reflect upon their situations and to elaborate on their perceptions of what was happening to them during the process of study" (p.6). Analysis of the interviews was based on a conceptual framework developed from a variety of sources in psychology and sociology. Needless to say, any conceptual framework is rooted in certain assumptions, but with recognition of this limitation, Herrman's study is a useful model for further research into learners' understandings of distance education.

Inglis (1988) investigated the development of independent learning in university-level distance education students. He used a hermeneutic process to analyze interviews with forty people--students, tutors, and officers in charge of centres. Thus, the analysis was an interpretation of the words not only of those developing learning autonomy but also of others who observed the learners going through that process. Inglis immersed himself in the language of the interviews, but he also made use of "key informants", people representative of those in distance education in that area. They helped the researcher 
to reflect on the interviews and to identify issues from the perspectives of the interviewees.

The results of the study are disappointing. Inglis presented a list of 33 statements and phrases which were "the language of independent learning from key informants" (p.252). He also presented a list of 26 statements and phrases which were "the metalanguage of the participants" (p.253). The lists were used in the development of a distance education survey. While a list of 59 statements and phrases may be useful for designing a survey, it is of little use to the educator who wishes to know what individuals understand independent learning to be. To arrive at such understandings, or conceptions, the researcher would have to return to the interviews and discover common elements in the statements.

This survey of the literature shows that there has been some research of learners' attitudes, perceptions, and understanding of various aspects of adult education and distance education. Most of the studies have used the positivist paradigm, which usually ignores the learner's context and, in fact, tells us little about the learner as an individual. The learner emerges as a generalization. on the other hand, a shift towards the naturalistic paradigm is now occurring, as illustrated by researchers like Stalker, Quigley, Mason and Morgan, Taylor and Morgan, Herrman, and Inglis. While all six of these studies offered 
insights into learners, only stalker's research along with

Taylor and Morgan's used a truly rigorous method of analysis. That method, phenomenography, was chosen for this study 
CHAPTER III

\section{METHODOLOGY}

\section{The Naturalistic Paradigm}

Phenomenography is a qualitative method of analyzing data; it is used within the naturalistic paradigm. A brief outline of the basic assumptions of naturalism makes it clear that the paradigm provides the perspective necessary for revealing understandings held by distance education learners. The following draws on a summary by Lincoln and Guba (1985) .

In the naturalistic paradigm, "There are multiple constructed realities that can be studied only holistically" (p.37). That is, reality is not an entity "out there" which can be fragmented into discrete variables and processes. Each distance learner experiences a different world, and his/her realities are derived from that personal world. A learner's understanding of distance education is not separate from his/her experience.

The naturalistic paradigm holds that the inquirer cannot be independent of the subject of inquiry (the person); interaction between the inquirer and the subject is inevitable. In an interview everything the interviewee says is influenced by the presence and questions of the interviewer; the interview is constructed by the interaction 
of the two players. It is impossible for them to be completely unaffected by each other.

The naturalistic paradigm aims at describing individual cases, which are time and context bound; this builds up into "... an idiographic body of knowledge in the form of 'working hypotheses'" (p.38). Distance learners can form an understanding of distance education only from their own point in time and in relation to their own position in the world. If researchers denude these understandings of the context which was instrumental in creating them and if they amalgamate the now incomplete understandings in order to generalize, the result can only be meaningless statements.

The naturalistic paradigm maintains that it is not possible to distinguish causes from effects; there is "mutual simultaneous shaping" of all entities (p.38). Does the learner develop an understanding of distance education in a linear cause-and-effect manner, or is his/her understanding the result of a more complex and integrated process? The latter seems likely.

Finally, in the naturalistic paradigm inquiry is seen as value-bound. Every researcher has values and, consciously or unconsciously, makes assumptions; every decision about what to investigate and how to do it is influenced by those values and assumptions.

This outline makes it clear that the naturalistic paradigm provides an appropriate framework for an attempt to 
delve into learners' experiences and conceptions of distance education.

\section{Phenomenography}

...phenomenography is a research method for mapping the qualitatively different ways in which people experience, conceptualize, perceive, and understand various aspects of, and phenomena in, the world around them. (Marton, 1986, p.31)

Phenomenography is a relatively new method of research. In order to characterize phenomenogaphy, the writer will first compare it to phenomenology and then explain the concepts involved in a phenomenographic study.

Marton devised phenomenography, and he has compared it to phenomenology (Marton, 1981, 1986, 1988).

Phenomenography and phenomenology share certain basic features: both are relational, experiential, contextual, and qualitative. On the other hand, there are several significant differences.

Firstly, phenomenology has a first-order perspective; that is, it aims at revealing "the world as it is" (Saljo, 1979, p.2). It "...concentrates on observable behaviours or items" (Stalker, 1989, p.37). Phenomenography has a secondorder perspective; that is, it aims at revealing "the-worldas-perceived" (Saljo, 1979, p.2). It "...attempts to reveal how things look from the point of view of the respondent..." (Stalker, 1989, p.37). 
Secondly, phenomenology looks for the essence of an aspect of reality or experience. It looks for "...that which is common to different forms of experience" (Marton, 1986, p.41). Phenomenography looks for the variations of experience. Phenomenographers believe that "...phenomena, aspects of reality, are experienced (or conceptualized) in a relatively limited number of qualitatively different ways" (Marton, 1981, p.181).

Thirdly, phenomenology is concerned with pre-reflective thought about aspects of reality or experience. That is, the phenomenologist makes a "distinction between immediate experience and conceptual thought. In a phenomenological investigation, we should 'bracket' the latter and search for the former" (Marton, 1986, p.41). Phenomenography does not make this separation. "We try to describe relations between the individual and various aspects of the world around them, regardless of whether those relationships are manifested in the forms of immediate experience, conceptual thought, or physical behavior" (Marton, 1986, pp.41-42).

Finally, phenomenography alone is involved with the idea of conceptions and produces categories of description as results. The categories are not simply discovered and listed; relationships between them are also found. These terms, conceptions and categories of description, are more fully explained below.

Another way to describe phenomenography is to outline the concepts involved in a phenomenographic study. The 
phenomenographer believes that "...there is just no way in which we can look into ourselves. What we can do instead is to say how the world appears to us..." (Marton \& Saljo, 1984, p.38). Therefore, phenomenographers usually interview subjects and ask questions about their experience of a phenomenon. The questions are not introspective ones. The phenomenographer then identifies in those interviews comments that are relevant to the phenomenon under investigation. These quotes are called units of meaning and depend on the context for their meaning. As Marton and Saljo (1984) stated, "The meaning of a comment could occasionally lie in the words themselves but, in general, the interpretation [has] to be made in relation to the context within which that comment [has] been made" (p.38).

From the "units of meaning" emerge conceptions of the phenomenon. A conception refers to actual experience; it "...constitutes a particular way of viewing and thinking about an aspect of the surrounding world" (Dahlgren, 1984, p.30). A conception is contextual because it is derived from a particular context; it is not an inherent quality of the individual or the phenomenon (Saljo, 1988, p.42). It is also relational; that is, "We deal with the relation between the individual and some specified aspect of the world..." (Marton, 1986, p.33). In this case the "specified aspect" is distance education; it is of central importance. 
From conceptions emerge categories of description. While conceptions refer to actual experiences, categories of description are abstractions, the researcher's way of discussing conceptions. "In talking about categories of description, then, we 'bracket' the dynamic-activity perspective and we consider the categories almost as if they were 'frozen' forms of thought" (Marton, 1981, p.196).

The phenomenographer usually identifies three to five categories of description; taken together they are referred to as an outcome space.

The range of categories ... can be described as an outcome space .... It is therefore an empirical concept which is not the product of logical or deductive analysis, but instead results from intensive examination of empirical data. Equally important, as used here, the outcome space is content-specific...." (Dahlgren, 1984, p.26)

Unfortunately, there is confusion in the literature around the terms "conception" and "category of description". Several phenomenographers (Marton, 1981; Renstrom, Andersson, \& Marton, date unknown; Saljo, 1988) use the terms interchangeably when referring to the researchercreated descriptions which make up the outcome space.

The distinction between the learners' conceptions and the researcher's categories of description is a critical one, yet discussion using these two terms can become confusing. Therefore, in this study the term "category of description" is not used. Instead, the learners' personal understandings of distance education are referred to as "the learners' conceptions"; the researcher's descriptions of 
those conceptions are referred to as "the conceptions found by the researcher" or as "the conceptions in the outcome space".

An outcome space is the final result of a phenomenographic study; it is the set of conceptions discovered by the researcher, a description of the range of conceptions of a phenomenon that have been found. In this study the outcome space is a description of the range of conceptions of distance education held by some adults new to distance education.

The researcher also finds relationships within and between the conceptions in the outcome space. To discover those relationships a number of analytical concepts can be used. Beaty, Dall'Alba, and Marton (1990) stated that "... a conception is a way of delimiting a phenomenon from its context (and relating the phenomenon to its context as well) and discerning component parts of the phenomenon and the relationships between them" (p.35). This statement contains two important concepts. First, a conception exists within a context. Individuals discern that context differently and see the relationship between the phenomenon and that context in different ways. Second, a conception has component parts.

One of the component parts is the "what" aspect of the phenomenon. (In this study, what is distance education?) It is the overall meaning of the phenomenon as seen by the individual and is sometimes expressed in metaphors (Beaty et 
al., 1990, p.15). The other major component part is the "how" aspect of the phenomenon. (In this study, how does distance education take place?) It can also be referred to as the process. Different individuals focus on different component parts. Focus is another important concept in the analysis of conceptions.

Renstrom et al. (date unknown) concentrated on finding the focus of conceptions. They hypothesized that shared and/or shifting focus in different conceptions might be a "candidate for an internal explanatory mechanism of transitions between conceptions. ... A certain focus may recur within different conceptions and hence provide a bridge between them. ... On the other hand a certain focus can develop into a conception or a subconception...." (pp.51-52).

In reality conceptions are integrated wholes, but phenomenographers break them down for purposes of analysis. In this study the concepts of context, meaning, process, and focus are used to analyze the relationships within and between the conceptions in the outcome space.

What is the use of an outcome space, a description of the range of conceptions held by people? simply knowing these different understandings can be useful in itself; it expands our knowledge. In addition, "A careful account of the different ways people think about phenomena may help uncover conditions that facilitate the transition from one way of thinking to a qualitatively 'better' perception of 
reality" (Marton, 1986, p.33). It is to be hoped that a better understanding of learners' conceptions of distance education will lead to greater congruence between learners' and educators' perspectives on distance education and ultimately to better practice.

\section{Selection of subjects}

The subjects of this study were adults who had recently begun distance studies through the open Learning Agency (OLA), a distance education institution based in Richmond, British Columbia. They were students enrolled in one of four Arts programs which can lead to a bachelor's degree from the Open University of the OLA. The four programs were: Bachelor of Arts, Major Program; Bachelor of Arts, General Program; Bachelor of General Studies; Bachelor of Arts in Administrative Studies.

There were several reasons for selecting these students. As has already been mentioned, the writer is interested in distance education because of its potential throughout the world. Internationally, distance education institutions focus on university-level studies more often than on technical, vocational, or other studies. Because of this it was appropriate to choose learners in university programs.

Arts students do not have a laboratory component in their courses; therefore, they do not come face to face with other students or with teachers. Hence, Arts students 
appear to experience a relatively "pure" form of distance education. In addition, due to the great variety of courses in Arts studies, it seemed probable that the learners, too, would be varied and might hold a wide range of conceptions of distance education.

The students selected were new to distance education; except for two, they had never done distance courses before. The two respondents who had taken previous distance courses saw those courses as totally different from their present ones. One respondent had done most of her schooling by correspondence while she was growing up overseas. The other had taken several accounting courses by correspondence. The two students saw themselves as new to distance education, and the researcher felt that their own assessment was valid. An additional consideration in selecting respondents was their location. Only students living in Greater Vancouver were asked to participate. This was for practical purposes as the researcher lives in Vancouver.

In late November and December the OLA sent letters to all Open University Arts students who had begun their first OLA course on November 1, 1990. These letters outlined the purpose of the study and briefly explained the individual's role if he/she participated. The number of students who agreed to be interviewed was low.

The OLA again sent out letters in early January, this time to all students who had begun their first course on January 1, 1991, and yet again in early March to all 
students who had begun on March 1, 1991. Because of the low positive response to the November and December letters, these later ones were sent not only to students in the four Arts programs described above but also to students enrolled in the Bachelor of Arts, General Science program. However, none of the latter agreed to an interview.

The writer had intended to use purposive sampling in order to maximize the possibility of finding a wide variety of conceptions of distance education. Unfortunately, this proved to be impossible, and the researcher was limited to using learners willing to be interviewed.

The nature of the inquiry made it possible to interview only some twenty people. They could in no way be considered representative of all distance education learners. However, the purpose of the study was not to generalize but to identify the conceptions held by some distance education learners.

The final number of subjects was eighteen, three for pilot interviews and fifteen for the main interviews. All were enrolled in an Arts program; all were new to distance education; all lived in the Greater Vancouver area.

\section{Data Collection}

When the OLA received positive responses to letters, they passed on the names to the writer, who then telephoned the students. In each case a convenient time for the interview was arranged, usually at the learner's home. 
The setting of the interviews was considered to be important. Most of the subjects did their distance studies at home; for these learners home was the usual setting for distance education, which was the focus of discussion. In fact, carrying out the interviews in the home had two advantages. It provided the most appropriate setting for discussion of distance education; in addition, the interviewees were on home territory and could feel more relaxed than elsewhere.

In fact, twelve of the eighteen interviews were in the respondent's home while one was at the writer's home. Four were at the respondent's place of work, which, in one case, was also where that individual did his distance studies. One was in a cafe.

All interviews except one took place while the respondent was still doing his/her first OLA course. The exception was a student who had finished her first course approximately one week before the interview. She had completed it in just over half the usual time and had immediately gone on to a second course.

Three pilot interviews were carried out. Careful reading of these interviews and discussions with colleagues led to modification of the questions. They were modified so that they were more likely to elicit responses containing conceptions of distance education and so that the interview flowed more smoothly. 
The fifteen main interviews were all semi-structured with open-ended questions. The interview schedule was designed to allow the interviewee to talk about all aspects of distance education. The interviewer also asked further, probing questions on the basis of what the respondent said, thus following leads given by the respondent. In addition, when it was appropriate, the investigator: (1) asked the learner to clarify statements, (2) paraphrased statements in order to verify her understanding of what the learner had said, (3) requested elaboration, and (4) verified the completeness of what the learner had said (Taylor, 1986). Thus, during each interview the researcher constantly made decisions about what questions to ask. Her decisions were based on statements already made in the interview underway as well as on knowledge gained from previous interviews. That is to say, analysis took place during the interviews. The interviewer formed hypotheses then asked further questions in an attempt to elicit evidence to support or refute them. This was in keeping with the position of Hammersley and Atkinson (1983). They contended that every researcher is inevitably influenced by the social world, the world of commonsense knowledge in which people continually make hypotheses in their everyday lives. Therefore, it is proper for naturalistic researchers to make hypotheses too. The content of each interview was determined partly by the investigator and partly by the respondent. 
Interviews lasted on the average about forty minutes, and at the end of each interview demographic information was obtained using a standard form. In addition, the investigator asked for more in-depth information about the individual's background, namely his/her family, work, past education, and future plans.

All interviews were tape-recorded, and the tapes were transcribed in full. During the weeks of data collection the writer also kept a journal in which she recorded steps taken, discussions with others, decisions related to methodology and the reasons for those decisions, plus relevant thoughts or insights that emerged. It was anticipated that this record would help in further analysis of the data and in establishing the trustworthiness of the study.

\section{Data Analysis}

The collection and analysis of data were not separate. While talking to learners, the interviewer constantly made decisions about appropriate questions to ask. Each decision depended on on-the-spot analysis of the interview underway; knowledge gained in previous interviews also influenced these decisions. That is, analysis of the data began while interviews were in progress.

All interviews were transcribed word-for-word by a professional typist. However, on receiving the transcripts, the researcher listened to each taped interview, made 
corrections in the transcripts, and confirmed that they included indications of hesitation, laughter, interruptions, and so on. In addition, during the interviews the researcher had made notes on perceived feelings, tones of voice, gestures, and the like; these, too, were noted on the transcripts. Consequently, the researcher became very familiar with each conversation.

The investigator read each transcript a number of times and identified quotes relevant to distance education. During the first two readings she picked out the quotes, or "units of meaning", representing the respondent's most central conceptions and highlighted them in one colour. Using those most salient "units of meaning", she also wrote a brief summary of the essence of distance education as seen by that respondent. During further readings the writer picked out other quotes that were less central to the learner's conception of distance education and highlighted them in another colour.

The next stage was to briefly restate each "unit of meaning" in one margin of the transcript. At this stage the investigator constantly referred back to the context, that individual interview, in order to interpret each "unit of meaning" as accurately as possible; the process was iterative. Since the "units of meaning" represented conceptions of distance education, the conceptions were being constructed in part by the learner through his/her words and in part by the researcher through her 
interpretation. In the other margin the researcher noted which aspect of distance education the "unit of meaning" was about, e.g. flexibility or study procedures.

The researcher then sent a copy of the highlighted transcript with its marginal notes to the respondent. In a telephone call about one week later the investigator asked the respondent if he/she agreed that the parts highlighted were, in fact, statements about or relevant to distance education. She also asked about the accuracy of the marginal notes. In general, the respondents confirmed the accuracy of both the highlighting and the notes; on a few occasions they suggested one or two minor changes. At this point the researcher also read to the respondent the summary of his/her most salient "units of meaning". Again, only occasionally did a respondent make a slight modification.

Once the respondent had confirmed the accuracy of the highlighting and marginal notes, the writer cut out those highlighted "units of meaning" with their notes from a photocopy of the transcript. These cut out quotes were pooled.

From this point on attention focused on the meaning embedded in the quotes themselves. It did not focus on their meaning in the context of individual interviews although on occasions it was necessary to refer to the original transcripts for clarification.

The researcher did not immediately pool the "units of meaning" of all fifteen transcripts. In fact, not all 
interviews had been transcribed when the next step commenced.

The "units of meaning" from four interviews were sorted into eleven piles, each pile representing an aspect of distance education. This was done by reading each quote and by referring to the marginal note about aspect. At this point it was necessary to make decisions on questions such as: Do quotes using different words in fact refer to the same aspect? Can similar quotes be integrated into a core meaning or are those similarities, in fact, not close enough for integration? (Stalker, 1989) Therefore, this was an iterative process in which the researcher referred back to the pool of "units of meaning" when interpreting meanings. She then reread all the quotes in each pile, grouped together those that seemed to express the same idea, and wrote down those ideas.

Following this, the investigator read all of these ideas in order to find themes. Thus, very tentative conceptions for an outcome space were noted. There was no expectation that these conceptions would stand up with further analysis, but the exercise proved useful. The researcher felt that she had found a satisfactory way to deal with the very large number of "units of meaning". In fact, this procedure was used to analyze the "units of meaning" of the next five interviews, then another three, and finally the last three. The conceptions evolved as more and more ideas were added to the lists and as the 
investigator gained experience. Once the "units of meaning" of all fifteen interviews had been thus analyzed, the researcher had a tentative set of conceptions, an outcome space.

In order to finalize these conceptions the researcher tried to fit all "units of meaning" into one or the other of them. She reread the quotes and modified the conceptions a number of times until satisfied that the group of "units of meaning" in each conception displayed similarities and was clearly delimited from the other groups.

At this point, then, the set of conceptions as well as criteria for defining those conceptions were established. The researcher described each conception in a way that identified its core meaning. Thus, the result of the analysis was a set of conceptions; these conceptions were interrelated and formed an outcome space. It represented "the qualitatively different ways in which people experience, conceptualize, perceive, and understand" distance education (Marton, 1986, p.31).

Marton (1986) has pointed out that:

The original finding of the categories of description [conceptions in the outcome space] is a form of discovery, and discoveries do not have to be replicable. On the other hand, once the categories have been found, it must be possible to reach a high degree of intersubjective agreement concerning their presence or absence if other researchers are to be able to use them. (p.35)

Therefore, at this stage three fellow students carried out reliability checks on the conceptions. 
The following procedure was used. The investigator wrote down her description of each conception and the criteria for placing quotes in each one. Twenty quotes were randomly drawn from the pile for each conception and all were shuffled. Each of the three judges then attempted to place those eighty quotes into the four conceptions on the basis of the investigator's descriptions. The extent of agreement between the investigator and the judges was a measure of the reliability or, to use the naturalistic term, the dependability, of the conceptions. In fact, agreement for each conception ranged from 90 to 100 percent; dependability was established.

\section{Trustworthiness}

From the beginning it was considered important to establish the trustworthiness of the data, that is, their credibility, transferability, dependability, and confirmability. These qualities are equivalent to internal validity, external validity, reliability, and objectivity in the rationalistic perspective (Guba, 1981; Lincoln \& Guba, 1985). The procedures of data collection and analysis already described contributed to trustworthiness. What follows is a fuller explanation.

Credibility refers to the truth value of the data. To quote Lincoln and Guba (1985), "In order to demonstrate 'truth value,' the naturalist must show that he or she has represented those multiple constructions adequately, that 
is, that the reconstructions ... that have been arrived at via the inquiry are credible to the constructors of the original multiple realities" (pp.295-296). Therefore, several procedures were followed to ensure credibility. Before their interviews the subjects had time to think about their perceptions and experience of distance education. This was because there was a time lapse between their receiving the initial letter, being telephoned, and actually being interviewed. This period of time was one safeguard against spur-of-the-moment "conceptions" of distance education.

There was a framework of set, open-ended questions for the interviews; however, during interviews the researcher continually probed for the students' perceptions and experience of distance education. At the same time she constantly carried out member checks; that is, the "data and interpretations [were] continuously tested as they [were] derived..." (Guba, 1981, p.85).

To be precise, at the time of the interviews the researcher gave the subjects a chance to confirm whether they actually intended to make their statements. subjects also had the opportunity to correct errors of fact, challenge the researcher's interpretation of their statements, and add more information. In fact, the final set question in each interview was; "Is there anything else you'd like to add?" Overall, the subjects were given the chance to assess the adequacy of the interview and to 
confirm particular points. Each interview was long enough to ensure that the subject had fully expressed him/herself about distance education.

Throughout the collection and analysis of data, there were debriefings with the researcher's adviser and fellow students. These ongoing discussions helped the researcher to become aware of her biases and her bases for interpretation. The discussions provided an opportunity to explore meaning and an opportunity for the development of further steps in the methodological process. The researcher recorded these debriefings in her journal.

Some weeks after each interview the researcher again spoke to the learner, who had been given a copy of his/her transcribed interview. On this transcript the researcher had highlighted the quotes she thought relevant to the student's understanding of distance education. She had also made marginal notes of her own interpretation of the student's words and of the aspect of distance education being talked about. The researcher asked the student to confirm or deny that the highlighted quotes picked out his/her main points and that the interpretations were correct. If the student disagreed, he/she was asked to make corrections. At the same time the respondent had the opportunity to confirm or modify a summary of the essence of his/her view of distance education, a summary which had been written by the researcher. 
Transferability refers to the applicability of the findings to other contexts. Since naturalistic investigators disagree with the positivists' expectation of generalizability,

... the naturalist can only set out working hypotheses together with a description of the time and context in which they were formed to hold. Whether they hold in some other context, or even in the same context at some other time, is an empirical issue, the resolution of which depends upon the degree of similarity between sending and receiving (or earlier and later) contexts. (Lincoln \& Guba, 1985, p.316)

In other words, the researcher should provide as much background information as possible so that other investigators will be able to decide whether there is enough similarity between the original context and another context for transfer of the findings. It had been hoped that two procedures could be followed to establish transferability: purposive sampling and collection of sufficient descriptive data.

In the event, purposive sampling proved to be impossible; however, descriptive data were collected. At the end of each interview the respondent filled in a standard form to provide demographic information. Following that, the interviewer asked further questions about family, work, education, and future plans. All respondents were forthcoming and provided a considerable amount of information.

Dependability refers to the consistency of the data. As Guba pointed out, because of the naturalist's belief in 
multiple realities and the use of human instruments, invariance is impossible but trackable variance is possible. That is, "... variance can be ascribed to sources: so much for error, so much for reality shifts, so much for increased instrumental proficiency (better insights), and so on" (Guba, 1981, p.81). Therefore, "... the naturalist seeks means for taking into account both factors of instability and factors of phenomenal or design induced change" (Lincoln \& Guba, 1985, p.299). In order to ensure dependability the researcher did the following.

Three pilot interviews were carried out and were very useful in the development of questions that elicited conceptions of distance education. The interview schedule thus developed contained a number of set questions, but they were open-ended, and each answer given by a respondent provided a springboard for further probing questions. These probes grew out of previous statements, so the respondent and interviewer together constructed the interview. The researcher tried to be equally rigorous and thorough in her questioning of all interviewees.

Throughout the interview period the researcher had frequent conversations with her adviser or fellow students; these debriefings were important. In addition, the researcher kept a journal in which she recorded thoughts, insights, etc. relevant to the interviews.

A second procedure demonstrated the dependability of the conceptions discovered. As described above, independent 
reliability checks of the conceptions were carried out by three judges. The judges tried to fit randomly drawn quotes into the established conceptions, and agreement with the investigator was high.

Thirdly, the researcher established an "audit trail", which consisted of the tape recorded interviews, the transcripts, and the researcher's journal. These make it possible for others to examine the process of the inquiry, that is, how the data were collected and analyzed as well as how interpretations were made.

The same audit trail can be used to establish confirmability of the data since, to quote Guba again, there is a "... shift by naturalists away from the concept of investigator objectivity toward the concept of data (and interpretational) confirmability" (1981, p.87). In addition, the use of open-ended questions in the interviews, the debriefings, and the reading of transcripts by peers contributed to the confirmability of the data.

By using all of the procedures outlined above, the investigator attempted to establish the credibility, transferability, dependability, and confirmability of the data. 


\section{CHAPTER IV}

\section{RESULTB}

The results of this study attempt to answer the two research questions stated in Chapter $I$.

1. What are the conceptions of distance education held by adults who have recently begun participating in universitylevel distance education courses?

2. How do these conceptions compare or contrast with the definitions of distance education in the literature?

\section{The Outcome Space: Conceptions of Distance Education}

The conceptions of distance education held by the learners are expressed in an outcome space, which is the set of conceptions as described by the researcher. Although these conceptions are constructed by the researcher, they are grounded in the learners' conceptions, which refer to "... actual experiences, understandings, and conceptualizations that people have of various phenomena.... [People's] conceptions have experiential reality" (Beaty et al., 1990, pp.8-9).

Each conception in the outcome space is fully stated and illustrated below. In addition, each conception of distance education is described by breaking it down into four aspects: meaning, focus, process, and context. 
This breakdown is purely for reasons of analysis, in order to discover relationships within and between conceptions. In reality conceptions are integrated wholes.

Table I provides a summary overview of the conceptions found by the researcher. The complete description of each conception follows it.

\section{TABLE I}

Summary of conceptions of distance education in the outcome space

1. Distance education is a door opener

a) to future goals.

b) in everyday life.

2. Distance education is freedom

- from restrictions.

- to make choices.

3. Distance education is difficulties.

4. Distance education is structure and learner actions.

1. Conception 1 - Distance education is (potentially) a door opener. This conception is divided into two parts:

$1 a$ Distance education is (potentially) a door opener to goals in the future.

For some learners distance education opens doors to further courses, to university, to degrees, or to future work. Distance education is also described as a stepping- 
stone, a tool, and a means to an end. Some illustrative quotes are:

A: .... Did you have any particular hopes before you started?

R: Well, I hoped that I would complete it, do well, (pause.....) that it would open a ... it would just open the doors ... the doors up ... is this ... Psychology and Bachelor of Arts, 'cause that's the way I want to go. And that question still hasn't been fully answered because I am only a month into the course. When the course is finished and let's say I get my B.A. whatever, that's ... that's really going to encourage me to what way, you know, I'm gonna pursue.

A: When you say you hoped that it would open the door, you mean to further studies, to ultimately a B.A.

R: Yeah, yeah. And actually I'm enjoying Psychology, and $I^{\prime} m$ also looking forward .... Like, I keep looking in the ... the calendar, a Bachelor of Arts and what you can do, and I'm also thinking, well, at least at this point, if $I$ take all my base courses, then if I don't want to major in psychology, I can switch the major and still have ... like' cause philosophy interests me and sociology, and I thought, "Well, I can always switch that way too." So this is very handy too. It opens doors, yeah, that's what I mean, yes. (pp.429-430)

P: ... like I've learned that [distance education] is a good tool, that you can ... you can ... you can try to ... (pause...) to use it for your own as the best of your ... with the best of your abilities, to like -- not to promote, that's not the right word -- go ahead? I don't ....

A: Get ahead?

P: Get ahead, yeah.

A: So you're saying it's a tool which you, the student, can use to get ahead. 
P: Yeah. Like, and you don't .... Like I won't be completely .... I don't feel I will be completely (pause...) like (pause...) bare when I will go back to UBC? (laughingly) It's like not knowing anything about .... I feel I have a good tool in my hand to ... to learn the language, and it would be easier for me to get an entry at the university. (p.376-377)

For these learners the meaning of distance education is that it is a door opener. They focus on an outcome, that to which the door opens (e.g. a university degree). The process is by acting; the learner does not simply react. The context of distance education to these learners is practical; that is, the focus (an outcome) is seen within a practical context of education or work in the future.

1b Distance education is (potentially) a door opener in the learner's everyday life.

To these learners distance education may be a door opener in very practical ways. For example, he/she can study while continuing to work or take care of the family. Distance education may also open doors by providing an educational opportunity when no other exists for that individual. An illustration of this is:

A: How did you come to that decision? [to enrol in a distance education course]

I : Primarily for convenience. I didn't ... I wasn't able to go back to school full-time right now, until [my son] is in school full-time himself, which will be september. So I thought what I would do is take a couple of night courses and then take a couple of correspondence courses as well ... as well. So it meets a need for me. 
I'm able to do the work at home, and not have to deal with daycare and still get to spend some time with [my son]. (p.187)

Distance education can also be a door opener in abstract ways. It can open doors to more knowledge, which the learner may relate to the real world. In addition, distance education may also open the door to greater awareness and new perspectives. The learner can learn to do new things, learn about him/herself, and develop positive attitudes and feelings. Some examples are:

M: ... I guess you take it for granted a lot of ... a lot of your knowledge, but taking the courses was really enlightening. Like, even if I didn't pass them, I would still think that it was money well spent, because of the knowledge that you ... that you learn from it.

A: So, what are you learning about Law, about Sociology?

M: About Law, a lot of specifics that I wasn't aware of. With Sociology I've found quite interesting, just different ways of looking at ... at people and what they do and why they do it, which is .... I guess it just teaches you to look at things in a different perspective than what you normally are used to doing.

A: You say in the Sociology you feel you're learning different perspectives. Is that true in the Law course as well?

M: No. Having a fairly good understanding of the legal system of B.C., it ... it opened my eyes up to more areas. I guess it did teach me to think from ... or look at things from different perspectives, because I .... Yeah, it did. (pp. 293-294)

R: ... I'm studying again, and $I$ ' $m$... I find $I$ can go right back into the flow of studying again? 
That it's so rewarding, like, it ... it really boosts the self-esteem. And it's like being .... Accomplishment ... it's a challenge, but it's a positive challenge? You know, it's like ... someone like me that...that's been out of school for so long, it's like an awake ... almost an awakening. Like, wow, I'm using my, you know, brain; I'm not just doing manual work and this and that. I feel like eventually I'm gonna make a difference. Like I want to do ... I want to find a purpose, and $I$ thin ... this ... this gives me the esteem to think: Yeah, I'm gonna make a difference one day. (pp.434-435)

The meaning, focus, and process of conception $1 \mathrm{~b}$ are the same as those of 1a. The context, however, is somewhat different; it may be practical or abstract. When practical, the context is work, family life, or education. When abstract, the context is learning.

The internal relationships of conception 1 can be summarized as follows: Distance education is a door opener (meaning). The learner acts (process) in a practical or abstract context to gain an outcome (focus). He/she uses the structure and process of distance education to attain that outcome.

2. Conception 2 - Distance education means freedom, flexibility, and learning on one's own, all in practical ways.

Learners who hold this conception may see distance education as freedom from or freedom to. Some learners see distance education as freedom from restrictions, from 
interaction with other people, who are viewed negatively, or from travelling. The following quote illustrates this:

L: It was Business Management, same course, but done in a classroom, and I only went for about four or ... five nights I would say. And I was bored out of my mind. ... by about the fifth night, I was just so incredibly frustrated at the speed at which we were going. I wanted things to happen quicker, and they weren't. ... And they ... they couldn't because of discussion times and .... You know, Business Management, there are formulas and processes that you can pick up very quickly, or I found that I could, and I found that people were not grasping those ... those things, and I found myself sort of rolling my eyes and thinking: Oh, my God! You know, I'm going to have to listen to this again. ... So that was the ... that was really frustrating. (pp.263-264)

Conversely, distance education is seen as freedom to choose one's own course of action, particularly where, when, and how fast to learn. This is sometimes spoken of as the flexibility of distance education. It is especially being able to choose one's own schedule, pace, and deadlines plus being able to learn when one is ready to oneself. Illustrations are:

s: ... Actually what I find, it's ... with the distance education as opposed to going to a classroom, it's much more convenient. It's so much more convenient because I can now sit through, and I can go through at my own pace, which I am, which is slightly faster right now, and if $I \ldots$ if $I$ need to slow down, I can slow down, whereas if you're in a classroom you have to do this and this and this by such and such a time, no matter what, if you expect to keep up with the class. And sometimes that can be really ... grueling.... ... and one of the things I find is I don't feel as under pressure for my ... for deadlines even though I'm making my own personal 
deadlines that are maybe faster than the course $I^{\prime} m$ in. So it works better for me (laughs), and ... than if I were in a classroom situation. (pp. 460-461)

T: And as far as night sessions, those are the sorts I were going ... I was going to, and even ... even then I had to be really careful that they were on the nights that I didn't work, and it was kind of hard to pick that way because they don't plan on just for me. So I just found, you know, rather than going through that hassle, to ... to find a course where I can set my own schedule up rather than having to meet somebody else's schedule. (p.504)

Another part of this conception is learning on one's own, which is seen as having control of learning. Learning on one's own is viewed in a practical way, not a developmental way. The following quote shows this:

Q: The similarities [between conventional and distance education] are learning the subject matter, but the differences are: I'm doing it on my own; I'm learning it in a more concentrated, I think, in a more concentrated way; I feel I have control .... There's another thing too because, I think, because I have taught and I've nursed for so many years, I trust my own intelligence more than I do a lot of other people's intelligence? I'm learning this. Mind you, I'm not too impressed with this textbook either. But, at least what's in there I figure out for myself; I don't have someone else telling me their impression of what they think the author means? (p.396)

Learners who hold this conception see freedom and choice as the meaning of distance education. Their focus is the structure and process of distance education. The process for these learners is by acting, by using the 
structure and process of distance education to control and make choices; they do not simply react. The context is practical; it is the real life-world or studies, and even learning is viewed in a practical way.

3. Conception 3 - Distance education means difficulties counterbalanced by other factors.

The difficulties (problems and uncertainties) expressed by holders of Conception 3 are of six types. They are: time consumption; lack of self-discipline; conflict with other aspects of one's life; learning problems caused by lack of interaction, boredom, lack of confidence, or such; the learner-tutor relationship; and worry about outside recognition of a distance education degree.

There are other factors that counterbalance these difficulties. They include convenience, a sense of accomplishment, more learning, relating the learning to one's personal life, goals, and having paid the fees. Sometimes learners spoke of these counterbalancing factors in conjunction with their difficulties, even mentioning that there was a trade-off. More often learners spoke of the other factors separately. Quotes illustrating that distance education means difficulties follow.

E: ... you are really isolated. You have nobody to, uh, to talk to about what the readings were, and so you do get these different viewpoints but, you know, you're just reading them yourself, and if you were in a class situation, then you're going to have other .... Maybe I might not say 
anything, but I'd be having other people listening, you know, to listen to besides the professor in the class, and I just .... Myself, I think $I^{\prime} m$, just ... I need the stimulation of other people in the class to keep me ... keep my interest up, I guess, and really, you know, I think I would get more out of it. ...it would seem more alive or something. I find that, you know, it gets kind of boring this reading all the time. ... I think you're still in a void when you're doing things by distance education. You just .... It's ... it's sort of like in a void; you just don't know. It's difficult that way. (pp.138-139)

I: I haven't talked to my second tutor, so I'll be really curious to see what my impression formed is of my second tutor, but I didn't like the first tutor I had?

\section{A: Why was that?}

I: I found that she was not a real-life human body, and I had no sense of warmth or compassion from her or no interest in me as a person. And no interest for me to know her as a person either. ... Like I'm sure a lot of it was just style because what she ... whenever I asked her something, how she reacted to me is that she would give me back a question. And I understand that for some people that might be a way that they would help somebody to learn, but it didn't work in what I was trying to figure out, and I didn't see what her problem was and why can't you tell me the answer. ... I don't think that it was all because of her. Part of it would have been something that triggers in me in that it really set up for me like a parent-child relationship ... where every time I talked to her, I left the conversation feeling like a stumbling, mumbling child, and it was a really uncomfortable feeling. So I didn't enjoy my relationship at all with her. (pp.195-197)

L: Oh, it's absolutely impossible. I cannot, I cannot do it at the level, at the speed that I'm going at. It's my .... I should say that when I started it, my job was going smoothly. I think I indicated that earlier. Everything was nice and smooth, and January 1 everything wasn't so smooth. 
We embarked on a new venture in my business, which I was to head up, so my ... my day, my hours away from home extended by probably at least an hour, possibly two, at each end. And so my time ... free time was dramatically reduced. I have a three month-old daughter as $I$ indicated, and that .... (pause...) Now how shall I put this? The ... the amount of time that I was spending studying was reducing the amount of time that I could spend with my family. And I really didn't like that. After about the first three or four weeks I realized that I would not see them really grow up. I would be studying, and I would have a degree, but I don't think they would know me. And I can remember sitting down in the basement and hearing the words of "The Cat's in the cradle" in my head and thinking: I'm not sure that this is the right time to be doing this. (pp.271-272)

For learners who hold conception 3 the central meaning of distance education is difficulties. They focus on the structure and process of distance education. The process for these learners is sometimes to act and sometimes to react, either by trading off the difficulties against other factors or by giving up their studies. The context is these other factors, which may or may not sufficiently counter the difficulties. These other factors are sometimes practical (of the real-life world or studies) and sometimes abstract (learning or a sense of accomplishment).

4. Conception 4 - Distance education is a structure (including procedures, content, and standards), which requires or allows certain actions from the learner. Learners who expressed this conception talked about distance education's structure and their actions in a descriptive manner. They did not express value judgments 
like those in Conceptions 1, 2, and 3. In addition, the structure and actions were frequently intertwined in the descriptions. For these learners their own actions reveal the structure of distance education, and that structure also requires or allows those actions to take place.

The structure of distance education (in the narrow sense) includes scheduling, interaction (or lack of it) with others, media, services, etc. Procedures include delivery of materials and contact with the tutor. Content is information to be learnt. Standards include entry without grade 12 and the quality of courses. The following quotes are illustrations:

L: It's quite nice the way it's structured. It's something that's important about the correspondence is the way that you're kind of nibbling away at little bits at a time. That's very good. You do a chapter and then you do an assignment and that leads to a certificate and then the certificate leads to the ... the ultimate certificate, and then diploma and degree, so it's like it's got bench marks along the way. (p.284)

$\mathrm{K}$ : I suppose I didn't realize how organized and how available it [distance education] was. I didn't realize how many courses were available by distance education. I didn't realize you could ... could achieve a degree, for example. I thought that the college courses were the only ones available but, you know, you would have to sort of finish off in a college setting or a university setting. It surprised me that there was so many services available through the open Learning Agency, you know, the tutors and the counsellors and ... and all of those things that basically I had envisioned only being available through a more traditional, you know, university or college setting. So, you know, just ... just realizing how large an industry it was, and that 
excited me like, you know, I didn't want to go into something that was a baby, you know. I wanted to make sure that it was sound and, you know, and that the credits that I received were going to be recognized and, you know, all of those important things. (pp.246-247)

Learner actions are: study procedures, ways of learning, working towards a goal within distance education, use of resources, relationship with the tutor, and working on one's own. Illustrations are:

S: You have to reinforce your learning as you go along 'cause you're basically doing buildingblocks on what you're learning, and if you just read and then start to try and build your pyramid, it might be more difficult than as if you go along and do it. And that's the way the course does it. ... But if you don't really apply it right away, are you gonna remember it when you finish the chapter and have to go back and basically would have to read it again and ... and then do the assignment then? So really you're doing ... you read, you do a bit, you read, you do a bit, you read, you do a bit, and keep going like that.... (pp. 458-460)

L: I'm following the structure [structured procedure suggested by the manual] with the exception of really probably going to the end of the manual and reading the questions before I read the chapter, because I think what they want us to do is read the chapter and then answer the questions, whereas I don't want to have to go back through the chapter and find out if I've missed something. I want to make sure that $I^{\prime} m$ doing it as I'm doing it. I think I'm, cutting down on one reading. Whether that's good or not, I don't know. That's what I do. (p.269)

A: How have you evolved as a learner?

L: (Pause....) Well, I think the process of learning definitely improved that this ... the highlighting technique that I ... I sort of came across on my own. ... So from that ... from that 
point of view, yeah, I feel that the actual technique of learning I have improved. I would say probably that was the only ... the only thing. (p.285)

For learners who hold this conception, the meaning of distance education is its structure and learner actions. The focus is virtually the same, namely the structure and process of distance education. The process for these learners is by reacting; one does not act but reacts to the structure and process of distance education. The context is practical, usually studies and occasionally the real lifeworld.

Table II shows the meaning, focus, process, and context of each conception in the outcome space. It summarizes the above analysis.

Relationships between conceptions

Relationships within the conceptions in the outcome space were analyzed by fragmenting each conception into four components: the meaning, the focus, the process, and the context of distance education. The same heuristic device helps in the discovery of relationships between the conceptions.

Conception 4 (distance education = structure and learner actions) is clearly different from the other conceptions in one important respect. Its meaning (structure and learner actions) and its focus (structure and process of distance education) are nearly identical. 
TABLE II

Aspects of each conception of distance education

\begin{tabular}{|c|c|c|c|c|c|}
\hline & & MEANING & FOCUS & PROCESS & CONTEXT \\
\hline$\infty$ & 1 & $\begin{array}{l}\text { distance } \\
\text { education is } \\
\text { a door opener }\end{array}$ & an outcome & $\begin{array}{l}\text { learner acts } \\
\text { (uses structure \& } \\
\text { process of distance } \\
\text { education to attain } \\
\text { something) }\end{array}$ & $\begin{array}{l}\text { (a) practical } \\
\text { (b) practical } \\
\& \text { abstract }\end{array}$ \\
\hline$H$ & 2 & $\begin{array}{l}\text { distance } \\
\text { education is } \\
\text { freedom \& choice }\end{array}$ & $\begin{array}{l}\text { structure \& } \\
\text { process of } \\
\text { distance } \\
\text { education }\end{array}$ & $\begin{array}{c}\text { learner acts } \\
\text { (chooses, controls) }\end{array}$ & practical \\
\hline u & 3 & $\begin{array}{l}\text { distance } \\
\text { education is } \\
\text { difficulties }\end{array}$ & $\begin{array}{l}\text { structure \& } \\
\text { process of } \\
\text { distance } \\
\text { education }\end{array}$ & $\begin{array}{l}\text { learner acts } \\
\text { or reacts } \\
\text { (by trading off } \\
\text { or by giving up) }\end{array}$ & $\begin{array}{l}\text { practical } \\
\& \text { abstract }\end{array}$ \\
\hline 0 & 4 & $\begin{array}{l}\text { distance } \\
\text { education is } \\
\text { structure \& } \\
\text { learner actions }\end{array}$ & $\begin{array}{l}\text { structure \& } \\
\text { process of } \\
\text { distance } \\
\text { education }\end{array}$ & $\begin{array}{l}\text { learner reacts } \\
\text { (to the structure) }\end{array}$ & . practical \\
\hline
\end{tabular}


Learner actions are, after all, part of the process of distance education.

Therefore, Conception 4 is inward looking and of a different order than Conceptions 2 and 3 . "Structure and process of distance education" is both the overall meaning and the focus of conception 4. In conceptions 2 and 3 it is only the focus; the overall meaning of \#2 and \#3 is something broader. In fact, Conception 4 can be seen as the core or kernel around which Conceptions 2 and 3 have developed. (Figure 1) "Freedom and choice" is a positive response to the kernel, the positive side of the seed of distance education. "Difficulties" is the negative response, the negative side of the seed. Conceptions 2 and 3 are less inward looking than Conception 4. Conception 4 also differs significantly from Conceptions 1 and 2 in terms of process. In Conceptions 1 and 2 the learner acts whereas in Conception 4 he/she reacts. Reacting is another dimension of \#4's inwardlooking nature. Conception 3 has an intermediate position since its learners both act and react. A change in learner behaviour from reacting to acting might also lead to a change in conceptions.

Conception 3 (distance education = difficulties) is also linked to conceptions 1 and 2 in another way. The "other factors" which counterbalance the difficulties of \#3 are parts of \#1 and \#2. "Convenience" is part of \#1b and \#2; "a sense of accomplishment", "more learning", and 


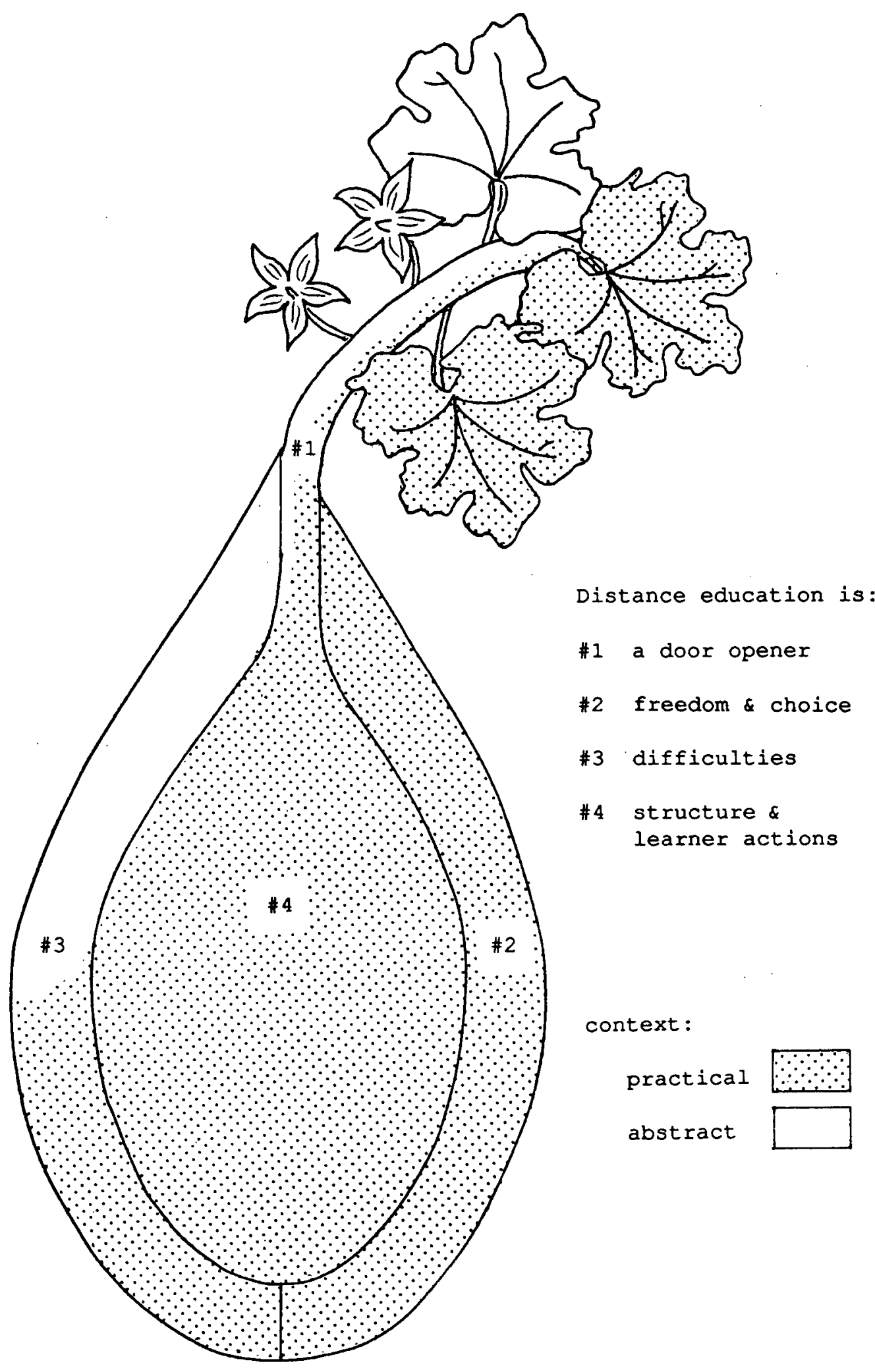

FIGURE 1

Relationships between conceptions of distance education 
"relating learning to real life" are parts of \#1b; "goals" is part of \#la. Only "having paid the fees" is not part of another conception. This clearly indicates that different learners perceive the significance of the "other factors" differently. It could also indicate a route for changing from one conception to another.

In all four conceptions there is a practical context; all learners see distance education as part of their real life-world. This creates a definite link between the conceptions.

only Conceptions $1 \mathrm{~b}$ and 3 also have an abstract context, that is, a context of learning in a developmental sense. In \#3 (distance education = difficulties) learning is sometimes a difficulty and sometimes a counterbalancing factor; in \#1b (distance education = a door opener in everyday life) learning is viewed positively. If an individual's view of learning shifted from negative to positive to more positive, this could represent a shift from Conception 3 to $1 b$.

Conception 1 (distance education = a door opener) stands out as different from all the others. This is for two reasons. First, while conceptions 2,3 , and 4 have the same focus (structure and process of distance education), the focus of Conception 1 is "an outcome" -- something which may even be beyond distance education itself. Second, while learners holding Conceptions 2, 3, and 4 act or react on the basis of "the structure and process of distance education" 
(the focus), learners holding Conception 1 do not focus on that structure and process. Instead they use it to attain an outcome. Conception 1 is more outward looking than the other conceptions.

Therefore, just as Conceptions 2 and 3 are of a different order than conception 4, conception 1 is of a different order than all three of the others. In fact, Conception 1 (distance education $=a$ door opener) can be seen as a sprout growing out of the kernel of Conception 4 (distance education $=$ structure and learner actions). It sometimes grows through Conception 2 (distance education = freedom and choice).

Relationships between Conceptions and Definitions in the Literature

In Chapter II nine themes were extracted from definitions of distance education in the literature. Although twenty-three different elements were mentioned in the definitions, these nine recurred most frequently. To reiterate, the themes are:

1. There is physical, and sometimes temporal, separation of the learner and the teacher or institution.

2. Study is usually individualized or privatized.

3. Media/technology are used.

4. An institution organizes the education.

5. Face-to-face contact and group learning are possible. 
6. The learning materials are prepared/structured by an institution.

7. There is two-way communication, sometimes referred to as interaction, between the learner and the teacher or institution.

8. There is an instructional process with a diversity of instructional methods.

9. The teacher or institution dispenses or imparts instruction.

The following is an analysis of the relationships between these nine themes and the four conceptions of distance education found by the researcher. Table III summarizes the relationships.

Conception 1 - Distance education is (potentially) a door opener (a) to goals in the future.

(b) in the learner's everyday life.

None of the themes relate to conception 1a. This is because the themes do not state or imply that the learner uses the structure and process of distance education to attain an outcome in the future. The themes are not outward looking. Nor is the practical context of conception 1a, namely education or work in the future, addressed in the themes.

It is possible to infer a relationship between Conception $1 \mathrm{~b}$ and four themes. For some learners distance education is a door opener because they can stay at home; 
TABLE III

Relationships between themes and conceptions

\section{Conceptions}

\begin{tabular}{|c|c|c|c|c|c|c|}
\hline Themes & $\begin{array}{l}1 \text { a } \\
\text { a door opener } \\
\text { to future goals }\end{array}$ & $\begin{array}{r}a \\
\text { in }\end{array}$ & $\begin{array}{c}\text { Ib } \\
\text { door opener } \\
\text { everyday life }\end{array}$ & $\begin{array}{c}2 \\
\text { freedom } \\
\text { choice }\end{array}$ & $\begin{array}{c}3 \\
\text { difficultieg }\end{array}$ & $\begin{array}{c}4 \\
\text { otructure } \\
\text { learner action }\end{array}$ \\
\hline 1 & & & $x$ & $x$ & $x$ & $x$ \\
\hline 2 & & & $x$ & $x$ & $x$ & $x$ \\
\hline 3 & & & & $\mathrm{x}$ & $\mathrm{x}$ & $x$ \\
\hline 4 & & & $x$ & $\mathrm{x}$ & $\mathbf{x}$ & $\mathrm{x}$ \\
\hline 5 & & & c & $\mathrm{x}$ & $x$ & $x$ \\
\hline 6 & & & & $\mathrm{x}$ & $\mathrm{x}$ & $x$ \\
\hline 7 & & & & $\mathrm{x}$ & $\mathrm{x}$ & $\mathrm{x}$ \\
\hline 8 & & & & $\mathrm{x}$ & $x$ & $\mathrm{x}$ \\
\hline 9 & & & $\mathrm{x}$ & $x$ & $\mathrm{x}$ & $x$ \\
\hline
\end{tabular}


this implies "physical, and sometimes temporal, separation of the learner and the teacher or institution." It also implies that "study is usually individualized or privatized." Other learners see distance education as a door opener because they can do courses unavailable at other institutions or even get an education when no other opportunity exists. This implies that "An institution organizes the education" and that "The teacher or institution dispenses or imparts instruction."

Although these four themes are related by inference to certain outcomes (the focus) of conception $1 \mathrm{~b}$, the learning outcomes are not addressed at all. They include the learning of content, the learning of new perspectives, and learning about oneself.

It follows that the abstract (learning) context of Conception $1 \mathrm{~b}$ is not addressed by the themes either. On the other hand, the practical context of the real life-world and studies lies implicitly behind all themes.

Conception 2 - Distance education means freedom, flexibility, and learning on one's own, all in practical ways.

Several themes relate directly to the essence of Conception 2. "Learning on one's own" is clearly related to "There is physical, and sometimes temporal, separation of the learner and the teacher or institution" as well as "study is usually individualized or privatized." From the 
same two themes it can be inferred that the learner has freedom from some institutional restrictions and from other people as well as freedom and flexibility to make at least some of his/her own decisions.

The focus of Conception 2 is the "structure and process of distance education". Therefore, the conception can be related by inference to all of the other themes since each of them refers to the structure and process of distance education. In fact, each theme is implied by statements made by the holders of Conception 2 .

Conception 3 - Distance education means difficulties counterbalanced by other factors.

All of the themes relate to Conception 3. Again, this is due to the fact that the focus is the "structure and process of distance education." This time the link between conception and themes is strong. The themes make statements about certain elements of distance education. In the eyes of the learner, it is these very elements that cause the difficulties or, in some cases, ameliorate them. For example, "There is two-way communication, sometimes referred to as interaction, between the learner and the teacher or institution." To some learners this causes a difficulty -a poor relationship with the tutor; to other learners it ameliorates a difficulty -- it personalizes distance education. 
The context of Conception 3 is sometimes abstract, including "other factors" such as a sense of accomplishment, more learning, and goals. No themes refer to these abstractions although they are important to the learner. While conception 3 and the nine themes are closely related, there is a basic difference in points of view. The learners see a value, either positive or negative, in each of these elements of distance education. The writers of the definitions have attached no overt value judgments to those same elements.

Conception 4 - Distance education is a structure (including procedures, content, and standards), which requires or allows certain actions from the learner.

As may be expected, all the themes relate very closely to Conception 4. Again, the themes refer to the structure and process of distance education, which is the focus of Conception 4. However, for the learner his/her own actions are also central and form a very significant part of the conception. The definition writers, on the other hand, seldom make overt reference to learner actions; those actions are simply implied.

Nevertheless, holders of Conception 4 and definition writers share the same point of view in another respect. They do not make overt value judgments about the various elements of distance education. 
When this writer analyzed the four conceptions in the outcome space, she found that learners saw themselves as acting or reacting, depending on the conception held. This is an important part of each conception (the process). Although interaction and control are extensively discussed in the literature (e.g., Holmberg, 1977 \& 1979; Garrison, 1989), the definition writers do not address this aspect of distance education. The reader of definitions can infer either that the learner acts or that he/she reacts.

Where does the Open Learning Agency definition of distance education stand in relation to these four conceptions? The OLA 1989 definition of distance education (Open Learning Agency of British Columbia, 1989) and the brief 1991 mention of it (Open Learning Agency, 1991a) were outlined in Chapter II. Five of the nine themes derived from the literature are explicit elements in the OLA definition; the four other themes can be inferred. There is a very heavy emphasis on one theme: "Media/technology are used."

One element of the OLA definition is not found in the themes. This element is the structured delivery to individuals of instructional materials. However, this element can be seen as an extension of other themes. Therefore, the relationship of the four conceptions to the OLA definition is the same as their relationship to other definitions in the literature. 
A caveat must be added here. The learners interviewed were taking courses by distance education; however, those courses were offered by the OLA in a broader context of open learning. Some of the learners' comments were, in fact, about open learning. For example, they talked about the recognition and transfer of credits from other institutions. Such comments were not "units of meaning" about distance education, and they were not used in the discovery of the conceptions.

To sum up, there are many relationships between the conceptions of distance education in the outcome space and the themes derived from definitions in the literature. At the same time, a number of important aspects of the conceptions are not represented in the themes.

\section{other Definitions of Distance Education}

At this point it must be recognized that there are other definitions of distance education than those in the academic literature. These other definitions are more practical ones and are often implied rather than openly stated. There are the unpublished but very influential "philosophies" of senior decision-makers of institutions offering distance education. There are also policy/ administrative "definitions" embedded in charters, mandates, mission statements, etc. The writer examined such documents 
from the Open Learning Agency and the UK Open University and found that conceptions $1 \mathrm{a}$ and $1 \mathrm{~b}$ are implied in them.

The charter of the UK Open University (Government of United Kingdom, Privy Council, 1969) specifies that the university has the power to collaborate with other institutions of learning and should attempt "... to promote the educational well-being of the community generally" (sec. 3). Both of these imply that future goals, educational and other (Conception 1a), are considerations. Another objective is "... the advancement and dissemination of learning and knowledge ... by a diversity of means..." (sec. 3) . Thus, Conception $1 \mathrm{~b}$ is represented; the "definition" promotes new knowledge and learning as well as diverse means of teaching, which allow learners to fit education into their everyday lives.

Similarly, a major theme of the open Learning Agency Act of 1987, the OLA mission statement, and the OLA mandate is collaboration with other educational institutions; this helps learners to achieve educational goals. In addition, the OLA's mission is "... to provide leadership in developing and maintaining a province-wide open learning system in order to make lifelong training and educational opportunities available to all the people of British Columbia" (Open Learning Agency, 1991b, p.1). This indicates concern not only with goals in the future (Conception 1a) but also with opening doors to education and work in people's everyday lives (Conception 1b). 
Both the UK Open University and the OLA "definitions" refer to open learning, and certainly, not all distance learners have the benefit of collaboration with other institutions. However, the other elements apply to distance education as well as to open learning.

These two examples show that there is some discrepancy between policy/administrative "definitions" of distance education and definitions in the literature. The former show concern for certain aspects of distance education that are central to the conceptions of some learners; the latter tend to overlook those same aspects.

\section{Learners Holding Each Conception}

The conceptions in the outcome space are constructs of the phenomenographer. They are abstractions that emerge from a pool of "units of meaning", and they describe the range of conceptions held by individuals. Learners' conceptions, on the other hand, refer to actual experience. Since each conception in the outcome space is constructed from the pool of "units of meaning" (i.e., quotes from a variety of respondents), it is possible that no individual respondent actually holds a conception that corresponds precisely to the one in the outcome space. "Units of meaning" do not necessarily represent understandings of central importance. That is, when a learner talks about distance education, not all of the statements are of equal importance to his/her understanding 
of the phenomenon. On the other hand, a learner's conception of distance education is central to his/her understanding.

Therefore, the writer returned to the interview transcripts and the summaries of the essence of each interview. She identified learner conceptions corresponding to the conceptions in the outcome space. The results are shown in Table IV.

Individual learners held from one to three conceptions, and there were at least four learners who held conceptions corresponding to each conception in the outcome space. The writer makes no claim that any one conception in the outcome space was more or less frequently held by learners in general. Generalization was impossible from fifteen learners, nor was it the purpose of this study. 
TABLE IV

Learners holding each conception

Conceptions

\begin{tabular}{|c|c|c|c|c|c|}
\hline Learner & $\begin{array}{l}1 \text { 1a } \\
\text { a door opener: } \\
\text { to future goals }\end{array}$ & $\begin{array}{c}1 b \\
\text { a door opener } \\
\text { in everyday ilfe }\end{array}$ & $\begin{array}{l}2 \\
\text { Ireedom } \\
\text { choice }\end{array}$ & $\begin{array}{c}3 \\
\text { difficulties }\end{array}$ & $\begin{array}{c}4 \\
\text { structure } \\
\text { learner actions }\end{array}$ \\
\hline $\mathbf{E}$ & $x$ & & & $x$ & \\
\hline $\mathbf{F}$ & & $x$ & $x$ & & \\
\hline H & $x$ & $\mathrm{x}$ & & & \\
\hline$I$ & & $x$ & $\mathrm{x}$ & $x$ & \\
\hline $\mathbf{J}$ & & & & $\mathbf{x}$ & \\
\hline $\mathbf{K}$ & & $x$ & $\mathbf{x}$ & & $x$ \\
\hline L & & & $x$ & $x$ & $x$ \\
\hline $\mathbf{M}$ & & $x$ & & $\mathbf{x}$ & \\
\hline $\mathbf{N}$ & & & $x$ & & \\
\hline 0 & & & $\mathrm{x}$ & $\mathrm{x}$ & \\
\hline $\mathbf{P}$ & $\mathbf{x}$ & $x$ & ' & $x$ & \\
\hline $\mathbf{Q}$ & & & $x$ & $x$ & $x$ \\
\hline $\mathbf{R}$ & $\mathbf{x}$ & $x$ & $\mathbf{x}$ & & \\
\hline $\mathbf{s}$ & & & $x$ & $x$ & $x$ \\
\hline $\mathbf{T}$ & & $\mathrm{x}$ & $\mathbf{x}$ & & \\
\hline Total: & 4 & 8 & 10 & 9 & 4 \\
\hline
\end{tabular}


CHAPTER V

\section{DISCUSBION AND IMPIICATIONS}

\section{The Philosophical and Epistemological Basis}

There are philosophical and epistemological beliefs that underlie this study of understandings of distance education. They underlie the choice of topic and methodology.

A philosophy is basic to both practitioners and researchers in education because it directs their actions. Apps (in Darkenwald \& Merriam, 1982, p.37) pointed out that, among other things, a philosophy provides a foundation for looking at educational problems and the relationship of adult education activities to society. A philosophy also determines one's view of adulthood and of ethical questions as they relate to education. By extension, the adult education researcher's philosophy influences his/her choices.

This researcher's philosophy of adult education is a mixture of what Darkenwald and Merriam (1982) call the philosophies of self-actualization, of personal and social improvement, and of social transformation. That is, she believes that a main purpose of adult education is personal development of the learner, who assumes more and more responsibility for learning and becomes more self-directed. At the same time, the learner lives in a social context. It 
is desirable to develop a greater understanding of society and to be an active participant in that society through lifelong learning. Critical thinking, which can lead to social action, is also important. Therefore, the learner should be the focus of adult education.

In addition, this writer views adulthood as a process, a series of developmental stages. Perry (1988) has identified different levels of cognitive development, Loevinger (in Cross, 1981, pp.178-179) of ego development, and Kohlberg (in Cross, 1981, pp.182-184) of moral development. The writer shares their view that adults go through a vertical progression of stages of development which are not dependent on age.

Adult education offers adult learners a way to learn for both personal and societal ends. Distance education is potentially of great significance because of the realities of adult life. Many adults have responsibilities that deter them from participating in classroom learning, and distance education can offer freedom from some of its restrictions. on a broader, global scale the education of adults is critical for the development of poorer countries and for international understanding. Poorer countries frequently lack the facilities and personnel for adult education by conventional means. Distance education is, again, potentially of great significance to such countries.

For these reasons the writer chose to study distance education. Because she sees the learner as the focus of 
adult education, she chose to elicit that learner's understanding of distance education.

The understanding of any phenomenon is a personal construction; this is the view taken here. A learner's understanding of distance education is based on his/her own perceptions, values, assumptions, existing conceptual frameworks, purposes, and activities. These do not exist independently but are related to the "content" itself, i.e., distance education, and the context in which the learner pursues distance education. In other words, the learner's understanding of distance education is a personal construction derived from his/her experience of distance education within a personal and social context.

How can the researcher reveal such personal constructions? Firstly, it is necessary to investigate the learner's actual experience of distance education, to have an empirical basis. Secondly, it is appropriate to use a second-order perspective, that is to attempt "...to reveal how things look from the point of view of the respondent..." (Stalker, 1989, p.37). Thirdly, it follows that the researcher should seek to reveal the variety of personal constructions, the range of conceptions, of the same phenomenon. Phenomenography is a methodology that satisfies these needs.

This exercise of revealing and describing conceptions is not normative; there are no preferred or "correct" 
conceptions. In addition, the researcher does not begin with an assumption of an external reality. He/she does not start with hypotheses about what is correct or what exists and then try to verify them by deduction. Instead, the researcher attempts to discover conceptions by induction.

Glaser and Strauss (1967) proposed the "constant comparative method" for the discovery of grounded theory. The four stages of the method are: "(1) comparing incidents applicable to each category, (2) integrating categories and their properties, (3) delimiting the theory, and (4) writing the theory" (p.105).

This study followed these four stages. (1) The researcher constantly compared "units of meaning" (incidents) with each other until conceptions emerged. As the properties of the conceptions developed, there was a shift. The comparison was no longer of "units of meaning" with each other. Instead the "units of meaning" were compared with the properties of the conceptions so that "...different categories and their properties tend[ed] to become integrated through constant comparisons that force[d] the analyst to make some related theoretical sense of each comparison" (p.109). (3) Major modifications became fewer; the conceptions were clarified and integrated. The analyst reduced the number of conceptions as she discovered underlying uniformities. (4) The researcher wrote up her procedures and findings. 
To summarize, the researcher chose to study distance education and, in particular, to focus on the learner's understanding of distance education because of her philosophical stance. She also chose a specific methodology, phenomenography, which fits within the constant comparative method. This was on the basis of her epistemological beliefs.

\section{The Investigator as Research Instrument}

The epistemological position outlined above holds that reality is not something existing "out there"; rather, it is a personal construction in the mind of the individual. Therefore, subjective understanding is involved, and "Human research is inherently dialectical" (Lincoln \& Guba, 1985, p.104). Because research is dialectical, the investigator inevitably has an effect on the respondent and vice versa. In naturalistic investigations this effect is recognized, and the researcher attempts to exploit the situation by regarding him/herself as the research instrument. "To idealists [naturalists], instruments do not have a standing independent of what they are designed to measure. They are extensions of the knowers and operate as an element in their attempts to construct or constitute reality" (Smith, 1983, p.9).

Hammersley and Atkinson (1983) noted that one aims to minimize the influence of the researcher but, at the same time, to understand how his/her presence shaped the data. 
For example: Non-directive questions can stimulate the interviewee to talk about a particular broad area. The identities of interviewer and interviewee can influence the data collected. If an interviewee is on his/her home territory, he/she is often more relaxed.

In Chapter III the writer outlined procedures undertaken to establish trustworthiness in this study. A number of the procedures were designed specifically to address the possible shortcomings of the investigator as research instrument.

one of the most contentious issues in naturalistic research is the investigator's use of intuition. According to Firestone and Dawson (1988), "Individual intuition is the richest and primary source of subjective understanding in qualitative research. However, how intuition is used is difficult to describe and understand. ... Through immersion and contemplation, findings emerge" (p.210).

They suggested that "...individual intuition should almost always be combined with other, more explicitly and deliberately confirmatory, approaches" (p.210). The approaches they listed were: (1) constant awareness of threats to validity (credibility and transferability) so as to avoid or minimize them; (2) generation of predictions or hypotheses during data collection and checking of them; recording of how one generates and rejects explanations (pp.210-212). This researcher attempted to do all three. The first was in accordance with her outline of procedures 
for trustworthiness; the second was during the interviews themselves; the third was in a journal.

Therefore, the researcher attempted to minimize her influence; on the other hand, she is human. It is probable that her own biases and assumptions did, in some ways, affect the collection and analysis of the data. What follows is an attempt to identify those biases and assumptions.

The writer's personal background has given rise to her philosophy of adult education, which was described above. Since she believes that personal development and social improvement are key aims of education, it is possible that she placed greater emphasis on aspects of learner understanding related to these goals.

In addition, the writer believes that distance education is a positive phenomenon. It is probable that the interviewees assumed this to be her attitude, and this, in turn, may have biased their responses. Again, it is also possible that the writer unconsciously gave extra weight to positive learner statements about distance education.

The writer assumes that most adults are honest, cooperative individuals, particularly when they volunteer to undertake a task, in this case the task of being interviewees. She also assumes that to these learners distance education was sufficiently important for them to 
think about it in some depth and respond in a thoughtful manner.

As the "research instrument" the investigator has a direct effect on the research. Therefore, it is possible that the above biases and assumptions influenced the collection and analysis of data.

Learners' Conceptions and Theories/Models in Adult Education and Distance Education

Definitions of distance education draw from and contribute to theories and models of distance education and adult education. Are learners' conceptions of distance education also a reflection of those theories and models?

Most models of participation in adult education focus on variables that are likely to affect an adult's decision whether to participate in adult education activities. The learners interviewed had already made that decision. It is possible that learners holding Conception 1a (distance education $=$ a door opener to future goals) decided to participate because of their goal, a goal being one of the variables often cited in participation models. Likewise, one can only speculate that holders of other conceptions anticipated that distance education would open doors in their everyday lives, allow freedom and flexibility, etc.

On the other hand, Boshier's (1973) congruence model deals with dropout and persistence as well as the initial 
decision to participate. The four conceptions of distance education found can fit into this model; for example, \#1a's goals are "motivation", \#2's freedom from others is avoidance of "incongruence", and \#4's structure and actions are "mediating variables". However, Boshier's model has a psychological basis; it is too narrow to fully portray learners' conceptions of distance education.

The corresponding distance education models are of dropout, not of participation -- a clear indication of the overriding concern with learner attrition. All of the distance education dropout models relate closely to Conception 3 (distance education = difficulties counterbalanced by other factors). Almost all of the variables in these models relate to either "difficulties" or "other factors". This is not surprising since learners with difficulties are the most likely to drop out. In contrast, Conceptions 1,2 , and 4 are represented in most of the models as only part of one or two variables. In other words, these conceptions have only a minor role in distance education models of dropout. Model builders should be aware of this imbalance.

other distance education models and theories do not focus on dropout. Munro's (1991) model of the learnereducator relationship in distance education is the most comprehensive; all four conceptions are represented by parts of it. The "difficulties" conception touches on all parts 
of the model but also extends beyond it to the learner's real life-world. The other conceptions are represented by different spokes and/or quadrants although, again, the extended real life-world context is missing.

Conception 2 (distance education = freedom, flexibility, and learning on one's own) fits into Garrison's model of independence and control in distance education (1989; personal communication, Aug. 1990). Different holders of Conception 2 place varying emphasis on the three elements of control (independence, proficiency, and support); independence, as defined by Garrison, is a very weak component of the conception. The model of independence and control appears to be built on a foundation of Conception 4 (distance education = structure and learner actions) .

Holmberg's (1977) theory of guided didactic conversation and Moore's (1983) theory of transactional distance form a part of all the conceptions except for \#la (distance education $=a$ door opener to future goals). Peters' (1971) theory of industrialization forms part of no conception. This is because the theory focuses entirely on the institution and its operation; learners relate to the institution only in personal ways.

The motivation or orientation of learners has been an important focus of adult education research over the last three decades. Like the builders of models of participation 
in adult education, these researchers have sought motivations or orientations which lead to the initial decision for participation in adult education. Nevertheless, it is instructive to relate orientations to the conceptions of distance education in the outcome space. Conception la (distance education $=\mathrm{a}$ door opener to future goals) is clearly represented in studies of motivations. To give just two examples: One of Houle's (1961) three types of learner is "goal-oriented". Several of Boshier's (1971) fourteen factors also relate to goals, e.g., "Other-directed professional advancement", "Innerdirected professional advancement", and "Educational preparedness" (p.10).

Conception $1 \mathrm{~b}$ (distance education $=\mathrm{a}$ door opener in everyday life) is also clearly represented. Learners holding this conception are two of Houle's types, namely, "goal-oriented" and "learning-oriented". To Boshier they would represent "Intellectual recreation", "Cognitive interest", or "Educational supplementation" (p.10). All studies of learner motivation include factors which relate to Conception $1 b$.

The same is true of Conception 3 (distance education $=$ difficulties counterbalanced by other factors). In this case, it is the "other factors", not the "difficulties", that are represented in motivation studies. Again, there are several factors in each study that relate to conception 3. 
In contrast, Conception 2 (distance education $=$ freedom, flexibility, and learning on one's own) is represented in only one of the six motivation studies surveyed. Burgess (1971) included among his reasons for participating "the desire to escape from some other activity or situation" and "the desire to study alone or just be alone" (p.11). None of the other studies listed motivations that relate to freedom, flexibility and learning on one's own. This appears to be a shortcoming of motivation studies.

Conception 4 (distance education = structure and learner actions) is not represented in the studies of motivation. This is logical since holders of conception 4 do not look beyond the structure and process of distance education itself. They simply react; they do not act.

There are a number of theories of learning and teaching in adult education. Several of the conceptions (1a, 2, and 4) are not about learning as such or give it a very minor role. However, in Conceptions $1 \mathrm{~b}$ and 3 learning is of importance.

Conception 1b (distance education $=$ a door opener in everyday life) relates to several theories. Some distance education learners see their learning as gaining more knowledge; others relate their new knowledge to the real world. Such different views of learning correspond to Saljo's (1984) five conceptions of learning as well as the 
concepts of deep/surface and holistic/atomistic approaches (Marton \& Saljo, 1984).

Conception $1 \mathrm{~b}$ also relates to theories of adult development. The outcome for some learners is being able to stay home with the family; this relates to a phase in adult life. For other learners the outcome is more awareness or new perspectives; this relates to stages in adult development. The learners also have "educational orientations", which may be "academic" or "personal" (Gibbs, Morgan, \& Taylor, 1984, p.170). In addition, they have "orientations to studying", the "meaning orientation" being represented (Ramsden, 1984, p.159).

Part of Conception 3 (distance education = difficulties counterbalanced by other factors) refers to learning, and it also relates to theories of learning and teaching. Sometimes the relationship is through a "difficulty"; for example, distance education yields little new knowledge. This indicates a conception of learning as "increase in knowledge" (Marton \& Saljo, 1984, p.53). More often the relationship is through "other factors"; for example, the learner relates learning to the real life-world. This can also indicate a conception of learning, or it can relate to adult development theories.

Two theories (if they may be called such) have not been mentioned. They are "perspective transformation" (Mezirow, 1978) and "andragogy" (Knowles, 1980). 
No conception contains the idea of perspective transformation; the new perspectives of Conception $1 \mathrm{~b}$ are not broad changes in the learner's view of life. Perhaps learners cannot be expected to have a perspective transformation during their first weeks of distance education!

According to Knowles (1980), andragogy is a set of assumptions about adult learners and a set of "process elements" (p.59). One of the assumptions appears in each conception: the learner is increasingly self-directed. In Conceptions 1 and 2 this is seen as positive; in \#3 it is a difficulty; in \#4 it is taken for granted. The only "process element" mentioned is a collaborative, supportive climate, or rather the lack of it; this is a difficulty in Conception 3. Distance education does not appear to be andragogical in Knowles's terms.

Thus, where learning is part of a conception of distance education, it is sometimes possible to relate that conception to theories of learning and teaching. It could be fruitful to pursue such relationships further; distance education may be able to build on the findings.

In conclusion, by relating conceptions of distance education to models and theories of adult education and distance education, one reveals both congruence and gaps. Likewise, definitions of distance education are related to 
these models and theories. The definitions have both drawn upon and contributed to them.

\section{Limitations of the study}

The position of the investigator as "research instrument" may have restricted the findings of the study. The methodology, too, may have created limitations.

The nine themes found were derived from academic definitions of distance education. If policy/administrative "definitions" from distance education institutions had been included, other themes may have emerged. As a consequence, other relationships between conceptions and themes would also have emerged.

The researcher found the themes in definitions of distance education before framing the interview questions and analyzing the data gathered in those interviews. It is possible that the investigator's familiarity with the themes affected both the development of the questions and the analysis of responses. However, there was a lapse of some three months between the discovery of themes and the development of the questions alone. The investigator did not reread the themes during those months.

The subjects were volunteers. Volunteers tend to have different characteristics from non-volunteers, and this may have distorted the data collected (Borg \& Gall, 1989). However, using volunteers was unavoidable since an individual cannot be interviewed without his/her consent. 
The interviewees were not geographically representative of all Open Learning Agency students. All of the respondents lived in the Greater Vancouver area; none were in remote locales. This may have restricted the number of conceptions found since remoteness or lack of it may influence a learner's conception of distance education. However, the purpose of the inquiry was not to generalize about distance education learners; rather it was to identify conceptions held by some learners.

Interviews were the method of data collection. Again, it must be recognized that the questions asked determined what data were gathered. Also, were the interviewees truthful and thoughtful in their responses? It is impossible to be sure, but there were safeguards. Because of a letter and a phone call some time before the interview, each interviewee had time to reflect on the topic of conversation. There was no reason for respondents to be dishonest since they knew that the researcher had no connection with the OLA beyond her research. In fact, they knew that the researcher was a student, like them. Only one respondent stated that he had felt intimidated in the interview itself, mainly due to the tape-recorder. In general respondents seemed relaxed and open.

Each interview was constructed by the interviewer and the interviewee. Nevertheless, to a large extent the set questions determined learners' responses, i.e., what data were collected, even though the questions were open-ended. 
The investigator's biases and her familiarity with the themes in definitions of distance education may have influenced the framing of those set interview questions.

The analysis of the data thus gathered also involved construction of meaning by the analyst. During the early stages the respondents checked the analysis. They confirmed that the researcher had identified both their "units of meaning" and the essence of their statements. Later stages of analysis moved beyond individual interviewees and could not be confirmed by them. Once "units of meaning" were pooled, the researcher immersed herself in the data. The conceptions that she discovered were very solidly rooted in the data, but, again, her own biases and assumptions must have influenced the construction of them.

Therefore, do the four conceptions discovered cover all the conceptions of the learners interviewed? Is it possible that a different researcher would have found different conceptions? Saljo (1988) spoke to this issue.

This type of work takes place in what Reichenbach (1938) refers to as the context of discovery, where the critical issue is one of providing concepts in terms of which the phenomena observed can be accounted for. It is thus not possible to prove that the categories [conceptions in the outcome space] are the best possible ones. The categories are the constructions of the researcher and there is always a possibility that another researcher would have arrived at a different categorization. (p.45)

In fact, during reliability checks two of the judges felt that certain quotes did not fit into any of the four conceptions in the outcome space. The investigator later 
reread all quotes and found that her original categorization of a few quotes was questionable. This indicates that while the four conceptions discovered appear to be valid, other conceptions might exist as well.

In conclusion, it can be said that there are a number of limitations to the study. Recognition of those limitations puts the study in perspective.

Learners' Conceptions and Educators' Understandings of Distance Education: Discussion

In Chapter IV the writer found relationships between the conceptions in the outcome space and definitions of distance education in the literature. The conceptions represent some learners' understandings of distance education; the definitions show some academics' understandings of it. The following is a discussion of the relationships.

There is a close correspondence between the conceptions and definitions in certain respects. In Conceptions 2,3 , and 4 the learner focuses on the "structure and process of distance education", and in Conception $1 \mathrm{~b}$ the learner attains his/her outcome by using that same structure and process. The definitions also focus on the structure and process of distance education. Therefore, most conceptions are represented by definitions of distance education. In addition, all conceptions found by the researcher have a "practical" context; that is, the learners' real 
life-world lies behind his/her conception of distance education. Likewise, the real life-world is implicitly behind educators' understandings of distance education as represented by the definitions.

On the other hand, there are important aspects of the conceptions that are not found in the themes drawn from academic definitions of distance education. These are: learner goals, the opportunity to get an education, learning, freedom and flexibility, and learner actions. All of them are learner-centred aspects of distance education.

For learners holding Conception 1a, goals in the future are of central importance; they are often the motive for undertaking distance education. Adult education research into motivation and a number of models of distance education include goals as a component. It would seem appropriate for definitions of distance education to include goals as well.

One of the "outcomes" of Conception 1b is getting an education when no other opportunity exists. Distance educators often tote this purpose as one of the most commanding arguments for distance education. Munro's (1991) model of distance education incorporates the concept, and motivation studies relate to it. However, only one definition, that of Garrison and Shale (1987), includes the purpose of distance education as an element. Providing the opportunity for education is generally considered an important purpose of distance education; including it in definitions would be logical. 
Learners holding Conceptions $1 \mathrm{~b}$ and 3 are concerned with learning. In fact, learning is a component of most distance education models and adult education motivation studies; it is the central feature of theories of learning and teaching. One assumes that it is also central to distance education, yet learning is hardly ever mentioned in definitions of distance education. Only Garrison (1989) emphasizes that distance education's "... primary concern is with learning in an educational situation..." (p.221). There is a need to incorporate learning into the definitions.

Freedom and flexibility are the essence of conception 2. Definitions of distance education imply that the learner has freedom and flexibility due to the structure and process defined. However, only Wedemeyer (1981) specifically mentions freedom -- this in connection with learner autonomy. Most distance education models, on the other hand, bring in freedom and flexibility, recognizing their importance. Because of this importance, it would be appropriate for definitions of distance education to explicitly include freedom and flexibility.

Learner actions are a very significant part of Conception 4. They are also implicit in the other conceptions, where the learner "acts" or "reacts". In definitions of distance education learner actions are taken for granted because the structure and process defined imply them. The same is true of dropout models; learner actions 
are not given as a component. Other distance education models do include learner actions, and one learning theory, andragogy, does as well. In fact, distance education learners sometimes "act" and sometimes "react", each having its appropriate moment. Acting, as opposed to reacting, is linked to freedom to choose. In definitions of distance education, statements about learner actions would be an appropriate accompaniment to statements about freedom and flexibility.

Thus, five important aspects of the conceptions of distance education which were found are not represented by the themes in educators' definitions in the literature. All five aspects are learner-centred, which is to be expected when learners speak about their own experiences, while the existing definitions in the literature are generally institution-centred.

Understanding Distance Education: Narrowing the Gap

At the beginning of this study two questions were posed, and they were later answered. The questions were:

(1) What are the conceptions of distance education held by adults who have recently begun participating in university-level distance education courses?

(2) How do these conceptions compare or contrast with the definitions of distance education in the literature? 
In this chapter there has been a discussion of the learner conceptions found as well as the similarities and differences between those conceptions and the definitions of distance education. What are the implications of the findings?

Educators' understandings of distance education are represented by the definitions in the literature. These definitions correspond in large part to two of the conceptions in the outcome space: \#3, in which distance education means difficulties counterbalanced by other factors, and \#4, in which distance education is structure and learner actions.

Conception 4 is of a lower order than the other conceptions; it is inward looking, and learners simply react to distance education's structure and process. Conception 4 can be seen as a kernel around or from which other conceptions may grow. In fact, no learner held conception 4 alone; it was held in combination with other conceptions. In Conception 3 difficulties are central, and the learner still focuses on the structure and process of distance education. These are the conceptions that relate most closely to the definitions of distance education because those definitions also focus on structure and process.

In Conceptions 1 and 2 the learner acts, which means he/she becomes more self-directed. In Conception 1b learning as a developmental process is important as well. In order to encourage learners to develop these conceptions, 
distance educators need to design programs that will do two things. They will encourage learners to act instead of simply reacting. They will help learners to develop their learning. Definitions of distance education that incorporate these notions, that the learner acts and that learning is important, could help to stimulate development of such programs. The same can be said for incorporating the notions of goals, freedom and flexibility, and the purpose of distance education into definitions. Present definitions form a good base on which to build.

The definitions and, to some extent, the practice which those definitions reflect and help to create appear to have drifted from the ideals of distance education. Much is written about the learner being the focus of distance education, but definitions are generally institutioncentred, focusing on structure and process.

What is needed is a renewed perspective, a learnercentred one. Learner conceptions of distance education show that the learner sees him/herself at the centre; distance education holds meaning only in relation to oneself. In order to make distance education more relevant and acceptable to the learner, distance educators should return to that focus -- the learner. 


\section{REFERENCES}

Bagnall, R. (1989). Educational distance from the perspective of self-direction: an analysis. open Learning, $\underline{4}(1), 21-26$.

Beaty, E., Dall'Alba, G., \& Marton, F. (1990). Conceptions of learning. International Journal of Educational Research, 13 (in press).

Beder, H., \& Valentine, T. (1990). Motivational profiles of adult basic education students. Adult Education Quarterly, 40(2), 78-94.

Borg, W., \& Gall, D. (1989) . Educational research: An introduction ( 5 th ed.). New York: Longman.

Boshier, R. (1971). Motivational orientations of adult education participants: A factor analytic exploration of Houle's typology. Adult Education, 21(2), 3-26.

Boshier, R. (1973). Educational participation and dropout: A theoretical model. Adult Education, 23(4), 255-282.

Brindley, J. (1988). A model of attrition for distance education. In D. Sewart \& J. Daniel (Eds.), Developing distance education (pp.131-137). Oslo: International Council for Distance Education.

British Columbia. Legislative Assembly. 1st Session, 34th Parliament, 1987, Bill 58: Open Learning Agency Act. Victoria, B.C.: Queen's Printer for British Columbia, 1987.

Burgess, P. (1971). Reasons for adult participation in group educational activities. Adult Education, 22(1), 3-29.

Calvert, J. (1989). Distance education research: The rocky courtship of scholarship and practice. International Council for Distance Education Bulletin, 19, 37-47.

Carl, D.R. (1989). A response to Greville Rumble's "On defining distance education". The American Journal of Distance Education, $\underline{3}(3), 65-67$.

Catchpole, M. (1988). student response to a distance education course incorporating live interactive television. A paper presented at the World Congress of the International Council for Distance Education, Oslo, Norway. (ERIC Document Reproduction Service No. ED 311 886) 
Cookson, P. (1986). A framework for theory and research on adult education participation. Adult Education Quarterly, 36(3), 130-141.

Cropley, A. (1989). Factors in participation. In C. Titmus (Ed.), Lifelong education for adults: An international handbook (pp.145-147). Oxford: Pergamon Press.

Cross, K.P. (1981) - Adults as learners. San Francisco: Jossey-Bass Publishers.

Cutress, N., Morrison, V, \& Palmer, F. (1983). The older Open University student. Teaching at a Distance, $\underline{24}$, 28-34.

Dahlgren, L. (1984) . Outcomes of learning. In F. Marton, D. Hounsell, \& N. Entwistle (Eds.), The experience of learning (pp.19-35). Edinburgh: Scottish Academic Press.

Darkenwald, G., \& Merriam, S. (1982). Adult education: foundations of practice. New York: Harper and Row.

Davie, L. (1988). Facilitating adult learning through computer-mediated distance education. Journal of Distance Education, $\underline{3}(2), 55-69$.

Eckles, S., \& Miller, W. (1987). Perceptions of 1987 master gardener participants toward the use of satellite telecommunications for educational/extension delivery. Ames, Iowa: Iowa state University, Department of Agricultural Education. (ERIC Document Reproduction Service No. ED 289042 )

Firestone, W., \& Dawson, J. (1988). Approaches to qualitative data analysis: Intuitive, procedural, and intersubjective. In D.M. Fetterman (Ed.), Qualitative approaches to evaluation in education: The silent scientific revolution (pp.209-221). New York: Praeger.

Foks, J. (1987) . Towards open learning. In Smith, P. \& Kelly, M. (Eds.), Distance education and the mainstream: Convergence in education (pp.74-92). Beckenham, England: Croom Helm.

Garrison, D.R. (1989) Understanding distance education: A framework for the future. London: Routledge.

Garrison, D.R. and Shale, D. (1987). Mapping the boundaries of distance education: Problems in defining the field. The American Journal of Distance Education, 1 (1), 7-13.

Gibbs, G., Morgan, A., \& Taylor, E. (1984). The world of the learner. In F. Marton, D. Hounsell, \& N. Entwistle 
(Eds.), The experience of learning (pp.165-188).

Edinburgh: Scottish Academic Press.

Gibson, C. (1990). Learners and learning: A discussion of selected research. In M. Moore (Ed.), Contemporary issues in American distance education (pp.121-135).

Oxford: Pergamon Press.

Glaser, B. , \& Strauss, A. (1967). The discovery of grounded theory: Strategies for qualitative research. Chicago: Aldine Publishing Company.

Government of United Kingdom, Privy Council. (1969). Charter of the Open University. London: HMSO Stationery Office.

Guba, E. (1981). Criteria for assessing the trustworthiness of naturalistic inquiries. Educational communication and Technology Journal, 29(2), 75-91.

Hammersley, M., \& Atkinson, P. (1983) . Ethnography:

Principles in practice. London: Tavistock Publications.

Hayes, E., \& Darkenwald, G. (1990). Attitudes toward adult education: An empirically-based conceptualization. Adult Education Quarterly, 40(3), pp.158-168.

Herrman, A. (1988). A conceptual framework for understanding the transitions in perceptions of external students. Distance Education, $\underline{9}(1)$, pp.5-26.

Hodgson, V. (1986). The interrelationship between support and learning materials. Programmed Learning and Educational Technology, 23(1), 56-61.

Holmberg, B. (1977). On the path towards a theory of distance education. In B. Holmberg (Ed.), Distance Education (pp.93-104). London: Kogan and Page.

Holmberg, B. (1979). Practice in distance education: A conceptual framework. Canadian Journal of University Continuing Education, 1(1), 18-30.

Hosie, P. (1985). A window on the world. British Journal of Educational Technology, 16(2), 145-163.

Houle, C.O. (1961). The inquiring mind. Madison: The University of wisconsin Press.

Inglis, P. (1988). Independent learning: what the students say. In D. Sewart \& J. Daniel (Eds.), Developing distance education (pp.249-254). Oslo: International Council for Distance Education. 
Keegan, D. (1986). The foundations of distance education. Beckenham, U.K.: Croom Helm.

Kelly, P., \& Swift, B. (1983). Post-foundation tuition: Student perspectives. Teaching at a Distance, 24, 3541 .

Kember, D. (1989). An illustration, with case studies, of a linear-process model of drop-out from distance education. Distance Education, 10(2), 196-211.

Kennedy, D., \& Powell, R. (1976). Student progress and withdrawal in the open University. Teaching at a Distance, $7,61-75$.

Knowles, M. (1980). The modern practice of adult education: From pedagogy to andragogy. Chicago: Association Press, Follett Publishing Company.

Lincoln, Y., \& Guba, E. (1985). Naturalistic inquiry. Beverly Hills: Sage Publications.

Lowe, S. (1991). Expanding the taxonomy of adult learner orientations: the Institutional orientation. Journal of Lifelong Education, 10(1), 1-23.

Marton, F. (1981). Phenomenography -- Describing conceptions of the world around us. Instructional Science, 10, 177200 .

Marton, F. (1986). Phenomenography -- A research approach to investigating different understandings of reality. Journal of Thought, 21(3), 28-49.

Marton, F. (1988). Phenomenography: Exploring different conceptions of reality. In D.M. Fetterman (Ed.), Qualitative approaches to evaluation in education: The silent revolution (pp.176-205). New York: Praeger.

Marton, F., \& Saljo, R. (1984). Approaches to learning. In F. Marton, D. Hounsell, \& N. Entwistle (Eds.), The experience of learning (pp.36-55). Edinburgh: scottish Academic Press.

Marton, F., \& Svensson, L. (1982). Orientations to studies, approaches to texts: A relational view of study skills applied to distance learning. In J.S. Daniel, M.A. Stroud, \& J.R. Thompson (Eds.), Learning at a distance: A world perspective (pp.97-102). Edmonton: Athabasca University/International Council for Correspondence Education.

Mason, R., \& Morgan, A. (1986). The rough and the smooth students' experiences of $O . U$. study. Milton Keynes: 
Student Research Centre, Institute of Educational Technology, The open University.

McCormick, R. (1985). Students' views on study at the radio and television universities in China: An investigation in one local centre. British Journal of Educational Technology, 16(2), 84-101.

Melton, R., \& Zimmer, R. (1987). Multi-perspective illumination: A case study. British Journal of Educational Technology, 18(2), 111-120.

Mezirow, J. (1978) . Perspective transformation. Adult Education, 28(2), 100-110.

Miller, H. (1967). Participation of adults in education: A force-field analysis. Boston: Center for the study of Liberal Education for Adults.

Moore, M. (1977). On a theory of independent study, Ziff papiere $\mathrm{nr}$. 16. Hagen, West Germany: Fernuniversitat, Zentrales Institut fur Fernstudienforschung Arbeitsbereich.

Moore, M. (1983). The individual adult learner. In M. Tight (Ed.), Adult learning and education (pp.153-168).

London: Croom Helm.

Morstain, B., \& Smart, J. (1974). Reasons for participation in adult education courses: A multivariate analysis of group differences. Adult Education, 24 (2), 83-98.

Mugridge, I. (1989). The language of distance and open learning. Journal of Distance Education, $\underline{4}(2), 83-85$.

Munro, P.J. (1991) . Presence at a distance: The educatorlearner relationship in distance education and dropout. Unpublished doctoral dissertation, University of British Columbia, Vancouver.

Open Learning Agency. (1991a) 1988 - 1990: Only the beginning. Richmond, B.C.: Open Learning Agency.

Open Learning Agency. (1991b) Open Learning Agency strategic plan: 1991 - 1994. Richmond, B.C.: Open Learning Agency.

Open Learning Agency of British Columbia. (1989). Open learning and distance education in Canada. ottawa: Minister of Supply and Services Canada.

Parer, M. (1988). Students' experience of external studies. Student diary project. (Report No. ISBN-0-909-170-15-0) Churchill, Australia: Gippsland Institute, Centre for 
Distance Learning. (ERIC Document Reproduction Service No. ED 311880 )

Perry, w. (1988). Different worlds in the same classroom. In P. Ramsden (Ed.), Improving learning: New perspectives (pp.145-161). London: Kogan Page.

Peters, 0. (1971). Theoretical aspects of correspondence instruction. In 0 . McKenzie \& E. Christensen (Eds.), The changing world of correspondence study (pp.223228) . University Park: The Pennsylvania state University.

Quigley, B. (1987). The resisters: An analysis of nonparticipation in adult basic education. Proceedings of the Twenty-eighth Annual Adult Education Research Conference (pp.201-207). Laramie, Wyoming. (ERIC Document Reproduction Service No. ED 283 936)

Quigley, B. (1990). Hidden logic: Reproduction and resistance in adult literacy and adult basic education. Adult Education Quarterly, $\underline{40}$ (2), 103-115.

Ramsden, P. (1984). The context of learning. In F. Marton, D. Hounsell, \& N. Entwistle (Eds.), The experience of learning (pp.144-164). Edinburgh: Scottish Academic Press.

Renstrom, L., Andersson, B., \& Marton, F. (date unknown). Students' conceptions of matter. Gothenburg: Department of Education and Educational Research, Gothenburg University, Sweden.

Roberts, D. (1984). Ways and means of reducing early student drop-out rates. Distance Education, $\underline{5}(1), 50-71$.

Rockhill, K. (1982). Researching participation in adult education: The potential of the qualitative perspective. Adult Education, 33(1), 3-19.

Rubenson, K. (1977) . Participation in recurrent education: A research review. Paris: OECD/CERI.

Rubenson, K. (1983) - Barriers to particiption in adult education. Discussion paper prepared for skill Development Leave Task Force, Ministry of Labour, Government of Canada, Vancouver, B.C., University of British Columbia.

Rumble, G. (1986). The planning and management of distance education. New York: St. Martin's Press.

Rumble, G. (1989a). On defining distance education. The American Journal of Distance Education, $\underline{3}(2), 8-21$. 
Rumble, G. (1989b). 'Open learning', 'distance learning', and the misuse of language. Open Learning, $4(2), 28-36$.

Saljo, R. (1979). Learning in the learner's perspective: I. Some common-sense conceptions. Reports from the Institute of Education, University of Goteborg, no. 76. Goteborg, Sweden.

Saljo, R. (1984). Learning from reading. In F. Marton, D Hounsell, \& N. Entwistle (Eds.), The experience of learning (pp.71-89). Edinburgh: Scottish Academic Press.

Saljo, R. (1988). Learning in educational settings: Methods of inquiry. In P. Ramsden (Ed.), Improving learning: New perspectives (pp.32-48). London: Kogan Page.

Scanlan, C., \& Darkenwald, G. (1984). Identifying deterrents to participation in continuing education. Adult Education Quarterly, 34(3), 155-166.

Seabourne, K., \& Zuckernick, A. (1986) Course design and development. In I. Mugridge \& D. Kaufman (Eds.), Distance education in Canada (pp.37-49). London: Croom Helm.

Seaman, D., \& Schroeder, W. (1970). The relationship between extent of educative behavior by adults and their attitudes toward continuing education. Adult Education Journal, 20(2), 99-105.

Smith, C. (1988). The educational value of computer-mediated communication. Media in Education and Development, $\underline{21}(4), 169-171$.

Smith, J. (1983). Quantitative versus qualitative research: An attempt to clarify the issue. Educational Researcher, $12(3), 6-13$.

Stalker, A.J. (1989). Reframing the issue of participation in adult education: An interpretive study. Unpublished doctoral dissertation, University of British Columbia, vancouver.

Sweet, R. (1986). Student dropout in distance education: An application of Tinto's model. Distance Education, $\underline{7}(2)$, 201-213.

Taylor, E., \& Morgan, A. (1986). Developing skills in learning. A paper presented at the 67 th annual meeting of the American Educational Research Association, San Francisco, April 16-20. (ERIC Document Reproduction Service No. ED 273220 ) 
Taylor, M. (1986). Learning for self-direction in the classroom: the pattern of a transition process. Studies in Higher Education, 11(1), 55-72.

Thompson, G. (1990). How can correspondence-based distance education be improved? A survey of attitudes of students who are not well disposed toward correspondence education. Journal of Distance Education, $\underline{5}(1), 53-65$.

van Enckevort, G., Harry, K., Morin, P., \& Schutze, H. (Eds.). (1986). Distance higher education and the adult learner. Heerlen, Netherlands: Dutch Open University.

Wedemeyer, C.A. (1981). Learning at the back door. Madison: The University of Wisconsin Press.

Willen, B. (1981). Distance education at Swedish universities. An evaluation of the experimental programme and a follow-up study. Uppsala studies in education 16. (Report No. ISBN-91-554-1228-9) Uppsala, Sweden: Uppsala University, Department of Education. (ERIC Document Reproduction Service No. ED 243 458)

Woodley, A., \& Parlett, M. (1983). Student drop-out. Teaching at a Distance, 24, 2-23. 


\section{APPENDIX C}

set interview questions

1. Let's begin with your decision to enrol in distance education. How did you come to that decision?

What influenced you?

Who did you hear about it from?

2. Which subject are you studying?

What did you expect it to be like learning ( ) by distance education?

3. How is learning ( ) by distance education different from learning it by conventional education?

How is it the same?

What do you actually do?

4. What were your hopes and fears about doing ( ) by distance education before you started?

Now that you're into it, how are you finding it?

5. What are you learning about ( )?

What are you learning about yourself?

What are you learning about distance education?

6. What are the most important things about distance education for you?

7. I've written down what seem to me the key words you've used. Is there any relationship between them?

8. If you were talking to another person like yourself about doing distance education, what would you say?

9. How are you evolving as a learner by doing ( ) by distance education?

10. Do you have anything to add? 
APPENDIX D

Personal information form

PERSONAL INFORMATION

Name:

Sex:

Age:

Occupation:

Address :

Phone number (s):

Highest level of education completed (please check):

Less than grade 12:

Grade 12:

1 or more university courses:

Bachelor's degree:

other (please specify):

Present OLA course(s):

I plan to obtain a Bachelor of Arts degree: Yes no 


\section{APPENDIX F}

Results of independent judge reliability tests

Judge

Agreement after

first reading
Agreement after discussion

Conception 1a

\#1

$\# 2$

\#3

Conception 1b

$\# 1$

\#2

$\# 3$

Conception 2

\#1

\#2

\#3

Conception 3

$\# 1$

$\# 2$

\#3

Conception 4

$\# 1$

\#2

\#3
$80 \%$

$100 \%$

$70 \%$

$80 \%$

$90 \%$

$50 \%$

$90 \%$

$90 \%$

$90 \%$

$100 \%$

$100 \%$

$90 \%$

$80 \%$

$80 \%$

$75 \%$
$100 \%$

$100 \%$

$90 \%$

$100 \%$

$100 \%$

$90 \%$

$95 \%$

$100 \%$

95\%

$100 \%$

$100 \%$

$100 \%$

$97.5 \%$

$85 \%$

$95 \%$ 
APPENDIX G

Interview transcripts

\section{INTERVIEW \#4}

Interviewer: A

Respondent: $\mathrm{E}$

Position on tape: (000)

(001 - 014) Introduction and interruption.

A: (014) Yeah, the first thing was, I said, uh, let's begin with your decision about why you decided to enrol. You know, how did you come to the decision to enrol in distance education?

E: (017) The reason I decided is just that we had moved a number of times, and I've taken courses, and every time I've moved, the new institution has never accepted every credit I've ever taken. So I seem to go 2 steps ahead and one step behind, so I .... Somebody had mentioned to me about the Open University and that they would probably accept most of your credits or all of your credits and that hopefully that you could ... when we move back to New Brunswick, I could take courses either still from correspondence or at the University of New Brunswick, have them all credited to the open University and get my degree from there. Because it just seemed, like, shorter (025) in the long run to do it that way than start all over again. You know, not all over again but, you know, to start with ... //A: Lose those credits.//... lose 
those few credits. So that's what I decided to do, and I sent for my transcripts, and they accepted everything that I've ever taken. So ....

A: You mentioned that someone had mentioned it to you. Who was that?

E: (030) Well, [Susan Smith], who's doing her doctoral thesis in distance education too. So, uh, she's in Social Education Studies, and she just mentioned to me .... Well, it's the first I had really heard about it. I know in Nova Scotia they do have some kind of course, not correspondence courses, but they're television courses that you can take from .... We lived in a smaller town away from Halifax, and people were doing that. I myself wasn't doing it, but it really wasn't widespread as it ... Here it seems to be quite .... Everybody seems to know about it, and with the Knowledge Network everybody knows about it, and it's accessible to a lot of people.

A: (037) Yeah. You mentioned that you would like perhaps to have these courses accredited by the University in New Brunswick. Do you know if they will credit them?

$E$ : Well, I don't know. I ... either ... whether I would have .... When I spoke to the person at the open University, she said I could take courses at the University of New Brunswick and have them accredited here instead of doing it the other way. Because I didn't think that the University of New Brunswick would accept 
this. I don't know. I mean, to me it didn't seem like ... if they would realize it was a real university, but now that I know more about what it is, I think they probably would, and it's probably .... It's just that my perception of what it was .... I didn't know whether it was ... in the rest of Canada they'd know what it was. But I think ....

A: (047) So you say when you go back to New Brunswick, you may continue to take courses from B.C.

E: From here. Well, because what the woman told me at open University is I can take courses at U.N.B., just tell the people here, and then have your credit transferred here. If I wanted to do it in person or if I wanted to do it through, you know, through correspondence then they can still do it through the mail or whatever, the same way I'm doing it now. So I would have that option.

A: So ... so your ultimate, not your ultimate purpose, your purpose at the present is to get a degree after a time.

E: Yeah, I'd like to finish it. Hopefully!

A: What subject are you doing right now?

E: (056) I'm doing a History course. It's a Preconfederation History course.

A: Is that what your major is?

E: Uh, originally I started out in Atlantic Canada studies, and it .... I was going to st. Mary's University in Halifax, and a lot of my courses are: Women in Canadian Studies, Blacks and Other Minorities, a lot of Canadian 
courses and that, so I just thought I would take it. I haven't taken a course for a number of years, so I thought I'd get back in this way. (laughter) It's not as easy as I thought. It's different studying this way than it is going to a course.

A: Well, before you actually started, how did you expect it to be studying distance ... studying history by distance education?

E: (064) Um, I didn't think there'd be as .... There's an awful .... It's a history course; that's .... Everybody's told me it's not, maybe not everything is like this, but friends who do teach at the university, who teach History. I mean they just give you a phenomenal amount of reading, and I just was surprised at how much reading, and there's quite a few, um, papers that are due too, which isn't .... I mean, I have to get back into writing papers, which is a little difficult too. But I find that there's an awful lot of reading. I suppose it's taking up the time that you're not in class, but, um, I don't know, I think that's something that has to be looked at. (laughingly)

A: (073) So are you saying it's more time-consuming than you thought it would be?

E: It's more time ... much more time-consuming, and especially at the very beginning I was very, very conscientious, and they said, you know, 8 to 10 hours and I was spending 30 hours doing it, and I just 
thought, "This is crazy!" If I was taking more than one course, there's no way I could do it.

A: You say they said 8 to 10 hours, but you were doing 30 . Why do you think you were doing so much more than they said?

E: (077) Because ... Well, at the end of each reading there's these questions that you should answer, and they said to answer them in ... I mean, this is the instructions, say to answer it in a couple of lines, and I would sit ... I was sitting down and answering them in little paragraphs, and I was spending too much time trying to do a good job. And so the next time my husband said, you know, "You're not supposed to do that. Just make a one-line answer." It's what they said too, but I had to feel confident myself that I knew what I was reading. So that's the way I did it, but it's ended up taking me way too much time.

A: You said there, "I did .... I took a lot of time because I felt I was doing a good job." You call that a good job, so, in other words, you think they would call a good job something less than what you're doing.

$E:(088)$ No. It .... I don't think my time was organized well enough, or something. To me, because I hadn't taken a course for a number of years, and I really wanted to think about the answers, and write it down, and instead of writing one line or 2 lines about... summing it up what the answer should be, I was writing a paragraph, 
and, you know, spending time worrying about it. (laughter) And, you know, I just .... You know, it might not be just the History course, but just me not having a course for a long time. But I was surprised; it's only a one-hundred level for the ... the amount of work that's expected of us. I was real .... 'Cause I've taken three-hundred levels before, and I've ... I thought there was a lot ... a lot of work that was expected.

A: (098) This is actually compulsory reading or compulsory plus suggested extra, which you're doing?

E: I never did any extra. (laughingly) I mean, I did all the readings that they say, and, you know, if there was something that somebody would suggest that might have something to do with the topic, then I might have looked through it, but $I$, you know, didn't spend hours reading it. But I just found that, uh, just the readings that they said was a lot of reading.

A: Yeah, right. Uh, connected to this, how do ... how do you think then that learning History by distance education is different from learning it by conventional education?

E: (106) I don't think it was that much different. When you go and sit in front of a professor who's talking to you, maybe he could emphasize more of the points that are stressed -- what's more important or what he feels is more important. And when you're reading yourself, then you're going to have to just make that judgement 
yourself, although there is the ... the text. It goes along with it, and it quite ... summarizes it quite well. So, I mean, there's both those things. And there's, uh .... The course I'm taking has audio, and it has slides too. I haven't found the slides .... If you were sitting in a classroom, and they were talking, and you're looking at slides maybe it's one thing, but I didn't find them as ... I was learning a lot from looking at the slides particularly. The guide ... audio section, it was interesting, but it's just ....

A: (118) Do you mean the audio goes with the slides?

E: Yep.

A: Oh, I see. So there is the commentary, and you (unclear) the slides yourself.

E: Yeah, that's right. It's just that there is the ... little carousel of slides, and you can look at so many slides for each tape. //A: Oh, I see.// And, you know, they're nice pictures.

A: Pictures of what?

E: of, you know, maybe what Indians looked like years ago or what .... You know, I didn't feel I was learning anything from them or from what the (Pause...) houses looked like or, I can't think right now, but, you know, just, just pictures. I mean it wasn't anything ... paintings and things, you know.

A: (125) You feel you weren't really learning anything from those slides .... 
E: Well, I think if.... If somebody was ... a teacher was maybe pointing it out, had it up on the wall, I might have (Pause...) learned more. I don't know. I just found .... When I was listening to the tape and looking at them, I just ....

A: So what's the difference between listening to a tape and listening to a professor?

E: Well, just .... I don't have a slide projector for one thing (laughingly), and I was just lookin' up in the air, and I was just thinking.... Well, you know, so ....

A: That really reduces it, doesn't it? (laughter)

E: It does reduce it! But that, yeah ....

A: (133) OK. Um, let's go back sort of to the beginning in that, uh, wh.... Before you actually began, sort of what ... what were your hopes, your fears, your expectations before you actually began doing distance education? (Pause...) I should say before you began doing this History course in distance education.

E: Well, I hoped that, um .... Well, I have an interest in history, so I hoped that it was going to be an interesting course and that it would enable me to sort of get my feet back in to studying again, just, without having to go out to a class because of trying to organize with 3 children and time and my part-time work. I just (143) thought it would be easier for me to do it this way. And it was less expensive because $I^{\prime} m$ on a cheaper, not very (laughingly) expensive lifestyle right now. so 
I thought that would be easier to do it that way, and I ... after I heard about the open Learning Institute, I spoke to a number of people, and I was surprised at quite a few people who had taken one or 2 courses and then went on to here at UBC. So I just thought, well, I'll give it a try and, you know, and see how it goes.

A: What did those people say about the courses they'd taken?

$E$ : Um, one person told me if she didn't live nextdoor to her tutor and practically drive the tutor crazy, she would never have passed. (laughter)

A: (153) What kind of course was that?

$\mathrm{E}$ : It was a calculus course, I think. //A: No wonder! (laughter)// Something I wouldn't even tackle! And, um, you know, one person took an English course, couple of people took English courses just to (Pause..) I guess 100 or something to get into the university. So, uh, you know, they seemed to like it all right. But then they didn't go on and continue to finish their university through the continuing education, but that might have been because .... You know, I'm living in family housing, and one spouse has to be going to university, and the access is there if, you know, if you can arrange your own schedule to be able to go to the classes.

A: (162) Sure. You're right beside it. Yeah. oK, so you told me what some o... what your hopes were. Did you have any particular fears, negative feelings about it before you started? 
E: (Pause....) Well, I didn't have any. I went in with an open mind. I mean, I had hoped that it, you know, it would fit to my lifestyle, and I'd be able to do it. I didn't have any particular fears that it was ... except for my ... to make myself sit down and do it. And, uh, you know ....

A: And do you find that can make yourself sit down and do it?

E: (169) I was really good at the first part, but then Christmas came, which is a very difficult time. //A: With 3 children!// Yes. And, um, I must say I didn't do much; I didn't do ... have anything. Now, I took on this extra job, which I should .... I mean, I needed to do it, so I really let this go. And having the option of doing it in 4 or 6 months was good because then I could catch up. I'm finished this particular job I was doing this week, so now I can spend more time on, uh, you know, catching up. And then over Christmas the kids weren't in school, and I find I need quiet to study. I can't have distractions of people running around or making, you know, asking me to do stuff. And I don't work .... I don't like to start at 9 or $100^{\prime}$ clock at night when the kids go to bed. So what I originally had thought I would do on when my youngest is at pre-school so I would have, you know, 10 hours a week or 12 hours a week free, and I thought that would be the time that I would be able to do 
it. And it was in the beginning, and now I just have to get back into it.

A: (183) Uh-huh, yeah. Well, my next question was really going to be: And now that you're into it, uh, how has it lived up to your expectations or otherwise?

E: I've .... As I said before, I find the volume of work, like, of reading is ... is ... is a lot, but maybe I have to learn how to, um, how to read .... I read every line, and, you know, try .... My husband says you shouldn't do that; you should just sort of glance over it and sort of get the important parts. But that's maybe .... He has (laughingly) years of advantage of doing that, and I haven't, I mean, so I haven't been able to do that, and I guess that's just going to come with time. You know, that's just something that's going to have to, uh .... But right now $I^{\prime} m \ldots . . . I^{\prime} m$ spending a lot of time reading and have to really pay attention to what I'm doing.

A: (195) Yeah. Uh, a little while ago you said: I expected that it would be interesting. Does that mean that, in fact, you have or haven't found it interesting?

$E$ : Oh, no. I've found it interesting. I'm ... I really .... You know, I'm interested in, um, most of the stuff. I'm doing some stuff on the Loyalists now, and it's just interesting an... because the ... a lot of Loyalists settled in Nova Scotia and that's where I'm from, and it's just interesting. And with the whole French issue, and, you know, and the Indians and the whole oka this 
summer, so, you know, a lot of it... It's nice to have the background and to see where everything comes from, so I enjoy it. It's just that, uh, I have to get more disciplined (laughingly) I guess!

A : (205) Yeah. The word 'discipline'. D... do you think it's very important to be disciplined to do distance educ... to do, let's say, a History course by distance education?

E: Oh, yeah, yeah. I think anything like that it's... it's ... you have to be disciplined to be able to do it.

A: And when you say 'disciplined', you've mentioned making yourself sit down and taking the time. Is there anything else that 'disciplined' brings in?

$E:$ (Pause...) No, I don't .... Well, I think .... No, I think the time is, for me, it's ... is what I need is the ... it's the quiet and the time to sit down and really do it in and ... to ... to write the paper and, uh, get that over with, and .... It's ... We have 6 papers to do, so. And I'm really worried about the exam too. I ... it's been a long time since I've taken exams, so that's, uh .... But that's something to come up in a while, so hopefully ....

A: (217) Is that a big worry?

E: It's a ... it's a big worry. I, uh, I don't like exams; I never liked them ...//A: Who does? Yeah, right. (laughter) // ... you know. So, so, we'll just see. And then, the papers I've gotten back, I've done very well, 
so I'm just hoping that, uh, the time the exam comes that, you know, I'll just have the memory of what I've studied. One disadvantage of not having a professor or somebody to tell you .... Usually there are hints of emphasis of what's going to be on the exam, and this way you don't have any. I mean, with having to read 500 pages a week or something, and then you have.... What are you gonna ...? It's just the volume of information is ... is so immense you have to figure out, you know, what ... what is important and what's, uh .... You shouldn't be studying just for the exam either. That's another thing, which I suppose you can't really here because you don't have any idea what the exam's going to be. so it's, uh ....

A: (230) Y... You said there there isn't a professor; there's no one from whom you might get hints. Is there nobody that you talk to?

E: Well, there is a tutor, and I've never... She's called before I started, and I've never talked to her. That's another thing I was .... I guess, I suppose I could call her for specifics of ... which I haven't done. But she has never called me either, so .... Except for at the beginning to introduce herself, and this is before the course started to make sure I got all my, um, books and everything.

A: Why have you chosen not to contact her? 
E: (237) Well, I guess it's because I didn't have any ... I didn't know what specific questions to ask her, I guess, and so I just, uh, never had that relationship before. Maybe (Pause..) if sh... if she called me. I don't know whether I should be the one to initiate it or if she should. But I ... I guess that's the type of person I am. I'm not going to sit on the phone and cry to her (laughingly) about what's the problem or whatever, so I just, uh ... I just haven't ever called her, that's all.

A: So you feel that the, uh, the reason why you would call a tutor would be if you had a problem.

E: (246) Right. Or, I mean, suppose as you ge... exam gets closer or something, uh, maybe for .... I'm ... I'm gonna have to get $h .$. see if she can narrow it down to what the exam could possibly be on. So, and you know, something like that, but, uh.... Otherwise, to ... I don't think her purpose was to talk about each week of what you're supposed to do. And I ... I assumed their purpose was just if there was a problem to call her, and you sent her, uh, (Pause..) any kind of papers that you do, and then she marks them and puts a comment on them and sends them back, so .... And if you disagree with the comment or your mark, then you can call her too, so

A: (256) Which means you have agreed with her comments to date! (laughter) 
E: Well, you know, they were fine. I mean my mark was fine, so I guess I .... I think the relief of knowing I did all right, I don't even care anymore. (laughter) Just glad it's over with, so ....

A: Yeah. Just when you mentioned the exam there you mentioned, uh, having to remember, memorize things. Is ... is that what you anticipate the exam to be like?

E: (262) Um. Oh, I don't think it's going to be a memori... And I ... Just the text of this Sharon Meen, who wrote this text, she ... she tries to bring in not just memorizing; she wants to ... interpretations of ... of the different histories and the .... So I ... I don't think it's going to be memorizing, I think; it'll probably be my interpretation of what happened during a certain time, so .... But, uh ....

A: That's an interesting thing, what you say there. If I came back to one of my former questions where I said: H... Do you see learning History by distance education as different from learning it by conventional? speaking now about, like, 'my interpretaion of it', do you think that would be different or the same in the 2 forms of education?

E: (273) I suppose it would really depend on the professor. You're going to get a particular view from whoever, you know; they're going to have their bias, so you'll have to take that into consideration, but, uh, one thing with these readings, and I'm sure if it was in a class too, 
that there's different interpretions from each of the persons who's writing. What they try to do in this course is they give you 6 readings or 4 readings on one particular thing but from different viewpoints, and so that, uh, you sort of get an idea of, you know, where this guy's coming from and where this person's coming from so that, you know, you do get some different interpretions of it. So I suppose it ... it would depend on the professor if, you know, how he taught or she taught, so, uh ....

A: (285) So, d.... You used the word 'bias'. Do you think there's perhaps less bias in the distance education form of presenting it?

E: There probably would be because you're getting, you know, different viewpoints and, well, the person who's writing the course text, I guess, would be that .... Well, there'd be every different viewpoint, so, I mean, I can't see that you would get anything ... one particular one except for the person wh... writing the ... the course text, and then you're... if you write towards the exam, then you're going to have to write towards her ... her viewpoint, I guess. (laughingly) //A: Yeah. Who knows!// Who knows!

A: (296) OK. Uh, I've asked you about: Before you began, what did you expect? Now that you're in it, what are you finding? I wonder if you could also speculate? If you continue for 6 months, a year longer, do you think that 
your experience, your view of distance education will change? Or your view of learning History by distance education? Do you think that might change? It's already changed a little bit.

E: (303) Yeah, I ... I don't think that I would, if I was going to continue the degree in History, I would do it through continuing ed... uh, through distance education because I don't find that, uh ... because you are really isolated. You have nobody to, uh, to talk about what the readings were, and so you do get these different viewpoints but, you know, you're just reading them yourself, and if you were in a class situation, then you're going to have, uh, other .... Maybe I might not say anything, but I'd be having other people listening, you know, to listen to besides the professor in the class, and I just .... Myself, I think I'm just ... I need the stimulation of other people in the class to, uh, keep me ... keep my interest up, I guess, and really, um, you know, I think I would get more out of it.

A: (317) Mm-hm. How would you get more out of it with other people there?

E: Well, I ... I think I just would feel that I was ... (Pause..) Well, it would seem more alive or something. I find that, you know, it gets kind of boring this reading all the time. (laughingly) I can't explain it any better than this way. 
A: Yeah. Y... you ... no ... you used the word 'feel' there. So you do definitely have a feeling about this.

E: (324) About whether I would take another History course this way?

A: That, and also, again, learning History in this way rather than with a group of people in a class.

E: I think that there should be maybe a happy medium. I understood that quite often in these courses that they did have a study group that would meet, and I ... but I guess this isn't one of them, and I thought that would sort of be the ideal situation so that you weren't tied down to going every couple of days a week to go to a course, but then you would have, maybe once a month or something, that you could, uh, go and have other people (334) to talk about what they're doing at the same time that you're doing something so that, um, you know, could bring out things and ... or reinforce things that you've already, you know, thought you learned or to know how well you're doing because, uh, I think you're still in a void when you're doing things by distance education. You just, uh .... It's ... it's sort of like in a void; you just don't know. It's difficult that way.

A: So could you in one or 2 sentences then describe to me what to you would be the ideal way to learn History if it were a distance education mode? You mentioned there something in between. 
E: (345) Yeah. Well, I think the idea of having, um, maybe study seminars or study groups of people who live in a particular area and meeting every 2 weeks or every once a month or something to talk about the course with the tutor. I mean, I ... I think that would, uh, be good. I know that, you know, it's a lot of people taking it in a gréat area, but, uh, in Vancouver, each section, I'm sure there's a number of people even if it was only 4 or 5 people in each group. I don't know what the tutor does besides, you know, correct your work once every 2 or 3 weeks when you send in your paper. So, uh, I think meeting with a group of them every 2 or 3 weeks would be an added bonus to the course.

A: (359) And what would you expect to get out of that study group?

E: I ... I don't know what I would expect. I think it would be just reinforcement of ... of, uh, what you're learning, I guess, and just to make you feel better about like, you know: Are you getting what you're supposed to be learning? Because when you're ....

A: So in ... in terms of History, wha... how would you better learn the history by being with a study group? E: (365) (Pause....) Well, maybe it was just to talk about the ideas of the different philosophies or of the historiographics of the different people who were doing it. To, um, I think just to speak out loud about things sometimes gets things clearer in your mind so that .... 
You know, sitting there reading by yourself as an isolated person, you have nobody to argue with or to, uh, bring out an idea or, you know .... I think that would just, you know, help me anyway. I don't know other people, but I feel that way.

A: (375) Yeah, yeah. Mm, I think a lot of people feel that way. Um, OK, um. You're doing History. Um, in this distance education course which you're doing, what are you learning about .... Uh, t... tell me again the exact title of your course. It's the History of ...?

E: No, it's, uh, it's a Canadian history, Pre-confederation.

A: Pre-confederation History. So what are you learning about pre-confederation history?

E: (385) Uh, it's just Canada before it became Canada and ... and Lower Canada and Upper Canada and ... and the Loyalists and the ... the, uh, just the French issue, the Indian issue, and the ... the, um, impact of Americans, of the French Revolution, and the American Revolution, sorry, on Canada.

A: What are some of the things that you learnt about that? The impact of the American Revolution on Canada, for example. (Pause..) //E: Well, um ....// I'm not examining you! (laughter) I don't know the answers. E: (395) Well, I ... It just talks about different areas of Canada or it ... it mostly talks about ontario, Quebec and then the Maritimes, and it doesn't really go into anything past, and, um, to the p... of the Loyalists 
coming up here what an... you know, what ... what they had to do with, uh, changing the laws of Canada and, uh .... You know, it was just interesting. And I found with the French, too, and the Indian trade and I could really relate to, um, part of what was going on this summer [the oka crisis] because of reading some of this, and, uh, so .... You know, I ... I found it was interesting.

A: (406) So you $\ldots$ being able to relate it makes a difference.

E: Yes. I think .... And that's why I like some of the history, and I ... I'm enjoying part of the Maritime history that's .... I've taken other courses in Maritime stuff because I ... I can relate to what has gone by in other days. I just, uh .... (laughter)

A: sure. OK. Th... so, uh, another question: Wh... what do you feel you're learning about yourself by doing this?

E: (414) (Pause.........) Uuh, I don't know. (Pause......) Well, I guess I'm learning whether I think ... whether it's important to ... have to decide whether it's important to me to spend the time that I am doing in taking courses. What I want to do with my life, and so I'm just, you know, deciding what I want to do and where I want to go from here. So I guess it's sort of making me think whether this time that I'm spending is a good time or to go o..., uh, you know, put on to some place 
else. So I guess it's helping me redefine what I want to do.

A: (428) So in a sense this is an intermediate step for you, perhaps towards something else?

E: Yeah. I have decided what I was doing before I didn't want to do, and I wanted to, uh, to do something else, and $I$, uh .... So sort of a stepping-stone into something else.

A: Yeah. D... do you know what that something else will be or you're just ...?

E: Well, yeah. I ... I ... I'm half thinking of doing a degree in education, so, uh .... I don't know.

A: That's not what you were doing before; you said you were doing something different.

E: (438) No. I was a legal secretary. I had thought of going into Law too, but i... it's just where we lived there's a glut of lawyers, and so I don't know if that's the place to be or not. And I ... I thought ... I thought Education would be, you know, would be good, and just because it ties in a lot with what my husband's doing and (unclear) and stuff. (laughter) //A: And children.//

A: Then, I've asked you 2 learning questions: Wh... what are you learning about the Pre-confederation History? What are you learning about yourself? A third question: What are you learning about distance education as you do this? 
E: (450) Well, I ... I have a little bit of a ... a slant to it because I just did, you know, 15 tapes and transcribing (laughter) of Hardwick and ... and McGeer and all these people who ... John Ellis, all these people from distance education, so I learned a lot about it, just where it came from and how it, um, how it came to be and the importance of it and all the in-fighting between the universities and the colleges and, you know, the whole system here, which is different than it is from where I've come from -- just the college system itself and the university. So I guess I learned .... But if I didn't have what I d... what I've done, I mean, that's unusual for somebody to have done that, I guess I didn't really learn anything. I mean, I ... just the booklet they've sent me, and I would've ... that what I've read and, uh .... So I've just learned, you know, as practical things; I haven't learned anything particularly more.

A: (468) So you ... you feel it's practical things that you've learned.

E: Yeah. The p... the things that they have sent me; the information that they've sent of, uh, what courses that are available and what courses you need for graduation or credit. I don't think I've learned anything.

A: But then, on the other hand, you must have found there are some differences from standard education which you 
didn't expect (Pause...) either in the actual doing or in your feelings about it.

E: (478) (Pause...) Um. I think the quality of the courses i... are ... it's very good. I mean, I ... I think that, uh, as compared to a standard course, it's as good as a standard course. I just, as I said before about the work load I thought was excessive, and, um, I think you're in isolation too much. And I ... I think it sort of takes a certain type of person to take that isolation. And maybe that's not me; I don't know. But then, I was told that you can take courses at the different universities, it doesn't matter where you are, and then still do it through the Learning so that if there was something that I wanted to take through the open Learning University, then I could do it that way or I could take it at a university. It doesn't matter where I am. So that I ... that was the advantage that I thought would be good for me.

A: (496) Mh-hm. You mentioned before something like 500 pages a week. Is it literally that?

E: I never added it up, but ...//A: It's really a lot, eh?// ... it's a lot. I think 500 is probably an exaggeration, but, I mean, I could check for you. (laughter)

A: No, no, no. But I .... These are all pages that they suggest quite strongly you should read? 
E: (502) Oh, yeah. You have to read.... You have so many readings; it's, uh, you know, every.... It's set out in time periods, so I think 500 is an exaggeration. It just seems like a lot at the time. (laughter) so say you have, um, you know, 6 or 7 readings, 8 readings or whatever, and some of them are 50 pages, and some of them are ... you know, less and .... So .... And then the each ... at the end of each chapter of each reading, then you have 10 questions to answer about it. And I think that's what takes the time, and that's what I have to learn -- not to take the time in doing that. But until I feel more confident myself with studying, then I need to have these notes of what I read. You know, that's because I haven't, you know, done something like that for a long time. For somebody who's used to doing history courses, is used to doing ... wouldn't probably spend as much time doing that than I would.

A: (520) If you were to do a second History course by distance education, do you think that it would be easier for you or still pretty difficult in the ways you've mentioned?

E: It w... would probably depend on the course. I don't know; it depends on who's .... I just find for a one hundred course, a one hundred-level course, I think it's a very heavy course. I mean, if it was a 4 hundred and you were ... had ... at the top had done a lot of courses in history, then you should be expected to maybe do this 
because you had the study backgrounds and you had the background in the ... in the history, but as a one hundred course, I just thought that they expect a lot out of you. (laughingly) Never, ever would they get away with it at a regular university.

A: (534) Oh, i... it's that much, is it? oh, wow! (laughingly)

E: (laughingly) People would be really mad at the professor if they did. I don't know, so that's another reason if you had a study group where you could see other people who were taking the course .... Maybe it's my ... maybe it's me. Maybe, you know, if I listened to somebody else, they'd say, "Oh, no. It was all right," you know. They didn't mind, and maybe $I^{\prime} m$.... But ... but myself, this is how I feel; I find it's a lot.

A: So if you were talking to a friend, who like you she's a mother with 3 young children, what would you say to her about distance education? This person was perhaps thinking of doing a History course in distance education. E: (548) I think it's a good way to start if you don't have the time to go into traditional school, and, uh .... You know, I would just tell them that, you know, it is timeconsuming. My... myself, I just thought it wouldn't be as time-consuming as it i... or has been for me, but, um, I think it's a ... it's a ... certainly it's a good way of studying, and I think using the television, some of the programs, I ... I'm ... not, not with this course, 
but, I mean, some of them .... I've watched some of the programs, and it seems like, uh, they're interesting, and people with VCR's certainly have the advantage of taping it, and then they could watch it again.

A: (563) D... Uh, just, TV and video, um, you said you think that would be a good way to learn. Why would it be a good way?

E: Well, I ... I think it would bring more into the personal. I ... I find when you're just reading the books all the time, you have no feed..., not that you'd talk to the television, but you have somebody else, you know, talking or .... I guess it's the isolation of being by yourself all the time that it's ... it's a little more difficult. So I think the television (Pause....) even though it's only somebody sitting o... standing on the television talking to you, it makes it more of a personal thing than just by yourself. But that could just, you know, be me; I don't know.

A: (577) Yeah. I ... I've been trying to write down what struck me as some of the key words that you were using. Certainly you talked about .... Well, we're talking about History; that's important, a History course. That's, of course, important. You ... you've mentioned a lot of reading several times. You've mentioned isolation, feeling isolated. What do you see as the relationship between those? Is there an 
interrelationship between having ... doing a History course, reading a lot, feeling isolated?

E: (588) I don't think it would make any difference if it was any course, if it ... it would be History or an English course or ... or whatever. I think that is one of the drawbacks with the ... with distance education; it is the ... for me anyway, is the isolation. And whether it's ... to try and do away with it by having study groups or, um, more telephone communication with the tutor or, um, I'm not sure, but I don't think it would make any difference whatever subject it was. I think it would be worse in some subjects, like if you were taking a ... a maths course. I have a friend who's taking it, not through distance education, she .... It's distance education but through one of the community colleges in math. I mean, she's quit because she ... you get too frustrated by yourself if you have nobody to ... even if you're just complaining and you're getting somebody's shoulder to cry on, at least sort of you get some kind of feedback, so I think that, uh, I would never attempt a math course anyway. (laughingly)

A: (612) So, in other words, you're saying if you were doing a math course where you need to ask a lot of questions, you feel you wouldn't get the necessary feedback by distance education.

E: Um, from what I've ... you know, my ... my relationship with my tutor is nonexistent, so I ... I don't know. It 
would just ... it would depend on the tutor. I don't know how accessible, I mean, in ... whether .... on the telephone, too, I think it would be more personal if you were seeing the person. I mean, at least you have the access to the telephone when you wanted to have an important question answered, but if you saw them once in a while, I think it might help a little bit more -especially if it's something where you ... involves something like math or any kind of science course or not just readings and answering questions and things.

A: (630) So you think science courses would be more difficult to do by distance education in general.

$E:$ I do, yeah.

A: Because of the feedback thing.

E: Yeah, mm-hm. I think that a lack of feedback is already difficult, but I think in any kind of the sciences or the maths it would be very ... be very difficult.

A: So just to sort of sum it up: what are the really ... the important things to you in distance education?

E: (639) I think the access is important. I mean, you have a whole range of courses that they offer plus there's the range of all the universities in Canada or wherever you are that can be transferred back to the ... to the open University, so you have .... I think the access is truly good. And the time of when you can work. I mean, for myself and trying to ... with 3 children and my own work and the house and whatever, I can ... I can choose the 
time. And maybe, if I had to go to a class twice a week at a certain time, I mean, I would probably get there. I mean that's .... If I made that choice, then that's the thing. But at least this gives you the option. I think if something came up over ... with Christmas, too, I mean, I didn't have the time, but now that I ... I'm back on a ... kids' school's back in and the kids are gone that I could spend the time. So I think that's important too. And, uh, I think the quality, you know, it's well thought out what they want you to do, and, uh, the instructions are good of ... of, uh, of the course of what has to be in, and it seems to work well with sending your ... your ... your reports in and they get it back to you in a certain time, and I find that works out really we11.

A: (670) OK. Well, that takes care of my questions. Is there anything else that you'd like to add?

E: Um, no, I guess not. I was just curious what other people if ... if they felt isolated or is that just me or

A: Uh, I've spoken to 3 people. I would say 2 of them... well, actually, one of them definitely yes; the other 2 , it didn't seem to bother them too much. They did mention they would like to have a discussion group or whatever, but they weren't terribly bothered by isolation.

E: I certainly wouldn't give up because of the isolation, but I think that certainly would be a bonus, although if 
I was in another province, I certainly couldn't have a ... a discussion group. But, I think, if, you know, within British Columbia, within the different study sections of whoever they have the tutors in the different areas, I think that might be something they could look at. I don't know.

A: (Pause...) Well, that's great. Thanks very, very much. 


\section{INTERVIEW \#5}

Interviewer: $A$

Respondent: $F$

Position on tape: (000)

(000 - 016) Introduction.

A: (017) 0.K. Well, in that case we might begin with....

This is your first course. You fairly recently

enrolled. How did you come to enrol?

F: My girlfriend was taking courses, or has been taking courses, so I thought I would give it a try.

A: Yeah, and so that's the person who told you. Was there any particular reason why you thought you would do it?

F: Oh, always the desire to study more,...so, and it's convenient because I don't have to go to classes at certain times of the day. So it fits into my lifestyle right now so I thought I would give it a try.

A: Yeah, and it's English 101 you said.

F: Yeah.

A: Yeah, I should remember that. When, before you started or when you started, what did you expect it to be like, doing English 101 by distance education?

F: (029) Well, I guess I was a little bit apprehensive because I had taken correspondence course as a child, and did not enjoy it, because I like the interaction with other people. So just in that way I...I really didn't know what to expect, if it would be tedious and 
boring, you know, or if I had any questions who would I ask? Those kind of things where...

A: And have you met those problems.

F: Well, fortunately yes, (laughingly) God has led me to some interesting people that have been able to help me. And I'm able to contact the teacher just twice a mo... a week, so I've phoned her once so far, and she's phoned me twice I guess. So it's.... I think it's good.

A: (039) You said that you did correspondence courses as a child. That was when you were in Japan?

F: Yes.

A: Would those have been courses from Canada?

F: From Ontario, yeah. Grades, I don't know, one, two, three, five and six, I...I can't remember. But anyway, enough of that. (laughs)

A: Bad memories?

F: Oh, it's just a little boring; that's all. You know, every subject you read the directions, you read, read, read, read everything. Whereas this I've been able to watch television; once a week there's a program and a few tapes that have come with the course. So I listen to it, and I find all those things are quite helpful.

A: In English 101 nowadays, what does it cover?

F: Uh...this is modern poetry and drama.

A: (048) Is that what you get on T.V.? 
F: The T.V. is a little bit different. It's not for this course, but it's a little similar, so they interview some of the authors of the poems, so you know just, I think it just broadens my horizon (laughs).

A: Yeah, so you feel having a T.V. component is useful?

F: To an extent, I would hate to have it as the only source without the reading, reading material.... You know the instructions, because they talk so fast, they go through things so fast, that I just say "Hey wait, stop", (laughingly) you know?

A: Is that right?

F: Yeah, but it's.... I think it's good.

A: Yeah, yeah.

F: I missed it yesterday though.

A: Oh, children?

F: No, homework (laughs) (unclear) get my homework done.

A: Yeah, O.K. Learning English by correspondence, by distance education.... How do you feel that it's different from learning it through conventional education?

F: (059) Well, I guess the...your teacher is the manual that you send, that they send to you. Therefore you can read it and reread it, and you don't have to take notes from just listening to somebody in a class. So I think it's good in that way.

A: So being able to reread is very handy. 
F: Right, to look back, and you know, hopefully they're accurate, whereas my notes may not be.

A: Uh, uh. So you have a manual which comes with.... Do you have textbooks?

F: Textbooks and....

A: Uh, uh. And what is in the manual?

F: Oh, so far it's been examples of different poems, and different things to get out of the poems. Examples how to do things with the poems. Some history on the poets.... More or less, and instructions along the way to stop and read and... and take a poem and write some notes on it, and they then give their answers and you get something to compare it with.

A: When they suggest that you stop and do such and such, do you always follow their suggestions, or...?

F: (069) As much as I can, yes, yeah.

A: And that seems to be useful.

F: I hope it is. (both laugh)

A: You have an exam at the end, do you?

F: Yes.

A: Yeah.

F: (070) so we'll find out (laughingly), but, uh, since.... Well, I guess I never really liked poetry, so.... It's new; I feel if I don't do everything correctly, then I have nothing else to rely on?

A: Yeah. When you were in school doing English, did you have poetry in school? 
F: Yes, I think I did have some poetry.

A: So....

F: Uh, just that my background is so different. Going through correspondence courses, some Japanese courses, some American schools, and then to do my last year of high school in British Columbia. I just didn't have all the subjects, and they're from various...like the American School stressed certain subjects and the Canadian School certain subjects. B.C. schools are different than Ontario schools, so my whole education has been quite mixed. (laughs) Hodge-podge.

A: So it...it was only grade 12 that you did in B.C.? In place so to speak?

F: Right.

A: Oh, that does make you a little different from most other people.

F: Yeah. I was... I always want to improve on my English, and so I hope that this would help me.

A: When you were in Japan, you...you mentioned that you were taking correspondence courses. Did you also attend a regular Japanese school?

F: Yes, I did. For grades five and part of grade six.

A: Oh, for two years.

F: Just for two years.

A: I thought perhaps most of the years of school.

F: No, we just stayed at home and did correspondence courses. That was our school. 
A: Ah, so that's why you were a bit off put. (laughs)

F : $\quad \underline{\text { Yeah! }}$

A: It's courageous of you to try another one now.

F: (089) Yeah, yeah. I did try Kwantlen college, but their class time was, you know, just when the children come home from school.

A: Oh, yeah.

F: It just wouldn't work.

A: Yeah, right, yeah.... O.K. What I'm going to ask you now is partly repetition of what you've said, but before you started this particular course, this English course, what were your hopes, your fears, your expectations of taking this correspondence course?

F: Well, I.... It was fearful to face an institution again (laughingly), sort of an ed.... To go back to school after ten years or more of not going to school. So there was this fear of: Can I manage? (099) And, uh, expectations.... I think it's hard to say right now. I expect to learn a lot, I expect it to be exciting, and I think so far it has been.

A: Oh, good.

F: Yeah, so...so I'm very pleased with everything so far.

A: So far, right. (laughs)

F: So far. So I hope the end result is good.

A: Yeah, right.

F: But we just happened to change churches after we've been going to church in Vancouver for ten years to a 
[Surrey] church. And my Sunday school teacher is a...a professor at UBC of English.

A: Oh, really?

F: And poetry is his thing.

A: Uh, huh!

F: So I have been led to some good source, that if I need some help, not just on Wednesday night or sunday night, but any night ... //A: Oh, how useful.//... I can call him up and get some help.

A: Yeah, if you didn't have such a person to help you, do you think it would make a big difference?

F: (110) Well, because I've been brought up in Japan, and I have, uh, not as much confidence, maybe in myself, being brought up in a different society with a different language and different customs. Although I speak the language, there's a whole lot of things that you learn by just being brought in that country. So, I feel not.... Sometimes I don't have enough confidence in myself, whether it's valid or not.

A: Right. Yeah. So are you saying that if you didn't have this professor to whom you could speak sometimes, you might be more lacking in confidence. Is that what you're saying?

F: (118) Yeah, yeah, yeah. It's to double check on how I'm doing kind of thing.

A: Yeah, right. 
F: Yeah. So I think this system is good because they have a teacher that you can call up. The open Learning Institute offers that, and I think that's very good.

A: You said that you have spoken to that person one time I think?

F: I think I called her once, yeah.

A: Once, and she's called you....

F: Yeah, yes.

A: Did you find that very useful?

F: Yeah, it was very nice. It added a personal touch to the paper.

A: $\mathrm{Mm}-\mathrm{hm}$. Oh, have you already written a paper?

F: Well, I mean to learning, reading a paper. You know, the teacher being somebody that...//A: A piece of paper.// ... a piece of paper, yeah. So it's nice to have somebody to talk to and say well, you know, I find this poem very difficult to understand or difficult to read a play, kind of a thing. Yeah, it's been good.

A: (128) Yeah, that's good. O.K. Well, I asked you just now: Before you started what were your expectations, fears, etc.? Now that you are into it, what is your experience of it so far? What are your views of it now, of learning English by distance education?

F: Uh (Pause..) It's exciting (Pause..) hopefully I won't, uh, bore everybody else in the family with what I'm doing, to keep the excitement within myself, you know. If I can share it, so it doesn't annoy them, 
because it's cutting into family time, my studies is, and I have to discipline some time to spend just doing that. You know, less time for the family kind of thing, so... So that's a bit of a challenge, but on the whole I'm enjoying it very much (139).

A: When you first said something there about the family, I...I thought that you meant that you talk about it with them....

F: Well, I talk about it, and I don't want to bore them so that they say, "Oh, quit studying", you know.

A: Yeah, are they quite interested when you do talk about it?

F: Well so far my husband is interested, but I do want to be careful.

A: Yes, I...I understand. (both laugh)

F: Yeah.

A: Oh well, and through this method, what do you feel you are learning about English, about the poetry and so on?

F: Hmm (Pause...) What am I learning about (Pause...) (148) I was thinking I'm learning to look at words carefully, and to look up words, so I'm increasing my vocabulary. And poetry, my whole view of poetry has changed, quite considerably.

A: In what way?

F: Well, I always thought a poem you could read, and understand, and that you should...you should be able to enjoy it, by just reading it. But this modern poetry 
you're not just supposed to read and understand it; you don't understand it usually the first time; you have to pick at all the words and try to imagine the situation that the poet was in, to understand why they are writing that? It's sort of a.... It's almost like solving a mystery. (laughs)

A: Uh, uh, right, yeah...yeah.

F: (159) So that's what I found out. And so far I've just finished the poetry section. I'm just starting into drama. So I'm starting something new now.

A: Yes, that should be interesting too.

F: Yeah, I hope so.

A: And a question partly leading from that. What do you feel you're learning about yourself by doing this course?

F: Hmm, (Pause...) well. Learning about myself. I guess I...I enjoy (Pause....) a challenge, new challenges in my life. (Pause...) It's not...it's not a burden maybe as I thought it may be learning. (169) That I enjoy having challenges, that I'm learning, that I enjoy learning more and finding that I don't know that much more. (laughs)

A: And that earlier you mentioned this thing about lack of self confidence....

F: Yeah.

A: You feel you're gaining more confidence, through it? 
F: From studying? Uh, (Pause...) maybe. Yeah. I think my lack of confidence is more of a culture shock? And I've been here now 18 years, so it.... I think I've come a long way than eighteen years ago. The first five years were terrible, and it's not a language thing; it's a cultural thing.

A: $\quad$ Sure.

F: (179) So, most of the time I'm quite... I have enough confidence to do different things. So, I don't know. It's hard to say right now. I think I'd have to accomplish a little more. (laughs)

A: Yeah, yeah, you started in...

F : January.

A: In January, so that's only 5, 6 weeks....

F : Yeah, yeah....

A: Six weeks....

F: So it's still just.... I'm just starting, you know. I don't want to say too much till I accomplish something. A: Yeah, right. Have you actually written any papers that you've had to send into your teacher?

F: Yes, I've had to write several essays.

A: How did that go?

F: Well! The essays aren't bad. It's the questions that... the shorter answers that I think I have some troubles with. Not understanding the question that is being asked me, interpreting it a different way.

A: (189) Oh, I see. 
F: It's not clear enough to me. So my essays have...the structure of the essay and so on has been very good. The teacher has responded positively, so that has given me more confidence to keep going.(laughs) Yeah, hmm, hmm it's o.k.

A: And a third question in the same line here. What do you feel you are learning about distance education by doing this course?

F: (Pause..) Well. What am I learning about distance education? Well, I think it's a real neat thing to have. Really.

A: Why is it real neat?

F: (198) Because you can fit it into your life, being a housewife and a mother, you know. I can meet those demands and also be a part time student, and I'm really excited about it. I told my sister, and she's quite eager to start too.

A: Oh, great. (laughs)

F: Yeah, so.

A: Your sister was also in Japan with you....

F: Yeah she was born in Japan actually. Yeah. She said "Oh tell me about it." Good.

A: Yeah. Since you are doing a university course, does that mean you are thinking that you might go on to a degree, or....

F: Oh I hope to. Yeah, it's always been my dream, but things have happened that have prevented me from 
pursuing my education. (209) Like, I went to Bible School for a year and a half, so I did that. But... and then I was doing night courses while I was working before I met my husband. Then get married, have children (laughs), sort of busy.

A: Right.

F: So...so now that they're a little bit older, it's time that I started, again, maybe heading towards something. It's just that I don't know what I want to obtain, what degree I want to go for. That I'm not quite certain about it yet.

A: Well, time to decide that I'm sure.

F: Yeah. So, take each day at a time.

A: One...one interesting thing here, because you are a person who did correspondence courses quite a lot as a child, and here you are doing one that seems to be quite different now. (218) This question I've just asked you, what are you learning about distance education by doing this course. Could you make a contrast between the courses you did in Japan and the courses, this course that you're doing now?

F: Well, I guess my.... It's.... I enjoy...I enjoy it now. I didn't enjoy it then. Being a child wanting to be with other children, and finding some subjects really difficult to just read all the time. I was thinking it would be nice to have somebody talk about it and bring it to life. Like history I found really 
boring. I studied French for a year, (229) and I had no instruction on pronunciation, so when I came to Canada a year later and found out that you don't pronounce half of the letters that are added on, that was a real shock, for instance.

A: There were no cassettes with that.

F: There were no cassettes or anything, 'cause that was quite a long time ago; I guess they didn't incorporate things like that. So this I find is good by having a tape and having somebody, sometimes the author, sometimes the writer of the course read the poem so I know how they're read even.

A: Sure.

F: And it adds a nice dimension to the course, I think. But it is more interesting than what I did as a child.

A: (239) Yeah, yeah. I...I've written down just a very few words that you said here. You...you mentioned that it's convenient to your lifestyle to do this, and you've said that you find it exciting. And, of course, it's English that you're doing. Can...can you fit those things together? Is there a particular interrelationship between those things?

F: There may be. (Pause....) I...I also teach and do some interpreting and things like that, so that makes my life exciting as well. But as you probably know, you teach a certain level, and it's always the same and it's repetitious, so that sometimes it can get boring, 
you know. (249) I used to fall asleep in the class teaching (laughs) if that is possible. And then the routines of daily life can get, not boring, but it's a routine, so this adds a new flavour to my life, a new challenge, a new dimension, and I think in that way it does tie in and the spare time that I have during the day while the children are at school, then I can structure it. And housework is very boring, so if I have something else to do, then it encourages me $0 . K$. from 9 to $9: 30$, get the housework done. Now into something else.

A: Right.

F: So in that way I think it may all tie in. (259)

A: Yeah, yeah, right. If you were talking to another person, who, like you, she was a housewife, she had a couple of children, what... what would you say to her about doing a distance education course, doing the English course?

F: Well I think it would depend on that person if they're disciplined or not. I think you need a lot of discipline...to...to do something like this. If they're the type that...they do everything in an undisciplined way, then I wouldn't recommend taking on something else because it would add too much stress to the family situation. But, for somebody who enjoys a challenge I would give it to them.

A: (269) When you say, disciplined, what do you mean here? 
F: Well, I think that you have to have your priorities set in your life, and if you're married, I think your family is your first priority. So you would have to be able to fulfil your housewife or mother duties, and then be...also be able to meet the deadlines of your course, which they give. For each assignment you're given two weeks to do each one and then an exam at the end. So you have to be disciplined, or else you're just.... Instead of being something that uplifts you it'll pull you down, you know. Get a bad image of yourself?

A: Yeah, yeah, right, yeah. (280) I was going to ask you a question; it's gone out of my head. So for you what are the most important things about distance education, about doing an English course by distance education?

F: That I can call the time when to study.

A: That's the most important thing.

F: That's the most important thing.

A: Yeah, working around the family.

F : Yeah.

A: O.K. and one other question here. Do you feel that you are evolving as a learner, by doing this course?

F: Yeah. (289)

A: Can you tell me how?

F: Well, if I'm a student I should be a learner, learning something, and growing, changing. Is that what you mean? 
A: Yes, and in what way do you feel that you are changing?

F: Well, mainly it's more like fulfilling a dream instead of changing, in a more structured way. If I... When I wasn't going...taking a course, then I was studying different things on my own. So now, I...I think it's just a little more structured.

A: Do you find it useful to have a little more structure?

F: (299) I hope that it will be useful in my career as teacher and interpreter and translator and whatever else.

A: of course, you're studying English. Do you.... Do you feel that you could learn English by yourself, without taking such a course, in a less structured way?

F: Yes, but then I think I would be very choosy about what material I read. I tend to be that way. I don't like to read things that are depressing or dark, and a lot of this poetry is depressing and dark. (309) so it's not my choice of literature, but I'm forced to read it, so hopefully I will gain something positive from it.

A: Right. Well, that more or less takes care of my questions. There...there is one question I'd like to come back to. I asked you before how... how do you find learning English by distance education differs from learning it by conventional education? Now, I realize that you did not have very much conventional education. F: Right. 
A: But on the other hand you were in classrooms part of the time.

F: Yeah.

A: Do...do you think there would be much difference if you were taking this English course in a classroom with other people?

F: (319) Well, I've thought about that. While I do it, you know, I think about that, and it's really hard to say. I...I took one course at Langara, English course, and the teacher happened to be a homosexual so that a lot of the literature happened to be, tended towards that way. So, you know it might be according to the instructor that I have. I may be... have to read different material or study different poetry or drama, whatever, so....

A: (329) And actually being in the classroom as opposed to being in your own home. Does that...?

F: Well, I think that being in my own home saves me a lot of time, which is very precious right now. I don't have to commute, right? It's in the house. So I think it's good for me, yeah. I hope to go to a class eventually, but at this stage, right now, I think being able to study at home is very nice.

A : Yeah.

F: I don't know if that answers your question. (laughing) A: Oh, yes. 
F: It's hard. You know I've only done this for a little while, so it's hard to make a whole lot of judgment and I change. My opinions may change in a few months time.

A: (339) Do you think they will change?

F: So far no, but you never know. Like I... It might be fine for English, but maybe another subject it would be different.

A: Why do you think that?

F: Well, my girlfriend has taken a psychology course, and I think she's had to spend a weekend in Victoria, she's had to interview different people, like you're doing. You know doing more things that take you away from home. So, and that added stress to her family and her life. So right now I don't have those things; this course is pretty stay at home type (laughs).

A: And that's what you want right now.

F: That's what I want right now (both laugh)

A: (350) Yeah, you mentioned early on that there is a, there's a T.V. program once a week?

F : Yeah.

A: Which, I suppose it's optional. You can watch it if you want to.

F: That's right, yeah, it's optional.

A: And, you said that you found it good. If you didn't have that, do you think it would make much difference?

F: I just think it adds another positive dimension to the study where I see some of the professors from Simon 
Fraser and UBC, and see what they're like and hear how they talk, and see how they treat the poetry, so it's interesting.

A: (361) And so it personalizes it.

F: Yeah. It personalizes it. It's not always the same way as I pictured it by just reading it at home.

A: Sure. Yeah, right.

F: So I guess if I had a class to attend, it would be maybe quite different depending on the professor and how he brings things out.

A: So it would be basically the professor who would affect how it was.

F: I would think so. I think so now, at this stage in my life, you know (laughs). And the way universities are it's quite impersonal, isn't it?

A: Well, it depends on the class obviously, but I... English, English 101! I think you're right, you know, 200 in a class.

F: (370) Yeah! Like I think you'd just sort of be a number, and you would listen and hopefully get something. You might meet somebody, some friends, but..... So, yeah it's an interesting experience. So far, so good (laughs).

A: Oh well, that's it. Well do you have anything that you'd like to add, or ask me?

F: Not right now. No.

A: No? Nothing to add? 
F : No.

A: O.K. Well that's it then. Good, great. (378) 


\section{INTERVIEW \#7}

Interviewer: A

Respondent: $\quad H$

Position on tape: (000)

A: Just before we begin, do you have any questions that you'd like to ask?

H: Not that I can think of right now, no.

A: Well, if you think of any as we go along, go ahead and ask of course. Could we perhaps begin with...with your decision to enrol in a distance education course. How did you come to that decision?

H: O.K. I'm seventeen, so I should be in school right now, but I didn't agree with the school (laughingly), so (Pause...) I didn't do anything for a while. I've been working and stuff, and I found out you could take university courses, and so I did.

A: That means, although you're seventeen you have in fact finished school?

H: No, you don't have to finish school. You have to be sixteen and out of school for a year, so (pause..) I decided to...I mean I think like...think I'm ready to take English at university.

A: (011) And they accepted the fact that...

H: Yeah.

A: That was useful. And before you started.... Well, first of all, what subject are you taking? English did you say?

H: English, yeah. 
A: English what is that?

$\mathrm{H}$ : English 101.

A: Oh, yeah, yeah.

H: I just took one.

A: Yeah, yeah. And so what did you expect it to be like doing this English by distance education?

$H$ : I didn't know what to expect because I'd never taken it, and I decided to give it a try, and it's a bit different than I thought it would be like. Just the...just the course itself. Like I thought that would be... I don't know what I thought it would be (laughingly), but it's not...it's more analyzing than I thought.

A: Oh, yeah.

H: The stuff itself.

A: If you didn't expect so much analyzing what did you expect?

$\mathrm{H}$ : I thought it would be more reading, and I though it would be writing actually.

A: (020) In the English 101 what do you study? Is it the classics or poetry?

$\mathrm{H}$ : Short stories mostly. We read short stories and then write essays about them and about different approaches and that kind of thing. I thought it would be more creative writing (laughs).

A: Oh, I see. 
$H$ : Because you don't get a description of the courses really, so I didn't know what it was but found out! (laughter)

A: Yeah, right. Are you disappointed or...?

$H$ : No, because I'm going to have to take the course anyways, for.... (pause..) Everybody has to take the course for Arts.

A: Yeah, that's right. And since you're... of course, when you were in school, you had English in school. How do you find learning English by distance education is different from learning English in a regular classroom?

H: It's completely different. Well, first of all 'cause it's only one type of studying or whatever. I mean English in the classroom is.... I mean in high school it's everything.

A: What do you mean by everything?

H: (031) Everything, well, creative writing, and analyzing stories, and reading and different types of stories and that kind of thing.

A: So you're finding that this is a narrower kind of course.

$\mathrm{H}$ : Yeah.

A: O.K. And, so that's the difference. In what ways is it the same as studying English in school?

H: It's just the same as the homework, I guess. There's no teacher, I mean. It's...it was fun learning English at school because there was a teacher to.... (pause..) You know, it just made it easier to do and that. 
A: So having a teacher makes it easier.

H: I think so, yes.

A: Why is that?

H: (Pause....) I don't know. Because you're not so much on your own, and you feel like there's somebody else, sort of. And you know that you're doing it right because you can ask them at the time. We talk on the phone here, but it's not the same as you can go up and show them, and they can tell you if you're on the right track.

A: (040) So if you do make contact on the phone, how do you approach that?

$H$ : Haven't tried it yet.

A: Oh, I see (laugh)

$\mathrm{H}$ : I only tried it once because my assignment was going to be late, and I just wanted to tell him it was going to be late, so that was fine. It's the only time I've talked to him.

A: Oh, I see.

H: But, when... when you're in a classroom you can tell if the teacher is busy or not, and on the phone you can't tell what he's doing or anything.

A: You mean you feel....

H: I feel like I might be intruding upon him kind of thing.

A: O.K. And this question is partly the same as the first one I asked you. Before you actually started doing the course, what were your expectations, and also your hopes, your fears? What did you see it as being like? 
$H$ : I'm not sure if this is what you want, but I was kind of...I was sort of worried that I wouldn't be able to do it because I haven't been in school for so long, and thought maybe I'll be able to do it because I read a lot. I thought I'd go for it because I'd never know unless I tried. (pause...) I didn't expect it to be so.... I thought it'd be freer? I didn't know it was going to be on such a set schedule?

A: Oh, I see.

H: Thought it was going to be, sort of, you can take your time and that type of thing, but there's deadlines and that.

A: So when you say that it's not really very free, you're talking about deadlines?

H: Yeah. There's certain time limits on an essay, yes.

A: Yeah. And what about the structure of the course itself, does that seem fairly free, or...?

H: I don't know what you mean by that.

A: You said you're doing short stories, and you've already said that's narrower than you thought it was going to be, so when you say that there's less freedom than you expected, are your talking about only in terms of time for assignments.

$\mathrm{H}$ : Yeah.

A: (061) 0.K. Well, that was before you started you had certain hopes and fears and so on. Now that you're into it, how do you find it? 
H: I can do it. I can do it, but it's so different from what I've done before, that I'm finding it kind of hard to get myself to do it, because I don't like writing essays about... about other stories kind of thing?

A: What do you mean by other stories?

$\mathrm{H}$ : Well you read a story, and you're supposed to write an essay on the story and what... analyze it sort of?

A: Oh, yeah.

$\mathrm{H}$ : And there's a lot of grammar, and I'd rather do more creative things. I don't know.

A: Are you saying that the way that the assignments are set up, they're...they're quite directed. There isn't much freedom within the essay topics or whatever?

H: (070) sort of. It's just...I (pause...) I don't like...I don't like the content.

A: The types of short stories.

H: O.K. I like...I like the whole thing, reading all the stories and they're different stories, and I don't think I would ever have read some of them if I didn't take this course. But then, there's always different approaches you have to know, and... and stuff like that.

A: Is that what they are trying to teach you or...?

H: Yeah, yeah and I just don't think it's really necessary. Because people interpret in their own way, and I don't think it has to be analyzed.

A: Oh, I see.

H: This is the way I think but. 
A: So you're saying you would prefer to read it and interpret it your own way and never mind other ways that other people....

H: Yeah, you don't have to...I don't think you have to write it down and have someone mark how you... how you think the story is.

A: (080) Yeah, sure. O.K. A little series of questions here. What do you feel you're actually learning about short stories by doing this course?

H: (Pause......) Learning about short stories. (pause..) I'm learning how they're different from other...from a novel or something. And I think that it's hard to write them. I don't know. I didn't really know the difference before? of let's say a short story or a book or a poem, and (pause...) that's about it I guess.

A: O.K. and what do you think... what do you feel you're learning about yourself by doing this kind of course?

$\mathrm{H}$ : (090) Learning to get myself motivated more, because of the deadlines and doing it and, um....(pause...) what I wanted to get the idea of is.... I had no idea what college or university is like.... I just.... I don't know what it's like because nobody ever.... They tell you but you can't.... I don't know how hard it is and that's what I wanted to learn in the first place, so I'm learning that. It's not as hard as people say it is.

A: Was that one of your purposes in taking the course, to find out what a university course is like? 
H: Yeah, yeah. And.... and get used to it before I start. And also because I can't get into university right now or college, and I just thought I'd have that under my belt before I started.

A: Yeah, that sounds like a good idea. You mentioned a couple of times there that you found it difficult sometimes to make yourself sit down and write the essay, and also you said getting yourself motivated can be a bit difficult. Is that... is that something that is perhaps a problem for you in this type of...in distance education?

$H$ : (102) It's not really a problem. It's just the time that you have, and I would like to sit down and read everything, but then I get the reading done and then... and then I think: "Oh, I have to write the essay now," (laughs) and I put it off and I put it off and.... And, um, I'm just sort of learning to make myself sit down and do it.

A: Perhaps that's something that you're actually learning as well. (laughter)

H: Yeah.

A: O.K. And a third question in this little series here. What do you feel you are learning about distance education by doing this particular English course using that method?

H: (110) Well, I guess there's nobody pushing you to do it. It's all yourself, you have to do it, nobody's going to say: Have you done it? You just have to do it, nobody 
cares whether you do or not, other than you. And I think it's really good that people like me can take it.

A: When you say nobody cares, what do you mean by that?

$\mathrm{H}$ : Oh, well in High school, I mean, you get in trouble for not doing your homework. I mean with the teacher and my parents that were always telling me, "Do your homework. Do your homework." There's nobody; there's no peers; you don't have any peers, and you are the only one who's gonna read it and sit down and do it, and nobody is going to say...tell you to do it. The professor's not going to phone you up and ask you, "Have you done it?"

A: So...so you're saying this is an advantage. or perhaps...

H: It could be both (laughs), yeah.

A: And you mentioned there having no peers. Is that an advantage or a disadvantage?

$\mathrm{H}$ : (120) (Pause....) I don't know. It depends on the person. It depends on if you like having... working with people and, uh.... It's completely different than High School.

A: What about you? You say it depends on the person.

H: I think it's fine. It might be better if I had a friend doing it with me. But I don't mind.

A: Do you think it would make a difference if there were one, two, three other people that you could talk to. H: Oh, yeah. Yeah, it would. A: In what way? 
H: It would be easier on me. If you got together then you'd all be.... You could help each other, and you know you could ask people.... They've read the story too; you could ask them: Does this make sense? And you can ask before you give it to your teacher; you can ask if there's any mistakes, or that kind of thing. That would be easier that way.

A: (131) 0.K. I've been writing down what seems to me some of the key words that you've used. I wonder if you could tell me, is there some kind of interrelationship among these words? You're doing English 101. That's central. You...the fact that you are young and have actually left school but can still enter this course, that seems to be an important thing. There's a lack of creative writing, you find, and also you've talked about the difficulty of motivating yourself sometimes. Is there a particular connection between them?

H: (Pause....) I don't.... Not that I can say. (unclear)

A: (140) O.K. To you... what... what are the most important things about doing English by distance education to you?

$\mathrm{H}$ : Most important things (pause....) I...I don't really know what you mean.

A: Don't know how else to put it. Well you might... you have told me why you are doing this. And, of course, that's related, and you have told me that because you have now been doing it for some weeks, you have discovered certain things about it. What are perhaps some negative things, 
some positive things? What seem to you the most important things about doing English in this way?

H: (150) Just what I've said before, that you have to do it yourself, and (pause....) it's just important to get it done, and I guess it's importnat that I'm learning from it. (laughingly) And that it'll help if I want to go to college, I hope. 'Cause if I've showed them that I've done that, then I'll show them that I'll be able to do something there.

A: Yeah, sure. You mentioned the word learning there. When you say learning, in this context of English, what do you mean by learning?

$\mathrm{H}$ : Oh, I'm learning grammar, and... and all the... and what a short story is and about different writers, and just what's in the course.

A: (160) What's in the course. If you were talking to another person, in your own situation, someone your own age who had left school and wanted to go on to university, the same situation, what would you say to that person about doing English by distance education?

H: Oh, I'd say just, and not even English, if you want to do it, just pick a course and get through it.

A: Would you advise the person to do it?

$\mathrm{H}$ : It really depends on the person, what they want to do. I don't know if it's going to work or not. I mean I don't know if it's going to help me but.... I...I might be able to talk to them after I've done it. While I'm doing 
it, I can't really say if it's helping or not. I'd probably advise them to do it because it just shows you basically what you can be expected to do in university.

A: (170) So perhaps that's the most important thing about it for you, that it shows you what a university course would be like.

H: Yeah...yeah, exactly.

A: And coming back to this idea of learning, being a learner. Do...do you feel that you are evolving, changing as a learner because of doing this course, while you are doing this course?

$H$ : (Pause........) I'm just learning more; I mean, I'm not changing the way I learn or anything like that. I've always learned the same, and I'm.... (pause....) The only thing is you're...you're your own teacher sort of. You have to take what's in the text and teach it to yourself, and by yourself. And that's what I'm learning to do as well.

A: So you say that how you learn hasn't really changed. But can you describe to me how you learn?

H: How I learn? I watch people if I want to do something, I watch what other people do or I try to just figure it out myself and .... (pause...) I don't think anyone really needs a teacher. They just need the information and can pick it up themselves. Sometimes you do need a teacher to show you certain things, but you learn it yourself, 
and if you don't want to learn something nobody can make you learn it.

A: Right. Quite true. O.K. That...that really about takes care of my questions. Do you have anything you'd like to add to that?

H: No, I can't think of anything.

A: O.K. Well, that's fine. Thanks very much. 


\section{INTERVIEW \#8}

Interviewer: A

Respondent: I

Position on Tape: (000)

A: O.K. well perhaps we could begin with your decision to enrol in a distance education course. How did you come to that decision?

I: (007) Primarily for convenience. I didn't...I wasn't able to go back to school full time right now, until [my son] is in school full-time himself, which will be September. So I thought what I would do is take a couple of night courses and then take a couple of correspondence courses as well...as well. So it meets a need for me. I'm able to do the work at home, and not have to deal with daycare and still get to spend some time with [my son]. And I like it. so it...it works (pause..) I just finished this first one...this first correspondence course, and I was able to complete it in eight weeks, so I felt reasonably....

A: That was psychology?

I: Yeah.

A: Which number would that be?

I: Psychology 100 or 101 .

A: That basic one. Yeah.

I: It was a very...yeah...the very first basic one.

A: So you did it in eight weeks? 
I: Yeah, and so what my plans were, is...because I wasn't too sure what a work load would be like taking two evening courses and two correspondence courses together, so what I did is started one correspondence course, and then if I could complete it in eight weeks, then I would do two correspondence courses in one term but back to back as opposed to doing them simultaneously. And so that worked, I send away for my second one, probably about three weeks ago, and just started it this week:

A: (019) So you've actually finished the first one, and you're on to the second one?

I: Yeah...yeah I wrote my exam. And so it's interesting because you have to... you have to advise them that you're going to write the exam a month before, so in actuality I'm already advising them that I'm going to be writing the exam for the second course now, even though I'm only.... I just finished the first assignment.

A: Yeah, right.

I: So it...it makes for an interesting experience. One of the good things that I found about doing it that way is that you don't lose...you don't lose time, that the material stays reasonably fresh. And that was why I wanted to do the exam immediately, rather than waiting for the, I guess, the scheduled exam. So the typical time that I would be doing it in would probably not be until June. But I would... by the time I would finish the course in June, and especially I think in the beginning 
psychology courses, there's such an incredible amount of general information to remember? And just because of that really general stuff, I'm wondering: How much am I going to be able to retain, and how much is going to, you know, go in Never-Never Land? That I would do it quick. (030) And it's nice. It's nice now to have it done. I never have to do Psychology 101 again (laughs).

A: (laughs) True, yes, yes.

I: It's not the way it should be looked at, but... But I think... and again I think that in any courses, they get more interesting as you get more into depth. And so for me, some of the really general courses like that, they have areas and there'll be spots that I find interesting. But at a general level a lot of it is just basic information that you need to know, but it's not information that I feel I want to spend a whole lot of time concentrating on.

A: So are you saying that you feel that in that first Psychology course it was really a matter of getting information?

I: Yeah, yeah, basic information, and general information that gives you, I think, an overall knowledge. Really... at a really low level. And then you build in certain areas from that, but even in the second course that I can see, is that much more detailed.

A: Building on that first one. 
I: (040) Yes, yeah, yeah. And... and though it's all pertinent information that you couldn't do, or you wouldn't begin to understand the basic fundamental beliefs in the field if you didn't go through that very first program, so it meets, I guess, lots of needs.

A: Yeah, and just to come back to what I asked you a little earlier, when you decided to do a distance course, was it because someone had told you? You know how... how did you actually know about it?

I: No. I think I...I just think it's one of those things that I've always known. I had done... I had completed I think as I mentioned to you on the phone, a high school course years ago, which (pause..) But even probably before that I knew that... that the open Learning Agency offered like an almost second, alternate way of educating yourself.

A: Yeah, yeah right. And you've already mentioned to me that you're actually doing evening courses at the same time. so how.... What do you find is...? Is there a difference, a great difference?

I: Yeah.

A: (050) What difference is there between doing psychology by distance education or if you were doing psychology in the classroom. What would be the difference?

I: My understanding from people that I've talked to in my classes is that psychology is such a common course for people to take. So almost everybody at a first year 
level takes psychology. So lots of people have given me their inputs about it, and what I think is true is that it's much easier at the class level. Again, probably depending on the instructor, I would imagine that would have some contributing factor. But I think it's harder to learn by distance education?

A: Why is that?

I: Well, I don't think you have the feedback, and... and your scope is... is only as wide as what your vision is, and obviously the whole purpose of education (pause..) at an undergraduate or a graduate level is to widen your...your knowledge and broaden your...your horizons. (060) But part of what does that is the experiences of other people. And when you don't have the experiences of other people to offer their insight and their input into what you're learning, I think it makes the process more difficult? So I think what ends up happening to a certain degree is that you...you rely on memorizing material as opposed to actually learning, because somebody triggered something in you that you didn't know.

A: So when you were doing your first psychology course, did you feel that your scope was fairly limited?

I: I had a lot of biases coming into it.

A: Your own biases, you mean?

I: Yeah, and surprisingly I think that it was able to...to widen some of my...my personal prejudices about 
psychology, and it did open up, it did go out of my world a little bit.

A: How did it do that?

I: (pause...) (070) I don't know. Maybe just the material, maybe the material was...it...it enabled me to look at the field of psychology in a more holistic sense than probably what I would have myself. I...I come from a belief that your environment is incredibly strong in shaping who you are and, probably because of my lack of knowledge in psychology, have been way overly.... Like I've leant... leaned way over in that side. And so what it did enable me to see is that, no, it has...it's a combination of factors. And so, I do feel that I was able to learn something from it. But I think that the learning.... I think I put a lot of time into it. And then I think that if anything from what I can understand from people who have taken some of the same...the similar course at school is by nowhere near do they have to put the same amount of time in...into their...that psychology course at the class level as opposed to what I've put into it.

A: Is that right?

I: I really believe that, yeah. (080) Ah, like the one...this one that I'm doing now. I spent three hours on it yesterday morning, three hours on it this morning, and that will be...it will by typical of me to spend a couple hours a day, I think, just to do the assignments. 
And then go through whatever kind of process it takes me to write the exam. So I think it is a more involved.

A: What's more involved?

I: The...the distance education.

A: You're saying you, as a learner, are more involved?

I: The course is more invol.... You have to.... I think that you have to put more time into it, into the course.

A: So more time and more involvement. How do you connect those?

I: I think that at a classroom level, and I could be out to lunch, I'm only going by what... what I'm understanding from what people are telling me, but quite conceivably you can go and... and there is the required material that you have to read, so assumably (090) you're reading the same material, or something similar, but the amount of time that you would have spend in preparation I don't think is the same kind of time. So that's why I would say your involvement in the course, I think, is greater at this level than what it might be at a classroom level.

$A$ : Oh, I see. O.K. you talked about the differences between distance education, doing psychology by distance education or in the classroom. What would you see as the similarities?

I: Probably the core material. I would assume it has to be. If it's going to... If Kwatlan is going to accept this course, as simon Fraser is going to accept it, as UBC is going to accept it, as being relatively interchangeable, 
then some of that would be your basic similarities. You're going to learn pretty well the same materials, the same fundamental.

A: What about the process of learning by distance education and the classroom. What similarities would there be there?

I: (100) Well, you would still have to... you would have to read your material and know it. (pause......) You would still have an exam. (pause...) You possibly could still have an essay assignment to do. So I assume that the marking might be similar. And then again different instructors would have different measurements and different ways that they would go about marking. So I guess they would be similar; I'm not sure what other ... other similarities you would have, having not taken a Psychology course. I think that there's more differences than there are similarities?

A: Yeah. O.K. My next question is...no, not exactly related to that. Before you started doing the Psychology distance education course, before you started, what were your hopes, your expectations, or your fears?

I: About the distance education?

A: (110) Yeah. About learning psychology in that way.

I: That I would be able to learn it. Because I've always had that bias about distance education, that it was a more difficult way of learning. So that first of all, would I be able to learn it? And that...that most people 
that I had talked to in that field, I thought that there was a lot of similar thought that the first year level courses in psychology cover such a wide range of material to know that it can be difficult material to know. And I think you compound that by doing it by distance education. And my other thoughts were if...or an apprehension I guess beforehand would have been that I'm trying really hard to enjoy the process of learning? And I think that you lose something in... in distance education. I think that you...I think that a really large part of the enjoyment of learning is the classroom (120) experience that you get and so I...I really lose that. And when you are confused about something it's difficult to share that thought with...to discuss it with anybody. Even though you have a tutor, I don't feel that the tutor serves the same...the same kind of purpose.

A: Have you spoken to the tutor?

I: Yep, yeah. (pause..) I haven't yet talked to my second tutor so I'll be really curious to see what my impression formed is of my second tutor, but I didn't like the first tutor I had?

A: Why was that?

I: I found that she was not a real life human body, and I had no sense of warmth or compassion from her or no interest in me as a person. And no interest for me to know her as a person either. She was strictly there to give me my tutor-posed questions and to mark my 
assignments. And... and I always had at least something (130) to ask her whenever I phoned her to get my tutorposed questions. I a couple of times phoned her to say that I was stuck on something, and a couple of times it was obvious...like it was a repeated thing that I was stuck on, and when I studied for the exam I had a list of four or five different things that I was really confused about, and I was confused for wording, in an exam type of situation that if my understanding was clear and... and I couldn't get anything from her so I found her really uncommunicative. (pause...) I didn't feel like that there was...there was an overwhelming desire to help me. But it could have... Like I'm sure a lot of it was just style because what she... whenever I asked her something, how she reacted to me is that she would give me back a question. And I understand that for some people that might be a way that they would help somebody to learn, but it didn't work in what I was trying to figure out, and I didn't see what her problem was and why can't you tell me the answer.

A: (140) Yeah.

I: But maybe if you tell me the answer, to my question, then I'll be able to put it together and I'll be able to see it, but don't answer my question with another question, particularly a pattern is established that is not...I'm not getting it, not helping. And what was interesting is that, um, in that last time that I spoke to her, where I 
had four or five things to ask about the whole of the (unclear) in studying for the exam, and I never did ask her the final question, because I did... I'd given up by the time I got through four questions and it was the same response to all the questions, that I didn't even bother asking her the last question because it was pointless, and I'm not going to do that. And part of it, and then again I don't know whether...I don't think that it was all because of her, part of it would have been something that triggers in me in that it really set up for me like a parent-child relationship, and I think that that... I (150) think that that can happen in school anyway. But I think some teachers would...because of who they are, because of who I am that that would happen to a much greater depth, and it really was obvious with her to where every time I talked to her, I left the conversation feeling like a stumbling, mumbling child, and it was a really uncomfortable feeling. So I didn't enjoy my relationship at all with her. That the whole tutor-posed questions that I... and that was the other thing that I...that I didn't think was really fair about the assignments is that for each assignment that we did, we had to call the tutor, and they would present the question, and it was an unknown, whatever it was that... that they choose to ask you, and I had difficulty reacting with that...that kind of pressure or stress which I conceived it to be. 
A: Oh, you mean, you telephoned and you had to respond immediately?

I: (160) Yeah, yeah. And I don't see the benefit of that. (pause...) I...I actually did O.K., but the stress that it put me through was... was really hard. And it actually made me question whether or not I wanted to do it a second time because I really wasn't comfortable with the process. Strangely enough the second course that I'm doing, they give you the question, so you have time to think about it. They're probably more difficult questions, I would grant, but at least you have the opportunity to think about it. But, for whatever reasons, that wasn't the design of that first package.

A: Actually there is an interesting possible parallel there between the classroom situation where students are called upon to respond immediately and this telephone conversation. And yet you seem to be saying that it was more stressful to have that over the phone than it would be in a classroom?

I: (170) I think it was, yeah. I think it's a much different situation. First of all you have no, like you haven't established any kind of a... a relationship at all with this person on the other end of the phone. And perhaps some people you might be able to do that with, but for me in this particular case, I wasn't at all, so I never had...like I said I never had a sense of a warm live human body at the other end... at the other end of 
the phone, so I think that it...it immediately set me up in that kind of child relationship, so I felt disadvantaged. But my experience, and maybe it's just because of my experience so far with the two courses that I'm taking, is much more of a nurturing environment, and I don't ever perceive anybody ever being put on the spot, or verbally attacked, even though that was a too strong of a word, that's not what happened, but I use that word for lack of any other. (180) So I don't look at it as being the same kind of environment. You are encouraged to explore your thoughts in the classroom situation and ... and any of your thoughts are O.K. Like some more obviously would be right, and some wouldn't be right. Perhaps the subjects $I^{\prime} m \ldots$ I'm taking 2 English courses too, so it's much mo... maybe it's much more subjective? So a lot of it is your, I don't know, it's interpretation, but there's still a technical aspect to it that this can be right or this can be wrong, particularly in the poetry class.

A: So are you saying that in the Psychology course you felt that you were definitely not being encouraged to explore yourselves?

I: No, I wasn't. No, no. I didn't have that sense at all.

A: And one other thing that you said earlier was: doing the course by distance education, you felt that it compounded the amount of information. I don't quite understand what you mean by that. 
I: (190) I don't know if that it...that's what I meant to say, that it compounded the information. Probably what I meant is that the number of hours per course that you would have to put in, I think, would be far greater than what you do in the classroom.

A: Doing distance education?

I: Yeah.

A: To...to acquire the same amount of information in other words.

I: Yeah, yeah.

A: O.K. I'm not sure if you actually answered my original question there. You said some very interesting things, but I asked you.... (both laugh) Which is just fine, whatever comes to your mind. But my original question was: Before you actually started what were your hopes, your expectations, and/or fears about doing Psychology by distance education?

I: (199) Well, I think I told you my fears and my apprehensions about positive learning. What were my hopes? Basically that it would enable me to get a little bit closer to a goal and meet my needs, which was to be able to stay at home.

A: So that...you consider that your central need at the present.

I: Yeah, yeah. I can't.... (pause...) Yeah, I can't see choosing to do distance education for any other reason than maybe purely physical reasons? 
A: And now that you are well into it, and have in fact done one course, do you find, you know, has it met these expectations? What... what have been your experiences, your views of it in relation to how you started out?

I: (209) Probably quite similar. Yeah, I don't think I've been surprised one way or another. (pause....) When I look at it, it seems...like I look at, well, hey, like eight weeks later, and I just finished three credits, so that was a nice feeling. And, yes, I can do this. So that was the other thing. Because that probably would have been one of the other fears, like: how well am I going to be able to do this? To do at a distance education, and... and having...actually having never experienced a university course before. And so I didn't know what my expectations would be for an exam and (pause...) and it wasn't as horrible as what I thought that it would be. So that was....

A: The exam you mean.

I: Yeah. So I...I studied an incredible amount for it. I probably will get better at that I guess, as I go through the courses, and (pause..) But it wasn't.... Maybe if anything it might have been a little bit more difficult than what I expected?

A: (220) Difficult in what way?

I: The assignments I guess. They were complex, or the wording of the questions wasn't...like it didn't jump out at me, and say: Oh, this is the answer. 
(224-227) Interruption by children.

A: A little series of questions here. What are you learning, or perhaps I should make it past tense. What have you learned about Psychology by doing it through distance education?

I : (230) Is that like as opposed if I had have done it in class?

A: No, let's just leave it not making a comparison. What have you learned about Psychology in this course?

I: Well, this would be a really, really general statement. I think that the main thing that I have learned is the necessity and value of looking at the human person as a whole being that is composed of a...a biological and intra-psychic and a social being all in one.

A: And that relates back to what you told me earlier about having previously put everything down to the environment more or less.

I: Yeah, so for me that was a big (unclear) and... and probably like, just certain areas that...that I didn't know before that, you know, in...in understanding of some...some things that were innately determined and other things that were learned. (240) I just didn't...I didn't know. I had never experienced that kind of material before, so it was kind of...it was nice to understand some of that. Something like about perception and depth perception and different visual perception clues that we have that are learned and... and how studies 
that have shown that people who are blind and have had sight regained don't just walk out into the world and see. And so that kind of material that I never would have known, so...so it's given me the opportunity to learn things that I just...I just didn't know before. So I do feel that it's served the purpose and that it has broadened my horizons. So it's been good for that.

A: And the second question in this little series. What have you learnt about yourself by doing this course?

(248-251) Interruption by children.

I: What have I learnt about myself? (pause.....) That I can do it first of all. I don't know if I ever have .... I'd probably get hung up on... on goals. (pause.....) And then trying, finding a balance somewhere, I guess. And that....

A: What do you mean by goals in this case?

I: Oh, by...the differences between say being an $A$ student and $B$ student or a $C$ student and... and trying to find a balance somewhere between enjoying and learning and achieving, I guess? And... and I think... I think I found that balance oK in this course?

A: (260) Enjoying, achieving and learning. So those are three distinct things.

I: Yeah, they would all be something that I would want to get out of any individual course.

A: And what kind of balance do you think you found? 
I : (Pause.....) I'd love to say that I found (pause..) I don't... and I don't even know how to...I don't even know how to describe it in terms of percentages, but I would like to say that I have found that I could do all, that I could have a sense of achievement, that I had a sense of enjoyment, and I also learned something. Probably what I actually found out is that I still have some work to do on being hard on myself, (unclear) a really good example for me that was like I got an essay back last night that I wrote in one of my English classes and I got a B+ on it, and I came home and cried because I got a B+ on it and not an $A$. And so I realized I still have a way to go (laughs).

A: (272) That was one of your evening classes, was it?

I: Yeah, yeah. So I saw.... But it opened up those doors... it opened up those avenues to, I guess, to know that much more about myself. That, yes I've been saying for a couple years now that I'm not achievement-oriented anymore and I'm not goal-oriented anymore, and look at some of my reactions. But my first assignment that I got was in my Psychology course; I got a $73 \%$ on it, and I was devastated. I couldn't believe that I could get a $73 \%$.

A: That was your very first assignment in that Psychology course.

I: (278) Yeah, yeah. I even phoned the tutor, and more or less.... I didn't question how she marked; I questioned the process, because they...out of three assignments they 
pick one and only marked one, and there was one question on it that I missed completely, and so my theory was, well, if you marked all of them, I would have a better chance of doing better because I can assume that I'm not going to miss something major on all of them. And like she said to me: Look, you're getting too hung up on it, on your mark.

A: So what...do...do you feel that you have sort of overcome that?

I: Well, the...no, silly thing was on my last four assignments my mark ranged between 92 and 100 .

A: Oh, well!

I: So, I'm not sure how much $I$ overcame it, or else $I$ just was more determined that I wasn't going to be affected (laughs). (290) So, no. So if anything, what it's probably told me about myself is that I still have work to do.

A: On this... on this idea of not being too goal-oriented.

I: Yeah, yeah, and dumping on myself when I don't achieve what my idea of who I should be is. What happens if I'm a $\underline{B}$ student and I don't know? (laughs).

A: Oh, that's terrible, isn't it? (laughs)

I: Yeah, I'm really bothered that I can't even.... Like, I thought that I had... I had thought all this stuff out, long ago. And like it's now I need to experience it all, so sometimes the thought process is only the first half. 
A: When you say I had thought all this stuff out. What stuff do you mean?

I: That aspect of who I am. My personality that, you know, that I've been aware of that, that...that's somewhat of a major component of my character and... and I thought because I was aware of it that I was no longer like that now, that I'd changed, that I had come up with the formula and said: 0.K. I'm not like that anymore; I'm going to enjoy this process. And of course to find out that all...that it's not necessarily that easy and now maybe I have to do the work, on this process so....

A: (303) Very interesting. 0.K. yeah, and the third question in this little series is: What have you learned about distance education by doing that Psychology course?

I: (pause......) I think that there is a lot of effort made to enable us to learn. I really think there's a lot of input into it. (Pause....) I don't think that it's easy, and I think that the courses make you work...like whoever designs courses make you work for what you learn from them. And, yes, they definitely serve a purpose. And they mean....

A: (313) They serve what purpose?

I: The whole concept of distance education serves a purpose. You know, if I didn't know that prior to doing this, or maybe it just reaffirmed my belief that....

A: I don't understand the word 'purpose' there. Is it...? Whose purpose does it serve? 
I: The student's.

A: Ah, I see. So in your case your purpose was?

I: To do the course and not go.

A: To a classroom?

I: Yeah.

A: Ah, I see, O.K. O.K. just some of the things, the key words that I've been jotting down here from you are. First...very first sentence you said was convenience. That's obviously important to you. You said that you think doing a course by distance education is actually more difficult than doing it in the class. The student becomes more involved, partly because of that. And you've also mentioned stress in relation to it. Do.... Can you make an interrelationship of those things for me?

I: (Pause.....) I'm not sure (laughs).

A: It's a hard question, I know.

I: Let me look at the...

A: (330) If you can read my scribbles. Convenience; it's more difficult doing distance education, psychology by; the student is more involved in a way; and there's perhaps greater stress.

I: I don't how...I'm not sure how tied in that I would make them. (Pause.....) I don't know if the fact that they're convenient and that (pause...) has any meaning to how difficult the courses are or not if they're... I look at them almost as separate... as separate factors. (Pause...) I...like I... Something I never thought 
of, and I don't really think it would be pertinent, but is that, you know, for the convenience aspect you pay a price, in the terms of difficulty and... (341) But I'm not sure that that's something that... I've never thought of it before, so I'm not sure if anybody else ever has thought of it. I can't imagine these people making up these courses (laughs): O.K. She doesn't want to go to class we're gonna make this really difficult for her. And I'm not too sure if people would come from that side.

A: But from what you have said it seems that to you, convenience is one thing, and then these others are perhaps negative things. There is some kind of a tradeoff.

I: (348) Yeah, yeah, definitely. It's not, yeah I don't look at it as being an all positive experience. There is...there is a trade-off, yeah. And... and as I thought about taking that second course, I thought about.... The only stress that I had encountered with these tutor-posed questions. But it did cross my mind is: Do I want to do this again? Because I really didn't enjoy it. Like, you know, for that hour before I would phone the tutor, and trying to read over the chapter, and: what is she going to ask? Like, what is the pertinent stuff of this...this chapter, and... and then feeling my reaction to stress when somebody asked me that question immediately and how well I respond to it. And then what I thought is, it's only five times that I have to do this, so I can deal 
with it. I dealt with it five times before, and I mana... and basically answered all the questions, a couple of times not fully, but I know I can do it again, so that was the way I looked at it. (361) So I guess it was a trade-off too. Yeah, so I...yeah so I think that that would be probably be a true statement that I certainly do look at it as...that you...you (pause..), I don't like to use the word pay a price, but there is a trade-off for the convenience aspect of it.

A: Yeah.

I: Yeah, 'cause I don't see.... I don't know. I don't see why... why I would do a distance education course....

A: Except for that convenience.

I : Yeah.

A: (369) So perhaps related to that once again: For you, what would you say are the most important things about doing a Psychology course by distance education?

I: In particular a psychology course?

A: Not in particular, any course, but because that's your experience.

I: (Pause....) one of my reasons why I did it is because Psychology is such a popular course in school when I was a new student is that I was aware that I would not have a great success of getting the courses that I wanted. And I realized that it was a course that I needed to do. I have to do it at some point, and so I figured I might as well just do it by correspondence. And I don't have to 
go through that stress of not getting the courses I want at school. And I also thought, too, it seemed really clear that an awful lot of 18, 19 year-old kids that I knew, kids with parents, all took Psychology 101. (381) And I didn't want.... I choose to not be in that experience, to share that experience with a lot of really young people. And so that was another...that was a bias that I had that I would remove myself from that (unclear). So it met another need, you know as well as the convenience aspect of it, and.

A: So you're saying in effect there were really two important things...

I: Yeah.

A: ...one was the convenience and one was not to be with teeny boppers. (laughs)

I: Yeah, and I found that there was.... I guess I really believe, I have a... I have a really strong bias that I think that people...that mature students coming back into education approach education differently? And I think that they come up with different expectations. And I look at myself, where I've given up a job, and... and I'm a single parent, and... and I don't think that it would be unrealistic for me to say that I might want something more out of it, and so I don't... and a lot of people look at Psychology, those first couple...couple of Psychology courses as almost being like an easy course to take. And I didn't want to be in that same contact with 
possible...a general attitude that that was the experience and that I'm taking it 'cause it's an easy course to take and have no intentions at all of continuing on further. And I also think in the field of psychology I think your life experiences really contribute to my understanding of it. And I don't see how, if I look at myself at 18 or 19 , how, my lack of experience, I just wouldn't be able to (unclear) the same as what they do now.

A: (402) So in effect you're saying being isolated was better than being in a classroom with inexperienced, rather uninterested younger people...

I: I don't know if it was, but that was probably the bias that I shared, yeah.

A: Yeah. Another question. If you were talking to a person like yourself. She was a person your age, with two young kids, a single mother and so on, living in a similar situation. What would you say to her about doing a psychology course or another course by distance education?

I: Probably that it meets a need. But it...it's a difficult way to learn and that you really have to apply yourself in the learning of it. (Pause....) But that it can be done. I don't know if that really makes sense. (415-428) Interruption by children.

A: One other question. In a way you've already answered this, but perhaps you could say it again. Do you.... 
How are you evolving as a learner by taking courses through distance education?

I: (pause.......) I guess I could say it enables you to become more disciplined? Though I don't look at discipline as being a problem with myself. So that's certainly, for a lot of people, there's a real drawback for correspondence courses is that there isn't the discipline. I have another reason as to why I took Psychology. I wanted to take courses that were offered through open learning as opposed to simon Fraser or UBC through the open Learning, because I wanted to do it on my own time table. (440) And a lot of the courses you have to follow the university time table and send in the assignments when they ask for them, and I wanted to be able to do it quicker. And so I specifically looked for courses that I could (unclear) and I'll continue to do that. I'll continue to take courses through the open Learning throughout this year, and that will be one of my prime factors in what I take.

$A$ : So if you took it through SFU or UBC they wouldn't allow you to speed up?

I: No, no you have to follow their...their semester. It would be like you were in their class, basically.

A: Yeah, right.

I: And I have.... (phone interruption) That's a real advantage, and I haven't thought about that at all, and that advantage probably works both ways for people? In 
that you also have as much time. You would have up to six month.

A: Sure, right.

I: And so a lot of people actually that I've talked to say they...yeah, that they like it for that reason, and my reasons were the opposite. And then that... and then that brings me to another thought, because again, I wasn't sure as to how much of a work load I would be able to handle because it was my first experience, that I also thought that I could give myself that flexibility. Then something happened in my life, and just with a lot of life stuff that I was doing right now that was demanding of my thoughts and emotions and my time, that I would have some flexibility, and that if something happened then, if for a month I couldn't do anything, I wasn't going to lose that whole semester.

A: (463) So flexibility was another important aspect.

I: It would have been yeah, yeah. (unclear) would have been really important.

A: Just before you suddenly remembered that, you mentioned the word discipline. When you say 'discipline', what do you mean?

I: The ability to work on your own and to do your assignments and to get understanding. What I hear from a lot of people is that they don't feel that they can do that unless that they are told that they have to do something on such and such a date. So distance 
correspondence doesn't work for them. I also hear lots of people say that they just can't do it. They can't... They cannot do distance education; they can go to school and do quite well but are not able to succeed at distance education.

A: (475) Because of the discipline problem or...?

I: Well, I don't know. They...they just find it a very.... It's difficult for them learning.

A: People who have tried it?

I: Yeah. Yeah.

(478-489) Interruption by children.

A: So you were just saying that some people feel they just can't do distance education.

I: Yeah, yeah.

A: Because of discipline and...

I: And because, and... and like I said I think that it is a more difficult way of learning. I think that you.... And my experience in my English class is, it's been really interesting because I'll read the novel. The poetry was really...was really indicative of that. I could read the poetry and just not get it at all. Go into the class and just through the discussions that you have in the classroom just opened up a whole new area that enabled you, in some cases especially with poetry, to understand it, period. 'Cause I just couldn't understand on my own. But in the novels, where I would read and mainly enjoy what I was reading and 
feeling...feeling that I was having a pretty good understanding of what was going on, and people would talk about things that I just had not got at all, just a whole new way of looking at something. And so that's the part that I think that really contributes to learning.

A: (505) Yeah, right.

(506-510) Interruption by children.

A: Actually that takes care of the questions that I want to ask. Is there anything that you'd like to add?

I: I don't think so. I think you've probably asked anything that I would have thought about distance learning. (Pause.....) I can't... I don't know... off hand I can't think of any...anything more. (Pause....) I think probably one of my.... If I had a request to make (pause...), it would be to make, possibly, I don't know... I don't even know if this would work, but perhaps, if you maybe were given a list of people who were taking your course, and ultimately it would be up to the individual if they wanted to have any contact with you or not, but just to be able to share some thoughts with (unclear), with somebody e...with some other people. I'd like that available anyway. And weirdly enough there seemed to be a really big emphasis on cheating. And like that was the reason why they only marked one assignment. Well, I still don't get it; I don't see what the difference is if you only mark one out of three assignments. I still don't see how that relates. 
A: Why do think that was connected with fear of cheating?

I: That's what she told me.

A: (534) Really?

I: Yeah. That there was so many people taking the course that.... I don't know. It's like I.... It's slmost like I didn't even get the conversation, because it doesn't make sense to me; I don't connect it. It's like it's just for ease, marking. I don't know, yeah. I don't know what the variable would be there as to why...why that ould.... But she did mention that, that it was a concern that there was so many of these questions floating around. And I don't think that.... My thoughts are that an institution.... I just don't know how hung up I would get on that. But ultimately, like, you do the assignments; you have the book there anyway; it's to your benefit whether or not you learn the material or you don't learn the material. You still have to go and write the exam, so.

A: (550) Sure.

I: I'd like to think that the idea of post secondary education is to help you learn. And I think they could do more to help.

A: So, how could they do more to help?

I: Have warm live human bodies as tutors. Perhaps by (unclear) a class list. Because of not having that much experience with it, I'll be interested to see what this tutor is like. Like I have some questions to ask this 
tutor that directly relate to the assignments. When I asked my previous tutor, she wouldn't tell me the answers, and I don't...I just don't see the point. Like there's still one question that was on an assignment, and actually the beginning of this second psychology course, is the first chapter... is you repeat the first chapter from the first time, and there's one question that is the same question that I had trouble with on the first one, and that I still have trouble with now. And I think it's really interesting that I'm still... Like I didn't learn what... what I was supposed to learn out of this. So I'm going to ask this tutor. I'll go through the same exercise with him and see if he's willing to help me rather than get stuck on a factor that you didn't know the answer. And I don't think that should be the point.

A: Yeah, yeah.

I: Giving me the answer; it should be whether or not I'm learning what it is that I need to learn. So, we'll see... see what he's like. So apart from that I can't think of...I can't think of anything else.

A: That's great. Thanks a lot. 


\section{INTERVIEW \#9}

Interviewer: A

Respondent: $\mathrm{J}$

Position on tape: (000)

A: O.K. So I have some set questions, but on the other hand, I'd like you to just talk about anything that seems relevant to you. So perhaps we could just begin with, you know, how...how did you get into distance education and, you know, how did you come to the decision to begin it?

J: The decision for me was that I have 2 and a half years of credits from U. Vic. back in the mid-sixties, and I always knew that I wanted to go back to finish my B.A. and... and probably do a master's in something, maybe an M.B.A. U.B.C. felt that my credits were not sufficient, my grade point was not high enough, and they wouldn't accept me, but both simon Fraser and open Learning (clears his throat), excuse me, gave me full credit for what I had. (010) In looking at the programs that were available at simon Fraser, they just didn't fit into my time requirements, and the desire's, of course, is I wanted to start with to get back into the studying mode. So I opted for Open Learning, and I'm taking Psych 100.

A: Psych. 100 .

J: Yeah. I'm not sure that now....after registering in it that it's the right way for me to go. I'm going to have to be a little more self-disciplined than I am. 
A: Ah-ha, so discipline is....

$\mathrm{J}$ : Yeah. When you haven't done it for years and then you've got to do the whole thing on your own, it requires a lot more. So, I'm sure the next courses I will do might be through open Learning, but they will be in the classroom somewhere.

A: Oh, I see. So you're saying that you would, in fact, prefer to be in a classroom.

$J:$ Yeah, for me it's much better.

A: Because of discipline. Any other reasons?

$J:(020)$ No, I think it's just 'cause of discipline.

A: When you say discipline, what do you mean?

$J$ : I just find it very difficult to sort of sit down and do all that work that's in front of me where I know if I'm sitting in a classroom, I'm learning immediately. And the results are some better feed.... I guess there's the opportunity for feedback, etc. when you're in the classroom.

A: So, when you're doing it at a distance you find that there's no feedback? Very little feedback?

$\mathrm{J}$ : Well, you only have the opportunity to talk to your tutor once a week, and that's not that long a period of time, and the rest of the time you're doing it on your own, and you don't have any contact with any other of the students because you don't know who anybody else is. So you're really on your own, and I find that difficult. 
A: Yeah, yeah. Do you get in touch with the tutor sometimes?

J: You're supposed to once a week or once every two weeks to answer...have a.... They ask you some questions that are then...you are marked on, so yeah, you're supposed to.

A: Oh, I see, so you don't have a choice really:

J: No, and at that point you have the opportunity to ask questions of what's going on.

A: (030) Right. Before you actually started doing Psychology by distance ed., how did you expect it to be?

J: (Pause...) I don't know if I had any expectations. Maybe a little easier; maybe the workload wouldn't have been nearly as heavy. I think that's...that's the real big thing. When you do it by, as in this case, correspondence, there's a lot more workload than there was, that I can remember, when being a student sitting in a classroom.

A: Is that right?

$\mathrm{J}:$ Yeah.

A: Meaning that there's more to read...?

J: More to read, yeah, much more to read.

A: More assignments as well?

$\mathrm{J}$ : In a way more assignment, in a way more assignments. Just a lot more information to learn from because you're learning on your own rather than an instructor teaching you. 
A: Ah, right. So you're saying there is actually more information to learn or it just seems like more because you're doing it on your own?

$\mathrm{J}$ : There's probably more information there too.

A: $(040)$ Is that right?

$\mathrm{J}$ : Yeah. Because where a prof. would be standing there lecturing to you and you would be taking notes over a half or an hour course, you've got three times as much reading as...to do as you would to get the same information from a lecture.

A: Ah, so the reading takes the place of the lectures... $\mathrm{J}$ : Right.

A: ....as well as the extra....

$\mathrm{J}:$ Yeah .

A: Right. So you're telling me that you have, of course, done university courses before so you can, no doubt, answer this next question: How do you.... How do you think learning Psychology by distance education is different from learning it in the classroom? You've given me a couple things here.

$\mathrm{J}$ : Well, I can't say for sure what the difference between learning Psych. by distance and in the classroom is 'cause I've never done a Psych. course before. (049) But in any other learning process that I've been involved in in the classroom, the professor is there disseminating information for you and teaching you sort of step by step, where when you're doing it by long distance 
correspondence, it seems like the student is doing all the research himself. You're finding out all that information that the prof. isn't giving to you; you have to go and find it all.

A: Uh-huh. So you said the prof. give...does it step by step. You get the feeling that what you're doing is not step by step.

J: No, it's step by step, but there's so much more information you have to get out there and gather on your own.

A: Uh-huh. It's just you...you feel almost as if there's an overload.

J: Yeah, yeah.

A: O.K. So that's a major difference. What are some of the similarities between doing a course by distance education and in the classroom?

J: Essays, book reviews, final exams, that's all the same. I would think that the only difference in the exams is that there isn't a mid-term, and there's only a final exam, and that counts. The weight on that is very, very heavy .

A: (060) 0.K. And what about the learning process, the studying process? How would that be the same or different again?

J: I think it's different in that... in that you're doing so much more of the studying and pick... and finding the information yourself, so it's completely different. In 
the classroom the instructor is giving you the information. Long distance, you have to go out there and get the information yourself. Although...even though they give you all the course material, you have to read through it and absorb it and understand it, and there's lots of ways to help you study at the end of each chapter, but it seems like really, really time consuming for the amount of information you're learning.

A: You're saying what they give you at the end of the chapter is questions is it...?

$\mathrm{J}$ : Questions and assignments and things to look for.

A: And you feel that's....

J: (070) It's well org...it's well organized, but the workload is very heavy for the.... It seems to be a lot more work than there is.... The workload does not correspond with the amount of information you're learning. In other words, your...the workload is heavier than the cour...the information you're learning.

A: In proportion, sort of .

J: Yeah.

A: Yeah. Oh, I see. When you are... When you're actually sitting down to do your studies, what do you actually do?

$\mathrm{J}$ : Pick up the books and read them, make notes, and then go through the study guides that they come...that come along with each chapter and go through what they say to look for and make sure you've learned that.

A: So, you find that you do follow the study guide. 
J: Yeah, you have to.

A: Why do you have to?

$J$ : It's just that it seems to me that the study guides are geared to the assignments for...that are to be handed in every two weeks. (080) //A: Oh, I see.// so if you don't go through the study guide properly, then when it comes to do the assignments....

A: You're lost.

J: Yeah.

A: Oh, I see. It sounds quite rigorous.

J: It is, it is. That's a good way to describe it.

A: (laughs) A... a couple of questions here. I already asked you: Before you started, what did you think it would be like, what did you expect it to be like? Let me ask that again in a slightly different way: What were your hopes and/or your fears about doing Psychology by distance ed. before you started?

J: My hopes were.... I guess my expectations were that the workload would be a little easier than it was, a little lighter than it is. (pause...) I guess my fears or questions were: How well would I do in it? At this point I don't know how well I'm doing in it.

A: (090) Yeah. So my next question is actually: Now that you're into it -- and you've been doing it since the beginning of January?

$\mathrm{J}$ : January and I've done very little of it. 
A: So that's...that's.... (laughs) so that's 2 plus something months. Now that you're well into it, how are you finding it?

$J$ : The information is... is interesting, but I find it a little boring. I think it would be a lot easier if I was in a classroom environment where you have the opportunity to talk back and forth.

A: You used the words interesting and boring. You said the information is interesting, but it is boring.

$\mathrm{J}$ : The process of learning it is boring.

A : Why?

J: It's not what I...not the way I'm used to learning I guess.

A: Meaning what you said now: in the classroom with...

$J$ : Yeah. I learn b...I learn better $i . . . I$ mean in a situation or an environment where you can talk and you can have one-to-one with either a student or a faculty. I find that much better.

A: (101) Right. You...you're saying there you could talk to students and/or faculty. It's important to be able to talk to both of them.

$J:$ Yeah, yeah.

A: Why is it important to be able to talk to them?

J: I guess just because that's the way I've learned as a student in high school and in university, but that was the way I learned to learn by that kind of communication. And that's what...that's what I'm used to. Like maybe 
for other people that aren't used to that it would be O.K., but for me that's...that's my learning process.

A: Yeah. And even though you've been doing this course for over two months, you're still finding that's something of a barrier, and you don't find you're changing your learning somewhat?

J: No. No, I'm not. No, it's gotten to the point where it's: Well, I've registered in it, and I'm gonna pass it.

A: (110) Good! (laughter) A little series of questions here: By doing this course, Psychology by distance education, what are you learning about yourself?

$\mathrm{J}$ : Well, I think probably the most important thing is that I learned earlier that $I^{\prime} m$ not well...I'm not good at being self-disciplined or self-directed. Otherwise I don't think I've learned a lot about myself. I think primarily because a lot of my friends are involved in social work or in psychology or psychiatry, and I've done a lot of volunteer work and peer counselling earlier, so what...the information I'm learning is not particularly new to me.

A: Oh, I see. Oh, so you've actually...you've worked in very related things?

J : (120) Yeah.

A: That's interesting, and you have friends in that. Do... do you think that influences the way you feel about it, the way you're learning? 
J: It might possibly. Probably a lot...there's probably a lot of stuff in my mind that says, "Well, I know that already." And that may be one of the reasons why I find it a little boring.

A: Yeah. And yet you say the information is interesting. $J$ : Well, there's some stuff that is interesting that I don't use in...wouldn't use in a day-to-day sit... environment. So that's new for me, but the general overall picture: I...I know that and probably a lot more from...from being involved in...with friends and with being in the field.

A: Well, the very fact that you've actually participated in such... in related work and so on, do you feel that actually helps you with the learning as well?

$\mathrm{J}:$ (130) A little bit...a little bit, but I don't think that I'm learning many...like I say, anything particularly new. A few small tidbits but nothing extensive.

A: Right. O.K. So I asked you there: What are you are learning about yourself? second learning question: What are you learning about Psychology by doing this course?

$\mathrm{J}$ : Nothing that I don't know. Nothing significant.

A: As you said there then, just a few bits and pieces.

$\mathrm{J}:$ Yeah.

A: And you feel that's worthwhile or not really worthwhile?

J: I guess it's worth.... The course would be worthwhile for somebody who's never taken any psychology or maybe who is considerably younger than $I$ am and is not experienced in the world. (139) But I think for somebody 
who's in their mid-forties and been involved in the kinds of things I'm involved in...been involved in and involved with the kinds of people and friends I've been involved with, that I'm not learning that much, or maybe I took the wrong course.

A: Did you actually have a choice? It's not compulsory for you?

J: No, no. It was a choice. I just.... I thought: Well, to get back into the studying mode, I'll take a firstyear course. Maybe that's...that's my fault, and I should have been looking at something in the second or third year.

A: Yeah, perhaps. O.K. Third question in this little series: What are you learning about distance education by doing this psychology course?

J: (Pause...) That it's not as satisfactory as I thought it would be.

A: Can you expand on that?

J: (149) Well, I think it goes back to the earlier questions about the way I like to learn and that, quote, correspondence course is not the way for me to go. I think for people who maybe have a little more time on their hands than I have, it certainly is O.K. But for somebody who's holding down a forty-hour job plus doing other hobbies, the workload is very high for the reward gained. 
A: So that's your feeling of distance education. It's really for a person who doesn't have time to do his education any other way.

$\mathrm{J}$ : Doesn't have the opportunity to do their education any other way.

A: 0.K. I've been writing down what seem to me the key words that you were saying. You...you mentioned that discipline is an important factor, (160) that to you more feedback is necessary from students, from teacher, and also you feel that there's a great deal of information in this course. Do you think there's any rela...a particular interrelationship among those for you?

J: (Pause.......) I think that for me to learn more of the information that's available in the course, feedback between...needs to be at a better level than it is. And also my own lack of self-discipline affects how much $\underline{I}$ learn.

A: Right, yes. O.K. So for you, what are the important things about distance education?

J: (Pause.......) (170) For me I...it's been important in that it's got me going back into studying again. (Pause...) It's also shown to me that that is not the way for me to go as far as achieving academic results. I don't know if there's anything else more than that.

A: O.K. And if you could talk to another person like yourself, you know, about the same age, working in a 
similar situation with outside interests and hobbies, what would you advise him about doing distance education?

$\mathrm{J}$ : Unless you've got lots of free time and you're very well self-disciplined, I would recommend you don't do it.

A: As simple as that?

J : Yeah.

A: (laughs) O.K. (180) O.K. Well, that...that actually takes care of my questions. Well, one other question. You've probably already answered this, but I'll put it in a slightly different way: How are you evolving as a learner by doing Psychology through distance education?

J: (Pause........) I still find that the best ways for me to learn are in, shall we say, a doing process rather than in the process that's involved through open learning.

A: Which is not doing but...?

$\mathrm{J}$ : (190) It's not doing so much as reading, and I'm better at doing things than $I$ am at reading them. I guess that's why I talk about the classroom situation being better for me, because there is a little more of an opportunity to, sort of, to be...to do in a class by sharing and talking about what you heard than there is in the... in the open Learning program. The fact that I'm involved in theatre, theatre is really a process of learning by doing, because you're acting, and I find myself learning much better in that kind of environment than having to sit there and read and make notes. 
A: So the fact that you're interested in acting, you're involved in acting actually has some influence on your learning?

$\mathrm{J}:$ (200) Yes.

A: Yeah. Oh, that's interesting. Well, that actually takes care of my questions. Do you have anything you'd like to add?

J: (Pause........) Hopefully distance education can be improved so that there's a better opportunity for students and faculty to have more feedback. I don't know if that can be done through a medium of television or...or what, but there.... I would think that with improving technologies that there's got to be a way where students and faculty can talk as if in a classroom, and I would think that could be done through television.

A: (211) In your Psychology course there is no T.V. component?

$\mathrm{J}$ : Well, there is one but it's just watching a video. And what I'm talking is the opportunity to have that feedback so everybody can share together what they're learning or not learning.

\section{A: Right.}

$\mathrm{J}$ : And I think that... For me that's a very important way to learn; maybe for other people it's not. For me it's always been that way. And I think that goes back to, you know, we're i...if we're in elementary or high school that's how we learned, from our peers and our.... I 
mean, when you don't have peers and you're taking correspondence courses, it's just that much more difficult to...to learn the information.

A: Yeah, right. Yeah. O.K. Great. Thanks very much. 


\section{INTERVIEW \#10}

Interviewer: A

Respondent: $K$

Position on tape: (000)

A: $0 . K$, well maybe we could begin with your decision to enrol in distance education. How did you come to that decision?

K: It was probably something that was not pinpointed to one point in time, but just, you know, an accumulation of experience that in... in searching for a different job or a different challenge within dentistry, I realized that you did need further education. Dentistry is one of those fields where you're very limited, you simply can't grow from one stage to another. There's no...no ability to mature, so you in other words, have to go right back to square one and start again if you want to become something different than what you already are. Therefore, I looked at my options in dentistry and decided that I did not want to become an hygienist or a dentist. So what else did I want to use the skills that I had acquired to do? (010) And that took a lot of work, actually; I went through the credit Bank assessment package, and that was very, very helpful to me to direct myself to look at the experiences I had to that date, and where I had been heading, and it really helped me to focus on, you know, my strengths, my weaknesses and where I might want to focus. So it was at that point that I 
felt comfortable and confident that I had a goal and a direction, and then it was just a matter of... of realizing that through distance learning it was going to take a long time to get there, but that in ten years I'm going to be ten years older, no matter whether I have it or not, so, you know, just take it one course at a time, realize that that's the way I have to attack it, so, you know, that...that's the way it will be.

A: What... Exactly which course are you doing?

$\mathrm{K}$ : I'm doing the Business Administration.

A: What number would that be?

$\mathrm{K}$ : Well, the course actually that I'm doing.... That's the degree that I'm working on. The course that I'm doing right now is just the English 100.

A: Oh, I see, so the program is Business Administration, and it's now English 100.

$\mathrm{K}$ : Yes.

A: (020) Everybody seems to do English 100, don't they? (laughter)

$\mathrm{K}$ : Yes, it was one of those very basic things that you do need. I have some accounting experience that I gained at BCIT night school, so I do have a few credits in the accounting area, so it felt good to have a few things under my belt before I started.

A: Sure, those are accredited by the program?

$\mathrm{K}$ : Yes. 
A: Great, great. Just coming back to my first question about: How did you make the decision to enrol? How did you actually find out about it? You said it had been in your mind for some time.

$\mathrm{K}$ : Through dental assisting, and I'm very active in my professional society, and through my exposure on different committees, I'm aware that the open Learning has a very effective Dental Assisting program. It's actually through open college. We have a number of ... of people who are involved in our society who are also students there or tutors there or in administration there. (030) So, I had the opportunity to be part of a program advisory committee meeting, and just really was impressed in the organization and... and the atmosphere that these people created around their education system. It was very uplifting compared to other, you know, programs advisory committees that I've sat at, for example, Vancouver Community College, you know, which are a little bit more staid; they've been in place for a much longer time, and they're not quite as innovative in their idea. So it was exciting to know that I could still live my life and earn my income, and gain an education at the same time.

A: You mentioned the word 'innovative', there. Is it important to you to be involved in something which is innovative? 
$\mathrm{K}$ : It's not number one in my list of priorities, but it's exciting to...to see someone attack things slightly differently, and I'm very involved in... in pursuing through dentistry, options for.... (040) we have a...something that we call a Career options Plan, which is allowing a dental assistant to...to advance into perhaps being a dental hygienist without returning full time to school, so as part of that process of... of going through, we've become a think tank to come with new ideas for being innovative in how to...to provide education for people while they're working. So that is probably why it excited me that it already existed in other areas because then you can draw on that model for...for what you're planning for your own education.

A: Right, yeah. That's interesting. And before you actually started this English 100 by distance education, what did you expect it to be like?

K: (048) I didn't realize how streamline it would be. I didn't realize how slick the whole process was. I thought it might be difficult to work in a distant situation. I wasn't sure if I would be able to...to concentrate and to draw the knowledge out of the material that I was, you know, required to have. But I thought: Well, you can't, you know.... I mean, everybody learns differently; let's give it a try and see what happens. I was...I remember the night the package was delivered. It was slick. (laughter) I couldn't believe it when I 
opened this box, and everything was there in this neat little box. It's no longer in a neat little box, but, you know, it was really amazing how well organized and thought through the whole process was. I haven't really had to call on my tutor a lot; I certainly value the, you know, the comments that, you know, through the marking of the assignments, but it's been amazing to me how well the material is put together, and, you know, just step, by step, by step, (060) and how much I've learned just in the very short time that I've been involved in the course. I see a big difference in my own writing skills, you know, so I guess that...that's the key to success.

A: So when you use the terms 'slick' and 'streamlined', what you mean in effect is it's very well organized; it's all there; it leads you step by step.

$\mathrm{K}$ : Yes, yes.

A: And do you find that a very positive aspect or...?

$\mathrm{K}$ : Oh, definitely. I mean $I^{\prime} \mathrm{m}$ a very organized and orderly person, so to me it appeals to my sense of order and organization, you know; it's just right there, you know; it tells you where to refer, and so you just pull out your books and away you go, and I've never had a problem finding the information that I needed (pause..) you know. It's been very, very easy to go through the stuff.

A: Right. And how do you... now that you're into it, how do you find learning English by distance education is different from learning English in a classroom? 
$\mathrm{K}:(070) I^{\prime}$ ve been thinking about that while I'm sort of reading and studying and going through things. Often a classroom is a very dry experience, you know; you're sitting, you know, you're tired or, especially if you've worked all day and you're taking night school courses, you can be exhausted, and it's just not, you know, conducive to a learning atmosphere. You might not be ready to learn that particular evening that the class is being held. So what I love about this is that at my own time and pace I learn. So perhaps I sit down for an hour, then I get up and move around and... and then I can come back to it, and... and I don't have a problem committing to that. I...I rather enjoy that; I feel I learn more, and I learn it when I'm ready to learn it. You know, I'll put aside the time, sit down and do it, but some days when I'm really tired, I know that even though I've decided that today was the day I was going to do an hour's worth, if I'm too tired and I know I won't absorb anything, then I'll go to bed and do it the next day. (080) So you have that flexibility, and I think if you're careful about it -- I mean, obviously you don't want to procrastinate to the point where you're, you know, weeks and weeks behind, (laughs) and many of us have that problem -- you know, it can be a very positive experience, and I think, you know, hour for hour more is learned in this distance learning than...than in the classroom. 
A: Why do you think that is?

K: Because I have to stimulate myself, or maybe I respond to my own stimulus, so... so that I don't have to be up when somebody else is up and ready to teach me. I'm ready when I'm ready, and that's... you know, I take advantage of that time to...to hit the books.

A: Right. So that... that seems to be a very centrally important thing for you that you can do it in your own time, at your own pace when you feel like it.

K: Yes, because I have a very busy life. (laughter)

A: Right, yes. O.K., and I...I asked you there: What do you see as the differences between doing it by distance ed., doing it in a classroom? What are some of the similarities between the two ways?

K: (091) Well, I suppose the...the assignments, the readings, I mean the material covered I'm sure is the same. I certainly have the benefit of a tutor if I need help; somebody is there to help me. I've never had any problems reaching my tutor when I have asked questions. So, you know, the similarities, I suppose, are just very much that: that the content is the same; it's just the way you attack the content that would be different.

A: You mentioned the tutor there, more or less as the same as the teacher. Do you see them as being much the same?

K: I suppose not. I mean, in a distance learning, you really rely on the directions of... of your... of your course, and yourself for the learning experience. (100) 
But when you... when you do need further clarification or there is confusion or whatever, then you draw in the tutor. A teacher can sometimes be more of.... You rely too much on the teacher in a classroom situation, and you forget to stimulate and then...you know, that you're responsible for learning, so you tend to, you know, sit there and expect the teacher to throw all this information on your lap, and often you don't quite catch what... (laughter) what they're throwing at you.

A: Yeah, yeah. You used the phrase there that you're responsible for the learning. Again, could you tell me more about that?

$\mathrm{K}$ : Well, I suppose no matter where you are or what you're learning you are responsible for it, but in the normal classroom setting I think too many people allow the teacher to be responsible for that, or the, you know, professor or whatever, whereas in distance learning I think the student has to assume more responsibility, and that to me is a positive thing. I think you learn better, you learn more, and what you do learn at the time I believe would stay with you much longer, because you've had to research it out, you've had to...to dig a little deeper, and so, therefore, the experience is a little bit more stayed in the brain.

A: (112) Right, right, yeah. And, when you do your studying, what do you actually do? 
K: I curl up on my chesterfield with my books and go to it. That's why my living-room is a disaster, 'cause I...I make sure I'm comfortable, that there will be no distractions, no noise, and that, you know, I'm going to stay there for a good hour. I don't want to be up and down. I want to be intense for at least an hour minimum every time I sit down, and so I just make sure I'm comfortable and settled and that's it, get rid of the kids for an hour.

A: You've mentioned an hour several times. Do you set yourself that particular length of time as a minimum?

K: (120), I try to because I think that, you know, your brain sort of has to get in that mode in order to...to absorb something, you know. If you're trying to do it in too short a little segments, then I think you lose the continuity, you lose the thought processes and then you, you're constantly having to review the material that you've just looked at, you know, twenty minutes ago. So I find for myself I retain more if $I$ spend a little bit longer time at it.

A: Right. I asked you before: Before you started this course, what did you think it would be like? Related to that, what were your hopes, or your fears, or both before you started?

K: My hopes were that...that I wouldn't procrastinate, that I would be organized enough to...to, you know, do it, and... and that it would be an enjoyable experience, (130) 
which it truly has been. My fears were that it would be too difficult, that maybe I were biting off more than I could chew time wise, commitment wise, and that maybe it would be too difficult to...to expect myself to learn in a distance learning situation, that maybe, you know that security blanket of the teacher or...or the classroom was maybe something I needed. I surprise, you know, myself by not needing that at all, and really enjoying not having it actually.

A: Right, so now that you're into it, in fact, how are you finding it?

$\mathrm{K}$ : Well, I mean, the time commitment is always the tough cycle to.... You know, there's always five hundred things you need to juggle in life, but $I^{\prime} m$ finding it to be much easier than I anticipated as far as the content and writing the assignments (140) and thoroughly enjoying it. I think adult education is exciting because you learn...because you choose to learn, and you have that desire and that goal, so it's much different than learning it as a teenager, and sort of feeling like: Well, I don't want to work, so I'll go to college, you know, and (laughter)... and you have more of a stake in it, I mean, you're paying for it and, you know all those other things that come into account, so.... I thoroughly love it; it's very stimulating, and I get really cranky if I...if I don't get the time to do it when I want to do 
it. You know, like this is my baby and don't take me away from it.

A: Right. Oh, well! O.K., I have a little series of questions next. The first one is: What are you learning about English by doing this course?

$\mathrm{K}$ : (148) There's a lot of grammar, so I'm certainly learning a lot of grammar and punctuation and thoroughly enjoying reading some of the...the short stories and sort of classic short stories that I'd never been exposed to that, you know, you hear people quoting or commenting on and that I had never ever taken the time to read. I love reading, and that was one thing that I totally gave up when I became a mother; that was the one thing that got shuffled to the back, and so now I...I'm very selfish about the time I read, and I...I love it, so it's a lot of fun.

A: Is the course mostly to do with short stories?

$\mathrm{K}$ : Yes, at least the part that I've, you know, gone into now. There are a couple of small novels that we'll be reading but short stories to date.

A: Right. And a second question in this little series: What are you learning about yourself by doing this course?

K: (159) That might be hard! (laughs) I guess that...that when I really want to do something, I'll find the time to do it. I mean I'm a very directed person, so once I make my choices, you know it's very clear in my mind, what I 
need to do. And it's exciting to know.... I mean, I always did well in high school; I always did well in college, but it's...but it's been ten years since I've taken anything, so I'm learning that, you know, the brain cells are still alive and functioning, (laughs) no matter what the age you're still capable of learning and growing. And probably that, you know, the little bit that I spoke about before, about setting the goals and having a direction, and I think when you go through, you know, your twenties, often you...you're very undirected, you're not really sure, and as you mature you sort of come more into focus, and so it feels very good to have a focus in my life, to know, even though I might not going to reach it till I'm forty, that...that it's there and, you know, step by step it will be achieved, so....

A: (171) So having a direction, a goal, perhaps also is important. And you mentioned that it's ten years since you were in school doing courses. Is that an important thing?

K: Well, I think that in our society, or today, and it's really exciting to see, that people don't stop learning. It's not, you know, you go to school and then work in the same job for forty years, and that's what I would want to foster in my children, and it's exciting to see so much attention being paid to adult education considering I'm an adult who wants to be educated...

A: Right. (laughter) 
K: ...at the same time, to be part of it. Yeah, it is important to me. There are other times in my life when I attempted to return to school, (180) like to BCIT at night school, and then I became pregnant; it just became, you know, too much to...to bear. But, you know, it's something that I have thought of for a long time. I've looked into, you know, night school through SFU and distance learning through other areas, I think SFU has...? I'm not sure if they have some distance, maybe it was through open Learning eventually, but it was something that I had looked at many, many times when I was a single parent for a number of years, so it was, you know, difficult to get out of the home, so I was looking for alternate ways to achieve education, and it's exciting that (unclear) and available.

A: You're saying, at that time, when you were a single parent, it was extremely difficult to get out of the home. Now I gather you're not a single parent again...

K: Yeah.

A: ....and, therefore, why did you choose distance education as opposed to going to one or two evening classes a week?

K: (190) Probably because I don't have one or two evenings a week that I could commit to that. I'm very involved in my professional society. You know, I like to get my exercise, and I like to stay home with my children too once in a while, so this way what I do is usually plan to do my work after the children are in bed, so that the 
time factor is not limiting. I don't have to be out the door at a certain time; I still get to tuck them into bed and make dinner for the family and do all those motherly things that are important to me and meet the needs that $I$ have, you know, as a human being, so it's the best balance for me.

A: Uh-huh. Third question in this little series: What are you learning about distance education by doing English 100 through it?

$\mathrm{K}$ : (pause.....) I'm learning that .... (200) I...I suppose I didn't realize how organized and how available it was. I didn't realize how many courses were available by distance education. I didn't realize you could...could achieve a degree, for example. I thought that the college courses were the only ones available but, you know, you would have to sort of finish off in a college setting or a university setting. It surprised me that there was so many services available through the open Learning Agency, you know, the tutors and the counsellors and... and all of those things that basically I had envisioned only being available through a more traditional, you know, university or college setting. So, you know, just...(210) just realizing how large an industry it was, and that excited me like, you know, I didn't want to go into something that was a baby, you know. I wanted to make sure that it was sound and, you know, and that the credits that I received were going to 
be recognized and, you know, all of those important things.

A: Right, yeah. You mentioned counsellors there. Have you been in touch with a counsellor?

$\mathrm{K}$ : I haven't been in touch with a counsellor, although I'm thinking that's what I would like to do next, to set out.... I mean I have in my head a goal, you know, and... and the list of courses and how I want to work through them, but just to confirm with a counsellor that that is a sound tactic to my particular goal. I have been in touch with Susan Brain, I think it's the woman who works through the credit Bank, and her and I did, you know, quite a bit of conversing by telephone, although I've never met her in person, as she went through my Credit Bank assessment, so, as I said earlier, that was a very valuable experience for me to go through. I learnt a lot about myself through that.

A: (221) what... what did you learn about yourself in that particular case?

$\mathrm{K}$ : Well, I was able to really focus in.... As I said earlier on, my strengths and weaknesses, or mostly my strengths, I suppose, and... and how much, even though I've worked in dentistry for fourteen years, it was all the extra curricular things, you know, and when I... when I had free time, and I chose to spend that free time doing administrative things for my profession or different things, I realized that that was my strength, 
and that I'm a very strong people person, that I have these organizational skills, that when I've won awards or...or, you know, made achievements that that is where they've been focused, so...so I began to see that, yes, I have what it might take to achieve this goal, you know in... in personal strength, and... and that was important too.

A: (231) So that was why you decided on Business Administration?

$\mathrm{K}: \mathrm{Mm}-\mathrm{hm}$.

A: Sounds logical. (laughter) I've been writing down what seemed to me some of the key words that you've mentioned. I wonder...I...I'll read some of them back to you. Could you tell me: Is there is any particular relationship among these words?

$\mathrm{K}: \mathrm{O} . \mathrm{K}$.

A: You're in... Your profession is dentistry, that's central, of course. You mentioned the importance of the credit bank. You talked about the slick, streamlined process and the fact that you are responsible for your learning. Is there a particular relationship between those?

K: (139) Well, I suppose it really just describes my personality (laughs). I mean in...in dentistry, you know, certainly a good certified dental assistant is a very organized person and.... and everything is very, you know, organized and detailed and orderly. So when you 
see.... When I see that, out in the, you know, the real world, then that is attractive to me because that's the kind of person I am. What were some of the other words, I...?

A: Dentistry, Credit Bank, slick streamlined process, you're responsibile.

$\mathrm{K}$ : Right. Well, I'm very definitely the sort of person in thinking that everyone is responsible for their own life and happiness and education and everything, so, I mean I raise my children to believe that, and I believe that very strongly, so that would certainly be the reason that that came out.

A: (250) Oh, well, that's a definite relationship, yeah. A more overall question: Do you.... What are the important things about distance education? About doing English by distance education, shall we say?

K: Well, I certainly think that the important things are that they're...it's available to anyone and any place. It's not limited by geographic location; it's not limited by -- well, financially somewhat limiting I suppose; you have to be able to afford the tuition -- but at least you don't have to afford a sitter or a car or anything else to get out of the home. I...I think that the accessibility is probably the largest benefit that I see. It can appeal to the masses as opposed to the classroom which is much more limiting. 
A: (260) So when you say 'accessibility', you...the aspects of that are: anyone can do it, it's not too expensive. Those are the main things you've said.

K: Yes.

A: Right.

$\mathrm{K}$ : And... and certainly, you know, time is at your discretion instead of the discretion of whoever is organizing the particular course.

A: Right. If you were to talk to another person whose situation was very similar to yours: a mother with a family, at the same time a working woman, perhaps in the field of dentistry, a very similar situation, what would you advise that person about distance education?

K: (269) People think I'm crazy for all the things I have on my plate. I love it. It would... You know, it is a lot to take on. You have to be.... You have to have that goal; you have to have that focus; you have to decide that it is important enough to you, that that is what you want to achieve, and... and then go for it, not be frustrated by the fact that it, you know, only one baby step at a time, you know, three credits doesn't seem like very much when you're working toward 120, but, you know, you have to... you have to look at the overall picture, and... and that if you start today, before you know it, you'll have a lot under your belt, you know, but if you procrastinate and... and decide you're going to wait until your children grow up and go back to school, 
well, you're probably going to be finished at the same time, you know (laughs). But.... So I would... I would caution them to really make sure that that's what they wanted to do. (280) I wouldn't suggest to anybody just jump into it. It is a...it is a very large commitment of time mostly and energy, but that it can be very rewarding, if that is truly what you desire, then...then you can be...it can be a very positive experience, and it can, you know, heighten like anything that we do, it can, you know, even though it takes time, and if it gives up energy and we're excited by it, you know, that can fit into other parts of our lives.

A: So to you it is exciting.

$\mathrm{K}: \mathrm{Mm}-\mathrm{hm}$. It is.

A: So you're also saying the person who you would advise to do it would have to be a person who can take a long term view of things and also a person who has the will to keep going.

K: Yes, I think those are two very important factors. (290) I spoke to a woman who had... who had started seven years ago, and her and I were working on a committee together in dentistry, and she told me she was taking an English course. And I remember distinctly saying to her: Why are you taking an English course? You're a dental assistant. And she said: Oh, I...I don't know. And now she has... she's just finishing up her Master's, she was 
able to by-pass her Bachelor's and went right into a Master's program....

\section{A: Really?}

K: ... and she is just about to finish up her thesis. So, you know, here she is; 7 years later that's what she's accomplished. So I had lunch with her a few weeks ago, and I said: Well, guess what? I'm taking English 100. (laughs) And she said: Well, you know, good for you. You have to remember, you know, like, you're gonna grow. old no matter whether you start today or whatever, like, life goes on, so you may as well be working towards the future starting right now. Don't wait for it to happen five years or ten years down the line.

A: (301) Right. Is it particularly important to you as an individual to have certain goals ahead of you?

$\mathrm{K}$ : Yes, it is. It feels really good because for so many years I didn't really have goals. You know, I...I did my job and I knew I wouldn't be there forever, but I didn't know what I wanted to do. You know, I...I've worked for the same dentist for 14 years, and, you know, I manage the office, and I do the book keeping and I'm his right hand arm, and all those wonderful things, but that doesn't satisfy me enough, and I want to...to go further, but I've just been.... I was really lost. Where did I want to go? What did I want to do? And so it feels very good for me to have the direction now, to feel comfortable that that is truly what I want. I mean 
certainly, like anyone, you can change your mind part way through, but for today that's, you know (laughs)...that's my goal and I'm...I'm sticking to it (laughs).

A: (313) Yeah, right. Oh, good. And...I only have one more question really. How are you evolving as a learner through doing English just by distance education?

$\mathrm{K}$ : (pause.....) Well, I certainly...in my...in my job especially here I do a lot of letter writing, so I certainly watch my grammar and my punctuation a lot closer. (both laugh)

A: Oh, very important!

K: I think you take note of things more. You become more aware. When I read, I enjoy reading. Now I tend to, because I've got in the habit now of reading my...my assignments and...my, you know, required reading, I'm more likely to say, you know, pick up the newspaper and read more of it, or to pick up a novel that may be laying on the table and get into that, and think: You know, if I can read my assignments, I can read this, you know, like, and just really sort of revel in the joy of... of reading instead of saying: Oh, you know, I should be folding the laundry or doing something else. (laughter) So I...I suppose I just tend to take more time for learning, and... and just...just try to remember that it's fun, (330) like I never want it to be a stress. I was ill for a week and I got really frustrated that I was getting behind. I sort of had a goal to hand in an assignment, 
and I got behind, and I thought: No, this is silly; like, you know, don't let it be a stress otherwise you'll never enjoy it. So I'm a week behind, you know; that's o.K.; in time it...it'll come around, you know. So I think you have to be careful not to...not to go too far in... in your commitment, like to over commit yourself in things, or to expect too much from yourself, you know. I...I always have to be reminding myself that I'm only human, and you know, I do do more than the average, you know, person in a day and not to just feel bad when I... when I don't accomplish what I was hoping to.

A: (340) Right. You mentioned there that you will now perhaps pick up reading material from the table which you wouldn't have before. Does that mean you feel as if you are extending your learning to other aspects of your life?

$\mathrm{K}$ : Yes, yes. And I think I'm just making more of a priority for reading in other areas of my life. I mean I have journals, and piles of things that need reading, and certainly...the more you read obviously the faster you become; all of those things are starting to come back, because I was getting very slow in my reading, because I... I hadn't been reading, you know, the same way that I did when I was younger. So I find yes, it...it's very helpful. (350) It also obviously expands your vocabulary, those kinds of other benefits that help me in my profession in my speaking in my profession because 
quite often I'm interacting with dentists or other professionals where I want to feel like, you know, I am an intelligent human being, and I have something important to say. So, you know, all of those are benefits that are just, you know, spin-offs of the learning process that you probably never really take time to note, but when you're asked the question then, you know....

A: Those are the spin-offs. Yeah, right, yeah. Oh, great. Well, that takes care of my questions. Is there anything that you would like to add?

K: (359) I think we've covered most of it. I...I'm really excited about...about the course that I am taking, and I try to be realistic about... about the goals that I've set, you know. For example, I'm wondering whether I should take another course next term, or whether I should just wait until september, but, when you get caught up with the calendar and you want to achieve so much in a year, it's hard...it's hard to...to know, you know, exactly what to do or...or, you know, what limit to put on yourself as far as it.... It's so exciting that I want to keep on going, but I have so many things happening in my life in the next six months, maybe I should sit back and not do that, you know. But it's...a dilemma . 
A: (370) Yeah, yeah. You've used the word exciting quite a few times. Can you, again, define for me: What do you mean by exciting, when you talk about this?

K: Well, the whole process I...I suppose is exciting. I mean it's exciting to me that I have a goal and that I'm working toward it; that is important to me, and so, therefore, I get excited about it. And, you know, certainly I'll be excited when I see another three credits go onto my transcript. (laughingly) And it's exciting because...because I believe in lifelong learning, and so I'm finally making the time for myself to practice what I preach. (380) I mean I've taken many, many continuing education courses through dentistry that were non-credit kind of things, that were exciting at the time and beneficial to my profession and everything else, but... but this is exciting because it's for me and only me, and not a lot of people know that I'm doing it, not for any reason other than I just, you know, don't really make it a topic of conversation, and so it's kind of like my little thing for me, sort of like my fitness, that it's my boost and it's mine and it satisfies my needs, so, you know, therefore, I get energy from it.

A: That's an important thing to have something for yourself.

$\mathrm{K}$ : Yes. Very, very.

A: Well, anything else to add?

K: No, I don't think so.

A: Well, that was great. Thanks a lot. 


\section{INTERVIEW \#11}

Interviewer: A

Respondent: L

Position on tape: (000)

A: O.K. I have a number of set questions, but on the other hand, I'd like you to just, you know, expand on them as much as you feel like, anything that's interesting to you.

L: You shouldn't give me license to do that.

A: Oh, I have a long tape. Don't worry.

L: suit yourself.

A: 0.K. Well, let's begin with your decision to enrol in distance education. And first of all, could you tell me what subject you're doing?

L: I'm studying Business Management, with a view to do the certificate followed by the diploma and then eventually the degree.

A: So the particular course is....

L: The particular course is Business 101.

A: I see. O.K. so, again, your decision to enrol in distance education. How did you come to that decision?

L: (010) For several years I felt that there was something missing. I had given up a course in Britain of study to come to canada, and I think that probably in the back of my mind the question was: could I do it? Was this something that I could do? And I'm the type of person that's...that looks for challenges, and the type.... If 
things are going too smoothly, I tend to...to look for other things to do, and my career was going fairly well, and running fairly smoothly, and I just felt that this was something that I would be able to handle, and I just wanted the challenge so that was really why I decided to...to pursue education again, but I... I had no intention of doing it through a correspondence course at that time, and I looked into several avenues, and it seemed the more I looked, the more difficult it became. (020) I would have had to cut down on the hours of work in order to study full-time or even part-time going to a college, and I have two young daughters, 3,3 nearly 4 , and 4 months, and that was totally impractical for me from a financial point of view, so I was really feeling kind of a little depressed. I thought, well, maybe I'm just not going to be able to do this right now, and out of the blue I had a friend visiting, and he mentioned a friend of his who was studying Business Management in Hawail, and I said: Well, how is he doing it? And he said: Well, he's enrolled in the Open Learning Institute, and this light went on, and he was here on the sunday evening and the Monday morning.... Actually the Sunday night I was flicking channels on the television, and Channel 5 was one of channels that I flicked, and the test card was up with the telephone number for the open Learning Institute. I phoned immediately, left my name and address, and they sent me all the literature. 
A: (031) It worked.

L: It worked; it was really.... It was quite whirlwind. The literature came within about two days, I read it, called a counsellor to check that I understood the way that the process worked, and I had, and ordered the material, and Friday evening of that same week it arrived as it said it would in the brochure (laughs), by courier, and $I$ was all set to go, so it was very exciting.

A: Yes, yes.

L: So that was how I....

A: And that was at the beginning of January that you started?

L: Yes, the course was January 1 to start, but because of the time...like the guy was visiting for Christmas, this...this friend of mine, and because of the way they...they work it out it's like an open enrolment, and the course material sort of came, I think it was middle to the end of December, so I was ahead of the game, and I started the assignments just prior to Christmas.

A: (041) Right. And before you actually started, how did you expect it to be, learning Business by distance education?

L: I really had no idea. I wasn't a very good student in school. I felt very frustrated at school in Britain because the curriculum was so regimented, and I always felt that I was looking for something else. You know, I'd get through the work and... and I hate to use the word 
bored, but be bored, and in fact in later years at school I sort of gave up studying in the classes and just did the exams and passed, and it was just a waste of time. I really felt that. My wife is a teacher, and she had indicated that curriculums here were considerably different, and I began to feel that I wished I'd gone to school here. (051) But, I had really no idea the way this correspondence course would work. Other than the brochure that I had received from the telephone call to the Institute. When this package arrived, I sort of ripped it open and read the...the literature that came with it and was very excited because I realized that I was going to be able go at my own pace and do as much or as little as I wanted to. And I hadn't really considered that aspect of it. I was used to school and having a teacher and, you know, doing what I was told, and this...this freedom, I guess, is... is nice; I felt good about it.

A: You mentioned there that you were generally bored in your conventional education classes. Can you tell me more about that?

L: (060) I felt it was so structured. You know, a teacher would come in in the morning or whatever at the start of the class, and they would...they would basically have an idea of what they were gonna do for that period of time. They would give you the literature that...or...or the talk that they... on the subject that they were gonna 
teach, but I felt that I'd absorbed that in a very short period of time and then felt for the rest of the lesson that it was just making sure that all the other people in the class understood as well, and I couldn't go on. I mean, I wasn't allowed to go on. I can remember in a math class once, sort of turning pages and doing equations and things on other pages, in other chapters. Well, I was severely reprimanded: You will do it as we do it. And I found that most frustrating, most frustrating. A: So...so your feeling was that being with other people, in fact, was a disadvantage.

L: (070) Yeah, it was. Oh, there's no question it was a disadvantage. At one point, they did put me into another class, because I had... or had gone on, and I said to the teacher: This is absolutely useless. I mean, I know this stuff. And that didn't go down too well, but they did put me into another class, and that was fine. But you can't leave school in Britain earlier than...than anyone else just because you happen to be ahead, so at one point I just had to duplicate a year, which was the most boring experience. You know I knew....

A: I had no idea that it was like that in Britain.

L: Well, it was then. It was... They were just testing out some new systems, and it was...it was a real pain. I felt really held back. And I was older as well. My birthday is September the 3rd, and the way the cut off worked for that school year, I was always the eldest in 
the class. Now whether that had anything to do with it, I don't know, but I felt like I was kicking my heels a lot of times. It did give me a full sense of... of, I don't know, 'superiority' is the wrong word, (080) but I felt that I was better than I was really because when I went to college, I started to feel like I was catching up or rather it was like at the right sort of level. In the... in the sort of secondary school grades it was one of the things I found really irritating, and those are the years that I remember most.

\section{A: Yeah.}

L: The college, university courses, I went.... I was going to study architecture, and there are two ways of doing it. You can either have...go and do your A levels to get into an architectural program, or you can work with an architect and study, sort of, part-time, and that's the way I chose to do it. I didn't want to be in a classroom environment again, so I worked for 2 years with an architect, and I just loved it, because I was going at my own pace again. So it was really....

A: So going at your own pace is a very important thing for you.

L: (090) Going at my own pace is very important for me. And although I hadn't really considered it, stupidly, with the correspondence course through the open Learning Agency, I think that was the thing that I... when I opened the package up and read it, I can remember reading 
it to my wife saying: oh, this is great! I don't have to send in assignments when they want them; I can do three in two weeks if I want to. Unrealistic realizing the work load afterwards, but I thought that I was going to be able to do things a lot faster than...than was stated. I'm not very good at staying within regimented guidelines. I like to break the rules a little bit.

A: Right. My next question you've already answered at least in part, but I'll ask it again. How is learning Business by distance education, different from learning it in the classroom?

L: Well, really the...the...the speed at which you can learn. I... (100) For the first assignment, I was coming home from work, disappearing into our study in the basement, and working till probably 10 or 11 at night and going at a much faster pace than I would have done if it had been in a classroom, where I would have been waiting for other people. And I can be very impatient when I'm in that sort of environment. So I would imagine that learning it in a...in a classroom, where you're being lectured to... Actually, I'm just thinking, I did start to do a course at Kwantlan about three years ago, but I...I was bored out of my mind, and that was the same reason; it was a classroom. I'd completely forgotten that until just now.

A: What subject was that? 
L: It was Business Management, same course, but done in a classroom, and I only went for about four or...four or five nights I would say. (110) And I was bored out of my mind. I mean, I used to come home here, and I'd spent, I don't know, whatever it was $\$ 180.00$ or something for the course, and I think probably after the second or third night that was the only reason I was going, because I didn't... I felt guilty about spending this money and not using it. But by about the fifth night, I was just so incredibly frustrated at the speed at which we were going. I wanted things to happen quicker, and they weren't.

A: Right. Yeah.

L: And they...they couldn't because of discussion times and.... You know, Business Management, there are formulas and processes that you can pick up very quickly, or I found that I could, and I found that people were not grasping those...those things, and I found myself sort of rolling my eyes and thinking: Oh, my God! You know, I'm going to have to listen to this again.

A: (121) Yeah, yeah.

L: So that was the...that was really frustrating. So I lasted four or five nights, and that was it. I felt very disappointed.

A: Are there any other particular differences between doing it by distance ed., doing it in the conventional classroom way? 
L: Well, (pause...) I...I don't have a lot of experience with doing Business Management in the classroom other than those five lessons, but I guess you lose...you do lose other people's opinions. You've got your tutor who you can talk to on the phone, and I've done that, but you do...you do lose.... There were a few people in the classroom that had very good points of view. I wasn't ...I mean, I wasn't the only one that felt that it was going slowly, because I discussed it with other people. (130) And there were several people that had excellent ideas, and some of the assignments that they gave us were to solve business problems within groups, and that was good. There wasn't...there's no doubt about that; that that was very good. Sort of role-playing type assignments, and, of course, you can't do that with a correspondence course, but it's not something that I say that I miss greatly because...because I'm studying in the field that I'm working in. I found a lot of the assignments I could relate directly to my own...to my own job, which I found very useful, and... and have been able to use things even from the very first chapter of the first assignment in my... in my work, so that was good.

A: That sounds good.

L: Yeah, yeah. It was great. Oh, and my employer was very pleased. 
A: (140) So you've told me about some of the differences. What are some of the similarities between conventional education and distance education?

L: (Pause......) Well, the textbook. (both laugh) We had a textbook. (pause....) I don't know. I found...I found it so different, I'm not sure that there were too many similarities really. The speed that I could go at; I wasn't being.... I wasn't receiving any lectures. The...I guess there were tapes that would probably supplement the lectures, which, you know, you could probably say were similar. You would listen...were listening to someone giving you a talk and a discussion on something.

A: You actually have some tapes.

L: (150) Yes. Oh, yes. Part of the course was...was audio tapes. So I guess from that point of view, but other than that, I mean, nothing. I mean, I used to take... I mean, being able to take tapes in the car and listen to them on the way to work was just excellent. I can't say that I found really anything similar. I mean, being out of a classroom, not having someone telling you what to do. The textbook and... and getting the marks back, I guess, were really the only thing that...that I would say were similar. Otherwise it was completely different, nothing similar at all.

A: Yeah. A couple of times you mentioned that the course you're doing relates to your work. 


\section{L: Right.}

A: Could you expand on that a bit?

L: Yes. The bus...the business management aspect and the way you can deal with people greatly improved my understanding. (161) I work for a...a small business, family-owned business, and obviously the...the ideas that they have in that business are fairly insular. There's one guy at the top, and what he says goes. And I've learned to adapt to him. I haven't always enjoyed what he says, but what he says goes because he pays the bills, and that's the way it goes. So, to have other people's views about similar subjects that we're dealing with -dealing with people, dealing with discipline problems, motivation, that kind of input -- has been very good for me because... and good for the company, because it's put a different perspective on things. And in fact, we were having a meeting yesterday morning with a new employee, and the president of the company said something which I could probably attribute directly to the course and that was that simon was very good at acting as a buffer between him and the rest of the employees and softening the...the otherwise harder blows that he would deliver, so I think that that could be attributed to the course, just...just a different perspective on dealing with people.

A: Hm, that's interesting.

L: Yeah. 
A: Yeah. When you're actual.... When you study, when you do your studies, what do you actually do?

L: (179) I go down into our basement, we have a study area down there, and I.... There...there are no windows, so I'm very focused. The.... You want to know how the course is structured and how I physically...?

A: Well, yeah. What is your procedure when you study?

$\mathrm{L}: \mathrm{O} . \mathrm{K}$. The procedure is: there is a course manual which you read through and answer questions to yourself during the course material. So you.... It gives you a list of instructions of how this next chapter is going to proceed. You then take the textbook, read through the textbook, and answer questions in the course manual. What $I$ do is prior to reading the textbook, I read the questions that are in the course manual. (190) I don't know if that's the way I'm supposed to do it, but I want to know what I'm looking for. Then I take a highlighter pen, and as I read the textbook, I highlight the points that I feel will answer the questions. And then I go back over those highlighted points after I've read the complete text that they're...that they're asking us to read, and then I answer the questions. So I've gone back over the...the text that I've highlighted. And there are two chapters read, and then an assignment is written. And the assignment is usually based on those questions that have appeared in the course manual, and so all the 
highlighted areas I read over again before I do the assignment. That's how I do it.

A: (200) So they...they are obviously recommending quite a structured procedure, and you're following that structured procedure.

L: I'm following the structure with the exception of really probably going to the end of the manual and reading the questions before I read the chapter, because I think what they want us to do is read the chapter and then answer the questions, whereas I don't want to have to go back through the chapter and find out if I've missed something. I want to make sure that $I^{\prime} m$ doing it as $I^{\prime} m$ doing it. I think I'm cutting down on one reading. Whether that's good or not, I don't know. That's what I do.

A: Yeah. Efficiency! (laughs)

L: Well, I think so.

A: Yes. I asked you before: Before you started, what did you expect it to be like? Diffe...slightly different this time: What were your hopes or your fears, or both about doing this by distance education?

L: My hopes were that within about six months I'd have a degree (laughs), (210) which I knew was absolutely, totally unrealistic, but I mean that's what I would hope, but it's just never going to happen. My fears were that it would...that it would take so long, was this something that I would be able to maintain? Because doing it this 
way at the pace that I can do it, incorporating my family life and not disrupting it too much, and keeping up all my business commitments, I'm looking at about nine years, eight to nine years. And to maintain that level of discipline, coming down and going down into the basement every night and doing that, I had a real fear that I wouldn't be able to maintain that. Also, this was the really the first time that I'd had a test of... of my abilities from an academic point of view in more than ten years, (220) and I honestly didn't know whether I had the ability. My wife kept saying: of course you can. I mean any...any average person can study; it's just whether you have the commitment to do it. But I'm not sure that I really believed her. I wasn't sure whether I could do it, and I probably set too high goals for myself. I kind of set a goal in my head that if I didn't achieve at least an $80 \%$ grade on the assignments, that I wouldn't feel that I was able to do it and probably would not continue. So that was a fear that I didn't know whether I would maintain that level. (Pause...) I'm sorry, you said fears and something else.

A: Fears and hopes.

L: (230) Hopes. My hope was... one of my hopes is, not 'was', 'is' that by getting a degree I will feel that...that I've achieved something. I...I'm really not sure even now talking to you whether I have the ability to have one. Everyone says: oh, of course you can. I 
mean, with your ability; look what you're doing at work. Yes, you can do it. But there's one thing to saying, "Yes, I can do it" and "Yes, I could do it" and actually doing it. And so, I still have the question in the back of my mind: Can I do it? So the hope is: Yes, that I will eventually have a degree and be able to use that degree to advance my, I guess, standing within the company, peers. That's what my hopes are.

A: (241) And now that you've actually been doing this course for going on three months, how are you finding it now?

L: Oh, it's absolutely impossible. I cannot, I cannot do it at the level, at the speed that I'm going at. It's my.... I should say that when I started it, my job was going smoothly. I think I indicated that earlier. Everything was nice and smooth, and January 1 everything wasn't so smooth. We embarked on a new venture in my business, which I was to head up, so my...my day, my hours away from home extended by probably at least an hour, possibly two, at each end. (251) And so my time...free time was dramatically reduced. I have a 3 month-old daughter as I indicated, and that.... (pause...) Now how shall I put this? The...the amount of time that I was spending studying was reducing the amount of time that I could spend with my family. And I really didn't like that. After about the first three or four weeks I realized that I would not see them really grow up. I would be studying, and I would have a degree, but 
I don't think they would know me. (260) And I can remember sitting down in the basement and hearing the words of "The Cat's in the cradle" in my head and thinking: I'm not sure that this is the right time to be doing this. So that...that's really what happened, and it was.... I felt really disappointed because I thought: I can't do it slower, because to think that it's gonna take me fifteen years, I mean, I just can't do that. So what I decided I would do was probably wait until they were a little bit older and then continue but probably at a faster pace. So $I^{\prime} l l$ end up with a degree in the same period of time, but I'm just not gonna stretch it over such a long period of time.

A: So at the moment are you actually...?

$L$ : I'm on hold.

A: You're on hold.

L: I'm on hold. I did very well on the first assignment, above what I had sort of...that goal that I had set. So I now know that, yes, I can do it. (270) This standard of... of education, I'm up to it, so that was a nice feeling; I felt like I had achieved something. But I cannot realistically take two to three hours every evening with my young family. I just would never see them. It's just not practical. I mean, I guess I have to make the choice whether I want to see them or not, and I decided that I want to see them grow up.

A: Right. 
L: So that's where I am right now.

A: I have a little series of questions next.

L: Sure.

A: By doing this course, what are, or what have you been learning about yourself?

L: (280) (Pause....) what have I learnt about myself?

Well, I've learned that I am...I'm at an academic level that I'm satisfied with. I...I wasn't sure, as I indicated, that I could...that I could physically do the work. I wasn't sure whether I had it, and I do, so that was... I've learned that I do have that. I've learned that, I guess, my family is more important to me than studying, because otherwise I'd be down in the basement and they'd be up here. And I don't think I really knew that before. I think I figured that I could fit everything in. I even considered getting up a little bit earlier. (290) I rise at five and I thought: Well, maybe if I got up at four, I'd be able to fit it in, but I'm not able to function at that time in the morning to a level that would allow me to do it. I tried, but I'm just... just can't do it. So, no, I think that probably the most important is that I...I want to see my kids grow up and I want them to know me and that (pause...) I don't have to have everything now. I'm very impatient, and so I think I've learned that: O.K. This is something that I can do, and I will have a degree, but I'm just gonna have 
to put it on hold for a little while until they've grown up a bit.

A: So basically you're telling me family is the most important thing...

L: Yes.

A: ... studies have to come second.

L: (300) Yes. Most definitely. I mean that's really the only reason I'm not doing it, because... and my wife, not just my kids, because, you know, we have a very happy marriage, and I really missed her when I was down there. You know, I would be studying away, gleaning all this information and feeling really good, and I'd sort of sit back and I'd think: Hmmm. You know, she's up there, and I'm down here, and this isn't...this isn't so great.

A: Yeah.

L: So I...I really.... I found that very tough.

A: Second question in this little series. What have you learned about Business Management by doing this course?

$L$ : Well, I'm really at the beginning. (pause....)

What have I learned about Business Management? Well, the...the course that I'm studying is an introduction to business management, or the course that I was doing maybe I should say, is an introduction to business management in the Canadian environment. So, I have.... It's given me a much clearer picture of the Canadian business system within the global picture. You know, when you come... when you emigrate from another country as I did 
seven years ago, specially if it's a... if it's a country, you know, where everyone's speaking the same language and basically looks the same, I didn't realize how many differences there were. (320) There are many, many cultural differences between Canada and Britain, which don't show up on the surface. I mean, one very simple one, which may sound silly but I'll give you an example, is that in... in the business environment in Britain, you would never, ever refer to a senior person in a business by their first names. And that is something that is very dramatically different about here. I mean, my boss, it's...it's his first name, and so that took a little while to get used to. And that's just a very surface thing, but it runs right the way through...through every aspect of... of business, and I think that the...the course has successfully given me a better picture and understanding of Canada as a country within the global environment, not just from a business point of view. So I guess that's what I've gained from it.

A: (332) Third little question. What have you learned about distance education through doing this course?

$L$ : Well, one: that it exists. I mean, I hadn't really considered it. I'd heard of people doing correspondence, and I imagined people on farms and I don't know what else. I had a very warped view of... of people sending correspondence in, and like it wasn't something that I really had even thought was available to me, so I've 
learned that it exists. A wonderful structure. I mean, I don't really have anything to compare it with, but (pause...) from what I've seen of the... of the course, and it is limited because $I^{\prime} m$ new to it, I'm very, very impressed. (345) I...I called into the open Learning Institute in Richmond and spoke to one of the advisors, and just the access...access to information is really excellent. I had.... I was very, very impressed. The...the use of SFU library, the speed at which they were able to...to give me the course material, and just the tutor, and just the whole structure of it. I... It was... it was something that I just wasn't aware of, and I was just very impressed with the whole system.

A: So what you're saying there is that the efficiency and the structure of the system seems to you to....

L: (355) Seems to me to be just excellent. I will add that when I was talking to the advisor, I indicated this to him. I said: You know, this is just fantastic. And he said: Well, it has worked particularly smoothly in your case. We don't always.... It doesn't always run this well. Sometimes people are, you know, waiting for courses to come out so they can complete degrees, and so it...not everyone would say that it is as glowing as you obviously feel it is. But he was very pleased to hear it obviously, and from my...from my experience it was just wonderful. I was very, very happy with everything. 
A: You mentioned an advisor and a tutor. What.... And you said that you had spoken to the tutor.

L: Both, yes.

A: What kind of...? What was that like?

L: The difference?

A: No, the tutor. What was your relationship with him like?

L: (365) Well, when I originally received the course material, it said that I would be receiving another letter from the tutor and to wait for that. And that arrived very quickly. And it gave me his telephone number, and there was like a questionnaire sort of within it, which was asking questions about how old I was and my family situation and dislikes and likes, so I guess it was just a, sort of, a little thing for him to... so that he could get to know people a little bit better. I'm not.... I phoned him, and he was extremely...extremely encouraging on the phone. He sort of said things like: (375) You know, don't feel bad if you get behind because, he said, that tends to happen with correspondence courses. You know, you...y you start off, and you're really gung-ho, and then you can...something will come along and, he said, just...just go ahead and go at your own pace and, he said, it won't worry me if you're a little bit late or a little bit early, he said, you just go at your own pace. I just felt very encouraged by it, very friendly, and it just made me feel really good. And, you know, call anytime if you've got any problems. 
And I... There was one important point of the chapter which I didn't agree with. I mean, I just... I thought it was wrong. And I called, and it was indeed a misprint. (laughs) So that was...that was the only time that I called him. But, yes, he said, yeah, he had sort of read over it, and it was just describing a formula which...I just couldn't work it out because it didn't make sense.

A: (387) Did you often speak to him or just those couple of times?

L: No, just those couple of times, just calling collect. I didn't really feel that I had to call him. It was like (pause..) if I had problems, and I didn't have. I sent in the assignments, and he sent back with, you know, a written report, and I read that, so I didn't feel that there was anything other than that time when I was confused about the error. I didn't really feel that it was necessary.

A: I've been jotting down what seem to me some of the key words you've said.

L: Sure.

A: I'll read them back to you, and I wonder if you can tell me: For you is there a particular relationship between these things?

L: $0 . \mathrm{K}$.

A: The first one is that you can go at your own pace; there's that freedom. The course related to your work. You talked about the importance of your family, and you 
also talked about this long commitment in order to finish the course...the program. Can you relate those to each other?

L: (402) (Pause...) Can I relate them? (Pause......) I guess that they come into those hopes and fears categories. The reasons for wanting to do it and the reasons for being unable. (Pause.....) I can't find one thing that pulls them all together other than me.

A: That's a good central point.

L: Yeah, I guess they just.... (Pause....) They are certainly the reasons for wanting to do it and the reasons that I am unable to, but.... (pause...) It's my lifestyle. My lifestyle does not allow me to continue...the lifestyle that I've chosen, I should say. So I could choose another, but I wouldn't (unclear) choosing right now.

A : (419) sure.

L: And that would.... It would be my lifestyle that made me go into it, because I was unable to go to...to university full-time, because, again, because I'm choosing the lifestyle that I have. And it's my lifestyle that's going to make it (unclear) for me to do. So I guess that's what relates them.

A: You've used the word 'choosing' several times there. Is that an important thing: choice, being able to choose?

L: Oh, absolutely, very important. If I felt for one moment that I was being directed to this course of action, I 
would feel absolutely.... Oh, what would be the word? I would be just mad, really mad. I cannot bear to be manipulated. I have chosen not to continue because $I$ have chosen something else. It's very important for me to make choices. To...to just sort of say, well, I can't do this because I want this, is a real cop out for me. You know, I...I'm choosing not to study right now because I'm choosing my family. And that makes it $0 . \mathrm{K}$.

A: (439) It's a very conscious choice.

L: Absolutely, absolutely. If I ever feel that.... I can't.... I'll try to give you another example; it's hard to describe. So it's like at work sometimes, you know; something's not going right. Well, you have to make the decision then, whether you're going to go on, whether you're gonna change your career or whatever or change your position. That's very important to me that I know that I'm making the choice. I mean, if someone tells me to do something and I don't like it and I have to do it, I have to, for myself, know that I'm choosing to do it. I mean I don't have to do it. I mean, no one can make me do anything. So if I do something, and I don't like to do it, I've chosen to do it.

A: Right.

L: (451) That's important. And the studying, going down into the basement every evening and studying, that was a choice, and over a period of weeks I decided that this 
was not a choice that was satisfactory to my life so I chose a different.

A: How long ago did you actually stop doing the studying?

L: It would have been the end of January, beginning of February .

A: That's right.

L: So it was very, very early. I just did...did 2 assignments, and I fall into the statistics on that.

A: (laughs) One of them, yeah. A sort of umbrella question now. What... what are the important things about distance education for you?

L: Going at my own pace, being able to... I thought, when I was starting to...being able to fit it into my lifestyle, and I will, because I don't think I'll ever go back to full-time education. I don't think I could stand it to be honest with you. After being in a business environment and... (470) I just don't think I could make that dramatic change, so it... it was very important that I would be able to fit it in. And maybe that's the problem because it's not a...it's not the number one priority, and maybe it should be. Maybe that's -- I don't know this -- but maybe that's the way that makes you finish and makes you do it, because it is a priority. So maybe one day I might have to make it a priority, but right now it isn't. So it was very good that I could fit it in. I felt that.... When I was talking to my friend who had the friend in Hawaii, I thought: Oh, this is 
great! I can do everything that I'm doing right now and continue at the same level and get a degree, and that was really important to me. That was...that was great. I felt that it was going to be something that I'd be able to do as well as, and I'm not so sure now in hindsight that you can do it that way. You...you cannot.... Well, the level of my...my lifestyle, I would have to give something up. And so it would have to replace something; I couldn't do everything that I do and that.... There's just not enough hours in the day.

A: (490) So you're anticipating that as your life changes, then....

L: Yes, I'm anticipating that, and I may be wrong, but getting the girls to bed at night time, you know, it's an hour, a good hour. That will... They will obviously not have us putting them, bathing, and all that stuff, so that'll diminish. I don't anticipate the...the... see I leave the house at seven in the morning, and I get home at about 6,7 at night. I don't anticipate that I will be doing that forever more. I don't particularly want to. And I don't know whether that will change, but I...I kind of feel that it will. I think that that will slow down. It may increase because... as I have aspirations of having my own business one day, and if $I$ do that, then maybe it'll be put back again. But I do...I do really believe that one day I will have a degree, and that's important. How I do it, I don't really know. 
A: Just the fact of having a degree is important.

L: That is very important to me, yes.

A: Why is that?

L: (510) I think.... None of my family, my immediate family were very interested in education. I grew up with people that were, and the...the importance of an education to me is.... It is important. I don't feel.... I feel like there's something missing. Just...just to know that I can do it (unclear) because I can keep saying: oh,yes. I can do it. But I don't really know.

A: So you're saying that actually doing it, sort of proving to yourself is an important thing.

$\mathrm{L}$ : Yes, that is very important. I'm always trying to prove to myself different things, and that's one of the things that.... It's in the back of my mind that I don't know if I can do it, and I hate that; I just hate it. I have to do it sometime. I would feel cheated if I didn't because I'd have made the wrong choices.

A: Yeah. If you were talking to another person who was in a very similar situation to you, similar work, similar hours, similar family situation, what would you say to that person about doing Business Management by distance education?

L: (531) I would... I would ask them if it was going to be a priority because -- and I'm very good at telling people what to do (both laugh) -- and most people don't like it, my wife included. It's.... I would say: Do you realize 
that you aren't going to see your family if you take this course of study? And you are going to be doing it for a very long time; you can pretty well say good bye to the next eight years of... of free time, completely. There will be no free time.

A: So you feel there would be no free time doing it?

L: If you wanted to do it within five to eight years, yes, there would be no free time. Otherwise.... Well, you could do it...you could do it longer, if you wanted... if you could say to yourself: Well, yes, I won't have a degree for 15 years. Well then, you could go at an incredibly slow pace. But I just don't think that.... I need some sort of momentum then I get going, and I don't think that I would.... I don't think many people would be able to drag it out over that period of time. It's quite nice the way it's structured. It's something that's important about the correspondence is the way that you're kind of nibbling away at little bits at a time. That's very good. You do a chapter and then you do an assignment and that leads to a certificate and then the certificate leads to the...the ultimate certificate, and then diploma and degree, so it's like it's got bench marks along the way. (560) You know how far you are. But to think that it would take you (unclear), I mean, I just don't think I could do it, over that period. I need to see a sort of shorter-term goal. So I would say to them: You've got...you've got to make it your priority 
and expect that this is going to be the number one thing in your life for the next, you know, five to eight years, which is quite a hefty commitment. I didn't realize how much before I started.

A: So, six months. (laughter)

$L$ : Well, I'm exaggerating. No, I realized... You know I...I... The degree time is three years, and I sort of figured that maybe I'd be able to do it, but it's just, absolutely no way. I mean, I wouldn't go to sleep. That would be the only way.

A: Right. (laughter) And, by doing this course through distance ed., do you.... How have you evolved as a learner?

L: (579) (Pause....) Well, I think the process of learning definitely improved that this...the highlighting technique that I.... I sort of came across it on my own. It was my idea to do it that way, but I came up and talked to my wife, and she said: Oh, that's a very good way of doing it. And with her background I sort of said: Oh, well, you know, I'm on the right track; I'm not such an idiot. (laughter) But.... So from that...from that point of view, yeah, I feel that the actual technique of learning I have improved. I would say probably that was the only...the only thing. I'm pretty good at reading something and memorizing it, so learning information has never really been a problem. The assignments were more challenging because they wanted my ideas about specific 
things, and I had.... (600) My...my writing ability, I wouldn't say was that great. Becau.... Having not, sort of, written for ten years from an academic point of view. But, again, I spoke to my wife, the teacher, and she gave me some pretty good tips about the way to write in an academic way, and I absorbed that fairly quickly and the assignments that I did were great. I felt very pleased with them.

A: You gave me a kind of dichotomy there. You talked about memorizing, learning information, and then you also talked about giving ideas when you wrote an assignment.

L: O.K., yeah. That was something that was new to me, or I felt it was new, maybe not new, but certainly.... After ten years it was a (unclear), getting information in, assimilating it, and then putting it out as your idea. (620) That...that was something that was a process that I hadn't done for a long time. I mean, in business you tend to... Y you formulate ideas from a whole lot of situations that are going on; you're not reading information. And so that was...that was something that I felt that I was gaining from a learning process point of view.

A: Well, that actually takes care of the questions that I have. Do you have anything you'd like to add?

L: (Pause...) No, I think it's a.... I think it...distance education is a wonderful idea. It seems to me that the practicality of it is... is way, way harder than the 
theory. I mean, it sounds, when you.... When I entered into it, I felt that I was going to be able to fit it in. So my perception of the... of distance education was completely different to the reality. It was much, much more involved and much more of a commitment than I (END OF TAPE 11, SIDE A)

A: (650) ...(SIDE B) What... what do you mean by involved?

L: The idea of being able to fit it in. It just... There was just so much more to it: the...the time involved to do the assignments. The losing of so much of my free time with my family was more than...than I had anticipated, or had, I think, probably been indicated by any of the literature or counsellors that I had spoken to. I don't think they were trying to hide the fact from me; it's just that, I guess everyone's situation is different, and they're not aware of... of your priorities, and obviously education is not the highest on my list. My family is, so it was more.... It was going to take away more than I had anticipated from my lifestyle.

A: Right. Well, thank you very, very much.

L: You're very welcome. It was great. 


\section{INTERVIEW \#12}

Interviewer: $\mathrm{A}$

Respondent: M

Position on tape: (000)

A: Perhaps we could begin with your decision to enrol in distance education. How did you come to that decision?

M: How did I come to it? Ever since I dropped out of high school in Grade 11, I've always wanted to...to do my education, and I just came to the decision. I saw a brochure for adult learning, and it was interesting, and I enrolled.

A: And did you learn about it from someone or was it just that you happened to see a brochure?

M: I saw a brochure. I'd been aware of different programs that were available, and I wasn't too sure which one I wanted to take. (010) There's the Canadian Credit Institute House and MCI program, which is again similar to a Bachelor of Commerce, and I thought about that one, and I saw the one from open Learning and figured that I should go for the Bachelor of Arts. (laughs)

A: Right. And exactly which course are you doing now?

M: Right now, I'm taking Business Law and Sociology.

A: Oh, you're doing two courses.

M: Yeah.

A: Oh, good for you. Business Law and Sociology.

M: Yeah.

A: What level courses would those be? 
M: They're beginning. They're both introductory, yeah.

A: Oh, you're quite busy then.

M: Yes. (laughter)

A: And before you actually started the courses by distance education, what did you expect it to be like? You know, doing Business, doing Sociology by distance ed.

M: Actually I kind of thought it would be like just about what it is. The...the course content is... is very good. (020) I like the way that the courses are set up and everything. I think the only problem that I didn't really expect to encounter was having enough time to actually do them. The Business Law is a little bit easier for me because I have a bit more knowledge of it. The sociology is brand new, and it takes a lot more time to understand what's going on.

A: Sure. You said that the way the courses are set up is good. Can you expand on that?

M: Just the way that they're...the course descriptions, the way they're laid out for you (pause...), the order everything is put in; it's easy to understand, easy to comprehend.

A: That's nice to hear. And, so you said that it turned out to be much as you expected.

M: Yeah.

A: (030) So, what you expected was that it would be well ordered like that and so on?

M: Yeah, yeah. 
A: OK. How do you find learning Law or Sociology different...? When you learn it by distance education, how is it different from learning it in a classroom, in conventional education?

M: (pause....) You don't get the input of other people. I find that's...that's a...a bit neg.... Also it's a big problem. It would be a lot more helpful, if you could have other people to discuss things with. There is a tutor, but I think you get a lot more in the classroom situation with everybody's input into it.

A: Why do you think it helps to have discussions?

M: Different points of view. There's certain areas that you might not really comprehend, and if you have other people that are saying different things, bouncing ideas of $f$ of each other, it's a little bit easier.

A: (040) You said you have a tutor, but the tutor doesn't compensate?

M: I...I haven't really talked to the tutor. I don't...I don't mean that they're not... that they're unhelpful; it's...it's more if you've got specific questions to ask, they're there to answer them for you or to help you answer them, whereas I think in a classroom you might not have...it might not be a specific question that you're having problems with but just the general idea, and with everybody's input into it, it's a little bit easier to understand it. 
A: Right. O.K., so that...that's a major difference between classroom and distance education.

M: Yeah.

A: Is there anything else that's different?

M: (049) It's nice that the distance education is a little bit more flexible as far as scheduling, but that works the other way as well whereas it's a little bit more difficult to make sure that you discipline yourself to actually make the time available to do the studying.

A: Do you find that's a bit difficult or...?

M: Yeah, I...I find I play catchup quite a bit. I'll put it off for two or three days, and all of a sudden you realize that 'uh-oh' and then really gear down, and try to get all the studying done in a short period of time.

A: So discipline can be a problem. (laughter)

M: Yes, yes, it can be.

A: O.K. And those then are differences between doing the courses by distance ed. or in the classroom. What would you say are some of the similarities between the two ways of doing it?

M: Similarities (pause...) I would imagine that the...the actual course material is pretty much the same, like what you learn is the same. (060) (Pause.....) Outside of that, I don't...don't really know how to answer that question. (Pause.........) Not much; I can't think of anything that'd be too much different. 
A: O.K., right. Well, when you are doing your distance education courses, what do you actually do?

M: What do I actually do when I'm doing them?

A: Yeah, yeah.

M: Read through the materials, study, make notes, sometimes I tape-record things that I'm reading so $I$ can play it back. (Pause...) That's about it.

A: When you say you tape-record things, you mean you read something and then play it back to yourself?

M: (070) Yeah, I'll... As I'm studying, I'll read out loud, tape-record it, and then I'll listen to it when I'm driving to and from work, just to help me learn things a little bit better.

A: Oh, you're the first person I've heard say that. Good idea! But does that mean that there aren't any tapes with the course itself?

M: There are...there are, with the sociology course there are some tapes.

A: Do you find them useful?

M: Yeah. Oh, yeah, yeah. They drone on a little bit, but.... You find your eyelids start to get a little bit heavy halfway through it, but overall it's not too bad.

A: That sounded like a very qualified 'yes'. (both laugh) So you're saying the tapes are a bit boring in fact. M: A little bit, yeah, a little bit. 
A: O.K. I asked you before: What did you expect it to be like? Related to that, what were your hopes or your fears before you actually started?

M: (080) My fears before starting (Pause....) was having or I guess just being able to...to understand the course. material. That was my, one of my biggest fears. I didn't know if I was biting off more than I could chew. My hopes were, of course, that I would do quite well on it and (pause...) learn as much.... I was really surprised with the.... I guess you take for granted a lot of...a lot of your knowledge, but taking the courses was really enlightning. Like even if I didn't pass them, I would still think that it was money well spent, because of the knowledge that you... that you learn from it.

A: So, what are you learning about Law, about Sociology?

M: (089) About Law, a lot of specifics that I wasn't aware of. With Sociology I've found quite interesting, just different ways of looking at...at people and what they do and why they do it, which is...I guess it just teaches you to look at things in a different perspective than what you normally are used to doing.

A: You say in the Sociology you feel you're learning different perspectives. Is that true in the Law course as well?

M: No. Having a fairly good understanding of the legal system of B.C., it...it opened my eyes up to more areas. 
I guess it did teach me to think from...or look at things from different perspectives, because I...yeah it did.

A: And, I asked you there about your hopes and your fears before you started. Now that you are actually into it -this follows up on what you've already said -- but what really has been your experience of the courses?

M: (100) Relative to?

A: Relative to your hopes and fears at the beginning.

M: Hopes and fears? (pause...) I'm sorry, can you rephrase that?

A: O.K. I asked you about your hopes and your fears before you started. Now, you've been doing the courses for a couple of months, and how have you actually found it, you know, what's your experience of it now?

M: (Pause.....) It's not.... I.... My fears have been...have changed a little bit from being able to comprehend the...the courses to, I think, of having a fear of making enough time on an ongoing basis to complete them. I can see how it would be very easy for people to drop out. (110) I don't think it's because of any.... In my instance at least, it's not because I don't find the courses interesting. I think it's just a matter of actually making a commitment to set aside $x$ number of hours per week to do the...to do the work.

A: So, is that important to make that commitment to set aside $\mathrm{X}$ hours a week? 
M: Yes, yes. Very important. You know, it's easy to sit back when you first go through it, and you... as you're, I guess, reading through the brochures and stuff, and this is really nice, and, you know, they...they tell you that you have to expect to spend this much time studying on a weekly basis, and when you first do that, it's: Sure, no problem, two hours here, two hours there, two hours there. And then...but then when you actually... when that translates into real life, it's a little bit different.

A: (120) It adds up to quite a bit, doesn't it?

M: Those two hours don't always seem to be available when you want them, or when you figured that you'd have them.

A: Right, yeah. You said there that your fear now is that you just might not be able to find those hours. If you got to the point where you found you...you were going to drop out. How would you feel about that?

M: Pretty lousy. I don't.... I'd feel pretty lousy about dropping out. I don't think I will, but I could.... (pause...) If I got much busier doing other things, I could see how that could become a fairly good possibility to do that, but I would feel really lousy if that happened.

A: So, are you saying that right now completing these courses is one of your top priorities, but your priorities could change? 
M: Yeah, I'd say it's in my top three priorities.

But, it is...it is for me that to finish the courses, it is definitely a priority.

A: I asked you earlier: What have you learnt about Law, about Sociology? A question related to that in a sense: What are you learning about yourself, by doing these courses?

M: (Pause......) Getting...I guess I'm getting more of a feel for.... What does it feel...? A reinforcement of the knowledge that I already had, or had gained over the years with equivalent work experience. (pause...) I guess trying, just being able to identify that with what the courses are actually teaching you. (140) It's...you know, you know more than you think you know, I think, is what it kind of comes out in the beginning.

A: So you're learning that you know more than you thought you knew.

M: Yeah, yeah. There's a .... I guess it kind of builds your confidence a little bit in yourself initially. I don't know when I get my higher level courses, it might be a little bit different, but initially it's...it's a bit of a confidence boost.

A: And do you feel that's important to have this confidence boost?

M: Yeah, it makes it a little bit more interesting.

A: How does it make it more interesting? 
M: Well (pause...) Maybe that's kind of stroking your ego a little bit, but it makes you feel a little bit better about doing the course, that you're learning things, but you have a lot of the basic elements necessary or the knowledge necessary to do it. (150) I think that would probably relate back to my fears of being able to handle the course material, and when you get into it, you realize that: Hey, this isn't so bad. And it makes you feel a little bit better about yourself.

A: Right. So you're finding, in effect, that the whole thing is not so bad.

M: No. Actually it's...it's quite fun it's...it's interesting.

A: Fun. Can you expand on that? (both laugh)

M: I don't know; I just find it a pleasurable experience to learn things. I like learning about things, and maybe fun isn't really the exact, or the correct word to use, but I find it very enjoyable.

A: Good. And, I've asked you: What are you learning about these two subjects? (160) What are you learning about yourself? What are you learning about distance education through doing Law and Sociology that way?

M: (Pause....) what am I learning about distance education? (pause.........) Good question. (Pause....) You'll have these long moments of silence on your tape as I ponder these things. (laughs) I don't know if I can really answer that. (pause.....) It's not...it's not as 
hard as I thought it was going to be. (170) All the materials and everything that have been supplied by the...by open Learning have been really top-notch as far as...as far as I can tell. I think it's a...it's a good way to...to get an education, especially if... if you have a full-time job to keep you busy for most of the day. That's about it.

A: One thing you said there was you feel the materials are top-notch. So that means that for you the materials are the essential part of it.

M: Yeah, yeah.

A: And you mention having a full-time job. That's an important factor as well?

M: (agrees)

A: (180) For you then, what would you say are the most important things about doing courses by distance ed.?

M: The most important things about doing courses?

A: Yeah.

M: (Pause....) Making a commitment to put the time aside. I think that's without question the... one of the most important things that you have to do. (Pause......) I... f find that having a place to study, too, is actually really quite important. It's very difficult to study in... in a home atmosphere where you've got people, your T.V. going, the radio going, people chatting and stuff like that. (190) And I don't think that the family members really (pause...) understand how much 
concentration is required or maybe even how important it is to you to...to actually do it, so it's...it's easy to be led astray a little bit, so if you can go some place, like I do most of my studying here after work by myself so.....

A: Oh, really. So this is, in fact, where you do your studying?

M: Most of it. Yeah, yeah. Which I find a lot easier because you don't have the distractions. (Pause.......) And outside of that.... (Pause.....) I think that's about it.

A: (200) So you're saying commitment and having a place to study are the most important things about it for you.

M: Yeah.

A: O.K. Is there a particular relationship between those two?

M: Such as?

A: Anything. You would know.

M: (laughs) (Pause......) I...I find it easier to commit, like if I'm going to study two hours a day, I find it a lot easier to commit two hours to studying when I'm at the office than I do when I'm at home. When I get home my priorities change. (210) It's go home, get changed, have supper, clean up, maybe catch a quick shower, and then you...all of a sudden it's, you know, 9 o'clock at night, and you figure: O.K., well, I can still study for two hours, but it doesn't often work out that way. 
Whereas if I stay at the office, it's...that's all I have to do is study, so it's a lot easier to study here than it is at home.

A: So, in effect, you're telling me that certain places are, for you, much more connected with studying than other places.

M: Yes, yes.

A: O.K. If you were talking to another person like yourself: He had perhaps the same job, like you he had not... he had left school early, and he had the same sort of family situation as you. What would you say to him about doing distance...about doing Law or Sociology by distance education?

M: (221) I'd strongly recommend it. I don't know if I would strongly recommend the sociology right off the bat, but....

A: Why is that?

M: I...I just find it to be a more difficult course than the...than the Business Law. Or perhaps only taking one course initially, and then as you build up your confidence, to increase the courses.

A: Does that mean you're finding two courses a bit much?

M: I think I could do much better if I was just doing one course. It's kind of a compensation thing. If I spent all my time studying on just one of the two courses, then I think that I would do better on it overall, and splitting that time, which I think (unclear) you're 
getting back to that time commitment. (232) You know, it's.... Maybe if I only had one course, I'd only do... spend half as much time as I do now studying.

A: You did say there that you would recommend to the other person that he do one course perhaps. That means you would recommend distance education rather than an evening class?

M: (Pause.......) I would have a hard time (pause....) doing a... (pause...) a fixed like evening class. I'd have a hard time doing that. I'd prefer the distance education because it's more flexible, and I can, if I'm busy this week, and I want to do a lot of cramming on the weekend, I can do that whereas if it's...if it's evening courses or night school, you have to...to do it, so it's kind of a double-edged sword, I guess. I...I would...I think I would still prefer the...the distance education over...over taking a night school.

A: For that reason that you have flexibility of when to study.

M: Yeah.

A: O.K. And one more question: How are you evolving as a learner, by doing these courses through distance ed?

M: (251) (Pause.....) It's... (pause.....) It was a...it's a little bit harder than... (pause...) than I first thought it was going to be. It...it takes, I guess, a fair amount of... of hard work to actually do the studying and learn the different aspects of the courses. (260) I 
think I'm doing that pretty good. It's... (pause......) (unclear) getting stuck for words (unclear) Should have taken an English course first. (both laugh) I just.... I don't know I...I find that I'm...I'm able to.... The more studying that I'm doing, the easier it is for me to comprehend things or pick things up as I go along, so I imagine that three years down the road, if $I$ 'm still doing this, it'll, you know, the study habits and being able to learn, comprehend, it will become easier. (270) It's...it's a little bit difficult at first because it's almost overwhelming that you haven't studied in any organized fashion for a lot of years to suddenly do that, and then you're...your poor little brain is just kind of aahh, aahh! (both laugh) But once you get over that it's...the...it's a little bit easier to learn and pick things up as you go along.

A: Do you feel that you're...that you're developing some sort of a system, or what?

M: Yes. They give you suggested ways of study, study methods and what not, and (pause...) (280) When I first started off, I was really excited about just getting right into the learning aspect of it, and all these study methods and what not where kind of like: Hey, let's get to the good stuff. But then after you get to the good stuff, and you start wading through it, you go back very quickly and look at the study methods and figure: Yes, got a good point there. 
A: You're talking mostly about study methods there, but, of course, the actual learning.... Do you feel that you're...you're... Do you feel that you are learning perhaps differently now from at the beginning of the course, or is that really the same?

M: (Pause...) No, I'd say it's about the same.

A: (290) (Pause...) Well, that actually takes care of my questions. Do you... do you have anything you'd like to add?

M: I think it'd be really good if they had informal study groups. I think that would be a great, a big bonus.

A: What do you mean by an informal study group?

M: Getting to or...being given a list of telephone numbers of people who are taking the same course that you're taking and be able to set up, you know, kind of like an informal study session. I guess getting back to the classroom aspect of it but a little bit more flexible.

A: You mentioned earlier that the lack of discussion is perhaps a problem.

M: Yeah.

A: This would get over that.

M: Yeah. I think that would help a lot.

A: (300) When you say informal group, do you mean only students, or perhaps with a tutor?

M: Either or. Either or. I...I don't...as...as far as, I think, being flexible or not, saying: 0.K., you know, Wednesday from 8 to 9 this is what we'll do. But have it 
more of a: Yes, this time is set aside for that. If you want to come, do it and join in, then join in. If you don't, well, you know, it's to help yourself if you're having problems with certain areas of it. And outside of that I...I think that's the one drawback to the distance education, outside of the time that you can find to do it.

A: So two drawbacks: lack of discussion and lack of time sometimes.

M: Yeah.

A: O.K. Well, thanks very much.

M: Oh, you're welcome.

A: It was great. 


\section{INTERVIEW \#13}

Interviewer: $\mathrm{A}$

Respondent: $\mathrm{N}$

Position on tape: (000)

A: So, maybe we could begin with your decision to take a distance education course. How did you come to that decision?

N: Mostly because I tried college before and when.... and dealing with the professor on the podium, and I just couldn't get into it. You have this classroom with 35 people. There were two people answering questions, I was one of them, and it got to the point where I was the students' aid. So, I was...the two of us in the class were the only ones that dealt with the teacher, and so when you get into a level like that, it's...it's personal; it's only me versus the teacher. And when you get to the personal, then you have the teacher's quirks and quarks, and the personal problems come up, and I just did not like the situation. And plus I found the college, the university level, I keep.... what I have found again is that really they're not teaching me anything new. (010) I've done this before. And what is the interest of doing it again and especially when I'm paying for it?

A: What were you studying at college?

N: I was doing basically almost the same course as I'm taking right now, because I dropped out of that. I just 
said, "I'm not...I'm not paying for this." The English, History, right now I'm taking a sociology, which I didn't take then, and I'm doing Geography. And even the Geography, which is a course I don't particularly care for, is not particularly difficult, and so you're just...you're sitting there going: $0 . \mathrm{K}$. I'd rather do it without the teacher.

A: So you're saying that you found it negative in college that there was this personal sort of relationship.

$\mathrm{N}$ : Well, because you sit in the classroom with 33 people who aren't saying a word, and the teacher, you know, can't be bothered to make them talk. So he looks at the two obvious prospects, and I happen to be unfortunate enough to be one of them. So, you know, given the choice I would rather be one of the 33 .

A: (020) You found it rather stressful to be one those two.

$\mathrm{N}$ : Yes, you're always the target. And just sort of then you get into being personal, then you get into the arguments, and then you get, sort of, ego conflicts. And just sort of... and just sort of, I didn't want to go to school and fight.

A: So, how did you actually know about distance ed. courses?

$\mathrm{N}$ : Actually from my sister-in-law. She mentioned something about it one day, and I sort of looked into it, and it seemed like a good idea.

A: That was here in.... 
$\mathrm{N}$ : She was in victoria (unclear).

A: Oh, I see.

$\mathrm{N}$ : I came over here to start my courses.

A: Why did you decide to move from victoria to here to do distance courses?

N: I was sick of the city, and I'd actually started the process over there, and I just...I'd gotten tired of my job and quit it and figured let's move to another city, and my little brother lived over here, so I had an automatic roommate, which makes things easier.

A: Sure, yeah.

$\mathrm{N}$ : So I'm over here now.

A: (030) You said you're doing two courses?

N: No. Four.

A: Oh, you're doing four!

N: English, History, Sociology and Geography.

A: Oh, wow! You are busy. So that.... Could you tell me exactly what they are? That's English....

N: English 101, Sociology (Pause...)

A: 100 something.

N: Yeah, the 100. They're all first level courses.

A: Yeah, and Geography 100 something. What was the fourth one?

$\mathrm{N}$ : History.

A: History. Gee, so this is full-time for you. Oh, well. You're an experienced person, even though you've only been doing it for a while. (laughingly) what did you 
expect it to be like, doing these courses by distance education?

N: (039) I expected it to be without the teacher's drive? And so, you...the self-reliance comes in, and you have to go and research yourself and find your own books and deal with the library yourself. You don't have the teacher saying: You can find these books in the library, and, you know, if you look on page 15 and get line 13, there's your quote for the essay you have to write and that sort of thing.

A: So you're saying this self-reliance, being forced into self-reliance is a positive thing?

$\mathrm{N}$ : Yeah.

A: Why is it positive?

$N$ : Because you don't...you don't have the teacher (unclear). You know, I always go back to the teacher; I hate teachers.

A: Ah-ha! (laughter)

$\mathrm{N}$ : You don't have the teacher telling you what you have to regurgitate back. And that's the one thing I find all their...found all the time is the teacher was the teacher was up on his podium, and he'd give his lectures, and you'd take your notes, and you'd underline the points that he would underline in his speeches, and basically the points that you were underlying were what he wanted to see in the essay, (050) and you could not do anything else but that if you wanted a decent mark. 
You could challenge the teacher at any time; you'd get your C+ or your $\mathrm{C}$.

A: So, are you saying that you're finding in distance education you're able to give your own points of...point of view, if you like, and that's acceptable?

$N$ : You don't have the direct contact with the prof, so you don't have the prof. sitting there saying: Well, I told you to say this. So and.... I've talked to one of my profs; I just don't feel any need to do anything else.

A: And when you talked to that tutor....

N: That was 'hello' at the start of the course.

A; That was it.

N: Yeah.

A: O.K. (laughingly) So you're learning several different things. How do you find that learning them by distance ed. is different from learning them in the classroom? You've already mentioned this teacher, self-reliance thing. Is there anything else that's different?

N: (060) You don't have to be.... The whole student part. You don't have all the things you get into, that whole socializing, and you sort of.... Actually I was talking to a prof. the other day about it from.... I guess he's out at UBC. And he teaches one of the computer courses, and he was saying that the whole thing about first, second year, pretty much the whole B.A. is a write-off. This is the learning process for the students to socialize, to get politically active, to learn about all 
these new things. So for the student who's going in to actually learn something, the B.A. isn't much help.

A: So, I think you said there, he figures that when a person does his first couple of years, he's learning to socialize, to become politically active and...?

N: To become more socially aware.

A: And you're saying that you don't want any part of that.

N: No, I would rather go on. Give me the books, and I'll find the other books I need, and I've learned something.

A: What... what have you learned then?

N: (070) So far? I've done grade 10, 11 and 12 over. And so far we haven't gotten into anything else. You know, you have a point you find in history that should have been mentioned back then but for some reason wasn't mentioned back then. You know, you get into the whole Louis Riel rebellion thing -- and in Grade 10, 11 and 12, and I jumped around to a lot of school systems, so I managed to get Canadian history three times -- they never mentioned, you know, a minor detail like, you know, McDonald paying off Riel, you know, to move...to go to the states.

A: So you feel that you're learning bits and pieces that were simply missed out before.

$\mathrm{N}$ : But effectively they're irrelevant anyways. So McDonald gave him 10 grand. Who cares? You know, if Riel had been smart, he would have stayed down there and slapped him for some more money. (laughs) He came back and got 
hung. That sort of deal. So really we're not.... I don't find in my first level courses anyways in the university that the... (080) What we've got is university courses without the university social structure, and I think that's a big problem there.

A: I think I missed something there. You said you don't find or you do find that they're university courses without the social structure?

N: No, they are the university courses, but without the university social structure. And so, you've got basically half of the university experience, and it's the half that really doesn't matter. Do you get me?

A: what...? No, I don't. The...you've got the half which doesn't matter?

$\mathrm{N}$ : Yeah, the learning, because they're not really teaching. They're just regurgitating what you've done before.

A: Oh, I see. So you're saying as far as the university is concerned, the most...the most important half is learning to socialize, etc.

$\mathrm{N}$ : (090) And become the proper adult human being, members of society.

A: Right. So from the university's...from the university's point of view, the actual learning, which is what you're doing, is the less important half.

N: Yeah.

A: Ah-ha. I understand you now. But you see it the other way around. 
$\mathrm{N}$ : Yeah, I would rather do the learning, which is why I did the open Learning. I figured that maybe with this you have the chance to do more, and you do have the chance. I mean, I...I'm being negative because...bad habit or something. But, uh, with.... You know, you have the chance to go beyond, but it's sort of the carrot and stick; there's no stick there and no reason to go after the carrot.

A: Right.

N: So, and sort of, that personal drive comes in as well.

A: Right, and you feel that you have personal drive.

N: Yeah.

A: Do you think that's very important for doing distance ed. courses?

N: Yeah, you have to want to do it.

A: And you really want to.

N: (100) Yeah, it's.... I'm at the point right now where I'm sitting and going: yes, no, yes, no, yes, no and just sort of looking at it and going: Well, I've done this three years ago; I can do it again. And you sit down, and you do it again and sort of.... You just have to get into it, get your heart behind it and that sort of thing.

A: Yeah, yeah. Of course these are just first level courses. Do you think that makes a difference?

$\mathrm{N}$ : Yeah, I think so. 
A; My original question there was: what do you see as the differences between doing these course by distance ed. or by regular education?

N: Well, effectively it's just the socialization, I think, is probably the biggest difference.

A: O.K., and what are the similarities between doing it this way or that way?

$\mathrm{N}$ : (Pause........) I suppose you've got the same books. You know, you've basically got the same course structure. (110) (Pause...) You've got greater access I think because, you know, from here I can go up to simon Fraser and use their library or UBC and use their library or downtown use the Main Library. So you've got.... You know, I realize you can do that if you're out at one of the universities as well. You've got more impetus to do it though.

A: Do you find that you are using the libraries?

$\mathrm{N}$ : Usually just the one downtown. I go out to UBC once in a while, not too often.

A: I asked previou.... little while ago, what were your expectations before you started? Related to that, what were your hopes and/or your fears before you started?

N: Well, my hope was that I'd find a challenge. And my fear was that I wouldn't. Because if there's no challenge, I tend to look at things and go: What's the point?

A: Right. 
N: (120) And sort of.... There's a bit of challenge that I'm doing it on my own, and I don't have the profs. sitting there saying: You have to tell me this. And so I have to figure out what I'm supposed to tell the prof, which is a neat little... You know, look at the question for your essay and figure out: Well, what's the prof's on it? Which you almost always have to do, whether you're looking at it or not, and try to figure out from the questions, which are usually very neutral, and figure out: What are the points that he wants, or that should be, you know, made? And go from there, I think that's the interesting part of it. And I've forgotten the question. (laughter)

A: The question was: What were your hopes and/or fears before starting? So I think I got lost there once again. I think.... You were talking about....

N: My only fear was the challenge.

A: $\quad 0 . K$. and then....

N: The hope that it would be there and the fear that it wouldn't be there.

A: Right. And when you talked there about the prof. wanting certain points which were his, you were talking about in the regular classroom?

N: (131) (agrees) But even the person marking the essay you've written around. I mean, it's not as direct, because I'm not get to meet this person. 
A: So now it's a guessing game. So now you're trying to quess what he would want.

N: Yeah, I would just look at the question, look at the...the situation that you're dealing with, and go from there. You know, what are the important points that you have to decide for yourself, without the direction... and plus with the course notes; you do have that direction.

A: So you say you have to decide the important points for yourself, but then there is help from the course notes. Do you...do you think that's a useful thing or...?

$\mathrm{N}$ : Oh, I find the course notes very useful.

A: And deciding for yourself, is that something that is positive or negative?

N: I think it's a good learning experience. I think, you know, it helps you to think on your own.

A: (140) O.K. So those were your hopes...your hope and your fear before you started. Now that you've been doing it for 2 and a half months, I guess? ( $N$ agrees) Now that you've been doing it for 2 and a half months, what has been your experience in terms of those things?

N: Not much challenge. Just sort of, you know, you do your work.... It's.... I don't really see it any different from when I was doing homework.

A: So you're finding that it's like doing homework when you were at school. In what way is it like homework? 
N: (Pause...) It's the drudgery. Yeah, sort of, it's not really all that exciting; it's not all that challenging. You go home, and you do your hour and a half or your 2 hours, and then you go out and do something you like. so it's tough to keep at the books.

A: So that challenge is...

$\mathrm{N}$ : It's not really there.

A: ...not really there. Do you think that's going to be a problem?

$\mathrm{N}$ : (150) I think probably it is. It's sort of dealing with it and telling yourself it's important and then trying to, you know, keep up the effort involved.

A: Right. OK. I have a little series of questions next. The first one is: What are you learning about these 4 subjects by doing them by distance education?

$\mathrm{N}$ : As opposed to? Well, I'm learning... //A: Just what are you learning?//...about structure.

A: The course structure.

$\mathrm{N}$ : What the courses are telling me.

A: Ah. When you say structure, you mean the content, what they actually say.

N: You know, most of them, except for the Geography, I'm actually learning something, which is... (160) I always stayed away from Geography in high school. (laughter) so it's.... Most of it's very new to me, and a lot of it's interesting because the courses interact a lot. So you've got that, but in terms of 
learning probably, you know, except the Geography, nothing that I haven't seen before.

A: When you say the courses interact a lot, can you explain that a bit?

$\mathrm{N}$ : Well, the Sociology is, you know, straightforward. You know, man's.... (Pause...) Ahh, failed the test, yes! (laughs) You know, man's interaction with his society, stuff like that. The Geography is human geography, so it's man's interaction with his environment and which is covered a little bit in Sociology. And the History is, you know, Canadian history, so you can look at a place like Red River and figure out why that settlement happened to stay there and succeed there for a little bit and become Manitoba. So you've got that.

A: (171) So you can make connections between the courses. $\mathrm{N}$ : Yeah.

A: And the second question here: What are you learning about yourself by doing these courses?

$\mathrm{N}$ : I'd say that I'm learning that I have a pretty good store of knowledge. You know, looking at these books and being able to say: Yes, I've done this before, and I've remembered it from before. (Pause....) I'd say that I'm learning professorship is definitely out for me. Further education beyond a B.A. and whatever else after that is really not my line, not right now. (Pause........) And I don't.... I'm finding that I don't like structures a whole lot. 
A: What do you mean by 'structures' here?

$\mathrm{N}$ : You're supposed to learn this, and all of this, all of this. I'd rather learn this and find something that catches my eye, go off on the tangents sort of thing.

A: And you find you can't do that in these courses.

N: Well, you can, but it's on your own time, and time is something nobody has enough of.

A: Right. You mentioned there that you have no intention of going beyond a B.A.

N: (190) Or.... Yeah, I might do a couple of courses and sort of grab something that catches my eye, but, you know, in terms of masters and doctorates and that sort of thing, I just can't see myself doing it.

A: Why is that?

$\mathrm{N}$ : Probably because I would.... I tend to rebel against systems? I just sort of: You have to do it this way. And I'd say: Oh, no. I'd rather cheat and get (unclear).

\section{A: A pragmatist! (laughs)}

$\mathrm{N}$ : Yeah. I've got nothing against learning. I love that. I love reading anything. And just, sort of, I'd rather learn that way than be told to read this book, this book, this book and you're going to miss this and this.

A: (199) So, in effect, you're saying that you love learning, but you want to be able to do it your way. You don't want someone to tell you: Learn this, this, this in this, this, this way. ( $\mathrm{N}$ agrees) And third 
question here: What are you learning about distance education by doing these 4 courses?

$\mathrm{N}$ : (Pause..........) I don't know that I've really given it much thought, sort of looked into the whole distance education thing. It seems to be a lot simpler; (unclear) very straightforward, but other than that, I really couldn't say.

A: When you say 'simpler' and 'straightforward', what do you mean by that?

$\mathrm{N}$ : Well, you get all of the books; you've got all of the notes. It's not a question of buying them, you know. (210) Having the notes with (unclear) is wonderful, the course notes, as opposed to going to class and doing your own notes and maybe missing something or missing a day somewhere so that you have a chance to set your own time schedule and work around it and with it.

A: OK. So, for you what are the most important things about doing these courses by distance education?

$\mathrm{N}$ : Well, the freedom. It gives me a chance to work as well.

A: So are you working at the same time?

N: Yeah.

A: Well, when you say 'freedom', can you expand on that a bit?

N: To set my own schedule, to know that I've got, you know, 5 hours on Monday before I go to work at 4:00 and, you know, back at 8:00 or 9:00 or 10:00, and then I've got a 
couple of hours, and I just... (220) You know, if I want to grab 2 hours on Monday, I can make it up on Tuesday or Wednesdays; you know, flexibility.

A: So the flexibility of this scheduling is what you mean by freedom.

N: Yeah.

A: And are there any other things that are important about distance education for you?

$\mathrm{N}$ : (Pause....) I think, you know, you can work at your own pace as well (pause...) and that pretty much covers it. Just, sort of, the flexibility and the pace.

A: And do those relate to each other?

$\mathrm{N}$ : Oh, yeah.

A: In what way?

N: (229) You can take 2 days off and go back. I mean, this week I've been sick, and my fiancee's in bed right now with bronchitis and just, sort of, not been a good week, haven't gotten a lot done, but I can make it up next week. You know, just sort of, it gives you that.... You're not always on edge going: Oh, my God, I've got to have that paper in on Friday; I'm going to be dead. Right?

A: Yeah. And from what you said before, I would gather that another very important thing is the lack of a teacher. //N: Yeah.// Does that in some way relate to this other kind of freedom that you mentioned? 
N: Sure. Yeah. You sort of.... You don't have the prof glaring down at you going: I'm deducting 15 points because you're a day late, sort of thing. And just, there's pressure that you know that you have to satisfy this person, and this person wants you to do this, this, and this. And whereas you've got the mailbox. (240) Shove it in the mailbox; it goes to some anonymous person; comes back with some notes written on it, and the notes are very straightforward and just, sort of, you know: You should have pointed out this or good, point out this.

A: So you said there it's an anonymous person and the comments...he makes comments. Do you find that's a satisfactory way to get feedback?

N: Yeah.

A: Why is it satisfactory?

N: Because he's dealing with the same anonymous piece of paper, and he doesn't have to look at you and say: oK, because you did this in my class the other day, sort of the revenge factor. And he's dealing with what's on the paper, he's not dealing with you personally.

A: And that's definitely an advantage, is it? The impersonality of it?

$\mathrm{N}:$ (250) Yeah.

A: OK. When you actually do your distance education studies, what do you actually do? 
N: Read my notes; read my texts; you know, go on to further reading if I need to for that particular assignment; then do my assignment.

A: straightforward, yeah. oK. If you were talking to another person like yourself, the same situation, what ...like yourself living in a place like this, had been to college but decided not to continue, with a job at the same time. What would you say to that person about doing courses by distance education?

$\mathrm{N}$ : (260) I'd say it's definitely a bonus. I mean, you have to have the education and that piece of paper if you're going to get anywhere, and it gives you the freedom because you've got the option of, you know, your 2 months or 6 months or your 4 months. And the structure is loose enough that it can fit in almost anywhere, so if you're inclined that way, you should do it.

A: You mentioned the words 'piece of paper'. Is that...is that how you see it?

$\mathrm{N}$ : Oh, yeah. I'm at the B.A., and there was a study a few years ago -- in Calgary, was it? -- where they took all of the doctorates or the upper level graduates and found that $45 \%$ of them were functionally illiterate.

A: They did? (laughs) 0o!

$\mathrm{N}:$ (270) Oh, yeah. You know, these were people in sciences and that sort of thing, but, I mean, you know: Great, your doctor can pull out your heart and that sort of 
thing, but he can't spell his name. You know, so what's he writing on his, you know, the prescription pad?

A: Ah! That explains why we can't read them. (laughter)

N: Yeah, and just, sort of, things like that are (unclear).

A: Uh-huh. Makes you think, doesn't it? And just one more question: How are you evolving as a learner by doing these courses?

N: (Pause....) I'd say I've had a lot of library practice before, so there's that, and you get to peruse the library, and you find books that you never discovered before and probably nobody would ever think of using this for reference. (280) So you're forced to look for yourself, and you're supposed to... and you're forced to find for yourself. So, which is all part of, you know, the learning process.

A: Right. The library seems to be an important institution for you.

N: Yeah.

A: Have you used libraries all your life, sort of?

N: Yeah. Grade 5, I think, sort of started as the library assistant, and just, sort of, never really left the library.

A: Are you still doing some work with them?

$\mathrm{N}$ : No. I only did, I think, a year of library assistant but stayed in the libraries after that.

A: Yeah, yeah. So you said there: Using libraries, searching for books yourself... //N: Yeah, and other 
material.// ...is.... You feel that's a learning process. (N agrees) Well, that actually takes care of my questions. Is there anything that you would like to add?

$\mathrm{N}$ : (Pause...) I'm not really.... I haven't given the whole process a lot of thought except for the doing. I'm just, sort of... You know, I look at the way I deal with my assignments and that sort of thing. But as to, you know, do the correspondence versus the classroom, I actually prefer the correspondence because you don't have the personal conflicts, and I tend to wind up in those (unclear). And (pause.....) you know, I think that's about it. I really haven't given it a lot of thought.

A: Well, that's interesting. Thanks very much. $\mathrm{N}$ : You're welcome. 


\section{INTERVIEW \#14}

Interviewer: A

Respondent: 0

Position on tape: (000)

A: O.K. So perhaps we could begin with your decision to...to do distance education. How did you come to that decision?

O: Well, I...I was a little undecided, what school and so on. I knew I wanted to get back and do...complete my Bachelor of Arts degree, but I...I guess it was just that it was more convenient, and it was attractive simply because I wouldn't have to attend classes. I didn't know what my schedule at work was going to be like and so on, so I...I guess that's what it was. It was very convenient for myself to be able to study at home.

A: Right. And how did you find out about distance education in the first place?

o: My...well, my husband-to-be actually. He was a student at Simon Fraser University, and he had taken a history class through the Open Learning Institute. (010) I don't know where he came across it, and on the PBS channel you see a lot of the Open Learning stuff, so that's more or less where I picked up on it. I thought, "Why don't I contact them?" So that's more or less where I've gotten it from. And he had, you know, he had a good time with it, and they seemed to be very accommodating for him, so... so I decided to go with that. 
A: What subject are you doing by the way?

$0:$ History 121.

A: History 121. And what did you expect that it would be like doing History by distance education before you actually started?

o: Oh, I didn't know what it would be like. History is the sort of course where it's much more interesting to have a professor speak to you and hear other people's views, and there's a lot of reading required, and sometimes what you pick up from a book is different than when somebody explains it to you or interprets it. (020) And you can only.... You know, there's so many facts and figures that it's hard to remember the dates and the places and what happened and so on, so it would have been nice to have somebody, to have the feedback from other students also, because you're always gonna pick up on something different because everybody finds things different so.... So I knew that it would be a bit boring and... and a lot of reading, but I didn't much mind. I thought it would be something that, because it is a lot of dates and times and places, that perhaps I'd have an easier time with that rather than statistics or something where that seems to be so much more complicated. History was something I knew I could understand on my own.

A: You say it's a lot of dates and that sort of thing. You're saying also that that's perhaps easier to learn by distance education or the same as in a classroom? 
O: Gee, I don't.... I'd taken a history course at okanagan College in Kelowna. (030) This was... it was a while back now, and I guess by...because I'm relying on the book so much more than having somebody tell me, I think it might be easier to learn it on my own, rather than having somebody regurgitate something out of a book, and you're sort of sleepily sitting in a class sometimes, so maybe.... I don't know whether...I can't remember whether it's easier or not, but I think that for me it is easier. And... and also because I can always go back for a reference.

A: Sure, right. But on the other hand, you've said that it's nice to be able to talk to other people. So, why is that nice?

o: I think that's nice in the sense that sometimes when you...you can relate something so much better when you think: Oh, even if I can't remember the student's name or whosever has said it, you can sometimes relate something to a person or something that's happened, and if you have a discussion about it, you're more likely to remember something whereas at home I just don't discuss it with anyone. (040) I think the discussion is what probably makes you remember something much better.

A: So that's...for you that's the main importance of a discussion.

$0:$ Yes, exactly. 
A: O.K. How is.... You've already told me some of this, but perhaps you can expand on it. How is learning history by distance education different from learning it in the classroom?

o: How is it different? (Pause....) I guess it's different in the sense that it's all up to me. It's...it's harder than having somebody in a classroom say, "We're going to learn... we're going to study the Red River settlement. So we may have an exam on this; perhaps you might study this a little bit more, with more depth than something else." Whereas at home it's difficult because you feel you have to learn everything, (050) which I suppose in a sense you should learn everything, but sometimes it's just not possible to retain it all. So I find that difficult.

A: So you're saying that when you're in a classroom situation, the teacher focuses on certain things, and therefore, it limits in a sense what you really have to study.

O: I think it does. I mean, not in all cases. I mean, sometimes you've gone into an exam, and you think: oh, I didn't study this, and I can't believe it's on the exam. But I think you sometimes have a... if... if you can at all read the professor or the instructor, you can sometimes pick up on what is likely to be on an exam versus having everything on the exam. I mean there's always that...that element of surprise where you can go in and 
all of a sudden something's not there, but.... So that's in... in a classroom it's...I think it's much nicer, and you can maybe go more in depth with one subject or one part of what you're learning more than...than at home now where I think I have to learn most everything. (061) And I've never written an exam with the open Learning Institute, so I don't know what to expect from them.

A: So exams are sort of a worry?

0 : For me they are. I sort of.... I more or less feel confident about myself on a day-to-day basis, but all of a sudden, when I'm forced to write something for three hours, I...I tend to get a little bit nervous.

A: I think most people do. (laughs)

0 : And I think that that's the hard part. It's because I do get nervous. If I could just remain calm and... and so on, it would come to me much better.

A: Right.

o: So yeah, exams do make me nervous.

A: Yeah, and it sounds to me as if the exam is always at the back of your mind as well?

o: I think it is. It...I guess if you're taking something for interest, it probably might not be. (070) I guess you don't have to worry whether you get a pass or a fail and so on, but you know, this is why I'm handing in these ten assignments and trying to do as best as I can. I think probably, too, because I've got a long-term goal in mind. If I didn't, then it might not be so bad, but I'm trying 
to hand in these assignments and do as best I can, not only for personal achievement, or personal goal, but also to make it easier when I go to write the exam.

A: Yeah, sure. You mentioned there that you're not doing it just for interest. So, why are you doing it?

0: Actually I would... I would like to become an elementary school teacher. Yeah, so that's why I would like to complete my Bachelor of Arts and... At which time maybe I, you know, will not choose to go on with it, or I'd like to have kids of my own one day, so who knows what will happen between now and then, but this is sort of what I'm wanting to do it's... is to put it toward an education.

A: (080) And you also mentioned long-term goals. Is that what you mean?

0 : Yeah. So...so $I$, you know, it's just.... I...I'm in the business field right now, and I just.... It's not that I don't like it; it's given me a very good living, and I've learnt a lot by $i t$, and I was in the CGA program, and...

A: What's that?

o: It's Certified General Accountant, and it's also by correspondence, a lot of it, so... But I just don't find number crunching very satisfying, and it doesn't allow you to be creative, or sometimes your personality's a little stifled and so on. And I've worked in a very good environment as far as that's concerned, but I just found business wasn't me, so I thought, "What do I really 
want to do? And even if I can't do it right now, you know, this is long term, and that's what I would like to do."

A: So you said that you have in fact done correspondence courses before?

0 : Yes, I have. Not through the open Learning, through the Certified General Accountants Program.

A: (090) So those were all accounting types of courses.

0 : Yes, they were.

A: How many of those did you do?

0 : Oh, I must have done eight of them.

A: Oh, really.

o: Yeah, it was a lot. I took them over a course of three years, and it was full-time study; it just went all year round. So that was difficult, although I found accounting... if you took Accounting 101, you know, 202 that sort of thing, and it seemed to come very easy to me. So it really wasn't all that hard. It's when I was starting the fourth level and taking tax courses, tax law, it really started to get difficult. (laughter) And when they say they give you four attempts, you need them sometimes.

A: Is that right. So you actually went right through and got a certificate.

0 : Not yet. Actually there's two more levels.

A: Oh, you're still at it? 
O: Yeah, but I've actually.... I've discontinued that. You have a ten year limit or something, but I just don't.... (100) I thought it would be nice to have that certificate behind me, and it could always become of good use, and maybe in time I will do it, but it just didn't interest me anymore, and it was becoming a struggle to open those books up. Not just from time limitations but just because I didn't have any interest in it anymore. So...so I thought: No, no more. Why... why put your efforts towards something you don't want to do.

A: Yeah, right. Yeah.

0 : I guess things change.

A: Yeah, oh, of course they do. What I originally asked you there was: what... what do you find is the difference between learning history by distance education or in the classroom. The opposite question: What do you find is the same about learning the two ways?

0: The same.... (pause....) I like.... (110) I don't know. I find that to be a difficult question. I guess you're...you'd be learning the same...the same history. (Pause....) I guess the same would be all the reading; you have to do the reading in order to know what's happening. Other than that I don't know whether there would be any similarities. I...I find the classroom environment to be totally different than studying at home. It's a little more structured and... which is nice.

A: Which is more structured? 
0 : Learning in a classroom. You have to be, I mean, when you've got so many students listening to you, but....

A: What do you mean by structured then?

0 : Well, the structure of your going from say seven till ten o'clock. You go once a week for how many weeks. So you've got certain material that you have to cover.

$A$ : (120) so you're talking about the scheduling and the amount covered.

0 : Yeah, and... But I don't know that there would be anything the same. Or not that I can think of or something that pops into my mind. I don't know.

A: Yeah, O.K., sure. I already asked you: what did you expect it to be like before you started? Related to that: What hopes and/or fears did you have before you started doing this History?

0 : The fears I had, which I am experiencing now, is that you tend to put off your studying: "Oh, I'll do it tomorrow. Oh, I'll do it the next day." And I always use sunday as my deadline. I have to have an assignment done by that time. So inevitably I leave it to the last possible moment. My hopes were that I would not do that, (130) that I would perhaps put myself into more of a routine, and not make it a strict routine, and I hoped that I would enjoy doing that. And the times that $I$ do spend on my studying I do enjoy. But my fears have materialized. (laughter) And... and that was my fear is that I would leave it and I...I wouldn't find the time that I should. 
And that I wouldn't enjoy it as much that way, and which you don't when you have to do something in a hurry, I don't get the enjoyment out of it. So that's, I guess those were my hopes and fears.

A: So in other words, what you're telling me about there is about the actual doing of it. Your hopes and your fears were related to your scheduling of your studying and so on.

O: Yeah. Although... and I hope I...I would learn and retain more facts. (140) I guess when you're younger, sometimes taking something like history would be extremely boring 'cause you don't care about what happened. But now I've found that I am enjoying history, and it's...it's a Canadian history course, so it's not near as exciting as what, say, U.S. history or European, but...it's...it's kind of neat in the sense that now I can understand what happened, why things are the way they are, the why...you know, why are native Indians are doing what they're doing now. And so those are my hopes that have been realized is that I.... It's meant something to me as a person now whereas when I was in high school, it was something that I more or less took because we had to take it. So I really have enjoyed it in that sense. I mean I'll even say to my boyfriend ..., I'll say, "Did you realize that Louis Riel was this, this, and this?" (150) And he'll say, "No." But I'm...I'm retaining the facts much more better now, so...so I do enjoy it that way. 
A: It sounds to me as if you're saying that you...you're remembering things better because they have some meaning to you now.

0 : Exactly. And I don't know what that meaning really is to me, but it does mean something to me. Perhaps now because I read the newspaper, I know what's going on in the world whereas... and I think that's an important part that students.... Students sometimes get busy in our own studies, and I think that we should take time out to read a newspaper and to relate in some remote way what we're learning to how the world is reacting to these things today because I don't think that things change all that much. I mean we're still fighting the same old battles that we were a long, long time ago.

A: (160) so you see it as important that what you're reading about in your studies relates to the real world.

o: Yeah, or I find that that's...that's how I learn it.

A: So you make that relationship.

o: I think I make that relationship, yeah. Nobody's ever told me to do that. But that's how I...how it makes it more important for me. So as far as that... You know, that's been something that...that's come out of the history class that I didn't really know it would, but...so I've enjoyed it in that way. Yeah, and as for my fears, I didn't really have any. I did...other than, like I said, just putting everything off till the last minute and not... and then not... And what's.... 
Looking for the word where you -- not routine but -- to discipline. (170) I'm... I'm not a very disciplined person, and that's what I.... What I thought might have happened has happened. So with my extra four months now I thought, "Better make the best of it and don't do this anymore."

A: When you say 'disciplined', what do you mean by that?

o: Disciplined in the sense that instead of doing it all, cramming all in one or two days, read it over the course, you know, through the rest of the week and sitting and taking the time to, say, take my cup of tea, go to my desk, sit down and do it rather than leaving it all at the last minute. It's much more enjoyable that way, less stressful, so...so I guess I just wish I was disciplined enough to make sure I had that time every...say, two hours every night, which isn't an unobtainable goal. It's...that's what I should do. I'm sure you can relate that as a student sometimes too. (laughter)

A: (181) Yes. So before you started those were your hopes, your fears, and your expectations. Now that you've been in it for some time, how are you finding it?

o: I'm finding it...I'm finding it a lot of work. But I think that's something that.... It's pressure I've put on myself? I think by doing it more frequently than once a week, it wouldn't be that hard, and it wouldn't be difficult or time consuming. So it's...it.... I guess, too -- and always in the back of my mind when I get home 
from work, no matter whether it's at five o'clock or whether it's at nine o'clock -- I've always got in the back of my mind that I have to work on my studies. (191) I love to do my crafts and have hobbies and so on, and... and I find that sometimes I'll pull those out and I can't enjoy doing them because I know I should be studying.

A: It sounds as if you're talking about guilt. (laughter)

o: Yeah. Oh, yeah. That's...that's the word I'm looking for. Yeah, you've always got the guilt, which is good because, I mean, I'm not going to achieve a goal if I don't work at it. So I just.... So I think what's happened now is this course is sort of putting a few things in perspective. When I go to work each day, I find I'm not enjoying it as.... I enjoy the people, but I don't enjoy the work as much. So by coming home, and when I do open my book, it's nice because I think, "Yes, this is.... I'm working towards my goal. Why don't you sit down and do it?" But it's sometimes difficult to do that.

A: (201) Right. So that seems to be really important to you that there is this ultimate goal. It's all leading to that.

$0:$ Yeah, exactly.

A: And that helps you to keep going.

$0:$ It does help me to keep going actually, so... 
A: O.K. I have a little series of questions now. First of all: What are you.... What are you learning about history by doing this course?

o: You mean the course context, or...?

A: Well, whatever you feel you're learning about Canadian history.

o: What am I learning about Canadian history? (pause.......) I'm learning that it's...it's not very exciting. (210) (laughter) (pause....) you mean, like learning as in retaining the dates, what actually happened in history or...?

A: What do you consider learning to be?

O: Well, I...I'm learning that...that Can... (unclear) I never even thought about what I'm learning from it. I'm learning how our country was born, what happened in the old days. I've learnt how big Canada actually is. We don't have very many people, but we're a big country, and I...I've learnt actually a lot of how we have progressed as a country. (220) So I guess...I guess...I...that if I had to sum it all up, I guess that's what it would be is that I'm learning that Canada, even though we're young, we are a big country with little popul.... I'd kind of like it to stay that way. But, yeah.

A: You said that it's not exciting. Why is that? What would you consider exciting?

0 : Well, I guess I don't know. We never really had any civil uprising or, say, what happened in the Southern 
states, where the.... I mean, we never really had a slave trade or market or anything like that, so this far.... I mean, I found that when I watched, say, "Roots" on the television for example. (230) I was a lot younger then, but I do reme... It just stood out in my mind, and I just couldn't believe how anything like that could have ever happened. And I found that Canada is sort of a relatively peaceful country. We... and we've had our problems. I think that problems that they were having in the early $1800^{\prime}$ s were with the Indians, native Indians, the white men coming in. We had a lot of...or they had.... With the Hudson Bay trading company they had had some people from the U.S. come in. They seemed to stir up a few problems, and I've learnt that if other people would have butt out, Canada could have maybe remained somewhat peaceful. But (pause.........) Trying to think of too many things all at one time. No, guess I don't have any more comments than that.

A: The next question in this little series: What are you learning about yourself by doing this course?

$0:$ Well, I'm learning that I'm not.... I'm not a disciplined person, that I do enjoy learning. I found that I don't...I don't expand my mind; I don't do things to work myself, and with this course -- I've only taken one other history course before -- (250) found that I...I'd like... I enjoy reading and $I$ don't do enough reading. So I think that could be what I've found about myself is 
that I should sometimes maybe relax a little bit more often with a book and not necessarily some science fiction novel or some romance novel, but that I do enjoy reading something that...that was important to our country, is an important issue, be it political or what not. So...so I have... I have enjoyed that, and I have learnt that that's what I...that I should make more time for that. And not being even a course.

A: I think you're trying to tell me there that you find it stimulating in a way that reading a romance novel isn't. o: (260) No, exactly. That's right.

A: And you feel that you should perhaps do more of that type of reading.

0 : Yeah, I think I should do more of that reading. And it surprised me. I...I'm one that will watch the news and just be aghast at sometimes what goes on, and that maybe by reading and learning a little bit more about an issue, that maybe I can do something about it, and that's where I had sort of...it was a New Year's resolution almost, that I'm going to read a few more books each year that will stimulate me and will, you know, expand my horizons whereas a romance novel just doesn't do that.

A: You used the term there 'do something about it'. Is that... is that something that you...that is important to you?

o: (271) Well, I think it is. Even though I'm a... I sit, and I can be frustrated by what I see on the news, and 
it's fine for me to say, "Well how can they do that to someone?" Or, you know, "Why are things like this?" And I can...I get very frustrated by it all. But all the frustration in the world, sitting in my living-room is not going to change or help somebody out in their time of need, and I think it is important to me to know that I am doing something towards a cause. Like I'll "Walk for Peace" when they have it here. What is it? We have a lot of derelicts and homeless people that go up and down the alleys. (280) They collect a lot of bottles, and people around here are quite good; they know that these people need them. And I don't know what they use the money for, and quite often it's some things that we wouldn't want them to use it for, but that's sort of their living. So we put them on the side. If I have left over food, I'll put it in a containers for them out there. And even though that's something small, it was something that I realized when I watched a portion of a news one time; it's important to these people to have this. And it's nothing for me to put something not in the garbage but on the side.

A: Sure.

o: Just like recycling. Recycling's something that's made everyone much more aware, and that's important to me is that I can feel that I'm contributing and doing something towards a good cause. 
A: (290) Third question in this little series: What are you learning about distance education by doing this history course?

0 : I'm learning that distance education.... Sometimes people think that a correspondence course, distance education, would be easy. I mean how can it possibly be hard if you have the books in front of you, they send the assignments to you, you send them back to them? I mean, it must be a snap. And I'm finding that distance education isn't a snap. And that...that was the one thing that struck me odd was that many people, I think, have a.... (300) They think, "Oh, you mean, you got your degree through correspondence, or through distance education." Well, to me it's just as much work if not more to do that.

A: You've done quite a number of previous courses which were in accounting. Could you make a comparison between those and this history course?

$0:$ No. The History class, or the History course, even though it's not...they're not looking for my opinion, sometimes you have to form an opinion. One of my books is women's history, which I'd never come across before. So in a way they are looking for your opinion on what happened in a certain situation or a piece of history. Whereas my accounting courses, it was you either got the formulas right or you didn't, or you thought Mr. Jones would make a profit this year and he didn't. And it's 
usually a numerical error whereas on history it could be that.... I mean, it's not numerical. You could have understood something wrong, or you missed...your opinion got in the way of actually what happened and how to interpret the facts. But I find it...that's how it's different is the accounting seemed to be so much more cut and dried whereas this isn't. You know and a lot of the time your opinion's involved, and it's an essay format where a lot of the accounting wasn't.

A: (320) Right. And a little while ago you said that you were finding that distance education is certainly not an easy way; it's harder perhaps.

0 : Oh, I find for me it seems to be harder.

A: And is that also compared to the accounting courses?

0 : I think it is. It could be that I haven't had to write essays for a long time. What I should have done, before I took a course like this, was taken an English course again just as a refresher. And I think we all need to do that every now and then. With my accounting you had to write business letters and so on and.... But it didn't.... Your grammar and so on didn't seem to be as important as, say, in this course because it's an essay format. (330) So that might be why, another reason why I find them a little bit more difficult was it's just not learning the history itself. There's a few other elements involved, so.... 
A: Right. And you also mentioned that you...you're expected to bring in your own opinions, or at any rate, you do. How do you find that?

$0:$ I like it actually. I'm a person that if I feel I don't know the complete story or the whole issue, if I've only heard a portion of it, sure I have my own little opinion, but I don't feel that I could perhaps discuss it with you, say if you have an opposing opinion, basically because I'm not confident about whether I know everything that's happening, and so quite often I'll stand back and be a listener because $I^{\prime} m$ not...I'm not sure on what's...what's all happening. (343) so in this course, if I... when they want your opinion, I find I go back and I might reread a bit more because I think, "Oh, O.K. I might not have picked up on everything, and they're asking me to compare, say, the women's history or how a woman may have dealt with it rather than how the man dealt with it." So...so I find I have to go back and reread it a lot. So it's...it's interesting; I'm glad that I'm being forced to do that.

A: So they're forcing you to make your own interpretations as well.

0 : Yes, exactly, exactly.

A: Sounds interesting.

$0:$ It is interesting actually. I really recommend someone to take it. And it's just a very basic history course. I mean, it's what we actually probably learned, or bits 
and pieces of it, we did learn as a child. But this just is sort of expanding on it a bit more.

A: (355) When you actually do your distance education, when you sit down to it, what do you do?

O: What do I do? I...I read a lot. They...they give you the required reading, and you...I always try to do that. But I also try to read a little bit more. I highlight what I feel I should go back and perhaps have to study later on. So I basically sit at my desk and read. I'm not a real note taker. I.... Maybe when I finally get to this exam, I'll know whether I should have taken more notes or by, you know, just simply reading the material is... is enough, but.... So I just put myself away for a little while and cram.

A: (367) (laughter) That's the word, is it?

0 : Yeah, that's the word.

A: Yeah. For you what are the most important things about distance education?

O: The convenience. I... That would have to be the whole about it for me is that it was convenient.

A: And when you say convenient you mean.... you told me before, you don't have to go to a class.

0 : Yeah, you don't have to be anywhere at a certain time, a place. You...you can sort of set your own hours. Also you have a little bit more time. You don't have necessarily a September to December time-frame. With this one I've found since then that I've gotten a longer 
extension, so it allowed me more freedom to work with my own life and routine and also squeeze in some learning time. So it was...it just made it much more convenient.

A: (382) Right. Just I've been jotting down what seem to me some of the key words that you've used. I'm just trying to pick them out here, and well, let me ask you: Do you see any particular relationship between these things that you've mentioned? Convenience, and you mentioned several things that make it convenient. You find it somewhat harder than in a classroom, I think, and you mentioned that you had fears about just being able to get it done. And you also mentioned that it seems to mean more to you than history did previously. Is there a relationship between those things?

o: There...there probably is in a... in a few of the key points. Being -- I'm only 27 years old -- but being a mature student versus going to a classroom where it's filled with 18 or 19 year olds, I think that the convenience was combined with the security of being able to be at home to do it. $(400)$ so perhaps the convenient part is a way of... of sort of hiding some of my fears, and then I can do it at home; nobody sees me; I don't have to keep up with anybody else. What else?

A: Convenience, it's harder doing it by yourself, you feared that you might not be able to get yourself to actually do it, and you're finding that it means something to you, it relates. 
0 : Yeah, well, I guess probably the meaning part is that I have more time. Or I'm more on my own to work on it. I'm not having somebody in a classroom more or less telling me what I'm supposed to do. So I suppose that's why it might mean a little bit more to me at the same time. I might not do it as much as I necessarily should, so... whereas in the classroom you would have somebody telling you: Assignment 2 is due next week. (416) So, even though it's convenient, you have to make that convenience work for you, and.... So I suppose in a way they all are related if I.... If some psychologist would take a look at all this (laughter), he would probably find...he or she would probably find that they are somewhat related.

A: Right. And I have just one...oh, no, two more questions. First one: If you were talking to another person whose life situation was very similar to yours -- the same type of job, the same hours of work, with a boyfriend, living in a place like this -- what would you advise that person about doing History by distance education?

$0:(428)$ I would advise them to make...to try to make time to do it, not only to complete your assignments, but so that they can enjoy it more and get more out of the course. You know, set it up like a classroom atmosphere. Make it...make it... Have a certain area. Like I now.... I have just moved here in December. That was another reason why I've been taking so long with this. 
But now I have my own little area. That's my school and my work area. So I think that they should try to have an area where they're comfortable in, the lighting is right, somewhere where they can familiarize themselves with learning." (440) Like, this is their area to open up their books, you know, to just concentrate for a couple of hours, no T.V., no nothing on, and let the whole world go away for a while. And they'll feel so much better after they've let themselves have that couple of hours because they know that they've gotten something done. And I think that that's a whole important thing is to sort of make it a learning atmosphere for yourself. And I know that now I enjoy it so much more because I've done that. I've got an area of my own. It's just...it's just easier on yourself. Rather than saying, "O.K. Gee, they've given me two weeks to do this." Don't leave it to the last two days, and really (unclear) distance education people do to make time for it and to structure it sort of similar to a classroom. But it's just yourself.

A: (455) Right. And do you think learning history by this method, distance education, is good, bad? What would you advise a person about that?

o: I think it's good. But I also advise them to...to encourage someone to maybe take the course with them or have somebody that may be knowledgeable about history, almost a person that you could speak with, sort of talk 
back and forth about the facts, the times, the dates and what happened and why they happened. It's... and I'm trying to do that now with somebody that I've since found that's interested in history. It's sort of a hobby of theirs. And it makes it a little bit easier, even if all I do is sit and listen to them because they know so much more about my...about history than myself. But I recommend to have, sort of have somebody that you can...you can have contact with and discuss what you are learning.

A: And again, why do you think that helps?

o: Why do I think that helps? Why do I think that helps? Well, I think it helps that you can perhaps relate back to a conversation if you have to remember the sequence of something. You can think: Gee, no, I remember when so and so corrected me because I didn't, you know, I didn't have so and so's argument in the right order. (480) I find that's easier for myself to...to relate back to something that's happened at a point in time. But I just think it's easier because maybe you've got somebody, or you're being forced sometimes to...to have to tell them what you've...or not tell them what you've learned but discuss something.

A: O.K., and last question: How are you evolving as a learner through doing History by distance education?

0 : How am I evolving as a learner? Perhaps I'm trying... I'm learning more? Maybe not more, but I'm...I'm learning to 
be more independent and to have to pick and choose -- not what I want to learn; you have to learn it all -- but perhaps...perhaps just to be more independent about it and not to rely on other people, be it their notes or what they thought they'd learnt. You know, I might.... Because I'm not necessarily a confident person about history, I might think, "Oh! Gee, you seem to be doing so much better than me, perhaps I should learn or read what you're reading." And as a learner I guess now I have to rely on my own self. So it's teaching me to sort of.... Well, I get.... I don't think it's learning more but be more complete about my learning? To.... Yeah, I guess that's what it would be, to be more complete.

A: When you say 'learning more', what do you mean by that?

0 : More in the sense that perhaps I won't skip a chapter for time purposes. Now I (pause..) I don't know, I guess before it used to be time that seemed to be the element, whereas now time isn't necessarily the element. (515) I find now it's more important for me to not only get my assignment in but to do well. And if I haven't done well on something, I now appreciate what somebody, when they critique my work, what they have to say about it? And I'll perhaps go back and relearn what I might not have learnt properly the first time, and I think it's important that these courses in particular, because you really rely on your tutor's feedback, and my first assignment wasn't totally off-base, but it wasn't exactly 
what they had wanted. And now I've... By having their remarks, it...I've gone back and learnt a more complete part of history because I've...I've...it's important to me now to learn it all rather than bits and pieces. And a lot of the time, well, maybe with my accounting I learnt it for the moment just, just to pass the exam and go to the next level? Whereas now I want to learn it because I want to learn it, not because I just want to complete the course and go on to another one. So I don't know whether it's distance education or just maturity.

A: (540) You mentioned two things there. I'm not sure if you meant them as the same thing. You said you're...you're learning in a more complete way and because you want to. You also said that it's important to you now to do well, and the im...the implication being that before, in previous studies, it didn't matter so much?

o: No, it didn't...it didn't matter as much. I don't know why. I just... Now it's more important to do well on something than.... And maybe the doing well has to do something with...with the complete part. In order to learn something completely I think you have to do well, or.... Yeah, you would, you'd have to...to do fairly well on your assignment in order to have learnt it completely, and maybe that's why I...I've changed in the sense: before I just...just wanted to get it done. And I always.... of course, you always want to get the best 
mark you possibly can, but it didn't seem to be as important. A 'pass' seemed to be more important than an 'A'; that sort of thing. (561) And I find it much more fulfilling now, and I guess I just wasn't ready for it before. I think I was doing it because I...I felt I should be doing it? And that could be the difference. I'm much more relaxed now about learning.

A: So you're saying that you're not doing it because you feel you should, you're doing it because you want to. And are you telling me that that is a very significant thing?

O: Oh, I think that it makes all the difference in the world. And that was why.... When I...I mean I went in to the Open Learning Institute, registered for the course, and I was ready to do that whereas -- which is why I'm wanting to become a teacher now. It's: I'm ready, I've taken a look at what my personality was like, my expectations of what I wanted in my life, and it's far different than when I was eighteen years old, not forced to make a decision, but I think that it's hard on kids, and I've just had a brother go through that. (582) He's 19 years old, and he thought he should go right out of high school to university, and he didn't know what he wanted to take. And I said, "Well, maybe take a little bit of time off, not a lot of time, because it can get away from us, which has happened to me. I think, "Oh, you know, you could have had so many more years enjoying 
your career doing what you wanted." But then again some... I don't know when it happened to me, but in those years, a lot of them, I didn't know what I wanted to do. So now my personality is that: No, I want to become a teacher; I want to help people learn; I want to learn myself, be a little bit more creative instead of punching numbers. And I find the business world's very competitive, and that's not me. And I don't want to be like that, so that's why I was ready to go in, take a history course, take an English course, a psychology course versus an economics and accounting. And it was... I was ready to do that. And I think it's important; people shouldn't do things because they feel they should, but they should do it when they're ready to, and it makes learning so much easier. And which could be why I'm enjoying this course.

A: (607) Sure. Yeah.

0 : And I'm sure of it actually. It gives you a little bit more confidence when you know you want to do something.

A: Yeah. Sure. You also mentioned there something about your tutor. Have you had much contact with your tutor?

0 : Just by correspondence, and he... and he wanted to know about.... It struck me odd when you first enrolled for the course. He sends you a questionnaire about what do you like to do, your hobbies, and so on and so forth, and till this time I still don't know why he wanted to know that other than, I guess, just for his own satisfaction. 
And...but...no, I don't...but other than he does let you know that if you require any extra help or would like to speak with him, he gives you the stated times to call in between or that are most convenient for him, but also that if you want help at any time, he'll drop by or.... So they are very accessible, which is nice to know 'cause sometimes even though you know they're there and that's part of the Open Learning Institute's.... I guess they have to have a tutor, and they have to have somebody do that rather than send it directly to them to be marked, but... but they are there.

A: (634) Well, that takes care of my questions. Is there anything you'd like to add?

o: No, I don't think there is. I hope that you do well with your thesis and.... I guess it must be hard because I'm not a very good.... I don't answer questions well.

A: Oh, no! I mean on....

o: I sometimes stray a lot.

A: But that's exactly what I want because, as you can see, I only had about half a dozen questions, and I'm hoping that people will, you know, start talking and talk about whatever is significant to them.

o: Oh, good. O.K.

A: So that's the whole purpose of it, to get you talking about what's relevant to you. (END OF TAPE) 


\section{INTERVIEW \#15}

Interviewer: A

Respondent: $P$

Position on tape: (000)

A: So, once again how...how did you come to your decision to enrol in distance education?

P: O.K. It was first because I plan to go back to university, and since I cannot hand my...my finest work in French, I decided I will upgrade my English. And I wanted to continue to work until I would go to university, so that was the best compromise I could find. So that's the only main reason why... and... and I didn't know it was offered, but a friend of mine brought me all the information, and then I just phoned, and I find it was really quick and easy.

A: Yeah. Oh, good. So you're saying that mainly because you want to work at the same time it's...

P: Yeah.

A: ...useful.

P: (010) Yeah, because I could have take some...like night course probably at a... at a.... But you don't feel sometimes to go to a class after work -- run again, take the bus, go to the class -- after you've been working all day, so you can just come home, have supper and -quietly -- and then go do your course.

A: Yeah, sure. What kind of work are you doing? 
P: I'm working two works (laughs). One is as a homemaker, and the other one is in a daycare, and I...like also I have to transfer job, take the bus during the day, transfer from one job to another, so it's too...too much travelling.

A: Yeah. That sounds like tiring work as well. It makes you tired?

P: I have to keep balancing with my emotion basically. It's not tiring physically. Homemaker with the elderly people sometimes you have not to get too much pity for them (laughs). And then children, you know, you have to be firm. (laughs)

A: (020) Oh, you've got the two ends. Right, yeah. By the way which subject are you studying?

P: Just.... It's called English 013.

A: English?

P: 013 ?

A: Oh, yeah.

P: It's called "Studying English". That's the name. I think it's considered as a... around grade 12 English.

A: Yeah, yeah. Right. O.K. And what did you expect it would be like doing English by distance education before you actually started it?

P: Oh, I had...I think I had no idea (laughs). I...I went to a...to kind of a English proficiency test to measure my level, and I knew I would have... I would have had to 
go through some grammar, and...but I had no idea how it was put. Now.... Should I talk about how I find it now?

A: Yeah. Sure, sure.

P: (030) Oh, it's just like.... I...I like it's really clear, formal. But I found out that.... I don't know; I think the texts are a little bit boring. (laughter)

$A$ : Oh, in what way?

P: Well, I don't.... There was one text called "Ticket Please" and another called "Elizabeth and Peter". I would have liked something like more (pause...) modern, talking about subject of today, of actuality. That's my own taste. Someone can like those kind of texts, but I like more (unclear). That's what I.... That's the level I try...I try to go to, like to be able to express more thoughts, feelings, but I quess this is a good beginning. (laughs) It's just that I was surprised. I had to...to go to...like to have those kind of texts.

A: (041) Are you saying that they're sort of made up stories and a bit childish?

P: Yeah, yeah, yeah. Childish. (laughs) I would have liked something more in the subject of actualities.

A: For example?

P: I don't know. Texts about what's going on in Vancouver. Like I don't really understand.... I'm new, and I don't understand like...like the political scene, or things.... Like at the same times I would have learned English, then I would have been informed of some of the things that are 
in B.C., happening. Like I wish.... Sometimes buy the paper...like I don't buy the paper, so maybe that would have been a good thing for me. Like I can imagine someone coming like from Hong Kong taking that course; he would like to know a bit more about vancouver city and....

A: Yeah, right. So, you said that before you actually started, you simply didn't know what to expect?

P: (051) No, like I didn't know what form it would...it would have, to be. I...I wanted it to be clear. It's clear enough, that's.... I'm pleased with that.

A: Clear in what way?

P: Clear, like you go slowly like and... and from.... It's gradual; like when...the way they put the question, and they give you enough exercise, and you come to it....

A: Oh, I see. And, so you're saying now that you've been doing it for some time, you find it is clear, but the content, what they're talking about, is not especially interesting.

P: Well, it could be improved. It could improve. (laughs)

A: $0 . K$.

P: It's not bad, but it could.... I think there could be some improvement.

A: Yeah. And what about the process of doing it this way?

P: As a correspondence course?

A: Yeah. 
P: (060) Yeah, 0.K. Like this was one of my.... Like the thing that I don't like about it: it's really hard on your own to get motivated. And sometimes I would like my tutor to call me and remind me where I am. (laughter) I just sent the first unit, and it's.... Like I have eight months she told me, and I have six units, and I just sent the first one, and it's like two months that I'm on it, and I don't know if I will meet the deadline unless they take another...like they...they gave me another deadline, (laughs) I don't know, at the end if $I^{\prime} m$ running out of time, but.... Like sometimes I would just wish.... It's hard for me to keep track, you know. I'm just doing it day by day; I try. But sometimes I...I just give up for a little while. I have my own personal life. And then I wish she can just phone and say like: "0.K., like maybe you should be doing your second unit and finish it by this time. (070) This would be all right." Then it's sort of giving me a... an idea where I am in time. Maybe I should do it myself like that. I wish she can be a little bit more encouraging. (laughs)

A: So...so from your point of view, it would be good if the tutor helped you to make the deadlines sort of thing.

P: Yeah. Like I should...I could have phoned her, but I w...I wish she would participate more? Like I know I don't go in class because I don't want to get to move everywhere. But in a class you can sort of get some motivation from the teacher, and then you go on your own, 
but you still think.... There's a person, you know; you still think: "Oh, yeah, yeah. I wish...." I don't know, I'm like that, you know; I need to...I don't...I find hard to do things for myself. Like that's what...the kind of job I'm doing too. I'm caring for others. (080) When it's for another person, I get the motivation; when it's for myself, I don't get it. So when there's a teacher and I'm in school, I know like: "O.K. I better do it." (laughs) I want to do it, and the teacher's there; it's like an eye-witness of your work. And now I got no witness of... whatsoever of what I'm doing. I just wish she could just pick up the phone and say: "Hi, you get...you still got two more weeks (laughingly) to finish this unit."

A: Yeah. Have you been in touch with the tutor?

P: Just at the very beginning to present...introduce myself. But that's about it. And I asked her after Christmas like how...how much time I have to do it. But it's...like it doesn't seem to.... Like she doesn't phone, but I guess she is expecting me to phone. But I don't feel like...I don't feel all the time it should be me phoning.

A: (090) so you're saying that you don't feel as if it should be you. You feel as if she should make more contact with you.

P: Yeah, like it should be...like on both sides...side. Like there should be a little part of...on her behalf 
just to remind me of (unclear). Well, it would be more interesting. Like I could do it by myself, phoning her, but it would be...make things more interesting. And, I don't know, I like to meet people; I like to talk with people too, so I don't know what she's feeling.

A: You mentioned there about Christmas. Does that mean you started before Christmas?

P: Oh, it's just that I...I enrol in November, but it was just like the day to enrol, and then the real deadline started the 1st of January. Because I could have...like, I worked a little bit on it in November, but not that much because I had to... I was taking my holiday, so I started the 1st of January.

A: (101) Right. O.K., and how is learning English by distance education different from learning it in a regular classroom?

P: Oh, different (pause....). Well, I guess there would be more experimentation in the class to get people involved and doing things together and trying to talk or.... (pause...) I...I kind of like it. Like this is one part that I like because I make my own experimentation, my own talk with the very own people that lives...live here, and it's not something like closed in a little laboratory. (laughs) (110) Like I don't feel like a little rat. (laughs) Learn the language. It's real situation. Like sometimes it's hard, I know it's hard, in a class to get that. Like you go through some kind of a...acting or 
doing things, and it's not natural. Like you.... I don't like those kind of...like.... For example, you take a.... I remember the book I had when I was in Quebec to learn English, and you get text like: "Mary is a secretary. She lives in Chicoutimi. Every day she...." Like it's so.... It doesn't mean.... so sometimes you go in a class, and they take those book and then...or they try to make you talk with people that are not anglophone, so (laughs) you try to make up story, and it's...it's not natural, it's not spontaneous. (laughs)

A: (120) Yeah, so you're saying that you find it very useful that you can immediately...that you're using this English with English speakers.

P: Yeah, I think you get more chance in -- like taking a correspondence course -- to do your own experiment or own... like meet the people you want and talk with anglophone than if you're in a class, all people that don't talk English trying to make...make up conversation in English. Like you only got the teacher. She only has... she only has that much time to give to everybody.

A: Sure, yeah, yeah. O.K. So, there you were telling me how distance... how doing English is different in distance education and in the classroom. What are some of the same things, some of the similarities between the two types?

P: (129) Well, I guess they can only teach the same.... It has to be the same grammar and the same...like those 
things that are basic in the language. Like, I think you can learn them as well in a class than in a distant education. This is one thing that's the same. And, well, the same, I guess you can also concentrate (laughs) like the same in a class as if you come home. I think there's no problem there, and.... What else is the same? (pause.......) I don't know right now. Like now $I_{0}^{\prime} m$ finding one difference again is.... (140) Like when you're...you go in class, you know you're gonna spend that much time, but then, when you come home, you know, sometimes it's like you're really tired, so you just go to sleep, and then you say: Well, I'll spend two hours tomorrow. But then you got all broken hours. This is different. I guess....

A: Do you find that a positive thing or a negative thing, that the hours are broken?

P: No, it's... I... Neither positive or negative. I'm just...it's just a "constatation". Because I guess if you want to really put yourself into it, you can spend...you can put yourself an hour (unclear). But again it's motivation.

A: Yeah. So what about motivation?

P: (150) Yeah, well, I was hoping that the teacher would (laughingly) bring some input in helping me doing the course. I try to still find some similarities, but.... 
A: When you talked about similarities you said:

Concentration, you can concentrate in the classroom and at home. In what way is it the same?

P: Oh, as...like... Well, if you take time in the classroom to...to do some exercise.... Like for the exercise part you would...you would... I would do it the same in a class or at home. Like it's as... When I take the time to do it, I get the same concentration that if I was having people around.

A: Oh, I see.

P: Like all working, I guess. I'm able to concentrate as well.

A: Well, what do you actually do when you do your distance education, when you do your English?

P: (160) Well, I just.... Oh, I find a trick that helps me. I say to myself like: "O.K., I'm gonna spend an hour, but I have to be sitting on this chair and not to move for an hour." (laughs) Because if I don't do that, I just like I go up for a coff...make myself a coffee; I go up to do that; now I feel hungry; I go in the fridge and.... So I just tell to myself: "O.K. you're gonna be sitting on that chair for an hour without moving." (laughs) And then I get.... If I do that, like the first ten minutes are hard, but then after I just go for an hour or even two, and I get things done.

A: Do...do you find that's important to make yourself sit in the same place? 
P: (170) Yeah, yeah. I have to absolutely be sitting at the same place. (laughs) It's my only...the only thing I can find with me; otherwise I just hop around, and I feel like I should do something.

A: Yeah, right. O.K. I already asked you: Before you started, what did you expect it to be like? Related to that question: Before you started what did you hope, or what did you fear it would be like? What were your hopes and/or your fears?

P: Well, I was hoping...excuse me...I was hoping that (pause...) it would be real long. (laughs)

A: It would be what?

P: That it would be long. That I would have a lot of time to do it, and I guess I was... (180) (pause....) I was...I was.... Like it's...I think it's time that is my major fear. Like, it's such a fear, you know, that I won't be able.... It has always been my fear at school too, like that I won't be able to do things on time. Like I had nightmares at night like this wake me up in the morning... wake...having a dream that I was late. It's my.... It's a phobia, not being able to do things in a deadline. (laughs) I don't know what they can do about that. I guess nothing because that's a good stress too; you want to finish it in time. But, maybe there should be some agreement that you can make. You have to respect that deadline, but it's not a failure if you...if 
you don't, if you are not finished after that deadline and they can...they can extend a bit for you.

A: (191) Yeah, yeah. So at...at this point in the course, is that still a fear?

$P$ : Oh, yeah. I mean, I don't know how I will do those six units in 8 months. (laughs) well, like two months.... I mean two months to do the first one. Like it means that if I was making one every two months I would only be finished in twelve months. (laughs) (phone rings recording stopped)

A: So, you were just telling me that before you started you hoped that you would have a long enough time, and you also feared that you wouldn't have enough time. And now that you're into it, what has been your experience of it?

P: (200) Well, now I went through the first unit, and now I know... I know I have to pace... ('Pace' is it?)

A: Pace, yes.

P: ...pace for the other one. And I'm started right now. Like I mailed the other last week, and I started the other one now. So I.... But I have so many things...so many other things to do. Like I have to prepare to go to...back to UBC and present a portfolio and things like that. So I don't know. I...I.... I think...I think you have to get into it like a little bit every day to be sure, and I'll see at the end. Near the deadline I'll see what... what's left. I don't know. I'm just going to take three days in a row just to study. (laughingly) 
A: (211) Do you have an exam at the end of it?

P: I think so. Like I don't know much about that. (laughs) I think they're supposed to send me some papers. I'm...I'm not too sure of how... how you go, but you have an exam I think.

A: You mentioned there that you...you're busy partly because you have to prepare a portfolio to take to UBC. And you said that you have been studying Fine Arts. Are you a painter or...?

P: Yeah, a painter. Mostly like drawing and painting. Sort of like (unclear).

A: So you intend to get your degree in Fine Arts.

P: Yeah. I want my doctorate in Fine Arts to be done, and I want also a diploma to be able to teach in primary school, maybe Art or French. (laughs) But, yeah. So the question was?

A: (221) What's your experience, your view of... of it now that you've been doing it for 2 months?

P: o.K. O.K. Well, yeah. So now I'm...I'm kind of settled about...about.... Like I didn't work for a long time about that unit, and I was putting it away, and then I finally take the decision that I had to, even if I just do like a little bit like ten minutes, fifteen minutes a day, at least to keep on doing it every day so that I don't also get to forget what I was doing, keep the thread of thoughts. And so that's what I'm going to do for the second one, and then just try to bring it 
everywhere in my bags (laughs), and everywhere, in the bus. (230) Just if I can take a... a few minutes every day and see how it goes for this one. Like I have that much more experience about doing the one...the first one. I've tried many methods on my own to motivate myself. This thing about sitting there, and now like this thing about taking the responsibility of doing it a little bit every day. You try to find things to accommodate your...your way of being to.... It's sort of.... It puts you more in a frame when you go to school. Like you're so free that you have to make up your own frame of the work.

A: So in...in a way the freedom of your own life makes it more difficult.

P: (240) Yeah, but maybe it's another way of.... Like maybe this is one thing you learn in a Open Learning Institute. You learn how to get yourself a frame of work. Maybe that will even...even help me to go back to university. That was kind of a problem too in... in Quebec, when I was there. Like you're doing painting; you know, you can sort of talk all day, and then at night at six o'clock you decide: "O.K. I'll work.", and then you work until one o'clock, and it was not really healthy. But then I figure out, like I was 19. (laughs) But now I can sort of picture that you really have to have more constancy, for whatever study you do. Well, I'm telling.... 
I...I'm telling you now. (laughs) I didn't think about it before. (laughs)

A: (250) Oh, that's great, and actually one of my next questions was going to be: What are you learning about yourself by doing English through distance education?

P: Yeah, well, that: I'm learning that I have to be more constant. I knew it already, but it's just to phrase it that it makes it more clear. I guess it's a.... Like, I.... You know, the... . I think it's even a syndrome. I've read things about this... about that. Like people that they...they put up the time, and they just go slowly, and at the end of the semester they try to...to make...to put all the... How do you say it, when you're late?

A: To cram everything?

P: Yeah, yeah. They put like everything in three days; they try to make every...all semester in three days. (laughs) (260) So, I've read many, many things. There's a word in French, but I don't have the English one for it, but you just put back things till you have no choice. But I think I'm learning that. I'm learning not to do that any more, to just like go a bit...bit by bit, day by day, doing a little thing, like even if it's not big. Because there is...there is certain day that you feel like...to work more on it. But at least the day that you don't feel like working, even if you put just ten minutes, 
there you are; you've been touching it enough to remember, keep on going.

A: You used the word 'framework' a couple of minutes ago as well.

P: (270) Yeah. To...well, like.... It's sort of a... Yeah, I use 'framework'. It's sort of: get you more clear. Not clear. What is the word I'm looking for? Like put things in order? Is there a word for that? An adjective? An orderly person?

A: Yeah, sure.

P: Like, yeah, it gives me more order. Like I have to also like...like I have put all my course there in this corner, and I have to know where... where it is and how I'm going to do it, and getting.... see it, I have to see it. It seems that it gets me to...to be more realistic about... (280) Like studying is not something that you take that up in the air. And I also think like, I've paid $\$ 100.00$ for that. It's not that I... I don't want to...to drop out because it's a lot of money for me, and it's...like it's valuable too. I'm gonna stay with it like after. So, like it's.... I learn.... What I learn about myself is...is that more...more order, it gets me to develop more order, this kind of framework, and not to put away the job I should be doing each day and to get more realistic about where it's go...getting me to go financially like this.

A: (290) How do you mean: getting you to go financially? 
P: No, I just didn't put the right.... I didn't put the comma at the right place. 0.K. Get me to go, and then financially this...because this course has cost me money, like I figure out that I should be doing it. That it's worth for me to...like for learning English, and it's worth that I get back in my money. (laughs) I know it's really dumb to heard, but I've paid for it, and that's motivating. Sometimes it's get me the motivation to say: o.K., I'm not gonna give up a course that I've paid that much and... and just let it out there in the air.

A: Yeah, right. O.K. Following that question, a similar one: What are you learning about English by doing this course?

P: (301) A lot. (laughs) A lot of things about English. Like, I didn't know nothing about the grammar. I couldn't write anything. Like I was...I was.... It's so easy to learn how to speak. Like it's just starting to flow now after a year; I can not just stop at each word I'm saying, words. But I learned that grammar was kind of really different than speak...spoken language and more, like much more complex, and... and people don't...they don't talk like the way they read at all. (laughs) (310) Well, I think it's the same in French in a way, but this is one thing I learned; it's really different spoken and written. And I'm glad like that they...that I can start to grasp a bit more, and they encourage me in that course too to read a lot. And 
this.... I have not talk about it...think about it like I was thinking: Well, paper should be enough to read. And then I started to ask my friends around, like: what books do you suggest? And I made them work too. Like sometimes English people they just say, like: You probably write and talk better than I do. And they're all complexed about the way they talk, but then they started to search, like: What do we have in literature? And they even have difficulty. Like in French we're so cultural -- cultivate? about the culture? Like we know, "Ah, yeah!" like, "Name me ten famous writer," like every Quebec people will tell you: Ah, yeah. This guy, this guy; this book is so great. (325) They read so much. Then you ask an anglophone like: What... what English writer do you suggest? And it's not everybody that can, like, just answer like that? And I have some friends, but they...they suggest me now some good books. Like I'm reading a book of oscar wilde, and, well, I think I'm gonna try. I don't really know him, but I guess it's a...it's a beginning. Like I didn't want to go in Shakespeare. (laughs) But, yeah, that's one thing I learned about English that... But I like the way it's...it's made. But I don't know for myself if I can... Maybe one day I'll express that much feeling. I have to read. Like I never read things: books, poetic books. I read like the paper and magazines and essays, really like scholar things, but I never read poetry, so I 
don't know what it is in English to express your feelings. (340) I'm learning that. I cannot say more about it now. (pause...) I guess that's all. I don't want to enter in the detail of grammar, because of course it's completely new. Like I went for that test about getting to know the level of my English, and the guy said to me like, "Are you French?", and I said, "Yes." (laughs) He said, "I could tell by the way you formulate the phrase." (laughs) I said, "Yeah, well!" so, but sometimes it's much more quicker. But it's so funny also what happens in your head when you learn another language. Now I speak English in my head too. At first I was not like.... Things in my head were French, and things I wanted to try to talk was English. But sometimes I...I think certain things in my head, and since it's quicker to say it in English, I will say it in English. (355) Like Vancouver city is quicker than "la ville de Vancouver." (laughs) So it's a.... Yeah, English language is sometimes more compact, and you can just put more stuff in quicker time. And I like...I like it, but then again I don't know how you can deal with feelings. Expressing feelings with that kind of quickness.

A: That seems to be an important thing for you to be able to express your feelings, etc. in English.

P: Well, it's just that I was...I was used to kind of write my diary when I was...well, in French, and.... Like I 
don't really intend to be a great writer, but that's one thing I would like to be able to do in English: have my own diary but in English. But it's not the same as writing essays, and sometimes I just feel words fail. I start and then, no, it doesn't work. I don't have that little hint that can express a, like a "nuance."

A: (370) A nuance. Yeah.

P: But, I don't want to say that English doesn't have that; it's just that I don't know it enough.

A: Oh, I'm sure it'll come.

P: I'm sure I'm forgetting things about... about English language because I have so many meditation. Like I like... I like learning this language. I'm sure it's...it's just like I had open a bit the door first, and I was thinking: Ah, well, I talk English. I know; I know about English. Like what else should I know about this language? And then I start to take that course, and I start to...to.... Like it was not only because of the course but because of staying here and then getting to know more, and I'm... Like the door has opened completely, and I thought: Oh, well, there's so many thing to learn about this language. (laughs) Like I was thinking that I can maybe learn English a bit and Spanish a bit and this. (385) But I...I think that you don't know a language until you get to know it in its deepness. You cannot just stay shallow about learning a language. 
A: And do you feel that you're getting to know it in its deepness now?

P: More, what I want to. I think I get to know it in its deepness as long as I get to look also at the people; the way they live are anglophone. Like it's also a thing of culture. You can just not learn a language by saying it's something in the air like theoric...theorical or technical. Like you have also to learn...to get to love and to appreciate...like, not to go... That is really hard in our time to, not to set barriers that you're French and they're English and all this, the question of the independence and everybody want...just want to bug you with it. (399) So you have to get that aside and then say: I want to get to know the people, the heart of the people. Like, why do anglophone talk that way? What's in their heart? Why do they formulate those... those sentence this way? It must be a way of thinking too, because then if they would think same as French, they would talk French. (laughs) I guess, I don't know. It's just, maybe it's just an hypothesis, but you get to know how... how to function inside.

A: So do you feel that by getting to know people better, by getting to know the language better you are understanding anglophones better?

P: (410) Oh, yeah. Oh, yeah. I guess like I was realizing that lately I said, "Well, now I'm not only francophone, I am anglophone."(laughs) After a year and a half and 
you speak every day English, you say, "Well, I cannot say to myself, not any more, that I'm a francophone. Well, maybe I'm a franglophone." (laughs)

A: A good mixture. Another question about learning: What are you learning about distance education by doing this course?

P: Like I didn't know the.... I didn't really know there was such a thing as distance education. Or maybe I know... I knew, but I didn't pay attention. But, it's hard to.... I don't know what to answer, what am I learning about distance education.

A: (425) you told me that before you started you had no idea what to expect, so what have you learned about distance education itself?

P: Well, beside the critic that I had, the negative critic I had for it, like I've learned that it's a good tool, that you can...you can... you can try to... (pause...) to use it for your own as the best of your...with the best of your abilities, to like -- not promote, that's not the right word -- go ahead? I don't....

A: Get ahead?

P: Get ahead, yeah.

A: So you're saying it's a tool which you, the student, can use to get ahead.

P: (439) Yeah. Like, and you don't.... Like I won't be completely.... I don't feel I will be completely (pause...) like (pause...) bare when I will go back to 
UBC? (laughingly) It's like not knowing anything about.... I feel I have a good tool in my hand to...to learn the language, and it would be easier for me to get an entry at the university.

A: So, when you say it's a tool, it's a tool for what different purposes? A tool to do what?

P: Well, like I would feel scared if I had not that course to help me writing. I would feel scared to go back to university. Because I know, like I won't have only studio courses. I will probably have a History of Art course, and I will have to write a...a text or something. (456) It's al... Always they ask for 1... Well, it's normal; like, I mean, they ask you describe maybe a painting and why you like it and why you don't like it, and you have to express what... what it is. So, I feel like more settled about going back to...like a big university if I have a little course on my own that I can play with. (laughs)

A: play with. What do you mean by that?

P: (laughs) Well, you don't...you don't.... Like you can follow the course but on your own. You can sort of.... Like I've tried certain things to... I'm really playful...I'm a playful person. Like I cannot only stay at the level of a course, so I... (470) Like I do the course, and sometimes I, when I write for...for the course, I talk with my friend, and we exchange certain things, and I would go and ask him like, "How do you say 
that or how would you phrase that?" And then he would help me, and it was like, "How come you say that this way?" And then I want to go in more detail, and sometimes when.... Once I wrote a letter to one of my friend, and I write it all in French but with subtitle in English, and I was trying to see how you can play with words and.... But I think she didn't...she didn't catch it the first time. It was.... I rea.... That's when I saw that English and French grammar were really different, completely different. (485) I was thinking there were certain things that were basically the same, but ah, no, it doesn't sound the same at all. And so that's what I mean by playing with. (laughs)

A: Yeah, yeah. So for you what are the most important things about doing English by distance education?

P: One of the most important?

A: What are the most important things about it?

P: Well, I want to have a university level of talking and writing. Writing most. Like I think...I think that a course...this kind of course is mostly.... Like I take it... I took it mostly to learn how to write, because talking I know I can always do it. People are really.... (500) Like they don't mind you making mistakes, and so.... But I don't think that they will...they will allow you that many mistake at the university for a final work, so like... Remind me the question again. (laughs) What is the most important thing? 
A: What are the most important things about doing English by distance education for you?

P: O.K., yeah. Well, I don't know if.... Like distance or not, like I knew I had to take a course to...to be able to write better and (pause...) this was one of the main reason...most important reason, write and....

A: (515) So, distance education as opposed to a regular evening course. Why...why distance education? what is important about that form?

P: Oh, well, it wasn't that... what I was saying in the beginning, for not to have to travel. Well, I guess, all those experimentation have taught me about.... Maybe I would have done those things if I had a class. But I don't know; it's...it's... in a way it's more...it's more plia...no, not pliable (laughs)...supple to go on with this course before going to university. Like compared to a course... Like if I would have take a course also I...I don't know.... (530) Like, I guess, if I was even going to university, this won't enter me to go. Like if I had a course too, maybe I wouldn't have meet the deadline? Like you.... Let's say I...let's say I would have decide to go to university in the summer semester. Well, maybe this course I was taking would still go on or won't meet... won't get with the schedule.

A: Yeah, right.

P: Like this I can just carry it wherever I go and whenever except for that deadline of this exam. And I...like I 
don't think.... Well, when you go full-time at university, you don't have the time to take a distance course, but I don't know what the deadline are. I don't know if they finish...it's finishing at the same time the university starts, but...like I'm not too worried about that.

A: (546) Is it necessary to finish it before you enter university, or...?

P: Well, I guess I wouldn't like to drag that on after. (laughs)

A: Ah, so it's just you would like to finish it?

P: Yeah, but I don't think you get in trouble if you don't, and if their exam final deadline is not... is overlapping with the university entrance, like I don't think this causes too much problem.

A: Yeah, so you're saying it's convenient partly because you don't have to travel and partly because there isn't that deadline to conflict with the university.

P: Yeah.

A: Anything else that's important about it?

P: (560) Like, always in comparison with...with a normal regular class or...?

A: Not necessarily.

$P:$ (pause......)

A: O.K. Well, in fact, I...I've marked what... what are some of the key words that you've used. If I read these key words back to you, can you tell me if you find a 
relationship between them? Is there a relationship between them? You say: Doing English by distance education is convenient -- no travelling, not with deadline. You also said that you can do your own experimenting. It...it will help you to get into university.

P: Can you stop it ? (Tape-recorder stopped for P to answer door.)

A: (574) Yeah, yeah. I was saying that I've noted down key words that you used You said it's convenient; you said you can do your own experimenting; it will help you to get into university; and you also mentioned that it's hard. I think those are some of the key things. Is there a relationship among them?

P: Well, there's certainly a relationship between convenience and...for university, and....

A: What is the relationship there?

P: Well, like, it is.... (laughs) O.K. I'm just gonna make it clear of word. It is convenient for me to go to university. (590) Like...like it's convenient to take the course, but it's convenient that I'll be ready to...to go to university. And, what was that? Do my own, oh, O.K., experimenting. Well, I guess, like it is a good introduction in anglophone world to...to begin with, because I... Like going at university I know already a bit that it's a...it's a world of experimenting but more intense and, like, more seriously, so I think it's a good 
introduction, this course, to further experimentation with the language, with the anglophone culture. And hard. Well, I don't know. (laughs) The connection is always there; you cannot do anything that easily. You have to put some effort.

A: (610) O.K. Sure, yeah.

P: But I want my teacher to phone me. (laughingly and plaintively)

A: Really, one more question here. If you were talking to another person in a situation like yours -- She was from Quebec; she had been in Vancouver one and a half years; she was doing the same kind of work etc., etc. -- what would you say to that person about doing English by distance education?

P: Oh, well, I guess I would... I would really advise her to...to take it, and... and we can work with together. No, I can get some observations, but.... Yeah, I will... I would advise, the same as this...this friend of mine talked to me about it. Like.... And I guess he has been taking some course too, but.... (630) Yeah he's been taking some correspondence courses, because he couldn't... he couldn't get at the college at the deadline, and you know, school is always like that. You have to start in September or in January; otherwise, that's it. If you don't go in... if you don't start the course there, you cannot start in any other way at any other date, so I guess if she was in the same situation, 
and she had to go to work, and let's say she arrive in November, well, and she want to get going to start something, well, I would say, "Yeah, go for it because you can...you can take it any time, so you don't have to wait until January or even to...like UBC (END OF TAPE) (BEGINNING OF OTHER TAPE)

A: (651) So you were saying that you would advise a friend to go for it because she could register any time....

P: Yeah, like if she don't want to lose her time in between deadline for school, that she can just take that course, and it give her something ahead like something that's done and that she can always even put on her resume or in... in her portfolio if she goes back to school. Like I'm always for that, like, get my mind to not stagnate, just learning. (laughs)

A: Sure. You mentioned there putting it in your resume or in your portfolio. That's something that you will be doing.

P: Oh, yeah. Yes, if I pass, of course I'll put that.

A: So, it has a practical purpose.

P: (660) Yeah. (laughs)

A: And, well, one more question. How are you evolving or changing as a learner by doing this course?

P: Waw! Big question. (laughs) (pause...) Well, I was mentioning to you all those things that I was learning, like the framework and... How I'm evolving as a learner. This is a big question because this is the 
story of a lifetime. You're always evolving as a learner all your life, and.... Like the more experiment you get in life then you can put them in practice with what you learn, and what you learn is.... Like you cannot disconnecting learning that...with...with living. So I cannot really answer it (laughingly) in two words that question. I need to think about it.

A: (671) Yeah. So you see learning and living as integral things, inseparable.

P: Yeah. Yeah, no it's not disconnected. Like, that's why like I'm learning language. I'm learning English because...because it apply in my life. Like it's...I'm not learning something dead or.... It's...it's living, and it's moving, and it's...it's, yeah, growing. So, yeah, like, I can really not.... I don't know how you can learn theory...theory without having a...a grasp of practice. You have to...to be able to...to integrate it, you know, like....

A: And you are integrating this with your life.

P: (680) Yeah. Yeah, and even this course... I don't know if it was through this course; someone mentioned that I should buy a...a book on idioms in English, and like this was also an all new dimension for me. All those verbs made up with 2 words I never knew before.

A: O.K. Well, that takes care of my questions. Is there anything that you would like to add? 
P: No, no. I was...I was happy to...to answer.... if it can help other people.

A: Oh, it will. And thank you very much. 


\section{INTERVIEW \#16}

Interviewer: A

Respondent: $Q$

Position on tape: (000)

A: O.K. Well, maybe we could begin with your decision to enrol in a distance education course. How did you come to that decision?

Q: Well, it was a long... by a long process, and what happened was that I tried to enrol at Kwantlen college in their course Psych 101, and when I went there, they had advertised that they had a course here in Langley, and that's what I was wanting to do. I went to register for that course, and when I got there it turned out that that was a mistake in their brochure. So from there, I phoned every...every college in the area to find out if they had a course, and they didn't. So I thought: Well, I guess my next choice is to do it by distance learning. It wasn't that I thought about it and decided that's what I wanted to do. It was a last resort.

A: (010) And, how did you actually know about the OLA and their courses?

R: Let's see now. I...I think what I did, I called Fraser Valley College, and it was actually them that suggested that I...that might be a resource for me. So I'm pretty sure that's where I got the help as I remember it. I'd heard of Open Learning before, but it never occurred to me. I'd heard of it through nursing, and I...I kind of 
thought it was more that type of thing; I didn't realize they had everything. They have a very good choice of courses there. So, that... and then I called them and got the information.

A: And you say the subject you're doing is Psychology?

Q: 101. First level psychology.

A: Have you done psychology before or not?

Q: Not formally. I did take some psychology and some sociology during my nursing training, but not.... (020) It was more abnormal psychology rather than.... Well, I guess this is gonna be abnormal too; but I didn't take the fundamentals? And that's what this is now is fundamentals.

A: Right. And before you actually started the course, how did you expect it to be? Doing...learning psychology by distance education?

Q: I just presumed that they sent.... I thought it would be laid out like a curriculum that a teacher uses, and that it would be an outline, and it would say, you know: This is course one or Chapter one, and these are the...the objectives of chapter one. And then I thought that I would just have to read the book and make my own notes, and I knew I had assignments to do, but I didn't expect it to be as in...well, I call it intense or.... 1030 I... I find it really good actually the way they have the questions so that you end up when you...by answering the 
questions, you end up going through the whole chapter and virtually making notes on the whole chapter.

A: So, when you say 'intense', what do you mean by that?

Q: The.... Well,I...I just, like I say, I thought I would just get the book, and I would just make my own notes, where this, the guided learning part of it, goes into every important thing in that textbook and asks you a question on everything that's important, and you have to answer it, so you're... I find it's a lot of work. You know, like there's maybe 18 questions for each chapter, and a chapter is only about 20 pages long, and I'll read through it, and I'll think: oh, yeah. o.k. But I don't realize that there's that much information in there? Until I start answering all the questions.

A: So 'intense' means 'thorough'.

Q: That's right, yeah.

A: (040) O.K., and you mentioned that you had done some psychology before, and, of course, you've done other studies in regular school. How... how do you find that learning Psychology by distance education is different from learning in a regular classroom?

Q: I like to be able to ask questions and discuss. I think it's the type of.... It's a communication course in my opinion, and I think that for me, when I read through there, I have questions, and the questions I have aren't necessarily the questions that are in the guided learning part of it? And I have.... I expect that I'm supposed 
to be able to phone my tutor and ask her questions, but my type of questions are more.... I enjoy theorizing, and, you know, going on and on about something, and you can't do that on a long distance phone call. It's not that I don't understand it; it's just more my type of mind. (050) I'm curious, and I'd like to say: Well, what about... what do you think about if this happens or that happens? Or what about if they tried this, what do you think would happen? And, you know, I find that's stimulating be...being able to discuss that type of thing? And that's what I'm missing. I'm learning it. And I'm learning it; I think I'm learning it really well. But I miss the, kind of, the social part of it -- let's put it that way; I guess that's what I'm saying -- or that extra stimulation.

A: So you're saying that you find there's a lack of discussion, and for you that means lack of stimulation and lack of social interaction?

Q: Right.

A: Is there any other reason why discussion would be important to you?

Q: Well, I find that by discussing it, if I can talk about it, I know about it? If I read about it, I don't necessarily.... I don't know for sure it's staying in there? And I was actually quite surprised at myself when I phoned her for the first time, and she had to ask me two questions? (061) And I just.... Oh, I was so 
nervous. And she asked me the question, and I was so surprised that I could actually give her the feedback, or give her the answer 'cause I didn't know if it was in there. Because I'm used to talking about it. And by not talking, I didn't know.... It's just a different.... Like obviously I got it down on paper, but I didn't know if it was going to be there tomorrow. And I had... Actually I was taken by surprise because my...my phone in time is Monday afternoon, and I thought it was Tuesday afternoon. So... and for some reason I took my books out, and I was going to review everything, and I looked at the page, and it said Monday afternoon. I thought: Oh, my God! It was a quarter to two, and I had from twelve till two. So I phoned her, and I said, you know, "I don't know if I'm ready for this or not." And she was really good about it because she said, "If you're not, I'll ask you the question, the first question, and if you feel you're not prepared to answer it, leave it then and phone me back on the Thursday night." But I was working that Thursday night, so that likely triggered my brain too, and then I thought: I got to answer this. And I did; I got full marks on it, so, it turned out o.k.

A: (072) What would you say your relationship with the tutor is then?

Q: Right now it's very, uh.... Well, that was my first contact. So actually what it says in our information is: When you get all this information, this is your tutor; 
phone your tutor up and make yourself known to your tutor. So I was going to do that, and then I have a friend who's taking this course too, and she said, "Well," she said, "you can do it if you want, but," she said, "I did it, and the response I kind of got was: 'Well, yeah. So why did you phone?'".

A: oh, really.

Q: (079) Yeah, and she was basically told you phone if you have a question or you phone if you have a problem; you don't phone to say "hi!". (laughingly) And so I felt.... I kind of went: Oh, I don't know. I didn't like that very much, so obviously I didn't phone her and introduce myself. But when I phoned then that first time, she knew who I was, and she, you know, she sounded like: Oh, good, you know; let's get on with what this is. But it was very short and sweet, which obviously would be the...the correct thing to do when you're, you know, when you're calling collect. I'm not paying for the call, so she's not going to carry on making social discussions with me on the phone. I do feel if I had said to her: I have a problem, and I.... At some point I may phone her up and say, "Look, I'm having a problem. Would you please explain such and such? I feel confident that she will do that. So. But, you know, I may be fooled, but I don't think so.

A: (090) You mentioned that you have a friend doing the same course. Is that making a difference? 
Q: (pause....) I guess it helps, except that both of us are really busy. I had thought initially: Well, maybe we could get together, and I had wanted, after we did the first assignment, let's get together and run through the answers and see, you know. But I don't think that's really such a good idea anyway? Because, number one, if she had a different answer, I might think mine's wrong, and I'd likely change it, and then I'd end up.... She got 78 on hers and I got a 100, so maybe it's just as well I didn't. But the other thing about it, I was concerned, was the tutor only.... There's three sets of quizzes A), B) and C), and there's multiple choice questions in each set. She only marks one?

A: One of the three.

Q: (100) Yeah, right. And so I thought: Well, in that case, how do I know if the other ones are right? But it appears, just looking quickly through that, that she checks them all; she just doesn't mark them. So I think that'll be $0 . K$., because I...I wanted...I want to know for sure that the answer's either right or wrong.

\section{A: Sure.}

Q: But I think that.... It looks like that's the way it is.

A: Yeah. How do you feel about that, having only one out of three marked?

Q: I don't care. All I care about is if I got it right or not. You know, if I didn't get any marks for any of that as long as, you know, I knew that I was on the right 
track. It's only important that I'm learning, and like I say, when I opened it, yeah, it's really nice to see 100\%, but with my personality now I'm going to strain myself for the rest of the course trying to keep up to that 100. (laughingly) I don't know if that's good or not.

A: How do you really feel about that?

Q: (110) oh, I'm really.... I'm the typical perfectionist. And achieving perfection on the first really upsets me in a way, because it puts added pressure on me. Because if I come up with a 78 next time, it's gonna be: Well, obviously that was a flash in the pan, you know; she's not that smart. So, but, I think after I do a few, then I...I'll feel better; I'll know whether I really did learn that well or whether it was just a fluke. I feel I did learn that well; I was quite...quite impressed with what I learned. A lot more than any course I've taken before.

A: Right. What do you mean by 'learning' when you use the word?

Q: Learning to me means it's in there, and it stays in there, not that I can regurgitate it, but that I know what I'm talking about. (120) And like I said before, I read through the chapter and (pause..) didn't feel that I got much out of it. But by the time I had answered all the questions, I had really gone through that chapter, and I was able to discuss it, able to explain it to my 
husband, and then when I did the... answered the questions to her, I was able to explain it to her. So that to me, that's learning. I not only have it in there, I can come out with it too, and I'll be able to use it.

A: When you say: It's in there. What do you mean by 'it'?

Q: The content of the chapter that I read or the two chapters.

A: O.K. I...I... Five minutes ago I asked you: what do you see as the difference between learning psychology in the classroom or through distance education? The opposite question: What do you find is the same about the 2 ways?

Q: (130) You're still reading the information. Because any course that I've ever taken, usually you read the chapter before you go, or whatever, how many chapters before you go to the classroom. So that's the same. You still have assignments, but you don't.... I've never had a guided learning book to follow before, and... and I also have a student manual, and that...that seems to.... It's almost.... They've laid it out so that you know exactly what's important. At the end of each chapter in the guided learning thing, it gives you a list of... of words and concepts that are important, and I feel that if you know that, that's obviously what they're aiming for in that chapter, that you know all that stuff. (140) So if you know that, you should come out of this course with the knowledge that they intend. Where I find in courses 
that you go to, you may have a list of objectives, but the objectives aren't anywhere as concentrated as these concepts are in this guided learning thing.

A: What do you mean by 'concentrated'?

Q: In other words, you have an overall list of objectives? And one of them might be that you get through the course, you know, or that you, you know, you attend all the classes. Or there's the other objectives, you know, that you will learn about this.... Oh, off the top of my head I can't think. But, you know, kind of the overview of what the course is gonna give you.

A: So less specific in other words.

Q: Yeah, yeah. That's right. And so I usually glance at those, and they go in one ear and out the other, and that's the end of them. (150) Where I know these concepts -- That's what they call them in here is concepts. -- I know when I go to review for my exam, I will know all those concepts because I know those are important. I guess that's....

A: And are there any other similarities between the two ways?

Q: (Pause....) I can't really think off the top of my head right now. (Pause...) There's certainly.... I think I see more differences than similarities?

A: When I asked you about differences before, we got onto other things. Were...were there any other differences that you didn't mention then? 
Q: Let's see now. What was I thinking of? I just thought of something. (160) The similarities are learning the subject matter, but the differences are: I'm doing it on my own; I'm learning it in a more concentrated, I think, in a more concentrated way; I feel I have control... There's another thing too because, I think, because I have taught and I've nursed for so many years, I trust my own intelligence more than I do a lot of other people's intelligence? I'm learning this. Mind you, I'm not too impressed with this textbook either. But, at least what's in there I figure out for myself; I don't have someone else telling me their impression of what they think the author means? And then I also have the guided learning one that... (170) That's another person that's written the guided learning book. So you have.... He'll add things in too. Like he'll say: This is how I see that. So I've got his impression too, but I only have two people's impressions. I still feel that I have control, and... But I don't know about the tutor, you know, when I start giving answers. Like I say, these...the...some of the answers in there, I'm not...I don't like any of them? And I put my own answer in, and she doesn't.... I...I forget what she said there, but she seemed...she understood what I was saying anyway, because it wasn't right; it was a mistake. And I feel that she's giving...likely giving me the right.... Look, I would have said that to a teacher, and the teacher 
likely would have said, "Well, yeah. That's not quite right." (180) But I wasn't sure what she was gonna do about it. I think I'm rambling. You better ask me a more specific question.

A: No, no. Rambling is more or less what I want because that.... When you talked about having control and being able to interpret for yourself, is that what you mean by control? That you can interpret it as you see right.

Q: Yeah, because sometimes I'll go to a course, and the instructor will say, "I believe that this is what this person means by that." Well, maybe I don't believe that, but right away, because I'm writing my ans...my assignments to that instructor, that then becomes the way I have to believe because that's what the instructor wants on the paper. And I don't like that, but I like to get good marks in what I take, so.... And then by the time you finish the course, that's in there. (190) You've already conditioned yourself that that's the right answer, and it's strange, but even though I'll say to myself, "No, I...I believe in this rather than that," the right answer comes up. I mean, not the right answer, but that instructor's right answer will come up as a response rather than my own answer?

A: So you're saying that when you're in the regular classroom, you would tend to, in effect, cling to the system.

Q: Yeah, that's right. 
A: Whereas here you feel you don't have to do that.

Q: Well, I.... This is how I'm feeling right now. I may find that that's not true either. But nobody is giving me that much, you know. I...I'm pulling out of this, and I'm pulling out of the guided learning, pulling out of the text and the guided learning, and hopefully I'll be able to come up with my own answers.

A: It sounds much more interesting.

Q: Yeah. It does, doesn't it?

A: (200) when you do your Psychology studies, what do you actually do?

Q: In other words now I'm preparing for the next unit. Is that what you're asking me?

A: Yeah.

$Q$ : First thing $I$ do is sit down and read the chapter, and each unit has two chapters in it. So I read the first chapter; then I go through the guided learning questions. I may... I may scan to see, you know, what he's getting at. But I found now I might as well just sit down and start at number one, and he says: Describe so and so's theory of such and such. And he even.... You know, you couldn't be...it couldn't be any easier; he puts in brackets: page 89 , you know. So you go to page 89 , and you read through all that. (210) so, basically, I read the chapter twice, which is really good, and then I write down everything. I write pages, reams of stuff. I write about twenty pages on each chapter. That's only on one 
side, but I know if I were in a classroom, I'd never have written down that much stuff?

A: This...this.... What you write is in answer to the questions at the end of the chapter.

Q: That's right. But, you know, when they say...they'll say: Discuss so and so's theory, whatever. And, you know, I go through the book, and I write down what they say in there, and then I write down my impressions, and, you know. So I'm going into it in much more depth than I would normally.

A: And what do you do with those writings afterwards?

Q: Oh, right. O.K. I forgot the question. O.K. So I go through all of that, the guided learning part of it. I keep it; I have it all written like notes in my threering binder. (220) Then the next stage is to answer the quizzes, and there's quite a lot. There's, like I said, quiz A), B) and C), and each quiz has maybe 20 (Pause...) What do you call those? I'm losing my train of thought now. The multiple choice, about 20 multiple choice. And then they go into the longer ones. The first one, went in great depth. Each quiz is set up exactly the same, which is kind of funny. It's 20 multiple choices; then it goes into about 10 longer ones, and the first one, the whole quiz.... All the quizzes had 10 questions each on: Was this an experiment or not? (230) And you had to read through what this person did. And did that make it an experiment because you have to have certain things 
to... in order for it to be an experiment? And it went on and on and on. This one now is going into.... (pause...) Isn't that funny; I lost...lost it again. It's not experiments. Oh, it's.... We're studying on drugs. And what kind of a drug would have caused this reaction in this person? So it goes into about 10 different scenarios in each quiz on drugs or brain damage or whatever, what causes the brain to act like that. So I do all that, and then I mail my assignment away to her. And I'm kind of about one week ahead right now, which is good, (241) so by tomorrow I'll have finished all my assignments. I'll mail those in, and then on Monday I phone her, and she asks me two questions, and that's that finished. Then the next day I start in all over again on the next unit. So, fortunately I'm not working full-time right now. I'm beginning to wonder; if I were working full-time, this would be very.... Well, I work about, I would say, maybe two or three hours a day on it. So it's more, again, more than I normally do when I take a course. Because usually I go to the class one night and write all my notes. That's it, and then often you don't even have assignments. So, there's a lot more hours that are going into this than normally would.

A: So, in fact, it's more time consuming than a regular course.

Q: (250) Yeah, yeah. But they always tell you when you go to...to the colleges that you're supposed to spend so 
many hours for every hour of class time. Well, I never do.

A: I wonder how many people do. (laughingly)

Q: Yeah, exactly. I think: God! How could you possibly? But in this you have to. So that's one of the drawbacks as far as I'm concerned, you know, being a lazy student. I don't know. I...I may talk myself into preferring this. I don't know, but we'll see. Time will tell.

A: I asked you before: What did you expect it to be like before you started? Related to that: What were your hopes and/or your fears of doing Psychology by distance education, before you started?

Q: (260) I didn't have any hopes other than to get through the course. That was the only goal I had, and I've taken so much that I knew that, you know... I I wasn't too concerned I wouldn't be able to. And what was the second part of that?

\section{A: Any fears.}

Q: My fears. I had no fears. I...I should have had more fears. (laughs) This is quite, you know, it's quite an undertaking. I don't.... I think I just went.... I had decided I wanted to take it, and that was it. I didn't have any kind of preconceived ideas about what's gonna happen at all. And like I say, I had no idea I was getting myself into as much work as I have. No fears. Education doesn't fear...fear me...scare me at all. 
A: (270) So in effect you're saying that it was a... it was in a sense a forced decision.

Q: That's right.

A: And because it was, you didn't particularly think ahead.

$Q:$ No, I just.... It was just a means to an end for me. Get the darn thing and get going at it and get it over with.

A: Right.

Q: But I'm actually quite enjoying it.

A: In what way are you enjoying it?

Q: It's very interesting. The course content is very interesting. It's more in depth than I had expected. It's a higher level. It's interesting, because I've taken a lot of courses, and for some reason this is a higher level, and I'm wondering if it's maybe because so many courses I've taken have always been college level? (280) And I took Health Care Management, and, you know, I thought that was fairly in depth, but I don't find that it was anything compared to this. Now I don't.... It's the, I guess, really the first university course that I've taken. And I don't know if that's the difference or whether it's the subject matter. So, I'll have to find that out as time goes along.

A: That would be interesting to know.

Q: Yeah. But it is.... And when he started at the beginning of the book, he talks about.... On each page he has a vocabulary in the corner? And he puts in words 
that are really simple. Some of them are really simple, and he apologizes to the student in the beginning saying: You know, I realize that some of these words are really simplistic, but there are people taking this course that will have never seen these words before. (290) And I'm thinking: With all the education I've had, I'm having a problem with this. He explains things like "et. al", and I think....

A: Like what? Oh, oh. "Et. al."

Q: You know, when they say some (unclear). And I think, you know, if somebody taking this course doesn't know what that means, they must be in trouble, and yet being English as a second language instructor, maybe for some...maybe that's for people like that that maybe have never run into that before?

A: Sure, yeah.

Q: I don't know but, it's not...it's not easy. Let's put it that way.

A: So, you've told me that before you started you didn't have any particular expectations or hopes or fears. Now that you are into it, how are you finding it?

Q: (301) I have no concern that I won't get through it because of the way it's laid out. And maybe I have a little more confidence now, that when...than when I started. (Pause.....) Now that I'm into it. No, I don't have any.... I guess I was a bit fearful the first chapter because it seemed so heavy, and even this second 
chapter, when I first started on again, I thought: oh, my God! I'll never...I'll never remember this stuff. But it's coming, and it's coming because of the way it's set up in the... in the guided learning part. It makes you have to get that stuff into your head.

A: (312) You're talking again about the questions and having to go through it again and again.

Q: Yeah, having to answer them and.... You know, you read something like the inhibitor transmitter or this inhibits that or excites that, and you think: on! You know, that stuff doesn't interest me at all, and I... when I first read the chapter, I thought: Oh, God! I...I don't even want to read this, let alone retain it. And then I...I could actually read, and when I finished reading the paragraph, I had no idea what I had just read. (320) But now having had to...I think dividing it up into questions -- what about this and what about that, and then going back and picking it out -- I think myself having to pick out the information and write it down in short form, I've made it more.... In point form it looks a little easier? or it makes a little more sense rather than just one continuous long paragraph? So it's coming, so... You know, now after having done.... Basically I've almost finished the second unit, so after that now I know that if I read the chapter and I answer all the questions, I'll be fine. It's not gonna get any worse, I don't think. Because it's getting into interesting stuff now, 
more the behavioral stuff and that type of thing, which is what I'm interested in. I don't care how the brain works. I just want to know what it does and, you know, what happens, and you study the different types of things like that.

A: (332) Right. You mentioned two things there that are perhaps related. You said you find because the course is laid out as it is, it's...you're finding it good. And you also mentioned that when you answer the questions, it's broken down into points or whatever. It seems that layout is quite an important thing for you, the form in which it's given.

Q: Yeah. I fee.... I'm very visual. And I've learned that over the years. Actually people talking to me...my mind will...can wander, and my mind will wander when I'm reading too. But if $I$ have it in point form, and it's clipped, that, that, that and that, it all seems to go in? I can't be bothered with excess of words. I guess that's what it is that complicates things. I don't know; I don't understand about learning, but I know if I see it, and I see.... It's like a picture; the picture is worth a thousand words. I find if I see something there, that'll stay. It's almost like, you know, photographic memory, but I can't be bothered with all those words; it's too...too much...too jumbled or whatever? so.... 
A: (351) My next question is actually a series of three little ones. What are you learning about Psychology by doing this course?

Q: I'm learning that there is more to it than the.... What do they call the...? I guess I was thinking kind of more along the psychiatric line than the psychological line? And I'm learning from this that it's not all labels and definitions; it's the working of the mind. And it's interesting. I've... Through my nursing career I've discovered, or I believe in the...the mind ruling the body? (361) Where a lot of people, you know, figure they just get sick, I know they don't just get sick. There's a...their mind does it to them. And it's either stress or people believe they're victims, or, you know, it's certain personalities that get certain diseases. And I'm finding in here now that that's my belief right now, but I'm finding that that's too severe too, that it isn't all necessarily the mind doing it to the body. The whole thing is related, and maybe the body does something to the mind, and then the mind starts thinking one way, and then.... So it... I'm finding it quite... You know, it's broadening my base of knowledge for sure.

A: (370) That's interesting. And the second question in this little series: What are you learning about yourself by doing this course?

Q: Well, I guess I've learned that I.... I was gonna say about this visual stuff. I kind of suspected that before 
that I was visual, and I'm not... I'm not in classrooms and I'm not seeing things. So it's making it more demanding for me and that I'm having to make my own little visual things that I can learn by. What am I learning about myself? That (pause....) (380) well, from what I explained to you about my belief in how the mind controls the body, I'm finding that I...I tend to catch on to an idea, and I go from there rather than seeing the thing. I haven't got enough knowledge in psychology to be able to see the thing in a broader sense, but I'm learning that my mind is still flexible, because I was beginning to think that in my old age I was starting to lose that flexibility in my mind. But I am still open to new... new concepts, which is good. Is that all you asked me? What am I... what have I learned about myself?

A: Right.

Q: (390) That I can actually spend two hours a day sitting down at my dining-room table and learning. I didn't believe that before. And that I can earn a $100 \%$ on an assignment. I guess that's a good thing to learn too.

A: Sure. And the third little question: What are you learning about distance education by doing this psychology course?

Q: That you're kind of more on your own. I...I didn't realize how much I rely on the instructor. I find there's a lot of students that will go to a course or go to a class, and they go in there, they sit there, they 
take it all in, and they go home. Where I'm the kind of student that makes...makes it a challenge for the instructor? And, you know, by asking questions, and wanting this discussion and so on, and I'm not getting this through the open learning...by the distance learning type of thing. (405) But I'm beginning to wonder if maybe that's not all bad. 'Cause I can almost get myself side-tracked by theorizing, you know, and I may be not getting out of it what I'm supposed to be getting out of it, but I'm enjoying it thoroughly. And it's not always supposed to be an enjoyable, you know, entertaining evening that I'm having. I'm supposed to be learning something too. So maybe it makes me focus specifically on what I'm supposed to be learning.

A: You made an interesting contrast there. You contrasted enjoyment and learning as if they were opposites.

Q: Yeah, yeah. Right. I know you can enjoy learning, but I'm a strong enough personality that I can side-track the instructor and...or side-track the whole class, you know, and get off on to.... I need to have an instructor that makes sure that I don't do that. Because... (420) And like I say, I'll learn that specific thing, but maybe what I've learned is that the instructor got side-tracked rather than really finding out what I was supposed to be learning through the evening, and then $I^{\prime}$ ve got to go home and, having again what I consider kind of a lazy mind -- because I, you know, I've never had to really 
study that hard -- I go home, and I don't bother learning what it was that I was supposed to be learning there. But I can regurgitate it on an exam, but maybe I haven't gotten as much out of it as I should have. So I'm likely getting more out of this, I think, as I work at it.

A: So, my question again was: What are you learning about distance education?

Q: Yeah, that.... I guess what that's saying is that for me, I'm going to learn more thoroughly. (Pause....) The cat just went inside the organ. (laughter)

A: That's not normal?

Q: No. (435) I've never seen them do that before. Anyway, so what have I learned about distance education? Are you.... Is this what you're getting at is specifically for me?

A: Yes.

Q: Yeah, that I think that.... I believe at this point I'm going to get more out of this course by doing it this way.

A: So would you say that for you distance education is perhaps a method... a way in which you can learn more than you would in a classroom?

Q: Likely, I'd hate to admit it, because then that would be a good reason to carry on doing it, but I think... I think that I am learning... I believe I'm learning more. Lonely but I'm learning. 
A: O.K. So for you what are the important things about distance education?

Q: (448) The important thing is that I learn, and that I pass the course, and I get the credits that I'm supposed to or that.... I... Whatever the credits are for that course, 'cause I'd like to work towards getting my degree, so that's...that's my goal to start accumulating credits.

A: As we've been talking, I've been writing down what seemed to me some of the key words that you've used. Let's see if I can pick them out now. And if I give them back to you, could you perhaps tell me if there's some relationship among these words? Just now you mentioned that distance ed. is important to you because you can get the credits and you can learn. Previously you said you have control, and you've also mentioned this lack of discussion as something important to you. I think those are the four main things. You get the credits, you learn, you have control, but you lack discussion. Do you see a relationship between those?

Q: I don't understand what you're asking me.

A: Is there some connection between two of those, three of those, all of them?

Q: (pause...) (470) This is just going right over my head. I... The relationship between those different things. Well, actually, I'm getting three out of the four things by taking, doing distance learning. Is that what you're 
asking me? The one thing, out of four things, I'm missing one. So, it sounds to me like if all I'm missing is the social part of it, I could go out with my friends and enjoy myself; I don't have to do it through education?

A: That's not exactly what I was asking. Let's see how I can put it. When... when you look at.... In your experience of distance education these are, it seems, four of the most important things about it. Is there any particular connection between them? Again, getting credits, learning, having control, lacking discussion. (Pause...) If there isn't, then there isn't.

Q: (486) I just.... I don't... Can you give me an example? Like use other things that could.

A: Well, using these ones, I suppose you might say: Because.... I.... There is a connection between having control and learning. Because you're able to make your own interpretations, perhaps you feel you're learning it better, as an example now. I don't know if that is what you meant there.

Q: (494) Well, definitely the fact that I have control, I feel that I'm learning better. I'm not learning someone else's impressions; I'm learning my own impressions. And...but, you know, obviously the...the credits. If I'm learning properly, I'm going to come out with the credits. I could likely come out with the credits without learning it totally properly too, so, you know, it's not 
really related. I could go to school and, you know, study the night before the exam and come out with the whole thing. So, the credits are always.... (505) They're something I need, but I don't see it.... They're not looming...like they're not hanging over me. I know I'll get them, but I'm just getting more out of it this way, I think.

$A: 0 . K$. If you were talking to another person in... whose life situation was very much the same as yours, a person who has a home like this, in this same area, who has had a career as a nurse but has recently changed and is perhaps also in the prison system now, what would you say to that person about taking Psychology by distance education or another course?

$Q:$ (515) (Pause.....) I think it depends a lot.... You know, if I... if I were telling somebody how I felt about doing it.... I've pretty well told you how I feel about it. It's...it's O.K. for me, but I might enjoy it more if I went into a classroom situation because I like being with people. But for her or for that person it would depend on.... I think distance learning could be pretty scary to someone that's not used to studying. Especially someone my age, because the longer you've been out of school... For instance, my students when I used to teach the Nurse Aid course, (530) and we had a fair number of mature students coming into that, and it was a really frightening experience. And a lot of what we did 
was encourage them that they were quite capable of learning, where I don't think anybody here has any idea, or anybody in the open Learning Institute, has any idea how much learning I've done and whether I'm $0 . K$. out here or not. And sure, in my information it says: If you're having a problem, call such and so and so. I...I don't have a tendency or I wouldn't... Maybe if I was frightened, maybe I would phone and ask for help, but somehow or other I think it's too loose. I think it would be really nice if someone from that place would phone and say: How is everything going? Rather than: Well, phone your tutor. And then you phone your tutor and she says, "Well, have you got a problem? If you haven't, don't phone 'cause it's long distance." (546) That's another stupid thing. I don't know why they couldn't have someone that wasn't long distance. She's in victoria. You know, obviously they're short of tutors, or, I don't know, maybe I.... That's my impression, but I would like someone to phone me and say, "Are you O.K. out there?" you know? Because I don't feel... This is the only attachment I have, and now none of my stuff even goes to them. It goes to the tutor in victoria. And it would be, like I say, really nice if someone would just say, "Are you... are you having any problems? Do you need any help?" I think she might say that when I phone in. You know, it might be a good idea for her to.... (560) I don't know if she doesn't 
understand that this is my first course. I filled out some paper. They sent a paper along and said you don't have to fill it out if you don't want to, but I did and sent it. And...but, you know, I think there has to be a little more to it than just the learning part of it? There has to be a little communication and support and.... I may be a little bit too much that way, but I think people need support in this world, you know, more than just three credits.

A: So, you're making the distinction here between the tutor and the OLA as an institution.

Q: Yeah, I guess to me they're one and the same. She belongs to them; they must have some kind of policies. But then they don't really know what she's doing, and I don't know if all tutors are the same. And I'm not about to phone them up and say, "Hey, is this the way you do things?" Maybe at the end of this course, I don't know if they have.... (pause...) How do you call that? Whether you write out a...

A: An evaluation.

Q: (580) Evaluation, yeah. And if so, then that's when that stuff will come out. But by the time I'm finished, it's too late, isn't it? Maybe they should have an evaluation part way through the course. And say...ask if everything is going $\mathrm{O} . \mathrm{K}$.

A: So you're saying that you feel there's rather a lack of support. 
Q: (agrees) Hmm, hmm.

A: Does that really bother you?

Q: Well, yeah, because I'd like to feel.... I don't know what it is, but I just would like to feel that they're concerned whether I'm O.K. or not? And that...maybe that's an immature attitude, but I think it's because I've never gone to university, I'm not used to being in a situation.... Any... any courses I've ever taken there's always been someone there, and if you're not o.K., they're right there, and you can say right away, you know, "I'm having a problem with this," or whatever. And where I don't... I'm not just sure if I could phone her up and say if you're having a problem. (600) Like, to me she should say on the phone to me, "If you're having a problem, phone me back, and we'll talk about it." But she hasn't, and I guess part of it is likely the response that my friend got when she phoned. Because I don't feel that the door is open? And I...I think she might say, "Well, God! You know, if you read the book, you would have figured that out." And this is kind of funny, 'cause my friend that's taking it, I said to her, "I'm really having a problem understanding this particular stuff. Did you have a problem with that?" "Oh, no," she said, "no problem." And then she gets a 78, you know, so she obviously had a problem and didn't know she had a problem. At least I knew I had a problem. But anyway, so.... That's just one of my complaints, but I guess, 
like I say, I'm used to being spoon fed or being in classroom situations.

A: (618) You used the word.... I'm not sure if you did use this word, but you talked about immediacy there. In the classroom you can immediately get a response. Is that a problem? Is that a difficulty or...?

Q: Well, you know, what I'm learning from this is that maybe I'm too used to, if I have a problem, asking for help right away where.... I did.... I've written down the last two units, when I've been doing them, I've written down questions for the tutor, and you know, I'm having a problem with this and a problem with that, and I don't understand this and so on. (630) By the time I get finished the whole unit, I understand, which is kind of interesting.

A: You're...you're able to answer your own questions, you mean?

Q: I don't have to ask. Yeah, yeah, right. Where I'm just used to, you know, "I'm having a problem with this? What's the answer to this, or how do I handle this?" or whatever. this is making me more... a more independent student, so I guess, you know, that's a good thing too.

A: So being an independent student is a good thing.

Q: Yeah, yeah. I think likely it is.

A: Why is it good?

Q: (640) Well, I...I guess when I finish all this I'll think: "Gee whiz! I was able to answer all those 
questions myself; I didn't have to have my instructor holding me by the hand the whole time? Rats! (both laugh) Now I really can learn this way in spite of myself.

A: I have just one more question. How are you evolving as a learner by doing this course?

Q: Well, I think that's... I just said it, didn't I? I'm becoming an independent learner, which is really (END OF SIDE A)

(BEGINNING OF SIDE B)

A: (656) So $I^{\prime} 11 \ldots I^{\prime} l l$ ask you that question again. How... how are you evolving as a learner by doing this Psychology course?

Q: Well, obviously, I am learning to be more independent and think more for myself and do more looking into the answers of the questions that I want rather than just asking for an answer. You know, instructors are usually pretty good or bad, whichever way you want to look at it; if you ask a question, they'll give you the answer rather than saying, "Well, you know, really, if you look in that chapter again, you'll find that the answer is there." So, I'm gonna become an independent learner and more capable of learning without help. I won't need that tutor at all. She'll just be there to ask me questions after a while.

A: (665) (laughs) O.K. That takes care of my questions. Is there anything that you would like to add? 
Q: I don't think so at this point. I think we've talked about everything that... of particular interest to me. Likely in another two weeks, in another four weeks I may have more to add to that, but I can see things changing already, so ....

A: How can you see things changing?

Q: Well, like I say, in the beginning it was: "Oh, my God! How am I supposed to learn this stuff when I've got nobody to ask questions of?" Now I'm learning that... which.... This is stupid because really I've taken so many courses and I...I have investigated stuff on my own, by doing assignments obviously, but there was always that back-up there, that if I didn't get the right answer or if I didn't exactly know how to do it, I could always even check in again before I did the assignment and get it right before I wrote it all down. And I still really think that obviously if I've got a major problem, I can phone my tutor, and I'm quite certain that if I run into something that I don't understand and I phone her and ask her, she'll answer it for me. (677) It's just that you hesitate, or I hesitate to phone and say, "Well, what about so and so?" And now I'm learning why; I'm glad I hesitated because I have the answers. And now I know that if I just keep my mouth shut and keep learning and keep writing, I'll have all the answers by the end of the unit. I think that's about it, all I can add to that. 


\section{INTERVIEW \#17}

Interviewer: A

Respondent: $R$

Position on tape: (000)

A: Well, maybe we could begin with your...your decision to enrol in distance education. How did you come to that decision?

R: Oh, I applied actually at simon Fraser. I was going to go into their Health and Fitness certificate, and I applied there, and they sent me a thing on distance education, said most students come in with at least 9 credits from another university or college or that and they suggested Open Learning.

A: Oh, really?

R: That's, yeah. I never thought of it before that.

A: Did...did you know anything about it before or not?

R: No. Yet, my husband was taking the open college, but I never really paid attention to it, so, yeah, and they gave me a brochure on it, so I phoned the open Learning and got them to send me the university and the college....

A: (010) The calendar, I guess.

$\mathrm{R}$ : Calendar, yeah.

A: Which course are you actually doing?

R: I'm doing Psychology 101. Actually I dro...I dropped trying to get the Health and Fitness certificate, and I 
decided to go for a Bachelor of Arts with a major in psychology .

A: What... what made you change your mind?

$R$ : Well, the last...during the last year I've been doing a lot of self...self-growth and searching and this and that, and I decided I didn't want to stay a forklift driver for the rest of my life. (laughter) I mean, it's excellent money, but I thought, "No, I want to...I want to start using this thing up here." (points to her head) So I thought, "Well, I really like...like to help people." And I thought I'd like to be a psychologist or therapist or counsellor or whatever. So after talking to a career counsellor, she suggested one way you can go is to get your Bachelor of Arts, major in Psychology, and then go for your master's. So I thought, "Well, a good step in that direction would be taking psycho...the first psychology course." At least that would give me an idea. So that's what made me decide to take Psychology.

A: (021) And are you finding it interesting?

R: Oh, yeah. I am, yeah. I've only been on it for about a month now.

A: Yeah, right. Before you actually started the course, what did you expect it to be like, learning Psychology by distance education?

R: I had... I really didn't know what to expect. I thought, would I get, like, a weekly papers or this or that? But I was quite pleased with what they sent me. They sent me 
a box with the textbook and instructions, study manual, and stuff like that, and I just found it...it was exciting like to get all this, and.... (pause....)

A: Why was it exciting?

R: For one...for one thing it gave me a bit of self-esteem, like: Well, all right; I'm actually doing something for myself, right? And I wasn't prepared to go in a classroom situation anyways. I work odd hours, 4 to midnight, and I just didn't want it...(030) didn't know if any university would, like, accept me without the 3 credits, so I thought, "Well, at least this will be a good start."

A: Right, right. So one of your reasons for doing it is to get those credits so that you might get into regular courses.

R: That's right. That...that was.... Now I think I'm actually going to take a few courses at Douglas College, 'cause first year you can get a lot of your first couple of years there, just to get the discipline of a classroom, just to help me in this. But I want to kee... I think I'm going to keep taking my psychology courses through the Open Learning.

A: Why is that?

R: O.K. Like, it's...for this course you need math. You need one math, and math and $I$ just ca...math and me just don't get along, so I figured I would be better off with 
a tutor, an actual tutor, working in a classroom situation than dist...than a long distance.

A: That's for math you mean.

R: (039) Yeah. So, like, to me for something that I think is a little bit more complicated or something that I'd have a harder time understanding, I would rather have the personal contact and the discipline of going every day, especially a subject I'm not going to really, think that I'm really going to enjoy. With psychology I'm all pumped for it, and all this and that, so...so actually the distance is nice.

A: So are you telling me that in order to do distance it's probably better if you're really keen on what you're doing?

R: Yeah. I think it's a good...it's a good first step to see if you even want to get into a university or college, if you want that kind of a load, because it really introduces you to a lot of study.

A: Yeah, right, right. This is your first university course, I guess.

R: Yeah. I've been out of school since '76. So it's.... (laughing)

A: It's a while. (laughs)

R: Yeah, it's getting back into it.

A: Yeah, right. And you mentioned there the classroom, distance education. How...how do you think learning 
Psychology by distance education is different from learning it in the classroom?

$R$ : (050) (Pause....) Well, of course, going to a classroom, you have to be there at certain hours, certain times and that, where this is more flexible. I think...I think you can learn the same thing. You...you might not get the interreaction between fellow students, but the...at least you can get a hold of your tutor. Unfortunately, I can only...I'm only supposed to call her.... There's two times a week. I think that should be improved upon more...'cause it's Monday, Tuesday, so what if I have a problem on a Thursday or Friday, you know? Thinking you have to hold it all the way to there. So that...that's one little bit of a disadvantage. And (pause....) I don't know. It's just the ti...I think it's more the time thing. y...you can go at your own pace at home, and it's...it's something that I want to do. So I'm disciplining myself to do this 'cause I'm enjoying it. So that...that...so Psychology, taking it in... at distance and a classroom, there's...the time...the time is the benefit; that's the difference. That's all I can (unclear).

A: (061) So, time is the main thing.

R: Yeah.

A: Is there any other thing which is perhaps not so important but it is a difference? 
R: (pause....) No, I.... You're...you're talking like just the Psychology course itself or any course?

A: Not necessarily.

R: Any course?

A: Just a difference between doing something by distance education or in the classroom.

$R$ : Well, the advantage of the distance is definitely, like, people like me that...that.... I mean, I graduated from grade 12 , but I never took university entrance courses and it's.... The en...they...they'll get you...you know, you just have to graduate more or less. I don't think you even have to do that to get in. Like you don't have to go through all the red tape?

A: Right, right.

$R$ : So that's a definite advantage for...

A: Not having to go through red tape.

R: (070) That's right. And then... and plus you just pho...you phone for your course. You don't have to wait in line-up and try to hope that your course, you know, isn't full. Yeah, that's it.

$A:$ O.K. and if those are some of the differences, what are some of the similarities between doing psychology at a distance or in a classroom?

R: I imagine the textbook. The work itself. (Pause.....) That's...that would be...the actual course, I mean. It would be the same course, I'm sure, if you take it in 
there or here. (pause......) That's.... I don't know. That's about...that's what hits me first anyways.

A: Yeah, o.K. When you actually do your studies, what do you do?

R: How do I set my studying?

A: How do you go about it?

R: (080) K. Make sure every.... No T.V., no nothing, unplug the phone, and I'm either here at my desk or at the coffee table, and I lie... lay my books out, I read... I read my textbook, and while I'm reading it, I make notes at the same time. I know I have read study guide where they say it's better to read it first then take notes, not... But for me I like to...even if I'm making too long a notes because I can revise them later. So that's how I start. And then I go into the quiz after I've read, like, the whole chapter, which will take me a couple of weeks to do. I should study at least an hour.... I try to study an hour to two a day, except for weekends. So that's my method of studying is reading and writing it. I haven't had a lot of questions for my tutor. I just...it's just...it seems straightforward enough to me. I haven't had to yet.

A: When you say 'straightforward', what do you mean by that? R: (090) To me it's basically: You read...y you read the text, and you go into the study guide, which is very important. It points out what point... what areas to pay more attention to or maybe to correct something or to 
update something, so I just basically do that, and I... and I quiz myself. Like, I'll go to the study guide, and they have questions, and I'll see how man.... When I can start answering them fairly regularly, then I know I'm ready for the quiz. And then I...then $I$ do the quiz, and I mail it in.

A: Oh, there's a quiz that you actually mail in. And you mentioned the tutor and questions. What's that?

R: Well, if you have any questions, you're allowed to phone your tutor up and ask...ask the, you know, like, you did not... say you don't understand a concept they're trying to get across, and I have two times... Monday nights and Tuesday, and it's about an hour and a half that I'm allowed to ask her questions. (100) But I just haven't found that I had to ask a lot except maybe about, you know, how often she expects the quizzes or something.... I haven't really asked about the core material yet because I'm new to distance education and this course. I've asked her a few little questions like that. But a bit of a problem too is when... when you try to phone, the line is busy?

A: Oh, really? Oh, that's awkward.

R: Yeah, so that's...that's 'cause she must tell about 30 students at least doing the same time, and that's a bit of a drag keep trying to phone her for like... I'm lucky; she's not long distance for me, but you get tutors that are long distance. But I...you still gotta take 
that time, and you gotta make sure you get her between 10 and 11:30. So that...that's something I think they could work on. It's the time thing or give you more times.

A: Like more days.

R: Yeah. Yeah.

A: (109) O.K. I asked you before: Before you started, what did you expect it to be like? A question similar to that: Before you started, what hopes or fears or both did you have about doing Psychology by distance education?

$R$ : Well, fear was that I'd be on that talking...asking the tutor questions all the time 'cause I didn't know how hard... I didn't know how hard the course was gonna be, and being brand new to it, you know, like it was...it was all a big, you know, mystery, and plus part of the fear is: Am I going to complete this, you know? (pause...)

A: Why was that a fear?

R: Just, would it be...would I think it was too hard? A lot of things I've heard about university courses though, (120) they're really hard and you...all you do is study, study, study, and that was just a bit of an influence, you know, just thinking, "Is that true or not?" you know, and.... But actually I'm finding.... I'm really enjoying the class. I don't know; I'm really glad I'm taking it, and I'm glad I'm taking it this way. A: Why is that? 
$R$ : It's just...just the way I can understand it, and it's...it's.... Again 'cause it's an introduction to university courses, and I'm doing it in my own atmosphere, when I want to, and they also give you a longer leeway than...than a structured class too. Like, they give you...they give you up to 4 months to finish the course, where I think it's about 14 weeks. So if you're ill for a week or so, you don't have to worry about, you know, missing those classes let's say at college or university where...where you just...you just take the time off you need and then you get right back into it.

A: (130) Yeah, yeah. So were there any other fears before you started? You mentioned that it might be too difficult and you might not complete it.

R: That was...that was the main one, and that I would be on... on the.... The tutor, I was afraid, too, that if I had questions for the tutor, would they be...would they be patient with me? And like, you know, like, "Oh, God! This person's phoning again about something like this," you know, and.... I haven't found that, but I haven't had a lot of questions, but at least they give you an introductory letter, and she says, you know, "Don't worry about asking any type of question in this, this, and that." And that really helped out too. Actually in her letter she came across very friendly, which the letter was really...really nice. 
A: Oh, that's nice.

R: Talking to her in person she was...she didn't seem quite that friendly, but I still feel like if I have to ask her anything on... on the course, I will, yeah. (140) And I can't.... Fear, I can't really say any other fear was fear just like...just like my own personal fears, maybe not completing it or this or that. That's why I'm starting one course.

A: Yeah, sure, yeah. What about hopes? Did you have any particular hopes before you started?

R: Well, I hoped that I would complete it, do well, (pause.....) that it would open a...it would just open the doors...the doors up... is this...Psychology and Bachelors of Arts, 'cause that's the way I want to go. And that question still hasn't been fully answered because I am only a month into the course. When the course is finished and let's say I get my B.A. whatever, that's...that's really going to encourage me to what way, you know, I'm gonna pursue.

A: (150) When you say you hoped that it would open the door, you mean to further studies, to ultimately a B.A.

R: Yeah, yeah. And actually I'm enjoying Psychology, and I'm also looking forward.... Like, I keep looking in the...the calendar, a Bachelor of Arts and what you can do, and I'm also thinking, well, at least at this point, if I take all my base courses, then if I don't want to major in psychology, I can switch the major and still 
have...like 'cause philosophy interests me and sociology, and I thought, "Well, I can always switch that way too," so this is very handy too. It opens doors, yeah, that's what I mean, yes.

A: Yeah, sure, yeah. And those questions I asked you were 'before you started'. Now that you have been doing it for about a month, how are you finding it?

$R$ : (pause...) (159) I'm find...I'm enjoy...I'm enjoying the learning, the finding, putting some knowledge into this brain, you know, after all these years out of school. And, I'm just finding the only little problem I'm having is sometimes the discipline. I'm saying, you know, "Come on; you got to do it," because I should have sent my second quiz in a couple of weeks ago, and I'm still not going to be ready for another couple of weeks and then I'm on holidays, and it's just hard getting back in.

A: Yeah. When you say 'discipline', you meant before getting yourself to actually do it. That's the main thing.

R: That's right. That...that.... I know that to me is the main... The individual, right. I mean, whether you're going to school or distance, if you're not a disciplined person then I don't think you're going to do well in distance. You gotta want, you know, you gotta want to do this for some reason, for yourself.

A: So are you making a connection there between being disciplined and really wanting to do it? 
R: Yeah, yeah.

A: (170) So for you there is that connection.

R: There is, yeah. I've just lapsed a little bit, but I know I'm gonna pick it up. And, of course, having that four months to complete it, too, I'm not...that's why I'm not also panicking. It's...it's a nice easygoing pace. Like, you don't have to work yourself to death...like, study to death, you know. of course, someone.... I realize that it might take me up to ten years to do this, like, do one course... one course after the other or whatever. But I'm prepared to do that too. So if you're, you know, if you're not in a hurry, I think this is a very good way. And, of course, I don't want an overload, so maybe eventually I will get up to two courses at a time, but right now one is just great.

A: You...you said that if you do it step by step, it could take up to ten years.

R: Well, I'm thinking, too, not only just a Bachelor of Arts but going into the master's too, like to...to get a full counselling degree that I want, that I think I want.

A: (181) So you're...you're taking a long-term view of things.

R: I'm doing it... Well, I'm working full-time now, so there's no rush. I mean, maybe if I had started this, like, ten years ago when I was in my early 20's or so, it'd be a different thing, but now... now I'm just taking it a step...I'm taking it a step at a time. Yeah. 
A: O.K. I have a little series of questions next. First of all: What are you learning about Psychology by doing it this way? What are you learning about Psychology?

R: Actually, what...the part I'm in, it's the study of the brain, how.... It's more bio...it's more biological, and it's more...it's more scien...this is more scientific. So that really opened my eyes, like: "Oh it's more scientific," where when I do counselling, I want to do, like, counselling for people that have been on drugs or alcoholics and that. (191) I want to do more of a person feeling, where it is a bit cold, scientific. But I realize you gotta know that part too, you know. Like... like I think...believe anybody in a profession should at least have some kind of background in something, and to me this isn't necessarily the way I might help people or do that, but at least it...it's giving me a knowledge...alternative knowledge, like, the basics, I guess.

A: So are you telling me that you're not terribly interested in the present section of the course, but you feel it's necessary because (unclear).

R: I feel it's necessary, and it is interesting. It took.... At first I thought I was not gonna like it 'cause I thought, "Oh, this is so cold and scientific," and I'm a real feeling person. I'm not a...I'm not an objective, scientific person. (201) But then I thought, "Well, this also opens the door to me to be more 
objective," 'cause you gotta have bal...I believe you have to have balance. So... so for someone like me it just, oh, it opened my eyes to another way, and after I got into it, I thought, "Oh, it's not so bad," you know, and then I thought, "Well, later I don't have to follow a textbook, buy a textbook. I could put my own views and this into it, but first I want... I should get a base to work on."

A: You used the words there 'I could put my own views into it'. Could you tell me more about that?

R: O.K. Like, well, as far as psychology goes I...I... I want to help. (209) O.K., I want to eventually help people that have had bad childhoods and drugs and alcohol and that, and I...I went through a lot of this, and I'm actually going through recovery stuff now too, so that is my own personal experience that I would think I would be able to put in to help people, and then also adding it with the base, with the textbook. That's where I think is the... is a...a goal, merging. Yeah, where I thought psychology was more...more why people think and that, which I'm sure it's gonna get that way, but in the first course they're doing the stuff like how your brain works, what the neurons do and all that.

A: Yeah, yeah. You mentioned that there's a personal connection. Do you find that's a significant thing?

R: (Pause...) Personal in....in? 
A: (220) You...you said because of your personal background and interests and that, this is...you find that this makes a difference to studying Psychology.

R: Well, for me it does, yeah, because it...it's given me the drive to go into this, and plus.... Like, a lot of people I've talked to, som.... O.K. to me, like, the biological viewpoint and psych...the textbook way is something like a psychiatrist would more go for. And a lot of people I talk to, the psychiatrist has never helped them, where they've gone to a couns...therapeutic counsellor and they say in a couple sessions they have found more than they have going years to a psychiatrist.

A: Is that right?

R: Yeah. Like, I mean, I don't want to really put them down, but I think there's a place for somebody more...more on a therapeu...counsellor level, more of a...more personal. (230) I think psychiatrists are more, like, they're cold...it's colder. I don't know how to really describe it. This is just, you know, I've got this from talking to... I've talked to a lot of people, and I've gone to a lot of, like, Twelve step meetings and this and that, and I pick up on all this stuff.

A: Yeah, yeah. O.K. My second question in this little series: What are you learning about yourself by doing this course through distance education?

R: About myself? That...I...that I'm...I'm studying again, and I'm...I find I can go right back into the flow of 
studying again? That it's so rewarding; like, it...it really boosts the self-esteem. (240) And it's like being.... Accomplishment...it's a challenge, but it's a positive challenge? You know, it's like...someone like me that...that's been out of school for so long, it's like an awake...almost an awakening. Like, wow, I'm using my, you know, brain; I'm not just doing manual work and this and that. I feel like eventually I'm gonna make a difference. Like I want to do...I want to find a purpose, and I thin...this...this gives me the esteem to think: Yeah, I'm gonna make a difference one day.

A: You said: I'm going to find a purpose. Can you tell me more about that?

R: Purpose? Like.... O.K., I'm sure I serve a purpose being a fork-lift driver and stocking shelves, but I want to do something more for people, more...more helping, and that's...again going into the counselling, I want to help people more personally. (250) So even taking this psychology course, it's...it's giving me...like, it's my first step. Like they say, one step at a time, and to me that...that's first step, and that's where I am, and that's great; it feels really good.

A: Sure, yeah. And you've mentioned a couple of times that it's a long time since you last were at school and studied. Could you tell me more about that?

R: I graduated in '76, and I never... Well, actually I did. I took a medical terminology course about five 
years after I graduated, and I found that really interesting, but I just let that drop. I just...I just didn't feel like using my...my intellect that way, like going to school and studying that way. I've been doing a lot more of... (260) I've been taking, like, selfimprovement courses, stuff like that, just personal development and growth and this and that, and I just.... I've just come to a step now where academic seems....it just fits right in right now. I'm ready for it where I wasn't ready for it before. I think I would... I would definitely not have had the discipline. Plus the opportunity never came up to me. I never heard of open Learning or distance education until I got that flyer from SFU. And I was almost going to throw it out. It's funny because I thought, "They rejected me." And then I

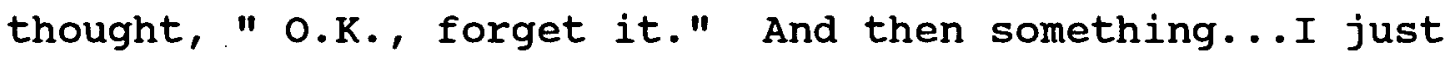
picked it back up, and I thought, "I think I'll...I'm going to give them a call and see what this calendar's about." And I saw all the courses. Oh, yeah, I'm....looking g...oh, good, I'm gonna... after this.... I can hardly wait till this course is over to take 102 . (270) Yeah. Like, I know I'm gonna keep...I want to keep taking course after course.

A: Right, right. Oh, great. And last question in this little series: What are you learning about distance education by doing this course? 
R: (Pause.......) The freedom it gives you. I'd say the freedom. And, again, not that red tape just to get in, no line-ups, hassles, that way. It's...it... (pause....) And it's good for anyone that, I would say, that would work shift work. (279) Like sometimes...sometimes I work overtime, and I work tenhour shift work, and it.... In slow parts at work, I'll bring my homework and do it there too, which I guess I would.... I could still do my homework even if I was going to a...a college, but also I'm more available for overtime if it comes, where if I was going to school, you know, I'd have to decide. And I also instruct aerobics, so I'd have to give a lot more of that up too if I would have a structured time. I'm not a person that likes structured time anyways. I work 4 to midnight. I don't like working your 9 to 5 shift, and I'm happy on it, you know. So for someone that doesn't like structure, I'd say distance is a good start, yeah.

A: Yeah. You mentioned the word 'freedom' there. In this context what do you mean by freedom?

R: (290) The freedom basically to study what hour you want, you know, to actually do it any time you want to do it: midnight, go ahead, you know, 8 in the morning, in the afternoon, whatever. And, I mean, if I want to throw it all on the floor and study, do my homework course on the floor, I can do it, you know, that... or I'm not sitting in a classroom. And, you know, sit at this desk and this 
and that. And also there's, like, there's not really the distractions where maybe in a classroom you'd have somebody keep asking questions over and over that...that.... You understand it, and you're going, you know, it's almost a waste of your time, where here there's nobody there, you know, to start that. As long as I can unplug the phone and make sure that I let people know not to come around, stop those distraction. (300) You know, it...it's just all up to you. It's...that's the freedom. It's all up to you.

A: And you also said that you're...you're not a person who likes a lot of structure. So how do you relate that to liking distance education?

R: There's not much.... I wouldn't say there's.... It's not a strict, confining structure in distance education. It's... You... I feel like you go at your own pace. Mind you, you've got the four months. You've got to do it in those four months, but... but I find even if you just study a couple times a week, you're gonna get it done in the four months.

A: So when you talk about lack of structure you mean...you're talking about the time constraints that aren't there.

R: (310) Yeah, yeah. Like, usually in a school you'd have to do it in 14 weeks, so if you had vacation or you had this or that, that's too bad, you know. You've got that 
14 weeks, and there's that exam, and you have to write it.

A: Yeah, right, yeah. So for you what are the important things about distance education, about doing Psychology by distance education?

R: (Pause.....) Basically, introduction to university courses because I needed that introduction to know if I wanted to pursue this way or not, in my case anyways. (320) Yeah, it's a good introduction to just get the mind going again 'cause, I...I don't know, I feel like...it's like starting an old engine up again, you know, getting into a study thing. It's really.... I didn't fall into it the first few weeks, you know, but I got... now at least I got a...a plan now or a...a pattern that I'm going by.

A: Can you tell me more about that?

R: Yeah, it's when I do my studying, I set everything out a certain way. I'm an exact...exact type person, you know; I like things here, here. And I'm gonna read, and I write, and I just... and that's all I do; that's all I think about is.... My study time is: I'm right there, and that's it, and I don't... and I almost overdo it, and it's almost: "Oh, my two hours are up." (331) sometimes I'll go a little longer, but shortly after that...'cause I don't want to burn out either. I feel that with distance education you're not going to burn out the same either. And I would attempt... I think I would...will 
attempt...I would attempt two courses through distance at one time but not yet. You have to build up to it.

A: Yeah, yeah, sure. Is there anything else that's important to you in doing Psychology by distance education?

R: Well, being only on this first course, it's...it's a...it's a basic course, so it's pretty good doing it this way. I have no real complaints about the course or anything. It's just the...the tutor should be available more often. Like, I asked her if I could have other...different times instead of two days in a row. She says she couldn't do it. She's gotta be at this phone at a certain time because she does more courses, and that...that was a little bit of a downer, thinking, "What if I have a problem on Thursday or Friday? I have to wait till Monday." (245) You know, I think that... that's one thing they could look at and having -- you know, those phone lines are always so busy -- maybe fewer students at that one time. You know, like, I can see going... when I get into the more advanced courses, and you...you might just need more explanation or that tutor input, that, you know, if I'm gonna get a busy line all the time, that's gonna be really frustrating.

A: Yeah, you're right. O.K. I've been...I've been writing down what seem to me some of the key words that you've used. I'll read them back to you, and I wonder if you could tell me: For you is there any particular 
relationship among these things? So, you've mentioned that being able to do it at the times when you want is very important. It opens the door to other university courses, perhaps to a B.A. for you. (360) You find that it's boosting your self-esteem, and connected to that, you're getting back into studies again. And then you've also mentioned this thing that getting in touch with the tutor is sometimes a bit of a problem. I think those are perhaps the main things you've mentioned. Do you

yourself see a relationship among those? Shall I...shall I say them again?

$R$ : Yeah, just, yeah.

A: I've scribbled them here. (Shows paper to R.) The time, that you can do it when you want. It opens the door to university courses, maybe a B.A. It's rewarding; it boosts your self-esteem. You're getting back into studies through it. And also there's this problem with the tutor.

R: That's right, yeah. Yeah, those...those...I would say those are the major things I...I feel about it.

A: And can you make any relationship among them? Is...are there connections, relationships?

$R$ : Oh, yeah. The freedom I was talking about is the time. The freedom.... Also opening the door to other...other universities or whatever. It...it's...it gives you a gateway if you, you know.... Do you want to continue doing this, or do want to actually go into university, 
like, or do you even want to pursue a different way altogether? Like, yeah. (381) so to me that...that's... this is all the freedom; this fits in with the freedom, you know, the freedom of choice type thing. (pause...) I can't...as far as the rewarding, boosts self-esteem, I can't see how anybody if they pass the course how they wouldn't...it wouldn't help their self-esteem in some way. Especially, well, if they're doing it for...for something personal, not because somebody else wants them to. And, of course, my freedom theme fits into that. (laughingly) And getting into studies, again, yeah, the time...getting into studies gives you the time to take that you have to take.

A: Yeah, sure. You mentioned an interesting thing there. You said this boost to self-esteem, at any rate if you're doing it because you want to not because someone else is pushing you. Can you tell me more about that?

R: (393) O.K. I just said that because it's...I've heard of people, they want to be a painter and their parents want them to be a doctor. Well, they're going...I think they're going against what their heart's desire is, and I don't think they're gonna...they're not gonna get the self-esteem from the doctor course, 'cause they're doing it to please so and so.

A: And in your case?

$\mathrm{R}$ : I'm doing it to please me, like nobody...nobody is telling me to do this. I...I decided that this is...this 
is a door opening for me. And if it doesn't work out, I'm not gonna...I'm not gonna dump on myself for do...for it not working out. I'm gonna be thankful for the knowledge I have learned because the stuff I've been learning, like on how the brain works, it's just.... I find it's...I find it fascinating. And even if $I$ don't use it in psychology, I'm still...I'm still gonna always know that. Like, they had a show on epilepsy one day, and because epilepsy is something we take, like, everything they were talking about made perfect sense. (410) You know, like...like it's just understanding, more awareness. So, like to me, knowledge is never wasted, of anything. You know, I'm even thinking of taking courses that might not even have anything to do with my Bachelor of Arts. You know, I just... I want the knowledge.

A: Yeah, and you said something there about more awareness. R: More awareness. Oh, yeah. Like, I feel like... It was, like, a show on the Knowledge Network on... on this boy that had epilepsy and an operation, this miracle operation they did. And the way they were describing it and that.... Like, my husband was watching it, and he was going, "I don't know what they're talking about." And (unclear) I did, and it made sense, like they...this miracle operation, I thought, "Well, it's not really that much of a miracle when you think of the basics." You know, it was just sort of fascinating, like, how I picked 
this up, and I'm going, "Wow, this is a...a medical type show, and... and this is just from taking the first chapter in Psychology 101, so..." (laughter)

A: Well, by the time you've done 2 chapters!

R: (425) You know, like I'm going, wow! And people find it fascinating, too, when you talk about...about certain things. Like, I try to word it in the way I feel it, not textbook language, and some people go, "Well, really? Is that what happens really?" you know. Yeah, so it's...it's great for sharing too.

A: Yeah, yeah. Sharing's an important thing?

R: I think... Well, yeah. Like, I...I know somebody that's...they're taking anthropology, and they're not going for a Bachelor of anything, and I've...now they've got me, so that's one of the courses I'm definitely going to be taking.

A: Oh, great. If you were talking to another person who was in a situation very much like yours -- a young woman who worked in the same kind of job as you, lived in this area in a similar apartment, had a very similar life to yours -- what would you say to that person about taking Psychology by distance education?

R: (440) I'd say it's good. It'd be the best course to start with if you want to go into psychology. If you wanted to go into something else like philosophy, I'd say take philosophy first. I definitely think...'cause that's the door opener to me. Yeah. 
A: And what about doing it by distance education?

R: Well, for one thing, places like simon Fraser, they want you to have the credits to start with, so you can at least take...they (unclear) recommend at least take 3 courses. And that was my goal at first, but I think I'm going to take more. But I would say, you know, it's a good place to get your credits is to start... and I would recommend to start...take...take something that you feel you'd be more interested in than maybe, like me, I didn't really want...I don't... not looking forward to the math one. So that's not what I'm gonna start off with whereas Psychology I was just all hyped up for it. So I would tell them: take the one you're hyped up for first. (455) And... and another thing I...that's a positive too is I don't have to drive all the way out to simon Fraser and forget UBC, you know.

A: Oh, from here, yes.

R: Yeah, so...so there is another convenience is I don't have to get in my car and drive and use the gas and extra time to go somewhere. That is a big plus, especially when you don't like driving in the cities and.... Yep. so for somebody out this way, that's a big, big plus.

A: How are you evolving, changing as a learner by doing this course?

R: Like I pointed out, like, picking up little things, like on T.V., like Knowledge Network, or just...just something 
in general. Wow! You know, of course that makes sense, and things just click. It's like being...like an awareness; things are just clicking. (470) And selfesteem, I'm feeling better about myself. I feel like... it gives me purpose, you know; it gives me a challenge, a mental challenge, which is something I lacked, and I realize that I did lack that way. So it gives me that extra boost and to know I'm do...I'm work... I work hard and I... and to get a good mark or something I know: Wow! I worked for that mark. Like, good marks don't come easy for me; I gotta work for them, but that...that's to me is the whole thing about it, that why get something that's gonna come real easy, you know.

A: Yeah, yeah. So in terms of actually evolving as a learner, how does that fit in there?

R: As far as learning. (Pause....) Well, I realize that studying isn't as hard as I thought it was going to be. once, you know, once $I$ 'm in that mode, I enjoy it. (485) Everything else just goes away for a while, and I just enjoy it, so... And I'm learning, and I know I'm picking things up.

A: Is that different from how you used to feel when you were doing courses?

R: Yeah, this is (unclear) way different because, like I say, I was taking more, like, personal development courses, or...or non-credit courses, and there's...with the credit it...the chall...there's definitely a 
challenge, and it's different. It makes.... I feel more.... It's more responsible; you feel more... I feel more responsible. Like, it's more...it's more, like, I don't know if 'serious' is the word, but it's more official?

A: (495) More official than?

R: Than a non-credit course. Just something you're just taking like.... It...one thing it... it goes on record, that this course, you know, what $I$ do is going to go on record, and it just fee... it feels serious. I don't want to make it sound stuffy; it's not stuffy; it's...

A: You used the word responsible there. Could you expand on that a bit?

R: Yeah. I'll try...you know, it's hard trying to get the feeling into the word. Responsible is...the ser...the serious...it's serious, it's responsible, it's... (pause.........) it's.... I don't know how... I'm trying to clarify it.

A: (510) When you say 'responsible', do you mean you feel more responsibility in some way?

$\mathrm{R}$ : In some way, but the course comes across serious.... It's an adult course versus high school where... where, you know, if you want to do... if you.... You're doing this 'cause you want to, not because you have to, and the fact that it's gonna be on your record, and if you want to build on that, there's more responsibility for you to, 
you know.... I feel like you wouldn't go into this unless you really wanted to to get anything out of it.

A: Right, right. So I think you used the word 'adult' there. Perhaps that's really what you mean.

R: Adult versus high school where... where there's, you know, you didn't feel so responsible. (524) you just went there 'cause you, I don't know, a lot of people because you're expected to go, and everybody takes the same type thing, and you're in the classroom, and they take attendance and make sure you're there, where this...this is...the responsibility is on to you, you know. It's up to you if you want... if you want to learn, and you know, they're not gonna take your hand and help you that way.

A: I gather you enjoy that?

R: Yeah, yeah. Non-structure! Yeah.

A: Well, that actually takes care of the questions I have. Is there anything that you would like to add?

$R$ : Just that when I do phone the open Learning and I ask them about Bachelor of Arts degree like, what courses, or if I want to take.... Like I told them I want to take some Douglas College, they're very good. They were very nice to me; they said, "Well, O.K. (539) This is equivalent to ours." And then when I went through what class I was thinking, like, they didn't act like, you know, like: "You're gonna go to another place?" It was really nice that they did that, and actually one woman said, "Actually their course would be better for you to 
take." Like the math one, she says, "It's a lot easier than ours." And I thought, "Oh, that's really...I'm really impressed that they didn't...." I didn't feel like that they wanted my money and just wanted me to keep going there. So...so the people on that phone, on the other side, they...they sound like they're very patient; they ask...answer all your questions. I really enjoy phoning them. If I have a question, I don't hesitate that way.

A: Oh, great.

R: Yeah. Very informative and.... And that saves time too, if you're making a counsellor appointment, going all the way out, you know, telling the counsellor, well, how to help you plan. You can do it on the phone, which is what I've been doing.

A: Sure, great. Anything else?

R: No, not really. Not that I can think of anyway. A: Oh, well thanks a lot. That was really great. 


\section{INTERVIEW \#18}

Interviewer: A

Respondent: $S$

Position on tape: (000)

A: O.K. So maybe we could begin with your decision to enrol in distance education. How did you come to that decision?

S: Well, I've decided that I want to get a degree, and my degree of choice was a Bachelor of Arts in Administrative studies, and I transferred all my credits from BCIT towards that...that degree program here at open Learning, and my credits put me towards... into, just one course into my second year of the program, so at this point in time I'm taking Math 102, which is Probability and statistics too, which is a continuation on into the program.

A: So you're saying that you transferred quite a number of credits from the BCIT courses.

S: And ended up.... My 50 BCIT credits translated into 33 credits here, so.... And I assume that, like, 30 credits is equal to one FTE, which is one full-time enrollment for one year, so I had 33, which puts me in my second year.

A: (011) Right and you're doing that one course, Math 102 .

S: Yeah, that's a continuation of.... in addition to the 33 credits now. So I believe it's a 3 credit course too; I don't (unclear, thinking aloud). 
A: If it's a 3 credit course, it's normally 4 months?

s: Yeah, that's right, yeah. You can do it as little as two months, or you can do it as many as six months, but the normal completion time is 4 months. And I...I'm trying for that right now. Actually I mi... I think I might be going a little faster (laughs), because I'm, you know, motivated, and I...I'm used to a certain speed from when I was at BCIT, so I...I guess I'm more disciplined because of that, my previous experiences with BCIT, schooling, and that motivates me more to...to do the work required for the course. I don't procrastinate as much I suppose. (laughs)

A: (020) You used the word 'motivated' there. Could you tell me more about that?

S: For me, I...I'm just a person that can't let something sit there and say, "I will not do it." To me, if you've got... if you've set yourself a goal, you fulfill it, and that means, in this case, following the time-line given for the course, except I'm just doing it a little bit faster; I'm a week ahead right now. But it's something I want to do, and I'm gonna do it (laughs) basically. I mean, it's as simple as that.

A: Yeah, and you also said that you felt that you were disciplined partly because of what you had already done at BCIT?

S: Yeah. I could...I can honestly tell you that if I'd never taken the courses at BCIT and I...this was my first 
distance ed. course, I would have real problems, I'm sure. I would...I...I wouldn't be as disciplined to sit down and do the work, and I probably might have problems understanding, whether it be a conceptual level or whatever, the course material that... (031) Because I've had the experience of bouncing off ideas off of classmates, off of teachers and most recently because of my BCIT experience, I think that's...that's partly one of the reasons why I'll probably do better than if I had never taken those courses (unclear) at BCIT (unclear).

A: What's the connection there between bouncing ideas off classmates and teachers and being disciplined?

s: It's more rigid, I guess, because you have to go to a class at least once a week; you're given a certain amount of work to do by a certain amount of time, and you have to come back and do that. You never know if you're gonna get spot quizzes or...or whatever the case may be. If you didn't understand something exactly the way you think you should, you always can turn to a classmate: "Well I read this...this segment, and what did you think of it? This is what I thought." (040) And we can collaborate and come to a consensus, and if we're still not clear on it, well, then we talk to the teacher about it whereas with distance ed. you don't have that kind of contact with other students. I mean, I could bounce it off my brother or sister who have been at UBC, and the contacts which I've had with my tutor so far, it's a little 
difficult because.... (laughs) well, she told me just recently that she didn't really agree with the course manual, so it's very difficult for me to understand if I'm going to do the course as laid out, as it is for this...this particular course I'm taking, and I answer according to the way the materials are teaching me, and she marks it differently. (laughs) That's one reason why I'm going to contemplate a tutor change from her, because I'm finding that...that those comments that she made to me are distracting me immensely in my studies 'cause now I'm thinking: How should I answer this according to what...the way she thinks it should be answered as opposed to the way the course is telling you to answer?

A: (050) So you said tutor is actually marking sort of contrary to what the manual says?

s: Well, basically her wording to me was.... 'Cause I enforced my answer with what I had in the course material plus other sources from the textbook, and when I...in a particular response to the one that I sourced from the course manual, which is written, I guess, from the OLA (unclear, thinking aloud) course writers, she said, "I didn't write that, and I don't agree with it, and the mark stands." And that was her...her statement. And I...I...I was just dumbfounded; I couldn't believe it. I said (laughingly), "Well, wait a minute. If I'm supposed to do this course and I'm supposed to do it well, how am I supposed to understand if you have biases against the 
course that are going to affect my marking? How am I supposed to interpret every step along the way how you're going to think it should be done when the course might be telling me a different way?" So, I mean.... (laughs)

A : (060) What... what was her answer to that?

s: Nothing really. She didn't really seem to be too concerned, and after a little bit of nudging and prodding in that direction, she finally said, "Well, if you want to, you can send in the ones that you still have problems with my...my response to, and I'll look at them again, and I could possibly, you know, send in a change of grade for your...for those questions." But, I mean, those are mutually exclusive comments. Everything she said is contradictory to the fact that she would do anything like that anyhow, which makes me think that I'll probably go to the coordinator and ask for a tutor change.

A: You can do that.

S: Yeah, I can do that. And I think I would...I'd prefer to maybe have the senior tutor in the course that obviously would support, hopefully, (laughing) the course manual and the textbook materials. That'll make me feel better because I'll know that what I'm doing is what the book says and that's the way I'll be marked. And that would seem more fair to me. I mean, because... (070) I...I mean, I was disappointed when I got my first assignment back because it... it was a 77\%. Now I know that's a B+, and that's, you know, good, but I usually...I get $80^{\prime}$ s 
and up, and it was sort of, you know, a little... I was expecting more, and I thought I'd done a really good job on the first assignment, and in one case I lost marks on a question that was worth ten marks -- I got 4 on it because it was just a misinterpretation of the way the question was worded -- and that's fine; I won't dispute that, but these other ones that I've mentioned, that she doesn't agree with the book, cause me great problems. (laughs) So, I think, you know, I'll just do the obvious thing and ask for a tutor change, and I think once I explain what I've explained to you, then I don't think there'll be a problem of getting one.

A: Yeah. How long ago did you start the course?

S: Beginning of March.

A: So that's one month.

S: Yeah, just one month. So I...that was...that first assignment was...reflected the first six chapters of the textbook (unclear, not thinking aloud) Unit one. (080) Now I'm in Unit Two, and it covers chapters 8 to 12. You can read 7 if you think you need the preparatory into 8 , and I'm at Chapter 11 now, so... And I...I say I'm ahead, so I'm, I mean, maybe I'm going too fast also, but I'm going to go back. I...I've reviewed everything so far, and my understanding of the material is fine according to the textbooks and everything so.... I...I just would feel more comfortable; also obviously there's that difference there, and she's not very flexible on the 
way she's gonna handle it, so... I don't have a lot of time to dilly-dally hoping that she'll change her ways before my 4 months is up if I follow the time-line. I don't want to think, "O.K. Well, maybe it'll be different with my second assignment," and then not get as good a mark again, 'cause I don't think I should have to suffer in my marking because of her use of the way the course material is.

A: (090) Right, so that...that's obviously a sore point with you. (laughs)

S: Yeah, well, I wasn't...I wasn't too pleased. I...I'm not gonna lie about it; I wasn't too pleased the way she was so blunt and... and as a matter of fact about it, you know, so.... There's really no point in even discussing with her, so I didn't bother. I mean, like I said, her comments were mutually exclusive. One says she'll... she'll consider it, but the other one, she says the mark stands and the other she says, "I don't agree with the course manual." (laughs) //A: Oh, yes!// I mean, I...I'm... I mean, I still think that from the course manual and the textbook that this is a course that I think anybody, you know, has a reasonable understanding of mathematics, they'll do really well at it because... I mean, I was never very good in high school at math, and then a couple of years ago I decided that I'd lick that, and I took an Algebra 11 through the school board, and I got an $A$ in the course. (101) And I think that was 
mostly because of maybe my immaturity in high school, and I didn't want to pay attention, and I had more at stake to want to learn when I did take it again later, and, again, also taking the course now, I...I have a personal stake in what I'm doing, and it's...it's something I want to do for me, and it's something that'll ultimately help in my career goals. And that's why I do it, and I think the.... I think it's very methodical the way the course is laid out; I really do. I was quite impressed. I mean, considering I've worked here as long as I have and I've never really seen a course manual, or a course, you know, in its entirety, entirely, like, from the box that you get, I was...I was quite amazed at how easy it is to follow. I...I mean, I'm sure people who.... (110) I mean, there's some things that I know that regular students might not know like filling out the TMA forms. Those are the tutor-marked assignment forms, you know, filling out your address on the reverse side and things like that, silly little things that obviously, I mean, make everybody's life easier if you do them, but if you miss it the first couple of times, big deal; you...you figure it out after that when you've been told that you're missing filling out the forms. But I think it's a pretty good course; I mean, I really do. I think it's.... Considering the content that it could be.... Probability and statistics, I mean, I'm sure that those ideas might frighten some people who aren't that great at 
math but, you know, have a fair level of understanding. They might just think: I don't want to do it. (laughs) And I know myself a couple of years ago, I thought I could never do that, but, you know, you change, and you...you try things, and you're successful if you really wanna do something good.

A: (120) Yeah, yeah. When you were talking about the course manual, the materials there, you mentioned the word 'methodical', and what... what else is your impression of the materials?

S: Well, first of all, it gives you a study plan that says: o.K. You're gonna read this chapter from this page to this page, and then, as you go along, you're gonna do this exercise under set $A, B$, and $C$ all the way along, so it reinfor...reinforces your learning as you go along in the reading of the chapter. I mean, it could just basically say: Just read the chapter, and then we'll do questions at the end. And that could be difficult, you know, in this kind of course. You have to reinforce your learning as you go along 'cause you're basically doing building-blocks on what you're learning, and if you just read and then start to try and build your pyramid, it might be more difficult than as if you go along and do it. And that's the way the course does it. You read, and as you read, you do the exercises that reinforce the...the bits you've just read, and then after that they have this section called "Comments". You have to read 
these comments about the chapter you've just gone through, and it reinforces the...the main strong points that you have to remember to be able to carry on, and then you have a few more test...practice assignm... questions, and once you've done those then you go on to do the actual assignments in the...for...for... which you'll be handing in. And each...for each one chapter that you do, matches like a question number in the assignment, so if I did Chapter one, the first part of Assignment one would be, like, Question 1, and sub to that they would give you review exercises from chapter one to do and maybe some additional ones that they've thrown in. (141) So, it's really quite structured (laughingly); it really is. So I don't think there's really much mistaking as you go along what you're... what you're doing. And then they have other reading -alternative (unclear) theory I think it was -- additional reading if you want to do it after that. And then you go on to the next chapter, and you go through the same steps. So.... (laughs)

A: You used an interesting metaphor there, you...you said it's like building-blocks...building a pyramid.

S: Yeah, I think so. I mean, because.... I don't know; it...to me it... you do...you read something and: oh, that's nice; that's fine. But if you don't really apply it right away, are you gonna remember it when you finish the chapter and have to go back and basically would have 
to read it again and... and then do the assignment then? (151) So really you're doing...you read, you do a bit, you read, you do a bit, you read, you do a bit, and keep going like that, and it's.... I don't think there's really much of a chance for not understanding it, you know, unless it's...they...they're trying to block too much of a...an idea into one area actually prior to the assignment. So.... (laughs)

A: Before you actually started doing this Math 102 by distance education, what did you expect it to be like, doing it that way?

S: I don't know. I was (pause....) I...I...I really wanted to do it. I've been wanting to do this particular course for some time. And it is a part of my degree requirement, so that's fine; I'll take it as my first one, and... (160) I don't know. I just get in these...these phases where I get so motivated I have to do something with my spare time, and it's been some time since I finished doing my...my courses at BCIT. In fact, it's almost been six months, eight months since I finished my courses there, and in between that I've only taken a gourmet cooking course (laughing) to while my time away. But, I don't know. I just wanted to do something, you know, that was towards my degree, and something I've wanted to do for a while and... and obviously it offers.... Actually what I find, it's...with the distance education as opposed to going to 
a classroom, it's much more convenient. It's so much more convenient because I can now sit through, and I can go through at my own pace, which I am, which is slightly faster right now, (170) and if I...if I need to slow down, I can slow down, whereas if you're in a classroom you have to do this and this and this by such and such a time, no matter what, if you expect to keep up with the class. And sometimes that can be really drooling... grueling, sorry, because, say you have to read three chapters within one week's time. Sometimes, especially if it's really heavy material, like, I mean, really intense stuff, I mean, that's a lot (laughs) to do, and especially if you're working full-time and you've got other things on the go just besides that, you know, it can really pull a strain on you. But I mean, that's...that goes back to this...the thing that I said before, that you get disciplined for what you do, and it comes to doing this course now, (180) and one of the things $I$ find is I don't feel as under pressure for my...for deadlines even though I'm making my own personal deadlines that are maybe faster than the course I'm in. So it works better for me (laughs), and...than if I were in a classroom situation. Some teachers like to go faster; some teachers are willing to hand out notes to you; some aren't, and they'll...they'll talk so fast that you'll never be able to keep up with them. But this way it's all there for you, and, you know, you can just 
highlight the things you need to know, and they also... in the course manual they highlight those, you know, by writing out what are the important points to remember, and it's all written there for you anyhow, so there's no mistaking what you be remembering.

A: So... so when you say it's convenient, I think you mentioned three things which come under that. You said that you can do it...you can take the time that you want, you can go at the pace that you like, and you are actually given the notes. Those would be the three things that make up convenience.

S: (191) That's right. Oh, yeah. Oh, yeah. For sure. When I first got the course...the course box, and I opened it, I...I mean, I probably did what maybe most students don't because I was just sort of testing because I work here; I wanted to see that everything was done. right. (laughs) O.K. So, I mean, I looked, and I went through everything that the contents page said that should be in the box. There was only one thing missing, but it was inconsequential; it wasn't a big deal. And when I started looking and I...I thought, "Oh, God! This is going to be so much." I thought at first, you know, because I thought, "Unit one, maybe one...." You know, I didn't know how many chapters it would entail, but each unit entails six chapters of reading, and then when you think there's five units, "My God! I'm actually gonna read this whole book," you know, (201) because in the 
courses at BCIT, you don't usually read the whole text that they give you, but I don't know. You do it in twelve weeks and you.... And another thing: you have a mid-term exam at BCIT whereas with this we have one test at the end. That's one...one thing I like is that... if you have a mid-term 'cause you can check how you're doing as you go along. That's the only thing I would think I would like to be different. Because when you have a midterm, it's not nec...it follows, in most cases, that what's on your final wouldn't have...it's been what you've learned since your mid-term, so you don't have to cram as much information into your mind to remember, whereas with just having one exam, you got... I got a lot to remember. That's the only thing.

A: (211) Yeah, right. So, this is something you've already touched on, but how do you find that learning math by distance education is different from learning it in the classroom?

S: (Pause......) Different in what way? Jus...just the different...the way....

A: Any way.

s: Well, there's.... The difference is you don't have student contact. That's one. You don't have.... I don't...from the dealings I had with my tutor so far, I don't really feel a connection there, even before what I found out just recently about her views of the course itself, which obviously distresses me somewhat because, I 
mean, if you're in the business to tutor the course, you should be there to fully support it. (221) I mean, she doesn't know that I work here. (laughs) I didn't want her to know that I worked here, and I didn't want her to know what job I did because I didn't want to bias her on marking me because I thought that could happen also. But, I don't know. I think it would be nice if you could have a combination of being able to do distance ed., which offers all the conveniences that it offers, to do it the way you.... You can do it within your time-frame but be able to still maybe have a student support system where you could turn to people and say, "Hey this is what I'm looking at, and this is how I interpreted this." You know, or get together and do study groups together, something like, you know, that. I mean, it's not essential. I mean, to me I...I work well alone, but maybe for some people that might be good also, to have that support system. (231) But obviously not every student would feel that way, and maybe that's... when they apply for their course, register for their course, there can be some kind of tick-mark they can put somewhere and say, "I would be interested in participating in student support system in this course." And then they'd, you know, they'd be the ones included; their name could be distributed between the student. That's really needed. A: But you're saying for yourself it doesn't seem/to matter? 
s: Not at this point in time for this course because I'm...I'm doing O.K. I feel quite comfortable in it. But, I mean, obviously there's gonna be some courses maybe that I don't feel comfortable with and that I really need that support system to be able to bounce ideas off of, to be able to check my understanding against someone else's understanding and interpretation of what I'm reading. (241) I mean, things like that can obviously come from a course like English maybe, which is open to a lot of interpretation. But I think it's important that a student might have that option.

A: So you see the main difference between distance ed. and conventional education as this having others, having interaction with others, and not having interaction with others.

s: That's right.

A: Is there any other particular difference?

S: (Pause...) You don't ever see your teacher, (laughs) which... or your tutor in this case, which would be nice. It's.... I...I don't suppose it really should make a difference, but it's... it makes it more of a personal thing, you know, instead of just this voice you hear over the telephone. (250) I mean, sometimes.... Like I know, when I used to work in exams, people will say things to you, and they won't be very nice to you because they know they'll never see you. And I... and I sometimes think that, you know, if you remove that barrier, maybe being 
able to maybe meet one-off with your tutor or have, maybe at the beginning, a course. At the course you get this opportunity to meet your teacher in person, maybe even if it's only that one time. Then you know who you're talking to not only from the voice but you have a picture in your mind of how that person is, and maybe you had a chat with him before, and maybe if I had had that experience with my tutor that I have now, I could have understood her biases before I went in and started answering my questions on my first assignment, and I might have been aware of that, and it might not be a problem like it is now.

A: (260) So you're saying that this lack of personal contact is a difference which is perhaps significant.

s: Yeah. Well, it seems to me that if I had known her biases towards the course right off the bat, I could have obviously compensated the way I answered my questions accordingly on the first assignment. But I didn't, and obviously my mark suffered because of that, and I... (laughs) I don't think it's fair, but I'm not gonna sit... I'm not gonna squabble over about five marks or so, because it's just not worth the headache. It's just easier to just get a new tutor and start afresh and then proceed from there. And that's what I'm gonna do.

A: If those are the main differences, what are some of the similarities between doing math this way or that way? 
S: (271) Well, I don't suspect that the...the course content could be much different. I'm sure it's probably gonna be the same, 'cause you...you still have to relay the same ideas and I...concepts behind the course. you're taking. It's just a different way of teaching it because you're doing it...basically you're doing it to yourself whereas in a classroom it's being done to you; it's being taught to you. Also (pause.....) well, I don't.... I suppose this is a difference again. With a classroom, you know, a teacher is going to obviously inject their ideas into something whereas when you're just doing it yourself, you're always... you only have your own ideas to put into it, and you haven't got.... (281) Again it's the support thing and the bouncing ideas off of it. similarities, let's see: course content.... (pause...) Well, you have a final exam, but there is no mid-term. You do have course work to complete, which is, in the case of the course...the dist ed., its the assignments and whereas if you get a classroom case you might have quizzes or you might have to do assignments aiso. It depends on, I guess, how the teacher would structure the class. (pause......) That's about it.

A: (291) There was one thing you said there. You said: Doing it by distance ed. you have to teach yourself. In the classroom the teacher teaches you. What really is the difference between those? 
S: You're relying on someone else to tell you how to understand something, whereas you're...you're obviously using your own independent thought and ideas into understanding the course material in distance ed.

A: So, what you're telling me is: When you do it by distance ed., there's more input from you.

s: oh, yeah. Oh, yeah. It...it just won't work without you. I mean, 'cause basically when you sit down to do a session of reading your chapters, you're doing your assignments, you're sitting down to be not only teacher to yourself but also student. (301) Even though you have the support system of a tutor, it's not the same because you can't sit there and tie them up on the phone for hours on end. You know, as you read through the chapter you...you want to talk about things. I mean, you're not the only student. There are other students that obviously would want to have some time with the tutor, and I...I felt that when I did phone my tutor the first time, it was like trying to rush me off the phone. (laughs) Because the...the letter that comes with your course package says: "Give me a call, introduce yourself, and so I can get to know you and you can get to know me." And when I did that, I...I phoned her up, and I guess I'm being naive, I don't know, saying, "I'm just phoning up to tell you I'm your new such and such." (311) I told her I worked at the Agency at that time, but she didn't remember me the other...the last two times I talked to 
her. She didn't because she was so disinterested it...it seemed at first to talk to me because all I wanted to tell her was about myself, which is what her letter asked, and I didn't want to talk about the course.

A: How...how did you feel about that when you phoned and that was her reaction?

S: Oh, O.k.! Sure, fine, if you don't want to talk to me, you know (in an offended voice). So I just left it at that, and I wasn't too...too impressed, but... and then the weird thing is next...the week after that she phoned me, and she was like, "Oh, hi. How are you?" and all this like she was so friendly, and I was like: Is this the same person I talked to last week? (320) And she was so interested in knowing where... what stage $I$ was at and all this sort of nonsense, and I said, "Well, I just sent in my first assignment today." And I said...I even talked to her about the one I...I could have misinterpreted the question, and I said, "This is the way I interpreted it. I don't know if it's the way you wanted it answered, but that's the way I...I've answered the question." She says, "Oh, no. No problem, no problem." And then I get it back; obviously I didn't get full marks on the question, but that's fine, but I don't know.

A: So it seems to me your impression is that, in fact, she's not listening to anything you say apparently. 
S: Well, yeah. Well, really, you know. (laughs) I don't know. I mean, maybe it's just her. (330) I mean, obvious... I mean, 'cause of my experience of working here so long, I have heard some pretty darn good things about tutors, and obviously I've heard some pretty darn bad things about tutors. You know, I mean, and you're gonna experience those things even if you're taking a course through a regular classroom situation. You get your good teachers; you get your bad teachers. And there won't be any difference if you take the course through distance. You'll still experience the same things, and you'll still have the same option to change your teacher 'cause we're (unclear), so I don't really think that's any different, you know, between dist. ed. or...or regular classroom.

A: So that's another similarity.

s: That's right. (laughs)

A: (340) I asked you: What were your expectations of distance...doing a course by distance education before you started? Also what were your hopes and/or your fears before you started?

s: I could tell you a fear. (laughs) I mean, it's silly. I mean, obviously I want to do well because I work here. obviously people who work in the records end who know me are going to see my marks as they get entered, and obviously there's that certain amount of peer pressure. I mean, not any student.... Any other student around here wouldn't have those feelings of concern about: "Oh, 
so and so is going to see my mark." (laughs) I mean, that's...that's for me one thing, I mean, because I work here, but for any other student that wouldn't be an issue I'm sure. (350) But fears? (pause...) Being able to complete it. Being able to complete it in the normal time. I mean, obviously if I really needed the extra time for the six months, I'd take it, but at least being able to complete the course, do all the assignments, and write the exam. That's a big thing for me because obviously I've never taken a course like this, through this type of mode, and obviously you're gonna have fears about being able to follow through, and now that I've been doing it for a while, I don't think I'll have a problem, but sometimes when you stop and think it's a little bit of overwhelming. (361) You think, "God! I still have all this to do," you know. (laughs) But as long as you keep, you know, your nose to the pavement and sort of keep...keep grinding away at it, you'll do o.k. And I...that's all I...I...that's all that keeps me going. I just know that as long as I...I do this much this week, then I'm O.K., and I won't have to worry about it and fear maybe understanding the material, hoping that's it's going to be laid out in a way that can be understood, and that, like I said before, I haven't had a problem either. (371) That's, I think, maybe is the most important factor in being concerned, apprehensive about whether a lot of thought has gone into the layout of the 
course in such a manner that anybody could pick it up and not have a problem understanding it. I think that's really important. I'm sorry, what was your other question?

A: I said: What were your fears and/or your hopes before you started?

$\mathrm{S}$ : Hopes, hmm. (laughs) My hopes were to do well. (laughs) (380) I was almost hoping at first, when I looked at it and I started and I did the first assignments quite quickly, and I thought, "Oh, God! Really, I could almost do this in 2 months." And then I thought, and I sat there, and I thought, "Naa, I can't do that in two months. That's ridiculous (laughs) unless I quit work for two months." But, I don't know. I was hoping I would do well; I was hoping it would be a positive experience, one that I'd want to do again because obviously, now that I've made the commitment in transferring my credits over to this program, I...I'm one who likes to follow through and finish what I start, you know, something that I start, and if it wouldn't turn out to be a positive experience, I'd obviously go back to the conventional method...mode of learning, which is the classroom. (392) And that might be more difficult and timely for me to do...to complete the requirements for my degree.

A: Timewise. 
S: Timewise. Whereas I have a greater degree of flexibility to do as much or as little as I want in distance ed. But with conventional means.... I could, I mean, I could possibly, I mean, this is probably outrageous, a threecourse load, but if I dedicated all of my time to the first one in the first two months and a bit, and then the next in the next two months and a bit and so forth, I could do the first one maybe, write the exam in the four months period, and the same with the second one, and the third course I could do the exam at the six months period, like that. (402) But with conventional means, you'd have to have three classes every week; you'd have to have three loads of course work every work... week, different course work. If they're unrelated in some way, then it makes it even more difficult, and it just compounds the problem. It makes it just so stressful and, you know, not...n not something that you want to do anymore. It just turns you right off. Really. But that's one thing with distance ed. You'd have that flexibility and freedom of choice to do it as you please, when you please within the time limits of the course.

A: (411) Yeah. And now that you've been doing it for a month, a little more than a month, what ar... Y You said your hope was that you would be able to manage it. Do you feel...how do you feel about it now?

S: I feel fine about it. I don't have a problem at all. I mean, this last long weekend I probably picked the wrong 
week... day to do all my studying. I...I chose Saturday, the nicest day of the weekend (laughingly), and then it rained the rest of the week almost. Got to plan that better next time. (laughs) I mean.... I mean, so I just basically sat down for about six hours on saturday and worked on the course, and that was, you know, what I did that day. (420) It's... You know, I mean, I'm...I'm married, but I have no children, so I don't really have to worry about, you know, a lot of things pulling me here or there. I suppose, if a student was married, it would...it's gonna probably be a different story again except, obviously, they still get the benefits of being able to have flex...flexibility doing a distance ed. course whereas probably a conventional class is, like, totally out of the question. I mean, they'd have to worry about getting baby-sitters and all that sort of nonsense.

A: When you said 'if a student were married', I think you meant 'married with children'.

S: (430) Children, married with children, sorry, yeah. Just like the T.V. series. (laughter)

A: And in...by doing this math course through distance ed., what are you learning about math?

s: Actually it...it...the...the course requires that you have some algebraic background, grade eleven, which I did get a couple of years ago. So...actually in...in... in retrospect, like, when I told [my immediate superior] I 
was going to take this course also 'cause if that would be benefit to the course...the...the job I would be going into, he said, "You don't need it. You don't really need that course." (441) I mean, because basically all of what I do right now is... revolves around computers and not being able to sit there and do mathematical complications of one sort or another, and the more I get into the course, I see that's true. But for me it sort of vindicates knowing that if I have that title of [ ], then I have a statistics course behind me, and I feel that much more confident in what $I^{\prime} m$ doing, and $I^{\prime} m . . . I^{\prime} m$ having no problems with it. I mean, I...I do like it. I'm learning a lot; I'm learning a lot. I just went through one chapter, which was quite hard (laughs), but I...I'm getting hold of it now, so I mean....

A: So, this course, I think you said, is actually probability and statistics?

s: Yeah, that's right, yeah. But I don't know. It just gives me a better feeling that what $I$ do now is sort of supported by a course that, you know, obviously goes in line with the title... (461) I mean, I do statistics in my job, sure, but nothing to the level that this course teaches me. But at the same time, it gives me a greater understanding of other possibilities that I could do if they are needed or presented, so it...it's, I don't know, it's sort of like a reinforcer. (laughs)

A: So it relates very much to the work that you're doing. 
s: Not at this point in time but maybe in the future. It could possibly. The way.... 'Cause the job I go into now, is partially what I was doing before, plus it's going to expand into do new different things....doing different things, new areas, and I could very well see that it could be an important factor, I mean, because a lot of what we do in the course relates back to the first two chapters, which talks about control and observational studies and the way the statistics you get work in conjunction with what type of study you're doing and how those types of statistics can support findings or not. And basically I can obviously see that those things will be important to what I do eventually.

A: (481) Right. And second question about learning: What are you learning about yourself by doing this course?

s: I can do it. (laughs) I didn't know if I could do it for sure, but, I mean, obviously 14,000 or so students a year can't be wrong. (laughs) Like McDonald's song. Really, I mean.... I mean, in the beginning stages I might have really, like many years ago, even have been more apprehensive 'cause, sure, we're new and the acceptance still has to be gained by other educational organizations, by the students themselves, and to me I might have not been fully convinced those many years ago, but now I do feel that obviously this is a viable alternative for people who just haven't got the opportunity to go for the conventional means of 
education. And I...I've been doing that for a while, conventional education, just recently, and now when I do this, it's really...it's...it works...it works, and it's something I like, and I'll probably do more courses for sure. (503) I can't see myself not now, 'cause I feel quite comfortable with it, and if they're as well laid out as this course, I can't see a learning problem being there. I'm sure the curve for learning will be quite steady.

A: So what you're learning about yourself then is that you are capable of doing math by distance education.

S: Oh, yeah.

A: Is there anything else that you feel you're learning about yourself?

s: (pause.....) I don't know. It's hard to say because (pause...) I might learn more about myself if I hadn't taken so many conventional classes before I took this course. But like I said before in retrospect, I can see if I hadn't taken those courses, I might have real difficulties being disciplined enough to sit down and do the course, but for me that's not a problem because I have been involved in other forms of education already. (521) So, potentially if I hadn't taken conventional training recently, I'd be finding that I probably am able to be disciplined if I...was doing...following through exactly the way I am right now. But I...for me, knowing me (laughs), I don't think I could have done it without 
being able to be disciplined in the conventional means first, and I think that might follow through for a lot of people who have been out of mode, out of the schooling action for a while that hadn't been doing anything and sort of just pick up a course all of a sudden -- $I^{\prime} m$ gonna do this. I feel motivated. -- but never follow through. I mean, I can speak from knowing that the amount of incompletes we have here is pretty high, you know; it's pretty high. (540) And that could attribute towards those types of people who are just reentering into the... into the education field for, you know, bettering themselves, or sometimes it can be attributed to the fact that people just want to take a course just because they want to take the course, just 'cause they want to get some knowledge of a certain subject that they...they've always wanted to do. They've never really wanted to go through all the, you know, jumping the hoops and all that sort of thing, take...doing the assignments, taking an exam. They just want to learn, just want to read just for (unclear). And that could obviously be attributed to, you know, high grades. So....

A: Well, a third learning question: What are you learning about distance education by actually doing a distance ed. course?

s: It works. I mean, (pause...) I don't think that many people question the fact that it's a viable alternative to education because it does work. It...I mean, not only 
my...a person who's proof of this as I go through, but obviously there's many other students who've been here with us before, now, will be in the future with us. (562) That obviously there's something that works for other people as well as just for myself. I don't know.

A: O.K. So, sort of bringing things together: For you what are the most important things about doing math by distance education?

S: (Pause..........) If... if there is a problem in my learning, I don't have to tie up a class, sitting there wasting time and the teacher. (Will you please explain this to me again?) I can sit there, and I can just go back, and I can learn it through as many times as it takes until I understand the point, and if I still have problems, there's always the support of the tutor. (580) But I feel that I don't have to be worried about what other people think about my rate of learning. I'm learning at a rate that works for me, and that's the most comfortable thing that works for me, and I think that could be true for anybody that takes a c... a course, whether it be math or any other course, through distance ed. You know, except obviously, like I said before, having a support system would be nice too but only as a last resort, you know, if you really need a tutor. Like for me, I will try as hard as I can going back. Even if it doesn't make sense, I'll go back and back, as far as I have to go back until I can start going through the 
process again and then maybe find out where my block in the learning was and then can just say: O.K. This is what I did wrong; this is what I gotta do right. (599) And then I can proceed forward whereas you don't always have that luxury in a classroom, and... and sometimes you don't want to frustrate another person with going through that so many times and to reinforce what you're trying...figure out where you went wrong. But if it really comes worst to worst, it would be nice to have some kind of support, other than a teacher sometimes, 'cause sometimes teachers can be condescending in a way, you know. Like you know they're not gonna say, "You're dumb, and why don't you understand this?" but can just feel that (laughingly) emanating from their...the tone in their voice, you know, like: Sorry I'm so ignorant, but.... (laughs) You know, and....

A: Yeah. So you mentioned two things that were important. one is being able to learn at your own rate, go at your own pace, not feel stupid in front of the others, and the other was this lack of...some lack of support. Is there anything else that you would say is important about it?

$S:$ (620) (Pause....) I don't know. Like to me, I feel like a...a real sense of accomplishment when I got that first assignment done. I thought, "Darn, that's good." And when I sent it in I felt really...really good about what I did, and I know I will with every other assignment that I send in. 
A: So a sense of accomplishment is another important thing. S: Oh, yeah. Oh, yeah. For sure. I...I mean I...I mean, obviously.... There was some apprehension in the fact that I hope I've done this right but obviously find out if I've done anything wrong, but when I got the assignment back, I found out the things that I did right, which were supported in the manual and the textbook, she didn't appear to think were right, which obviously is a problem, so... But then again, it's just her person, the teacher. I mean, you can just get a different teacher. I mean, you've got that flexibility, so...

A: (641) So it seems to me you've mentioned.... Actually I've been trying to write down some of the key words of what I think you're saying, so I...I'll read them back to you, and I wonder if you could tell me: Do you see any particular relationship among these main points, these key words? One of them is convenience, of which being able to go at your own pace is especially important, the other is there's some lack of support, and another is the sense of accomplishment when you send in an assignment. Do you see... is there a particular relationship among those?

$S:$ (Pause...) (END OF SIDE A)

A: (661) So just to repeat that last question.... The key words that I've written down are: You find it convenient, especially because you can go at your own rate in learning; there is some lack of support; there is a sense 
of accomplishment when you send in an assignment. What relationship do you see among those?

S: O.K. Convenience with support. With this mode of education there's gonna be that trade-off. I think that's obviously something that you have to forfeit, but I'm sure that.... I mean, I...I've heard of talk that they might, eventually.... Obviously open Learning is high on the technology side, and they're looking at ways of... of connecting students who want to be connected, whether it'd be by phone or by being able to...(670) because our students are all over the province, setting up like a radio situation where students who live in a common area can go to some classroom or whatever and students from other areas in the province can go to similar areas in their community and they can communicate through a radio system or through computers or whatever, some way to, you know, to have that kind of support, because I know that's one thing they've been looking at. I don't know if they're actually doing it just yet, but that's one way to countereffect...counteract the effect of the support not being there like it is right now.

A: Is that something that you would like personally?

S: Oh, sure, I would like to see something like that 'cause I'm.... Some courses you just... you just need that kind of, you know, space and time to be able to bounce ideas 'cause when you're with other people you do learn. (680) Even though.... I mean, you learn stuff from your...your 
course, sure, but you learn from other people's experiences, and there are obviously things that have influenced them to be the person that they are. You obviously get different ideas from them as they would be...your ideas might be different to them, and that could formulate maybe how you write a paper, you know, on a certain subject, all those sorts of things, you know, and things that you might not have even thought of, and someone who just sort of says them out of the blue, and you think, "God! That puts it all together for me. Now I know what I want to say," and things like that. And if they brought that in, the...the lack of support and the kind of...I mean you'd have everything. I think you'd just have everything. You've got the convenience; you've got the support; like, you would, you know, if you opted to have that support. Plus you always, you know, you'd have totally complete satisfaction, I think, when you send in your assignment 'cause you...you'd know that you're getting the best of everything.

A: (691) Right. Yeah, yeah. Something to work towards!

s: you got it.

A: If you were talking to another person whose situation was very similar to yours: a job like yours, married but without children like you, having done a number of courses through conventional education, etc. What would you advise that person about doing math or another course by distance education? 
s: Well, actually I have a girlfriend. She's single, but she's been very interested in getting some accounting background because her father is starting a business, and I said.... And she just didn't want to take the time to go to a course, and she didn't.... There wasn't anything really very good. It was only basic level stuff in...in the local community offerings. So I said, "Well, why don't you just take one of our...take our first accounting course. (700) I'm sure you'll like it. I mean, it's the most popular course here; it can't be wrong. I mean, it's accepted...our programs are accepted by the, what is it, the Accounting something-or-other of B.C." Anyhow, so she thought O.K. She took the course, and she got an $A$ in it, and she was really... She liked it; she thought it was a good course, well laid out. She went to take Accounting II, but then things in her life came about where she had to...to move, and she was engaged at the time and the.... So a lot of things happened in her life that prevented her from finishing the second course, but she has every intention of, you know, reregistering and going back and finishing it 'cause..''cause she knows that she wants to expand her career options, and she did enjoy this kind of course that she will have to take that course again, finish it off, and continue on in... in whatever direction she sees fit to fulfil her needs for her career. 
A: (711) So, in effect, you're saying that you would advise a person in a similar situation to do a distance education course.

S: Sure...sure. I mean, before when I was saying that and I hadn't taken a course actually myself, it might seem a little: Well, where do you get off, telling me to take a course like that and you've never taken one? But, you know, sure, they could come back and say that to me, and I'd say, "Well, it was just a suggestion, you know." But (laughs), I mean, now... now I think I could probably speak with more experience behind what I'm saying and really support my argument even more strongly than I did before, because obviously I've had the experience to say, "Well, the courses are really structured, at least the one I took. I can't see it being so much different from course to course because the...the course manuals are written by course designers here, and it's not gonna be too much different. (720) And I didn't have a problem with it. I know you're a fairly intelligent individual, just like me." (laughs) And, you know, I think that they could do it. I just.... I don't think it's really too hard. If you really want to do something, and you're motivated, you'll make up for a learning gap, I think. I really think so. 'Cause I mean...I...I mean...I wouldn't consider myself the most intelligent individual in the world. In fact, my girlfriend, she got better marks in high school than I did. But I mean, I... I've been more 
motivated, I've taken more courses, and I've done well in them, and it's because it's the desire in me to want to do something. And I think that tho...that kind of thing just can make up so much for, maybe, your intelligent quotient, but...'cause you're compensating for...you're doing more, and you...you're excelling because of it.

A: (730) You're talking about motivation there once again.

S: Yeah.

A: You used an expression which I didn't quite understand there. You said something about 'make up for a learning gap'. What do you mean by that?

S: Well, maybe... Well, I don't know. I mean, I didn't do terribly...too terribly well in high school. I mean, I was probably a $C+$ average person. But since I've been to BCIT, I've got a first-class average, an A average, which to me is like: Wow! (laughs) when I've been in high school, if I'd done something like that, I mean, if I'd gotten one $A$ in high school, I would have been like thrilled. I didn't though. I was in band though, but that doesn't really count.

A: Was in what?

s: Band. (laughs) But, I mean, I don't know. I mean, it's...it's really... The more A's I brought home, the more I tried, and obviously.... (Pause....) (740) This is something my father's always told me actually. When he was in UBC, he says, "You know, there's people that go in there that are naturally intelligent and don't really 
need to study as hard, and they'll get the same marks as someone who goes in there and tries and works their butt off, and they'll get the same good mark. And those people sometimes, you know, that might not necessarily get the good mark unless they put the effort in, you know, and they're making it." And that's...that's, I mean, that's the way I view myself. I might have to work that extra bit hard, but it's worth it to me because it just feels so good getting a good mark. (laughs) I wouldn't trade it for the world. I mean, that's what motivates me. I'm a high...person high on motivation. (laughter) I can't help it.

A: So by 'learning gap' you mean this difference between what... what some people can do naturally without studying and what others can do naturally without studying.

S: (750) That's right. Yeah, exactly.

A: My last question: How are you evolving as a learner through doing math by distance education?

s: (Pause...) Actually, it's interesting that you say that because already something that I learned in the course has already become directly applicable to something that came up in a staff meeting in my group before, a couple of weeks ago. And I just sat there and thought, "Gee, that's great! It's paying off already, that quickly." ... (laughs) something that was directly applicable right away, and I thought.... I mean, (pause...) (770) my knowledge... I wouldn't have had that knowledge without 
the course. And I see obviously myself growing from that point of view, and maybe not right away, but in the future, like I said, this course will also be applicable, in the things that I learn now, later on.

A: So it's the knowledge that you're gaining. Well, that takes care of my questions. Is there anything that you'd like to add?

S: I don't think so. I've said probably too much. (laughter) Probably bored you to death. 


\section{INTERVIEW \#19}

Interviewer: A

Respondent: $T$

Position on tape: (000)

A: O.K. So, maybe we could begin with your decision to enrol in distance education. How did you come to that decision?

T: Well, actually I had taken... I had taken some courses at... at SFU and... and also a couple of night school ones, and I found there was a bit of difficulty in... in getting to the facilities to...to take the courses. The...the travelling each way by bus and... and having to be there on certain days and at certain hours was... was a bit of a drag because...because I had a full-time job, and you know, I didn't always like having to put aside that time to...to go and come, that sort of thing. So then I decided that if I could find some sort of course that I could take at home, it would... it would be much more convenient. (010) I could set aside certain hours every day. I wouldn't have to add travelling time onto it, this sort of thing, and... and I can work better that way anyway than...than having to go somewhere and sit and write notes, all that sort of stuff. That was another difficulty I...I find is trying to take notes while a professor's up there lecturing me. I'm trying to listen to what he's saying and write at the same time, and something's lost there. I much prefer to just have 
something I can read, make my own notes, and this sort of thing. So that...those are some of the reasons why I chose to...to do a home study type course, and I chose the Open Learning Agency mainly because I have a brother that's taken courses through them and... and he said that it was really good -- the fact that they...they still can, you know, they can grant degrees, they're a degree granting institution and that they even work in conjunction with the...the other two universities -- all sort of fits...fit in with what I was looking for, so.... (021) So that's why I'm taking a course from OLA.

A: Are you actually intending to go on for a degree?

T: Yes, I want to get a degree, actually a Bachelor of General studies, and I just finished getting my assessment back from OLA the other day, and I've got a year to go, which isn't too bad.

A: That...that was your credit assessment.

T: That's right, yeah. They gave me 87 credits, which is just one... one short of three years, so I hope to complete that in the next two or three years. I may have to take more than one course at a time to do that.

A: And again the course that you're doing right now....

T: It's Business 241, which is Commercial Law or Business Law.

A: So it's Business Law, in effect?

$\mathrm{T}:(030)$ Yeah, it deals with contracts, torts, you know, such as negligence, those sort of things, all basically 
non-criminal code type things, although, you know, things like assault and that, which are mentioned, can get into criminal or civil type things. But it's...it's very fascinating actually. I'm enjoying it immensely.

A: Yeah, and before you actually started doing this distance course, what did you expect it to be like learning Business Law by distance education?

$T$ : I wasn't actually too sure. I was a little apprehensive, knowing that I...I wouldn't be able to have a weekly session with a tutor that... where I could maybe talk and ask questions that $I$, you know, needed answering, this sort of thing. I wouldn't be able to talk to the professor and... and get his views on things or... or find out information I needed. (040) So I was apprehensive in that way although, you know, I do have a tutor I can phone up and get information and ask questions that sort of thing. But I'm finding that I'm probably working faster and doing just as well as I would if I was going up to one of the universities.

A: Really? You...you've mentioned two things which are perhaps contradictory; I'm not sure. You said that when you were in the classroom taking notes was sometimes a bit of a problem; you found it a bit difficult, but you also said that you can't talk to the teacher or tutor every week this way. Is... is there a conflict there?

T: (Pause.....) No, not really. I don't think that taking notes and being able to talk to the tutor are really 
related. In...in one case, taking...taking the notes is taken care of in... in the course outline that I get. (051) It's got all the information that I would probably be given by a professor. But if there's parts of it that are confusing, that I don't understand, I can't sort of right there, then and there, ask a professor or...or a tutor, "What does this mean? Explain this to me." I have to phone...phone the tutor, who may or may not be there, and if she's not, I have to leave a message, she'll get back to me, this sort of thing. I don't get the instant feedback that I...I could get if I was right there at the time, sort of thing, so... so that's what I meant.

A: And how do you find that?

T: (Pause....) Well, I...I still eventually get the information $I$ need now. It just takes a matter of maybe several days because my hours and the hours the tutor allows us to phone her are different. So I have to phone and leave a message on her answering machine, and she'll get back to me, because I'm always working when she has her...her sort of open-line hours.

A: (061) Oh, I see.

$\mathrm{T}$ : So I have lots of questions that come up during my reading that $I$ just have to write down or underline or something and then find...get the information from her when she phones me back. 
A: Right. And are you saying that that's a bit of a problem or it doesn't really matter?

T: It's a bit of a problem is what I'm trying to say, yeah. Not major but a bit of a problem.

A: And how do $y .$. in what ways is learning Business Law by distance education different from learning by conventional education?

T: Well, I would think that probably in conventional education there would be a lot of group discussion because we...we do a lot...I...I study a lot of cases, individual cases, and I have to give my opinions and that sort of thing on them, (070) and I have to rely basically on my own feelings and perhaps talking to my parents or other people around me, smaller groups though. So in that way I would imagine that the ideas we come up with and the feelings may not be quite as broad as with a larger group. You know, there just...there...there isn't as much discussion and feedback and sharing of ideas. There can't be because I deal with a relatively small group of people whereas that's one benefit of the tutorial type system. I mean, you can sit in a group of 20 or 30 and... and say, "O.K. what do you think of this?" and you can get lots of feedback and input and probably come out with a better general understanding of what's going on.

A: So you're saying that you do talk about these things to people around you? 
T: (080) Yeah, but it's a small...a rather small group, yeah.

A: Right. Are there any other differences between doing it this way or that way?

T: (Pause....) Well, so far I found that as far as getting marks back on my assignments is very slow doing distance ed. It took a month from the time I sent in my first assignment to finally get my mark, and in the meantime I had sent in another one and almost a third one, and I had no way of knowing whether I'd done the first one correctly. But...but they tell us not to wait, you know; keep sending them in. And, like, it's usually a week in between assignments when you're going to a university and you have a tutor, this sort of thing. So that's a bit much, a bit hard to take. But I did discover at least that it wasn't... it wasn't my instructor's problem. She had sent them over to OLA right away. (090) It took them about two weeks to computerize and send them back to me, so....

\section{A: Is that right?}

T: Yes, yeah. Because they have to...there's dates they put on them all along the way: date when $I$ sent it in, date when she receives it, date when she sends it to Richmond, and then, when I get it back from them, I can just see how long it took, so... I don't like that aspect of it, but there's not much I can do about it. And, of course, the exams, it'll be the same sort of situation as it 
would be at a conventional university. I have to go to probably Kwantlen college and sit in a classroom and write an exam and... and pass the exam to...to pass the course, providing my assignments have been done adequately .

A: Right. Are there any other similarities then, between conventional and distance education?

T: Well, the exam, of course. (Pause...) (100) Now.... o.K. But getting back to some more of the differences, there...like there's no mid-terms; at least in the course I'm taking there's no mid-terms. Sixty percent of your mark is based on assignments and forty percent on the final. And I like that idea better because I'm not one of these people who does very well on exams. Mid-terms and finals have been my downfall. I've always done well on the assignment parts but not... not necessarily that well on examinations. So the...the fact that only forty percent of the mark will be on examination type things is to my benefit -- maybe not others' but to mine for sure. So I like that aspect of it.

A: Any other differences or similarities?

T: Yeah, I'm...I'm thinking right now about it. (pause....)

A: Heat up your coffee?

$T:$ (110) No, it's fine. (Pause...) Well, just that I think I make better use of my time when I'm studying at home. When I used to go up to university, I would waste my time, to be quite honest. I might go up there three or 
four hours before my lecture, and instead of doing something useful like going to the library or the computer lab., I would end up wasting it, you know. And... and that was kind of getting to me although at the time it didn't really bug me. I...I didn't mind wasting the time, but this way I... I'm more focused on what I'm doing, I guess, and....and, you know, I've got a nice quiet area to study, this sort of thing, so...

A: What do you actually do when you're studying?

T: Oh, well, I read the.... You know, the binder is set out into twelve units, and I...I read through the unit, step by step, you know, highlighting the important things. (120) Then they have key studies to read and self-tests to administer, and then they have an assignment to do at the end of every two units. So it's one assignment every two weeks, which sort of.... (Pause...) Now, most of the assignments, actually all of them so far, have been short essay type things -- short essay and then longer type essay ones for the case studies, and... not my favourite type of assignment, but I'm getting more used to it now. I guess that's the only way they can have them in this kind of a course. It's certainly not a true/false, multiple choice type thing. so a lot...there's a lot of writing involved. So far the two assignments I've sent in have been about seven pages typewritten, and I would imagine that the final is going to be the same sort of thing, so.... I...I have to get used to that again. 
(130) I haven't done that sort of thing for years, and... and it's tough, but I'm getting better at it. Practice...practice makes perfect they say, and the more practice I get at it.... It doesn't make me like it any better, but it does make...make it a little easier, sort of thing, so....

A: O.K. I have.... Oh, not yet! I asked you previously about your expectations before you started. Also did you have any hopes or fears before you started doing the course, about doing it by distance ed?

$\mathrm{T}:$ (Pause....) Actually, my hopes were that I would find it easier, not the content, but the...the whole process of learning. I hoped to find it easier by doing it at home, where I would have fewer distractions, fewer things to waste my time, that sort of stuff. Those were my hopes. (140) And so far, I think, those are...those are coming true. And now the...the fears I had are the ones I already expressed, where I figured that I'm not going to get any feedback, you know, except from just the people around me, close by, and that might not be enough; it might not be a broad enough spectrum. So I was worried about that, but then again I...I've now received back my first assignment, and I'm doing, you know, quite well. I...I got 79\%, which in this course is just one mark below an $A$. $A$ is 80 and above, so I guess when it comes to the sort of ideas and opinions I have, they...they must be about the same as everyone else's out 
there, type of thing. (150) I...I have discussed some of the cases with... with the people I work with, you know, just sort of run them by them and say, "What do you think about this? What would you do in this situation?" and... and, you know, I've got some interesting opinions there and have used some of them when I... when I've been doing my assignments, so... So it's kind of fascinating that almost everybody has a different idea as to what should have happened in a certain case, and I've got to try and summarize them, pick something that I think is suitable.

A: And the people you work with are not people who have ever actually studied this kind of thing?

$\mathrm{T}$ : No, no. But it's amazing how many... in how many cases it's just, you know, sort of common sense and going with our gut feeling, as they say, as to what should happen in this case, you know, what would be fair, this sort of thing.

A: Yeah. (160) O.K. and now a little series of questions: By doing Business Law through distance education, what are you learning about Business Law?

T: O.K. Well, maybe the easiest way to answer that would be to tell you almost like the course outline. The... basically the first half of the course, which I've completed now, has dealt with civil type law crimes, you know, what they call torts, things such as negligence, and (pause....) assault and those sort of things. Then 
a...a major part was on contract law and what constituted contract: the...the six conditions that must be met to have a contract, (170) and if you don't have these six conditions why that isn't a contract, and how a contract can...can be discharged, the sorts of remedies courts will...will grant in certain cases such as breach of contract, misrepresentation, and all, you know, all those sorts of things. And I'm trying to remember what the last half of the course is going to be all about, and... and it's.... I can't remember it now, but there is a course outline that I've read through, and... and right at this second I can't remember what the rest of it's about. But generally I've...I've learned, you know, a lot of stuff about business law that could help me in my everyday life, could help anybody in their everyday life (180) and, you know, just as far as what people's rights are and this sort of thing when it comes to contracts and the sort of thing that you have to watch and be aware of if they're ever signing contracts because there are so many rules and loopholes that I was simply not aware of but that I am aware of now. So I... in that way it's been very useful and very interesting. You know, I've given advice to lots of people, saying, "Did you know in such a case, for example, (I won't go to... you know, I won't say anything specific.) that this or this could apply?" and they said, "Well, no. I didn't know that." I...I gave advice to one person who was thinking of...of... of suing 
one of the crown corporations (190) as to some of the steps he might consider, and of course, one of those was to see a lawyer, since I'm not pretending to be one. I'm just... I was just telling him the steps that... that he should go through according to the commercial Law book. And he decided after that that he wasn't going to bother suing them. (laughter) Yeah, but I told him that he shouldn't listen to me; as far as giving him specific advice he should see a lawyer, because I'm not pretending to be one, but it (pause......), I guess, it just basically is very valuable information that...that anyone should have. And I think it's the sort of course that it doesn't matter what you're going in for, you...y you don't have to be going in for accounting or anything like that, it's just valuable information. (201) I have a brother who took it, and, like, he works for the Fire Commissioner's office, but he found it very interesting too and... and useful in some of the things they have to deal with.

A: So, what you're learning you're finding is already applicable to real life.

$T$ : Exactly, yeah.

$A$ : Oh, great. O.K. second question in this little series: What are you learning about yourself by doing this course through distance ed?

T: (Pause...) O.K. that one's gonna take a little bit of thought here; let's see. (19 second pause) (211) Well, 
one thing it's...it's taught me is that as far as the whole concept of distance education is concerned, whether it was this course or any other, that I...I can function as well as, if not better, working on my own at home than I...than I would if I was going to a university. And I wasn't sure whether that was going to be the case or not. But it's also taught me that, for example, I can't remember as well as I used to when I was younger, and I have to spend a lot more time and reread more often than I used to have to. I have to make more notes and highlight more things than I used to have to. (220) (Pause......) It's also helped me realize that...the fact that I want to go into accounting, you know, is something I really want to do. Taking this course has convinced me that it...it was the right choice. It's almost made me want to go in for Law, but I realize that that's a very long and difficult program, and... and that's sort of out of the question. I guess it's just basically renewed my confidence in myself that...that I can still study and... and do well after not having been in the system for 20 some odd years sort of thing, so...

A: (230) one thing you said there was you find that you function better in this type of learning than in the other. Can you tell me more about that?

T: Well, just like as I mentioned earlier, I tend to waste my time on other things when I...when I go to campus or somewhere else, you know, to learn, and when I'm at home, 
I don't do that, you know. Now I...I won't get into the specifics of how I waste my time (laughter), but the thing is.... It's...it's just one of those things, you know, like I...I can't stay on task, you know. I...I'Il go down and sit in the cafeteria for an hour or something and do nothing or go to the gym or go to the library but not go there for...to work on the course, just to whatever, you know. (240) I'll play on the computer, or...or I want to play the video games, that sort of thing. So, it was wasting my time, and... and at...at home I don't have the opportunity to do that. I...I can just... I can stay on task there because there aren't all these little distractions.

A: And you also said something there about it's renewed your confidence. Could you tell me more about that?

$\mathrm{T}$ : Well, yeah. When I first decided to go back and go into accounting, I thought to myself, "Well, you know, you've been out of the classroom for 20 some odd years. (250) What's it gonna be like? Are you still going to be able to do it? Are you still going to be able to write, you know, take notes, and this sort of thing?" And... and I wasn't sure, especially since I never really enjoyed university when I went to it 20 years ago. I didn't enjoy it much at all. I got some good marks, some mediocre marks, some poor marks. But I still didn't enjoy it. It was not a fun time of my life like a lot of people say it is in theirs. So there were all those 
apprehensions, but all I decided was, "Well, I'm older now; I'm more mature; I can make it work. I've got more reason for going now than I did then." Like, I started university when I was seventeen. I was just a youngster, and... and I had...I'd done very well all through school, (260) but the school I went to, a lot of how well you did was based on how well you could remember. It wasn't, sort of, a creative type thing, where they taught you how to write well and express yourself and all this sort of thing. So I found that the university courses where you had to remember things and memorize, the maths and sciences and things like that, I did well at. The Englishes and things like that, and History, I did lousy at because, sure I could remember the stuff, but "now write it in your own words" sort of thing, like, what's that mean? So there was all those fears, sort of, going through my mind again, thinking, "Well, is it going to be that kind of a course?" (270) (interruption: phone rings) And the courses I had taken at SFU just recently in Business, I hadn't done very well in the finals on those or the mid-terms although I had done very well in the assignments. So, you know, I had a lot of apprehensions, but I figured I should be able to do at least as well, maybe better. So, you know, those were all the things running through my mind when I decided to...to try a distance ed. course. And, of course, if I couldn't have found a place where these were sort of accredited type 
courses leading to a degree, I wouldn't have thought about it. (281) You know, like, I wouldn't have gone to one of these, sort of, mail-in university type things or...or a college-level type thing because it...it wouldn't have been meaningful for me, and even if they did grant a degree, it wouldn't have meant anything. So, I wanted to have something that was noteworthy but different from the university type setting that SFU and UBC and U. Vic. offer. And the extension courses that SFU offered didn't suit my needs. They...they don't offer any of...in the courses that I want them in. (290) And as far as night sessions, those are the sorts I were going... I was going to, and even...even then I had to be really careful that they were on the nights that I didn't work, and it was kind of hard to pick that way because they don't plan on just for me. So I just found, you know, rather than going through that hassle to...to find a course where I can set my own schedule up rather than having to meet somebody else's schedule.

A: Right. You...you said there if you got some kind of degree from a college, it would be different from this. In what way?

T: Well, by that I mean, you know, these things like Trend College, those sort of colleges. I don't mean a college like Kwantlen or Douglas, those sort of things. (300) I'm talking about these...the, you know, I don't even know how to describe them, but.... Well, 0.K. For 
example, Pitman, Trend, those...Compu College, those sort of things. Like, maybe I'm wrong, but to me, they're a college in name only. They're not really sort of a credit... a creditable type of place.

A: Oh, I see.

T: That's all I'm trying to say, and anyone listening might think, "You don't know what you're talking about." But anyway, that's just my opinion, so I wanted something that was at least affiliated with a university, sort of thing. So that's why I chose open Learning.

A: And you also said that now you have more reason for doing these studies. Could you tell me more about that?

$T:$ (310) Well, the reas.... Oh, yeah. O.K. Then before... Well, when I went to university 20 years ago, I just went to university because my parents expected me to go to university. I didn't know what I was going to do, but...so I took a variety of things. I took some arts, some sciences, you know, whatever, so that when I decided what I was going to do, I had a little bit of everything, and so I decided about my second year in that I was going to be a teacher, and so I went through, and I got my.... I went through the professional development program, and I got a teaching certificate, and...but I didn't know that when I first started, and I taught for...I taught for 20 years, and then I quit teaching and decided I wanted... I wanted to go back to university and go into accounting. (321) And that's where I am in 
my... in my career now. So it sort of was a conscious decision this time, but I know what I want to do, and I know what I want to take whereas before, when I first started, I sort of had to think about it. It came to me... As a matter of fact, it was even suggested that I...to me by somebody else that I become a teacher. It really wasn't my decision, and I thought, "Hmm, well, sure that's an idea. Why don't I?" sort of thing. You know, that's how it came about.

A: Yeah, what kind of teaching were you doing?

T: I was an elementary school teacher in [three different areas of B.C.].

A: Oh, you've been around.

T: (330) Yeah, those three districts. And that was, you know, I taught basically all subjects -- in elementary school you do -- and I taught grades three through seven along the way, generally about the grade five level though.

A: O.K. Third learning questions: By doing Business through distance education, what are you learning about distance education?

$T:$ (Pause.......) Well, O.K. I guess I'm learning that the...the course content, the material covered, if not... if not identical, must be very close to the same sort of thing I would be taking if I was going to one of the three major universities. (341) It's just the...the way it's presented that's different. It's... You do it 
basically all on your own with a little bit of telephone help from...from an instructor. I guess it's...it's obviously less expensive for the...for the centre that's giving the distance education than it would be for a university. (Pause...) All the facilities that a...that a university would need, something like open Learning wouldn't need. So, in that way, I guess it would benefit them. As far as the student is concerned, they have to be...they have to be able to...to be independent and work on their own. In some cases they might have to be more self-disciplined. I've had people tell me, "I couldn't do that. I could not work at home. How can you do it?" and I just say, "Well, I...I'm the opposite." (356) I find when I have to go somewhere to learn that $I$ 'm less efficient than if I can do it at home, so, you know, different ways for different people, I guess.

A: (Pause....) So for you being independent and selfdisciplined applies more when you're working at home than when you're going to a university.

$\mathrm{T}:$ Yeah, exactly.

A: O.K. Bringing together what you've already been saying: For you what are the most important things about doing this course through distance education?

T: As opposed to doing it at a university. O.K. (Pause...) The most important consideration basically was schedule, when I first thought about it, the fact that I could do my own schedule for it, and I didn't have to rely on 
somebody else's schedule, which in many cases was inconvenient. (370) (14 second pause) That...that was the major...that was really the only consideration at the time that I did that. I...I hadn't really thought about maybe some of the disadvantages.

A: And now that you've been doing it for some time, are there other things, either positive or negative that seem important to you?

T: Well, one of the things I'm worried about, and, you know, maybe it's just me, but I...I'm wondering: in some ways is this course that I'm taking through open Learning, is it easier than if I was taking the same course or one, sort of with the same subject matter, if I was taking it at SFU or UBC would...would it be a tougher course? (385) Would it be more challenging? Would it be...would it mean more if I passed it? So that's...that's one thing I've often been wondering about, you know. Is it an easier course? If I get a degree from open Learning, will it be (pause...) as good a degree as one I would get from SFU or UBC? And... and I've sort of convinced myself that it would be because I really don't have any other choice. Those sort of questions, and they're probably all open to interpretation. Somebody who is an instructor at open Learning would probably say, "Oh, sure. It's just as good as one you get at UBC." An instructor at UBC would probably say, "Ah, no. Nobody's are as good as ours." Somebody as SFU would say the same 
thing. So, I don't know. I guess it depends on...it'll depend entirely on when I go to get a job, what the person who's interviewing me thinks, you know. (400) But, of course, the guy I was talking to at open Learning said, "Oh, sure, you know. It would be acceptable...just as acceptable as any other university's."

A: And when you said you'd convinced yourself, you mean you've convinced yourself that it will be as good.

$T$ : Sure, whether that's true or not I have no way of knowing. So, you know, I guess that's sort of a concern, but then when I was going to SFU that was a bit of a concern too. Is a degree from them as good as one from UBC? I guess everybody has those fears. Maybe somebody going to UBC would wonder if theirs was as good as one from Harvard, and that sort of stuff, so, I don't know.

A: Yeah, yeah. Are...are there any other things that seem important to you?

T: (Pause...) Well, I...no, I just often have to keep checking and make, you know, to make sure that I am taking the right prerequisites, right courses for what I'm going in for, you know, and... and convincing myself again that: Yes, I should be taking this course; it's one of the ones that they recommend, sort of thing.

A: (418) Who are 'they'?

T: Well, this Certified General Accountant's Institute has prerequisites that they recommend you take before you write their exam. I suppose technically anybody could 
go...walk in and write an exam, but they're not gonna pass it unless they've taken the prerequisites. So that's what I have to keep checking and... and convincing myself of that...that they are the courses that they're expecting, and again that it...it's going to give me the same information that a course somewhere else would because, you know, they list all the universities and the different.... They all have different numbers the courses -- The one you take here is Admin. 100; this one is something else. -- that...that the course content is going to be equivalent to any one I take anywhere else and will be useful, you know. That...that's what I...I have to be convinced of.

A: O.K. I've been writing down what seem to me some of the key words that you've been using. I'll read them back to you, and could you tell me: Do you find a par... any relationship among these things? You...you've mentioned that the convenience of the scheduling and not having to travel was important. You've said you wonder: Is the degree as good? That's important. And related to that: Are you doing the right courses for the accounting exam? And you've also mentioned that it has renewed your confidence in yourself, and you've also talked about that...something of a problem of feedback being a bit slow. Do... do you see a relationship among those things?

$\mathrm{T}$ : (11 second pause) Not right off the hand, no. I'm trying to. Do you? 
A: Well, I'd like you to say. (laughingly)

T: (450) Yeah, O.K. (20 second pause) Well, I see some sort of relationship between the...the three there: 'renewed confidence', 'is the degree as good', and 'are they the right courses', you know, in that, you know, those sort of all deal with my (pause....), you know, my expectations and hopes that... that I'm doing the right thing and that it's going to be, you know, a meaningful choice. (464) And... and I guess the first two, the convenience and the scheduling and the feedback problems and that, they're related, but sort of, in a way they're...they're opposite to each other, you know, because: yes, it is more convenient, the scheduling, but it's more inconvenient as far as feedback and that sort of thing goes. I just...I sort of.... One sort of outweighs the other. To me the...the convenience outweighs the fact that there's feedback problems. At least now that I've...I've gotten feedback on one of my assignments and found that it's not necessary for me to get a large, sort of, feeling of how people feel about things, I...I can rely on my own feelings and... and the small group of people around me.

A: O.K., good. (Pause......) If you were talking to a person whose situation was very similar to yours -- the same kind of work, living in the same place in the same sort of situation -- what would you say to that person 
about doing this course, Business Law, by distance education?

$T:(484)$ I would recommend it, that they do it by distance education, you know, all things being...being equal or, like, the same as in my circumstances. But it's not for everybody. As I say, there...there's some people who... they...they need the atmosphere of a...of a university to do it. The...the whole sort of scenario, you know, that...that they have there is... is what they need. Maybe...maybe the social life is as much...just as important to them as the actual learning that is taking place. With me it's not, you know; the social aspect of education is not important whatsoever. I guess it was earlier in my life, but not anymore. I...I'm much more businesslike, I guess, when it comes to learning. I have a job to do, and that's why I'm going there, and that's it. (501) And...but I found that even with that attitude, going up there, I would...I would sort of digress from what I was going up there for, sort of thing. So I decided I'll do it this way. So, yeah. I would recommend it to...to people. It's virtually the same cost, so they're not gonna save any money, and they...they're going to...they're going to miss out, as I've already said, on the, sort of, interpersonal type things between themselves and other students. But...but they're... If... if they can work on their own, I think they're gonna get it...it done quicker, just as well, 
and... and they'll have just as good a feeling about... about accomplishing something. So, yeah. I...I would recommend it. I've already recommended to people that they look into open Learning if... if they.... if they want to go back to school sort of thing. (520) I've had people say they want to, but you know, they can't find a schedule that fits them. And I say, "Well, have you thought about open Learning because you make your own schedule there sort of thing? The only schedule you have to worry about is the examination schedule at the end, and that's it." so... Yeah, for me it's the thing that's probabl.... I'll probably continue doing it this way. That's not to say I won't ever take individual courses from SFU or UBC because somewhere along the way there are some that I still have to take through SFU. Open Learning accepts them and they grant you the credits for them, but it's an SFU type course. They don't offer it themselyes, so.... So when that happens, I'll have to go to the campus.

A: Right. (END OF SIDE A) (537) I have just one more question, and that is: How are you evolving as a learner by doing this course through distance ed.?

T: (13 second pause) I'm...I think I'm becoming a more confident learner as far as accepting my own views and ideas on things. I'm becoming more confident in thinking that I don't have to check with somebody else to see if they agree with me necessarily, that...that what I think 
is just as often right as...as not right. And, of course, in this particular course anyway, a lot of...in a lot of cases it's just based on common sense and what you think is fair and just and that sort of thing, and... and I don't... I don't have to worry about checking with what somebody else thinks is fair or just. (550) I figure I've got as much a proper sense of that as... as anyone else. So as.... You know, I mentioned earlier, it's...it gives...it's given me more self-confidence in... in what I'm doing, and it's basically forcing me to rely on my own, you know, thoughts and feelings more than I used to because I don't always have the opportunity to...to get feedback and see what other people think.

A: How do you find that, having to rely more on yourself?

T: It's...it's sort of a good morale booster. It was a little bit nerve-wracking when I first started doing it because, you know, I've sort of been used to getting feedback on... on lots of things from other people, you know, whether it's the proper thing to do or the right thing to do. (560) Even if I think it is, you know, you know, it always seemed to me to be sort of selfish for me to figure: Well, I think that's right, so...so that's the way it's going to be or whatever. And now I'm figuring that, you know, it doesn't have to be selfish to feel that way; it's simply a matter of confidence. But, of course, overconfidence is no good either, so... Better find a happy medium! 
A: (laughs) Confidence seems to be an important thing.

T: It is to me, yeah.

A: Well, that takes care of my questions. Do you have anything that you'd like to add?

T: No, not really. I just wanted to add that I've sort of been nervous for this whole...this whole thing because I'm...I keep feeling I'm talking to a microphone instead of a person. (laughingly)

A: Oh, really?

T: (569) It might have been different, yeah, if it had been hidden or something, but anyway I...I just wanted to explain that so that, you know, if anyone...you know, whoever listens to this will understand that. That...that sort of threw me off a little bit.

A: Oh, is that right? Oh.

T: Yeah. The fact that there's a microphone here in front of me.

A: Oh, you sounded fine to me!

T: Oh! (laughs) I felt nervous (unclear). Didn't you notice me? I kept looking at that thing instead of you.

A: Well, I...I did sometimes, but to me you sounded quite natural anyhow. (laughs)

T: o.K. Well, that's fine. That's good. You can erase that last bit (unclear).

A: (laughs) Anything else?

$\mathrm{T}:$ No.

A: Oh, well. Thanks very much. 